\title{
How board network affects firm performance and innovation incentives in transition economics
}

Citation for published version (APA):

Poghosyan, T. (2019). How board network affects firm performance and innovation incentives in transition economics: the case of Armenia. [Doctoral Thesis, Maastricht University]. Datawyse / Universitaire Pers Maastricht. https://doi.org/10.26481/dis.20190130tp

Document status and date:

Published: 01/01/2019

DOI:

10.26481/dis.20190130tp

Document Version:

Publisher's PDF, also known as Version of record

\section{Please check the document version of this publication:}

- A submitted manuscript is the version of the article upon submission and before peer-review. There can be important differences between the submitted version and the official published version of record.

People interested in the research are advised to contact the author for the final version of the publication, or visit the DOI to the publisher's website.

- The final author version and the galley proof are versions of the publication after peer review.

- The final published version features the final layout of the paper including the volume, issue and page numbers.

Link to publication

\footnotetext{
General rights rights.

- You may freely distribute the URL identifying the publication in the public portal. please follow below link for the End User Agreement:

www.umlib.nl/taverne-license

Take down policy

If you believe that this document breaches copyright please contact us at:

repository@maastrichtuniversity.nl

providing details and we will investigate your claim.
}

Copyright and moral rights for the publications made accessible in the public portal are retained by the authors and/or other copyright owners and it is a condition of accessing publications that users recognise and abide by the legal requirements associated with these

- Users may download and print one copy of any publication from the public portal for the purpose of private study or research.

- You may not further distribute the material or use it for any profit-making activity or commercial gain

If the publication is distributed under the terms of Article $25 \mathrm{fa}$ of the Dutch Copyright Act, indicated by the "Taverne" license above, 


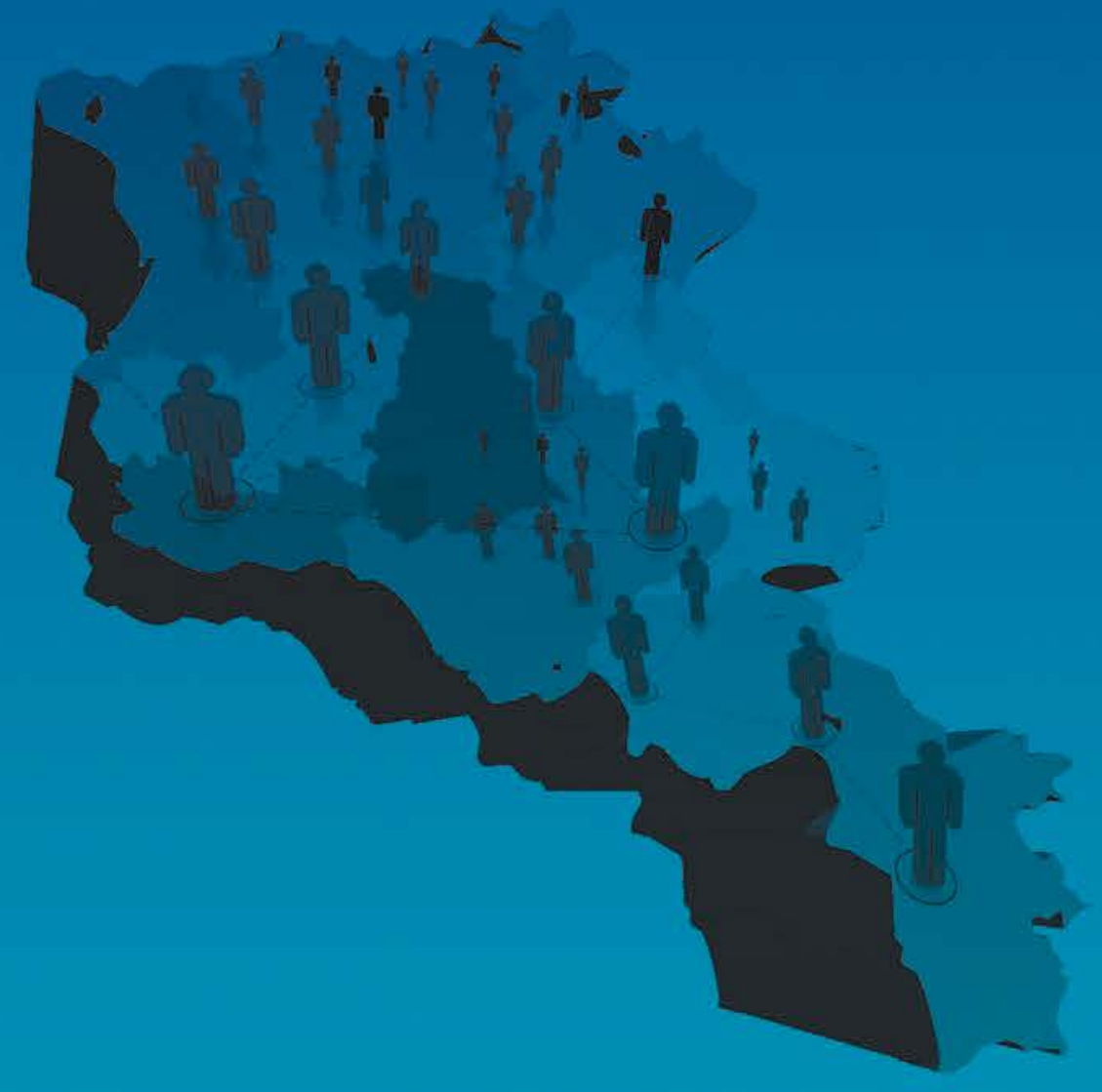

THE CASE OF ARMENIA

\section{How Board Networks Affect Firm Performance and Innovation Incentives}

TATEVIK POGHOSYAN 
(C) copyright Tatevik Poghosyan, Maastricht 2019

Printing: Datawyse | Universitaire Pers Maastricht

ISBN 9789463801966 


\section{How Board Networks Affect Firm Performance and Innovation Incentives in Transition Economies: The Case of Armenia}

How does the network structure of corporate boards affect firm performance and innovation incentives in transition countries: The case of Armenia.

\section{DISSERTATION}

to obtain the degree of Doctor at Maastricht University, on the authority of the Rector Magnificus, Prof. Dr. Rianne M. Letschert in accordance with the decision of the Board of Deans, to be defended in public on Wednesday 30 January 2019, at 12:00 hours

by

Tatevik Poghosyan

Proefschrift

ter verkrijging van de graad van doctor aan de Universiteit Maastricht, op gezag van de Rector Magnificus, Prof. dr. Rianne M. Letschert, volgens het besluit van het College van Decanen, in het openbaar te verdedigen op Woensdag 30 Januari on 12:00 uur 
Supervisor

Prof. Dr. Robin Cowan

Co-supervisors

Dr. David O’Brien

Assessment Committee

Prof. Dr. Pierre Mohnen (chair)

Prof. Dr. Victor Gilsing

Prof. Dr. John Hagedoorn

Prof. Nicolas Jonard 


\section{CONTENTS}

CHAPTER 1 INTRODUCTION........................................... 1

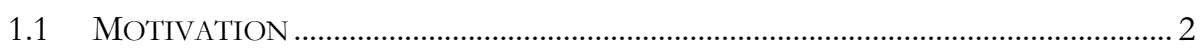

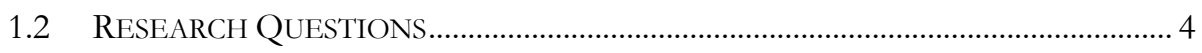

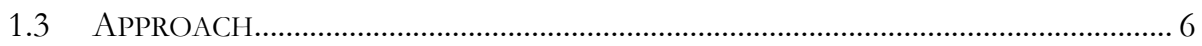

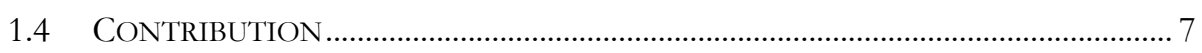

1.5 THE ORGANIZATION OF THE THESIS................................................................... 9

CHAPTER 2 BACKGROUND........................................... 13

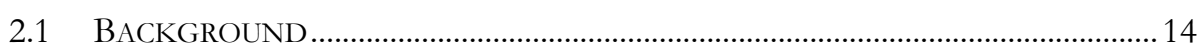

CHAPTER 3 THE NATIONAL INNOVATION SYSTEM OF ARMENIA..... 25

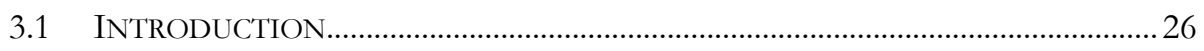

3.2 NATIONAL INNOVATION SySTEMS IN TRANSITION COUNTRIES......................2 27

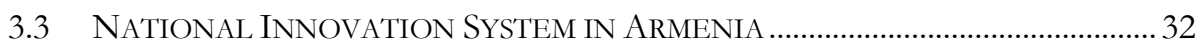

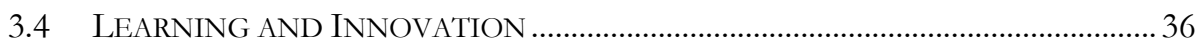

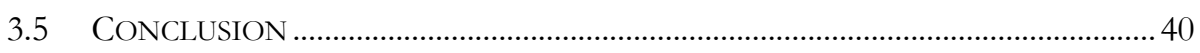

CHAPTER 4 BOARDS, PERFORMANCE AND SOCIAL CAPITAL............ 43

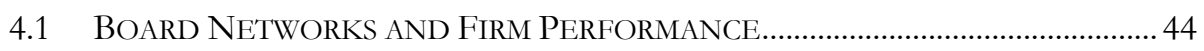

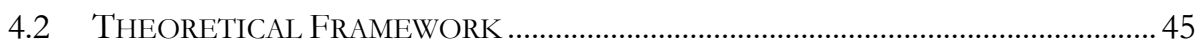

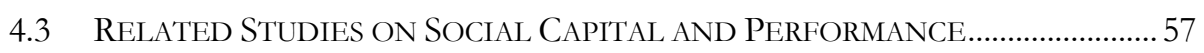

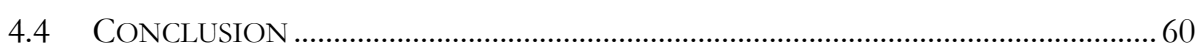

CHAPTER 5 EMPIRICAL APPROACH ............................... 67

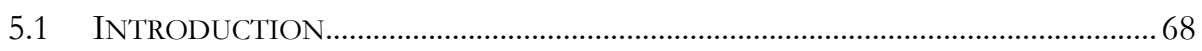

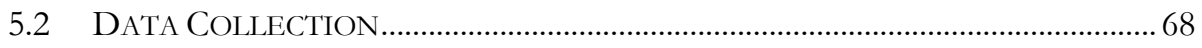

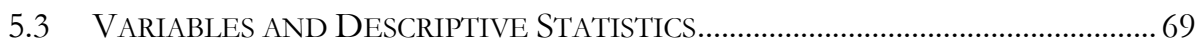

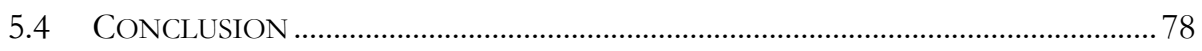

CHAPTER 6 ECONOMETRIC EVIDIENCE............................ 87

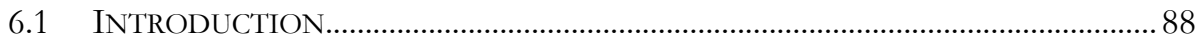

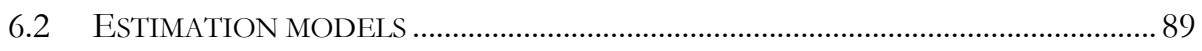

6.3 EFFECTS OF NETWORK STRUCTURE AND CONTENT ON FIRM PERFORMANCE ... 91

6.4 INTERACTION EFFECTS BETWEEN NETWORK STRUCTURE AND CONTENT .. 96 


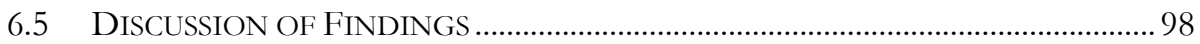

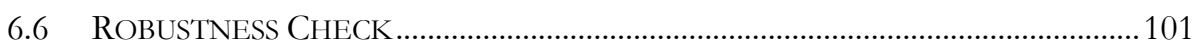

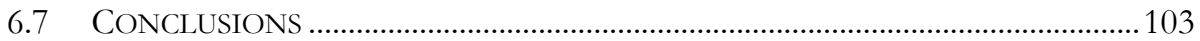

CHAPTER 7 FIRM INNOVATION: INNOVATION SURVEY ............. 113

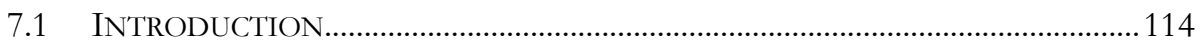

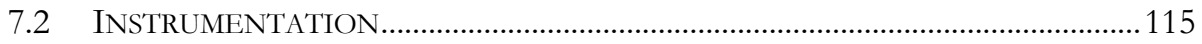

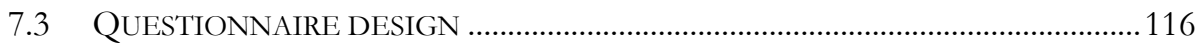

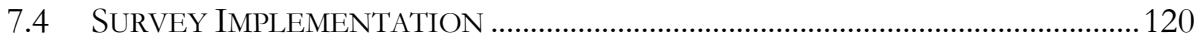

7.5 LESSONS WE LEARN THROUGH FIRST INNOVATION SURVEY IN ARMENIA. 123

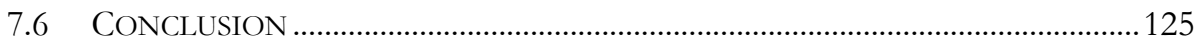

CHAPTER 8 PATTERNS OF INNOVATION OF PRIVATISED FIRMS.... 127

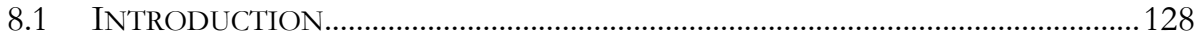

8.2 TAXONOMY OF INNOVATION REGIMES ............................................................... 129

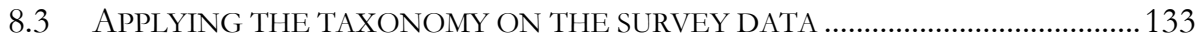

8.4 FACTORS THAT ARE CORRELATED WITH FIRM R\&D AND INNOVATION.....145

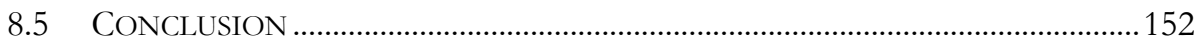

CHAPTER 9 THE IMPACT OF SOCIAL CAPITAL ......................... 157

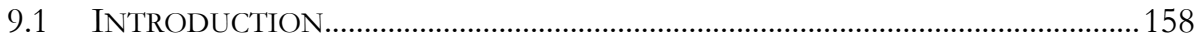

9.2 CONCEPTUAL FRAMEWORK AND HYPOTHESES .................................................. 159

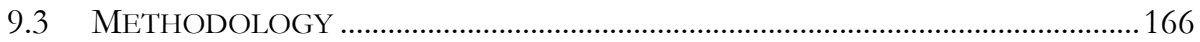

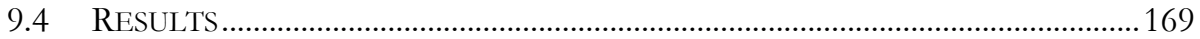

9.5 DISCUSSION OF RESULTS AND CONCLUSION …….................................................. 173

CHAPTER 10 CONCLUDING REMARKS.................................. 179

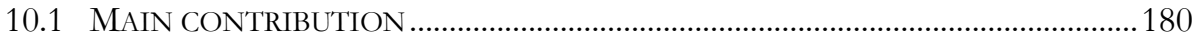

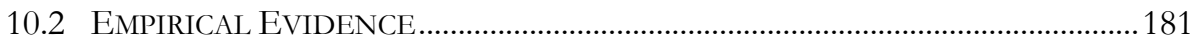

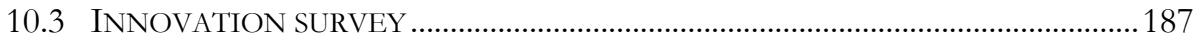

10.4 CONTRIBUTION TO THE SOCIAL CAPITAL LITERATURE ...................................190

10.5 DisCUSSION, LIMITATIONS AND FUTURE RESEARCH....................................... 191

BIBLIOGRAPHY .................................................. 207 


\section{Appendices}

Appendix A: Literature Review ....................................................................................... 63

Appendix B: Corporate Network ……………………………………………………... 79

Appendix C: Description of the firms' financial data......................................................... 82

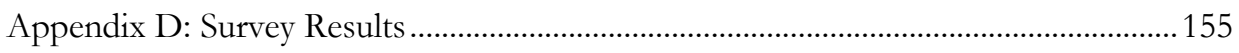

Appendix E: Results of probit and ordered probit models............................................176

Appendix F: The Survey Questionnaire ……………………………………………...... 193

\section{Figures}

Figure 3-1: National Innovation System........................................................................ 27

Figure 3-2: National Innovation System in transitional context........................................ 30

Figure 3-3: Annual GDP Growth Rate............................................................................... 34

Figure 3-4: GDP composition...................................................................................... 34

Figure 4-1: Conceptual model of social capital and firm performance …….................... 45

Figure 5-1: ROA and ROE by Industry ………………………………………………... 77

Figure 5-2: Export by Industry..................................................................................... 77

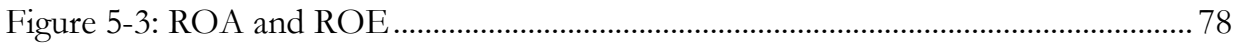

Figure 8-1: New to the market vs. new to the firm innovations ....................................136

Figure 8-2: New to foreign market vs. new to the local market......................................136

Figure 8-3: Distribution of R\&D and non-R\&D activities ............................................138

Figure 8-4: Proportion of innovating and non-innovating firms ................................... 141

Figure 8-5: Type of innovation cooperation partner by location .....................................143

\section{Tables}

Table 4-1: Empirical hypotheses for estimation of firm performance .............................. 62

Table 5-1: Distribution of degree centrality in percentage ……………………………….. 74

Table 5-2: Summary Statistics of Network Variables …………………………………... 75

Table 6-1: Results: Network Structure and Network Content: ......................................... 93

Table 6-2: Summary of Marginal effect of Network variables.......................................... 94 


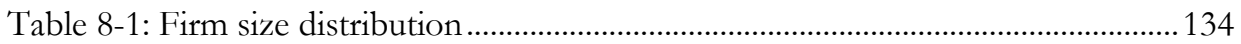

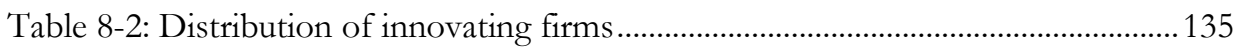

Table 8-3: The percentage of innovative firms conducting R\&D................................. 139

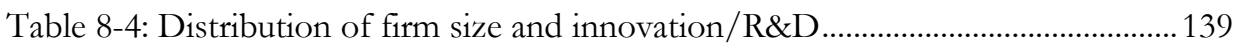

Table 8-5: Largest geographic markets in percentages................................................... 142

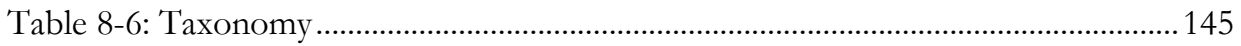

Table 8-7: Probability of performing R\&D: Probit model.............................................. 147

Table 8-8: Probability of the firm to introduce innovation ............................................. 149

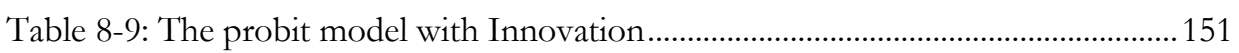

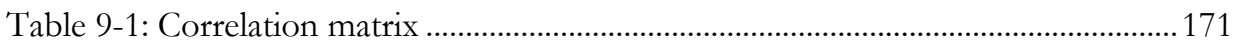

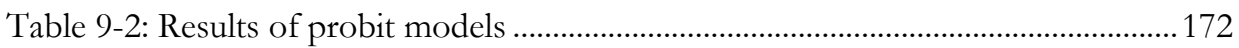




\section{SUMMARY}

\section{Objectives}

This thesis explores board member networks and their influence on firm performance and innovation and presents a conceptual framework for understanding and ultimately predicting the impact of board network features on firms in both established and transitional economies. A board member networks refers to the connectedness between firms in an economy resulting from individual board members who have membership of more than one firm boards. The study considers these networks as having an intrinsic business value for firms, known in the literature as "social capital". The thesis proposes that "structural" and "content" attributes of board member networks are the key levers underlying the social capital of these networks and their value for firms. Applying insights from social capital theory, the structural aspect of the social capital emphasizes the role of the firm's position in the board network, while network content suggests that attributes of partner firms are also significant factors toward firm performance and innovation.

\section{Approach}

We have collected panel data of 200 Armenian firms (Open joint stock companies) for the period 2000-2010, which include data on board members, firm's financial, industry, profit and other relevant variables. In addition we have conducted the first firm's innovation survey among selected firms.

We have constructed board network for four years and have generated various social capital variables using tools from social network analysis. The first part of the empirical analysis focuses on impact of social capital on firm financial performance as measured by the return on assets (ROA) and return on equity (ROE). In the second part we estimate the impact of social capital on firm innovation in Armenia.

\section{Findings and Conclusion}

Our empirical evidence shows that social capital embodied in firm connectedness has a significant impact on firm performance. The literature argues that shared board members serve as channels for transmission of information and knowledge, exchange of resources and assets across firms, which positively impact both their innovativeness and financial performance, and our results support this argument. It is not always true, though, that more connectedness is always better: under some circumstances, gaps in connectedness can actually be beneficial for firm performance.

The study finds that network diversity, partners' assets and export volume are important for improving financial performance and innovativeness (including the degree of novelty of innovativeness). For example, if a firms is embedded in a rich network, where its partners possess higher financial resources, it is more likely that the firm will benefit from the borrowing from its partners if the network is more closed, as cohesive network endure higher level trust among its member, they provide monitoring and sanctioning opportunities, especially when the legal infrastructure of the country will not protect the firms. In support of measuring and utilizing social 
capital, we contribute to the literature with new measures for assessing network content and provide empirical evidence how those measure explain the firm performance.

Further research could investigate the joint effects of board network and board members characteristics on firm's learning and innovative outcomes. Our approach can be applied also to other country context, and findings can provide important insight for policymakers in the field of corporate governance, firm's growth and innovation. 


\section{Acknowledgements}

I would like to express my profound gratitude to my parents, professors, friends and government officials in Armenia for their valuable support and contribution in fulfilment of this research. I am deeply grateful to a group of academics of the Doctoral Program at UN University - MERIT for their valuable comments provided me with thoughtful and insightful feedback, and have helped me both to sharpen and nuance my arguments and to deepen my understanding in econometric research. First and foremost, I would like to thank my supervisor, prof. Robin Cowan and cosupervisor Dr. David O'Brien, who provided a valuable and compassionate space for critical explorations of economics and social network analysis. I would also like to thank my MA thesis supervisors at Tsukuba University professor Hanaki Nabuyuki and Nakajima Ryo. I am grateful to my supervisors including MA supervisors for providing much appreciated input, interest and encouragements in this research, as well valuable guidance and advice on certain theoretical questions and dilemmas. I thank for their patience and tremendous help.

Prof. R. Cowan and Dr. D. O'Brien provided original ideas and interesting comments which have been extremely valuable for my thesis and professional development. I would also like to thank prof. Pierre Mohnen, for his valuable comments and professional guidance related to the modelling and econometrics.

My thesis was improved and shaped through the constructive comments of the members of the assessment committee, Prof. Dr. Pierre Mohnen, Prof. Dr. John Hagedoorn, Prof. Dr. Victor Gilsing, Prof. Nicolas Jonard. I thank for their time, effort and detailed comments that helped to improve and enrich the thesis. I am also indebted to Antony Arundel, for helping me with the design of the first country-wide Innovation Survey conducted in Armenia. This was a very challenging and brave undertaking, and his support and comments provided me much appreciated support and confidence to fulfil this task successfully. I am hugely appreciative for the collaborative support I received from the Ministry of Economy in Armenia, AM partners, and the group of people including my family who helped me to collect the data and conduct the survey in Armenia.

I am also thankful for the comments and suggestions of the participants to the International Schumpeter Society Conference in Montreal, the Globelics Conference in Bandung, SUNBELT conference in Florida, European Association for Evolutionary Political Economy Conference in Bodeaux, and Globalic Academy in Rio de Janeiro. I would also like to extend my thanks to Globelics Academy Alumni initiative for publishing the book and including one of my chapters, and in particular - Alexandra Tsvetkova, Jana Schmutzler, Marcela Suarez, and Alessandra Faggian - for their work and comments.

UNU-MERIT is the most exciting place in the world to pursue Ph.D. I would like to thank employees of UNU-MERIT for offering a stimulating and friendly environment. It was always great to know that I can count on them in any situation. I thank Eveline, in particular, for putting so much effort in helping each UNU-MERIT student to feel at home. My memories of UNU-MERIT are filled with warm and grateful feelings due 
to Eveline's supportive and kind attitude. I also thank Ad, Eric, Herman, Howard, Marc, Mitie, Monique, Mourik, Sueli, Susan, and Wilma for their daily support.

My family has always encouraged me and supported in this challenging endeavour. I would like to thank for my parents for their support and for directly contributing and supporting during the field survey in Armenia. Finally a special mention of my fellow $\mathrm{PhD}$ students who surrounded me with love and friendship during my Ph.D. years in Maastricht. I am glad to think that I have obtained life-long friends. Needless to mention say that our daily discussions, with Samyukta, Giorgio, Francois, Iman, Jocelyn, Jennifer, Daniel, Francesca, Alejandro, Shuan, Charlotte, Elisa, Simone, Stefania, Juan Carlos, Asel, Allison, Andrea, Kristina, Dorcas, Irina, Nasser filled my life with joy and encouragement which was essential to continue to work on the thesis. 
CHAPTER

\section{INTRODUCTION}




\subsection{Motivation}

The transition from planned to market oriented economies in Central and Eastern European countries and in the former USSR represents a rare opportunity to study a profound economic, social and political transformation. During the early transition period from 1991-2000, most scholars were focused on analyzing differences and similarities of development patterns of those countries (Berglöf, Thadden, and ErnstLudwig 1999; Commander 1998; Ees and Bachmann 2006; Batjargal 2006; Black, Kraakman, and Tarassova 2000; Frydman et al. 1999; Godoy and Stiglitz 2006; McDermott 2002; Kogut and Spicer 2002; Stark 1991). It was a natural experiment to test many economic and sociological theories that discuss behavior of economic agents in uncertain environment with the evidence that those countries provided. Interestingly, this literature (e.g., institutional economics, evolutionary economics) emphasizes the role of institutions and the interplay of political and economic institutions in shaping those societies. The transition from one system to another was so radical that economic agents - people, firms, organizations, and states - were replaced, re-organized or re-tasked in the new setting without any prior knowledge nor with any normally functioning market-supporting institutions. From an evolutionary economic perspective, this is a sort of "ideal type", as it allows the society to replace the actors in a highly uncertain environment, and lets them to evolve, to generate a new, or at least different society without a well-thought out plan, however the participants in the process must find ways of coordinating their activities in the face of this ignorance and lack of institutional support.

From a socio-economic perspective, the collapse of the Soviet Union ended a highly structured market system leaving privatized firms and new private firms to develop independent supply chains. In the turmoil that ensued, thousands of specialist and engineers became unemployed. All transition countries experienced a radical drop in GDP, which only recovered very late in Russia (2006), and in many countries (including Armenia, Serbia, Moldova, Ukraine, Georgia, Tajikistan and the Kyrgyz Republic) the output remained below their 1991 levels until 2013 (Berglof 2015).

Under the Soviet system many social and political issues were suppressed and as a result, the collapse of USSR was followed by many ethnic wars between and within the countries. Armenia was one of the countries that experienced such issues, and its transition was made even more difficult as a result of the war with Azerbaijan. Business survival in this context demanded a dramatic change in mindset.

Armenia is a particularly useful country to study because a) it was characterized with highly uncertain environment (e.g., war, economic reforms); b) it was highly industrialized during the USSR; c) due to its small size we could examine the social networks for all corporate companies. Despite its small size Armenia was an important link in the soviet production chain. The country enjoyed the highest proportion of scientists and engineers relative to its own population. However, the transition started with extremely challenging conditions: war, an economic blockade and the dissolution of the Soviet production system. Our focus is on large privatized firms, which were 
the main drivers for the Armenian economy during the soviet period. By studying privatized firms in Armenia between the period of 2000-2010, ${ }^{1}$ we provide empirical evidence on how firms passed through the transitional process, what mechanisms (i.e., social networks) were developed to stabilize the turbulent macro and micro environment and which factors drove firms to perform better and innovate. While studying the evidence from Armenia, we emphasize that transitional reforms and past USSR history ("soviet heritage") are important factors that affected the country's economic development. It is now more than 25 years since the collapse of the USSR, but former Soviet countries still experience the consequences of first-generation policy reforms.

During the early transition period many scholars were concerned with macroeconomic adjustments and structural reform policies. The international community was strongly involved in this process and was pushing privatization, institution creation, and so on. Though the countries went through dramatic economic and political reforms, with radical changes to how the economy was organized, less attention were paid to transformation of National Innovation Systems.

One intriguing question that is not answered even after reviewing the literature on transitional countries is what could have been done differently so that the transition would not have been so painful and destructive: in the literature review part we discuss the views of the gradualist reform approach, which argue against rapid liberalization approach. However, the goal of the study is not to contribute to this debate, but to bring it in our discussion to deepen the understanding of the transitional environment where firms were operating and discuss why firms had to find alternative strategies to survive in this environment (we discuss the relative performance of alternative networking strategies on firm performance).

One of the main and fundamental debates in the early transition period was whether countries should implement radical changes ("shock therapy" approach), or choose a gradual transition that emphasizes the importance of economic actors' adaptations to new institutions. This debate was reflected in the issue of the speed and sequencing of privatization policies. Proponents of "shock therapy" argued for mass privatization that is, privatization of the large-scale state property in a very short time (neo-liberal approach), while proponents for gradualism were against large-scale privatization policies, especially when the countries did not establish supporting legal infrastructure (new institutional approach). ${ }^{2}$ Although this debate is beyond the scope of our study, nevertheless the discussion and previous comparative studies shed light on consequences of the reforms that we believe affect the country's development, and the behavior and the incentives of the economic agents. Understanding those processes explains issues in transitional countries. This study examined privatized companies,

\footnotetext{
${ }^{1}$ From 1990 to 1995 Armenia was engaged in the war with Azerbaijan. As a consequence, the government was delayed in introducing the first generation of structural reforms, such as privatization. Compared to other newly independent countries, privatization lagged by several years and only began in earnest in 1998 and 1999.

${ }^{2}$ Kogut and Spicer (2004) reviewed the literature on the main debates on transitional policies and reforms.

And have extensively analyzed the publication of the scholars in both camps- "shock therapy" and gradualism. Some of the "Shock therapy" proponents were also consulting World Bank and governments of transitional countries (e.g. Sachs was Russia's president's advisor).
} 
because how the privatization policy was implemented had an important impact on the environment where firms were operating. The "shock therapy" reforms such as mass privatization created high uncertainty, and one of the survival strategies of the firms to cope with uncertainty was to rely on their personal networks and seek support in informal arrangements.

Early transition literature was very critical about rapid market reforms: researchers argued that reforms imposed market-supporting institutions without taking into consideration the local differences, which lead to consolidation of state property in the hands of the pre-existing elite in post-soviet countries (Kogut and Spicer 2004; Spicer, McDermott, and Kogut 2000). Mass privatization, which is supposed to transfer ownership into the hands of the population and improve production efficiency, has failed in post-soviet countries. Stark (1991) and McDermott (2002) argue that the fall of a planned system left economic agents and firms embedded in the pre-existing business and social networks; as such, strong personal ties, especially with the political elite, provide both resources and authority. Key here is the idea, or perhaps observation, that pre-existing networks serve as an alternative mechanism for markets that support organizations in their efforts to coordinate economic activities. This issue is central to the analysis in this thesis: Do firms that participate in informal networks and utilize social ties (which might serve as alternative coordination mechanisms) perform better than firms that do not?

One way to study those networks is to examine the initial board network that formed as a result of privatization. In studying transitional economies, including the Armenian economy, the notion of personal networks has several advantages: first, in transition countries collaborations among companies are highly personalized and second, many researchers describe how personal networks reflect the social relations in transitional countries (Salmi 1996; Ledeneva 1998; Ledeneva 2009). The anthropological study by Ledeneva (1998) even pointed out how some Russian expressions used on a daily basis reflect the power of personal ties. For example, the phrases moi krug (my circle) and krug znakomich (circle of acquaintances) show that unless a person belongs to the circle he/she will not be trustworthy. It seems very likely that the power of personal ties changed slightly over the transitional period as formal institutions became more mature and legitimate. As formal institutions emerge and are strengthened, one thing that gives social networks value, namely their ability to reproduce or replace the role of formal institutions, disappears. Nonetheless, we should not ignore their role, as a mechanism to gain a competitive advantage and to have access to critical resources and information that the formal institutions cannot provide.

\subsection{Research Questions}

The main objective of this study is to investigate the role of social networks of corporate board members in explaining firm performance in transition countries.

How important were social networks in explaining firm performance in
transition economies? 
A literature review of transitional countries leads us to the conclusion that the transition from a planned to a market economy is characterized by high uncertainty and lack of market-supporting institutions. These features strengthen the role of longstanding social ties in shaping the post-soviet economic reality, and partially substitute for weak and not entirely legitimate (formal?) institutions. The major structural reforms were slow in reaching their policy goals because market information was opaque, and corporate restructuring was slow, and actors of all types experienced difficulty navigating the turbulent economic conditions. In these conditions, we conjecture that social networks played a constructive role in opening up channels of communication and support through inter-firm information flows.

\section{What role did board networks play in supporting privatized firms?}

Our evidence is based on the examination of Armenia's transitional experience, where we traced the network of board members of privatized large firms. The role of the board network as a mechanism for firms to gain external resources and knowledge is recognized more often in research of developed countries (Mizruchi 1983; Talke, Salomo, and Rost 2010), but the small amount of evidence from transitional countries also contributes to this stream of literature (Stark and Bruszt 1998; McDermott 2002). Literature in this domain supports the argument that the board network is an important source through which the firm can access new and complementary resources, knowledge and information. In particular, board networks facilitate following mechanisms for firms: reduced uncertainty and dependence (Martin et al., 2015; Beckman, Haunschild, and Phillips, 2004), enhanced organization learning (Uddin, 2012) information sharing (Shropshire, 2010), and signal for higher trust and quality (Su and Zhang, 2008). Consequently, more relational and social capital visions of the board have emerged in the literature (Mizruchi 1983; Dicko and Breton 2010; Kim 2005; Wincent, Anokhin, and Örtqvist 2010).

\section{How can we apply social capital theory in this context?}

We applied social capital theory to explain the mechanism of how a firm's position in the board network explains its financial performance and innovativeness. Our conceptual framework distinguishes two aspects of social capital — structural and content. The structural aspect of social capital emphasizes the firm's position in a board network, while network content suggests that attributes of partner firms also matter for the firm's performance and innovation. ${ }^{3}$

In this study we also address the question of how social capital is utilized by the firms, and by what mechanisms. We do not address the mechanisms directly, as that is beyond the scope of our data. However, by addressing the role of "content" in the analysis we can infer what mechanisms underpin firms' use of networks to enhance performance. The structural aspect may indicate what potential resources are available to the firm through its network, while network content measures the actual resources

\footnotetext{
${ }^{3}$ Our concept "network content" is close in spirit to "relational content" (see Hansen, M.T. (1999) or Gilsing, V. \& B. Nooteboom, (2005)). Rodan, S. and D. Ch. Galunic (2004) used "network content" to refer to knowledge heterophily. We are referring here both to nodal attributes such as firm size, industry, location, but also some dyadic network attributes such as homophily of links.
} 
that partners possess. However, these two dimensions do not ultimately indicate how a focal firm utilizes the resources possessed by its partners.

To deepen our understanding of how firms benefit from social capital, we suggest looking at complementarities between network structure and content. For example, if a firm is embedded in a network where linked firms have greater financial resources, the focal firm has a greater likelihood of accessing financial support from connected firms than a firm that is not connected to a 'rich' network. But the likelihood of borrowing is higher in closed networks (network connectedness), as tight ties endure higher-level trust. The value of a closed network is increased particularly with environmental uncertainty and weak legal infrastructure, where formal regulations do not provide protection against deviation (here the transition context is important.), while these networks do provide monitoring and sanctioning opportunities.

The empirical focus seeks to identify which form of social capital (network structure and content) and which mechanisms of its utilization (interaction of these two dimensions of the social capital) enhance financial performance and innovation incentives.

\subsection{Approach}

To answer our research questions we first identify the population of firms for the further analysis. The focus of our analysis are Armenian companies formed as a result of privatization. The 207 firms examined were publicly listed firms with more than 50 shareholders. Such firms have a reporting obligation to the Armenian Stock Exchange and the Central Bank to provide annual financial statement and corporate board membership. These firms were the largest companies in Armenia during the soviet period.

Social capital we define using the network of the board members of all corporate firms, where two firms are connected if they share at least one board member. We construct the board network for 4 years in the period 2000 to 2005, where the board network of 2000 is the initial network formed as a result of privatization. ${ }^{4}$

Our first analysis concerns financial performance of firms. We collected archival data and with it constructed panel data for 10 years, for the 207 firms, which includes firmlevel information on Return of Assets, Return on Equity, sales, firm industry, etc. These data allow us to measure the effects of the board network on firm financial performance: testing how the past board network affects the firm's financial performance.

For the second part, on firm innovation performance, we conducted a countrywide innovation survey. This was the first innovation survey ever done in Armenia, and we were able to collect data for 2008-2010 on our 207 firms. ${ }^{5}$ We included retrospective questions to capture firms' past innovative performance; however, the main variable of

\footnotetext{
${ }^{4}$ Data limitations mean that it is not possible to construct networks for all 6 years, as we discuss in detail below. ${ }^{5}$ In this study we select all joint-stock companies that were privatized before 1999. This list was created in 1999. For the innovation survey, some of these companies ceased operating by 2010. See Chapter 7 for more details.
} 
interest is firm innovation for the period 2008-2010. The goal of this part of the research is to test the effects of the board network on the firm innovative performance.

The important aspect of this thesis is the application of social capital theory to conceptualize and empirically measure how board networks may affect firm performance. Following social capital theory and social network analysis we constructed variables that measure the levels of firms' embeddedness in the board network. We distinguish two aspects of social capital - structural, which captures the position of a firm in the board network, and content, which looks at the qualities of the firm's network partners. Lastly, we look at the complementarity of these two aspects of social capital. We applied social capital theory, which explains the role of personal networks, however this study tried to incorporate some specifications of transitional economies and provide richer evidence how personal networks are important for firms in transition economies.

The final chapter will synthesize the main findings, noting their implications for research and practice. We also discuss how the results of our study are interpreted in transitional context, and how it differs from developed economies.

\subsection{Contribution}

The study contributed to both social capital and transitional economies literature by providing empirical evidence from a small transitional country on how the social networks of corporate boards may increase firm competitiveness. The case of Armenia is not very well explored, and in the context of the social capital theory, we have the opportunity to examine the population of open joint stock companies and their board network. The collection of data was a critical point for fulfilling the goals. As part of the $\mathrm{Ph} . \mathrm{D}$. research project we created a unique dataset of privatized firms. First, we collected archival data (paper based) on all publicly listed companies $(\mathrm{N}=204)$, which included information on board members and the firm's financial reports (1999 - 2005). Second, we collected 10 years of panel data on firm level variables such as industry, sales profit, production, employment, etc. for the selected firms (provided by the Ministry of Revenue). Third, we conducted the first countrywide innovation survey in Armenia, which collected data on firm innovation $(\mathrm{N}=192)$ for the period of 2008 2010. The survey is a major undertaking of this study, and it contributed largely to the examination of the firm innovation in Armenia which was not examined previously. The survey data provided an opportunity to compare Armenia's innovation system and firms' innovation modes with that from other countries using studies based on the similar survey data.

The application of social capital theory on our data deepened our understanding of how firms that were important in the Soviet economy perform after the change of their ownership that accompanied transition, and how they are adapting to evolving and developing market conditions. We draw our conceptual framework to analyze the role of board networks in explaining firm performance. 
Social capital theory has addressed longstanding debates such as the relationship between a firm's network centrality and its performance or whether closed networks or "structural holes" are beneficial for a firm's performance. In this regard our study contributes to the social capital literature with new empirical evidence from Armenian firms. We examine these hypotheses in the relation to the firm's innovation and financial performance. Our data show that there is a positive but non-linear relationship between firm performance and the firm's centrality in the board network, and that in general, a network rich with "structural holes" or firm's brokerage position in the board network significantly increases firm innovation.

Our methodological contribution to measuring social capital variables enables improved operationalization of variables and interpretation. The review of the empirical literature on social capital shows that previous studies do not provide precise answers about how to measure social capital, ${ }^{6}$ or what the mechanism(s) of utilizing the social capital is (are). In this regard we contribute to the literature in the following ways: first, operationalizing network content measures such as network resourcefulness and foreign ties; and second, by providing empirical evidence how the interaction effects of network structure and network content affect firm performance. This is an area that has been relatively less explored in social capital literature, especially in the empirical literature. Our study examines what type of resources firm's network can provide access to, and how we can measure those resources (both tangible and intangible). And we also looked at how a firm's network structure complements the qualitative measures of the network. Previous studies have also addressed these issues (e.g., Rodan and Galunic,2006; Tsai and Ghoshal 1998; Reagans and McEvily, 2003), and in addition to the existing literature we suggest new measure for the network content as well as we brought insights from the country context in the development and interpretation of the social capital measures. By extending the notion of complementarity between network structure and content suggested by Rodan and Galunic (2006), we develop our framework by deepening our undetstanding through incorporating different network structures(e.i., network closure and structural holes) and network qualities (i.e., network diversity, network resourcefullness).

In terms of network content measures, we suggest using the diversity of a firm's connections in industry, region and firm type. Another measure we suggest is the network resourcefulness measured by firm's partners' assets, which is a proxy for rich and wealthy networks (rich and wealthy connections). In addition we used firm's partners' exports to measure how knowledgeable is the firm's network. The study finds that network diversity, partners' assets and export intensity are important for improving both the firm's financial performance and its innovativeness (including degree of novelty of innovativeness). In addition, we look at the complementarity between network structure and network content, firm's centrality and its absorptive capacity.

Social capital theory provides the analytical framework to examine the role of board networks on firm performance, and our application in the transition context has

\footnotetext{
${ }^{6}$ There is still lack of consensus in the social capital literature, particularly, in the qualitative aspect of the social capital.
} 
shown the extent to which social capital is important. Prior research would support the conclusion that social capital variables may have different effects on firm performance given the country's institutional set up. Similarly, wealthy and asset-rich networks are important in all societies, but when we discuss the transition context, wherein firms have limited opportunities to borrow from the banks and other formal financial institutions, social capital becomes even more important in how a firm finds a way to conduct its business. Batjargal (2007) has examined the effects of heterophilious (by industry) and high ranked (high-ranking officials among one's personal network) ties on entrepreneur profits in Russia. He argued that Russian entrepreneurs need to diversify their network ties - when business grow various needs rise, and these needs force to diversify one's network ties (Batjargal, 2000). Ties with high-rank official may provide some benefits to Russian entrepreneurs in accessing financial or other types of resources (Batjargal, 2007). Following this example, our study also tests the role of personal networks in transitional country, but with slightly different approach: rather than focus on the how entrepreneurs utilize their social networks for professional advancement, this study examines how networks created by corporate board members affect firm performance and innovation. Our study used board networks and privatized firms instead entrepreneurs compared to Batjargal (2007)'s study, and have used slightly different measures for social capital.

One of our assumptions is that in the transition context, given the lack of legal enforcement mechanisms, network closure and its complementarities with network content such as partners' assets may have a stronger effect on firm performance compared with regulated/developed economies. Trust and reliance on personal networks may partially substitute the lack of legitimate market-supporting institutes. In addition, the information commonly available to western firms was not present to Armenian firms, and this placed a premium on reliable information available through personal channels. This is consistent with the many studies that argue that during the economic transition, borrowing and barter are dominant strategies in inter-firm relations, but with the lack of a strong legal enforcement framework, social 'resources' such as reputation, trust and sanctioning mechanisms are the options to protect firms from opportunistic behavior of partners. In this respect, testing the complementarity in transition context (e.g., testing interaction between firm's network closure and richness of partners) may provide stronger evidence about the relationship between network content and network structure. Complementarity of a certain network structure and certain network content provide deeper understanding of what quality ties and what structure a firm could obtain through its board members to improve its performance. This information provide insight for firm's strategic decision on how to optimize its social capital.

\subsection{The Organization of the Thesis}

This thesis is structured into four main parts.

\section{Part I: Introduction and Background.}

Chapter 1 (current chapter) presents the overview of the thesis and discusses the research questions, the structure and the contribution of the thesis. 
Chapter 2 introduces the transitional context and briefly highlights the relevant historical and economic background.

Chapter 3: The main focus of this chapter is the case of the National Innovation System (NIS) of Armenia in the post-socialist period. It provides a description of an innovation system, identifying differences of a transitional context such as a historical heritage, technological specialization and innovation culture before and after the collapse of the USSR. As a highly industrial country during the USSR era, it faced not only the challenges for societal transformation, but also the need to establish a new innovation system on the ruins of the old one. This chapter lays the foundation for understanding the general macro-environment in which our study firms operate, and the challenges and opportunities that affected their innovation incentives.

Part II: Firm Financial Performance. The chapters discuss the role of social capital and firm financial performance.

Chapter 4 introduces the conceptual framework for the analysis and data on corporate board networks of privatized Armenian firms for the period of 2000-2010. Revisiting social capital theory, we developed several propositions on how social capital affects firm financial performance. In this chapter we develop the empirical hypotheses, which will be tested in Chapter 6. Our model is designed for measuring effects of social capital on firm financial performance. Key aspects of the framework are the relationships of network structure and content and firm performance, and also to network content and firm performance. We used measure of network centrality, structural holes and network closure to capture firm's network structure. And we used homophily/heterophily in the partner's attributes, the partner's total assets and export volume as a measure of network content. Another important part of our framework is to consider complementary effects of network structure and content on the firm performance.

Chapter 5 reports on the methodology we used to empirically analyze the effect of the board network on firm performance. First, our literature review identifies relevant empirical findings to predict the influence of our independent variables on firm performance. Building on previous studies, we operationalize key variables introduced in the previous chapter. This chapter provides detailed information about the data used for this study and variables that we constructed for different dimensions of the social capital. We then discuss the panel data fixed effect and random effect models used to estimate the impact of various social capital variable (measures) on the firm's performance.

Chapter 6 presents the estimation results from the econometric models. First, it examines the impact of structural independent variables on the firm's financial performance. Then, it shows the effects of network content variables on firm performance such as homophily, partner's assets and export volume, and lastly it tests the hypothesis related the complementarity of the firm's network structure and content. Panel data models were applied to provide robust estimates indicating the explanatory power of those independent variables for the firm's performance measured by Return on Assets (ROA) and Return on Equity (ROE). 
Part II: Firm innovation. It comprises chapters 7,8 and 9, which discuss survey instrumentation and analysis of the data, as well the role of social capital in explaining firm's innovation.

Chapter 7 gives an extensive account of the instrumentation methods used to collect data on firm level innovation activities and output. For the first innovation survey conducted in Armenia and covering the period 2008-2010, we used a subject-based innovation survey based on the EU Community Innovation Survey questionnaires and the Oslo manual guidelines. This chapter describes the design of the questionnaire, survey data collection and time-frames of the fieldwork. It also illustrates the different stages involved in the process of testing the survey instrument, and designing the final sample and conducting interviews.

Chapter 8 analyses the survey data and reports on various key innovation indicators and related variables of the selected firms by exploring the characteristics that explain a firm's innovative performance in Armenia. This chapter also lays the groundwork for the next chapter, which further advances analysis of the survey data and econometric modeling for estimation of social capital variables. Though this chapter is descriptive, it provides insight into the factors that are correlated with firm innovation. Key innovation variables are correlated to firm characteristics such as industry, size, exporting markets and inter-linkages. Firm innovativeness is analyzed from output and input perspectives, and the chapter also compares the results with evidence from other countries.

Chapter 9 reveals the multifaceted contribution of the board member network to the firm's innovation in part by extending prior research that addresses the effects of network resources. In this chapter social capital theory is applied to elaborate how the board network, which is powerful in the organizational context by adding competitiveness to the firm, influences a firm's innovative performance. This study also moves beyond the structural aspects of the board network ties, and again underscores the contribution of network resources, which directly capture the characteristics and resources with which partner firms are endowed. Analysis of 207 Armenian corporate firms suggests that the contribution of network resources to a firm's innovation varies with network structure.

\section{Part IV: Conclusion.}

Chapter 10 presents the main findings and conclusions, and recommendations for further research. 
CHAPTER

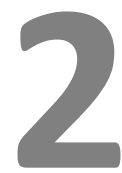

BACKGROUND 


\subsection{Background}

Over the last three decades the economies of Eastern European and former USSR countries have passed through remarkable economic, political and social transformations. The institutional changes happened very quickly, perhaps one of the only times in history when societies experienced such dramatic institutional changes in a very short time. In this chapter we review the studies on transition economies in order to analyze and explain heterogeneous outcomes of transition process, and identify the conditions and factors that most probably affect the transition process, before finally using this framework to examine the specific example of Armenia and the Armenian corporate network (board network).

\section{Transition Economies}

Neo liberal analysis and predictions of the development of post-soviet countries assumed that once the formal institutions of a market economy and democracy were introduced to the countries, it would lead to certain values and behavior, without considering that institutional learning itself could generate substantial (further) changes in the initial institutional setting. Institutional learning was one of the key concepts for the proponents of gradual change theory arguing that while market-supporting and democratic institutions were imposed on these societies, individuals (e.g., firms, employees, shareholders) shaped them differently based on their values and beliefs. These different responses to the change had the potential to create different institutional evolution in different locales. Understanding the processes of learning and adapting to a new institutional setting is a key to understanding why the outcomes of reforms are different in different transition countries.

More than two decades have passed since the collapse of the USSR, and only now can we discuss and compare the results of the reforms. Despite having started from more or less the same point, countries now show different economic, political, social and institutional outcomes. Some countries, especially in the Eastern European block managed more sustained economic development, while former-soviet republics were trapped with corrupt and autocratic political systems, which did not generate economic benefits for the society.

The durability of economic achievements was tested by the global financial crisis, which affected transition countries differently (Berglof 2015). All transition economies including both former-USSR and former-socialist countries in their early stages experienced a deep recession, which was followed by strong growth until 2008. The global financial crisis caused significant losses across countries, however some countries (particularly Central European and Baltic countries) recovered very soon after the crisis and resumed their growth, while others still struggle. Post-crisis (2008) analyses suggest that the growth experienced by transition economies before 2008 was related to their status as open economies. However, economies which accompanied their open trade policies with policies of industrial and technological upgrading were less vulnerable to the fluctuation in the global financial markets (Berglof 2015). 
Another important aspect of development for transitional countries was institutional transformation, which followed various trajectories. In general, a comparative analysis distinguishes two main blocks - first, Central and Eastern European and the Baltic countries, and second, former USSR countries (excluding the Baltic States). Countries in the first group were more successful than countries in the second group in terms of economic and political improvements, though there is a great deal of variation within the groups. The first group countries were geographically closer to Europe; they were socialized after the Second World War (being under the communist regime less than 70 years), and were better integrated into the EU infrastructure. As a result, these countries enjoyed higher capital inflows which facilitated rapid growth in the private sector (Berglof 2015). In contrast, countries of the second group had slower progress and less success in the quality of established institutions and political and economic performance. Within this group not all countries implemented radical institutional reforms: e.g. Turkmenistan, Belarus and Uzbekistan still keep the old soviet system, and they are characterized as having more authoritarian political regimes. Russia, Kyrgyzstan and Armenia passed radical reforms - they quickly destroyed the old structure and applied liberal macroeconomic stabilization strategies, whereas Ukraine, Belarus and Kazakhstan are characterized by a more moderate level of reforms - they implemented structural modification of institutional restructuring and their financial policies were oriented towards social stability and production recovery. Azerbaijan, Georgia and Tajikistan slowed down the transition processes due to their political instability and then followed a more gradual approach (Sargsyan and Markosyan 2014). Armenia followed Russian transitional policies until 1993, but then started to apply situational solutions after they did not see the expected results (Sargsyan and Markosyan 2014).

The question of the variety of outcomes among transition countries has been addressed in previous research. The main debate in the scholarly community has been when and how to implement the reforms, because these variables affected the outcomes of reforms (Kogut and Spicer 2004). Although all scholars agreed that there is a need for macro-economic adjustments and structural reforms, they split into two camps while discussing the speed and sequencing of implementation of transitional reforms.

The "shock therapy" camp argued that the bundle of reforms, which included privatization, stabilization and liberalization, should be applied all together and in a short time. According to neo-liberal economic ideology ${ }^{7}$ institutional reforms are secondary. However, this approach provides little guidance on restructuring marketsupporting institutions. In contrast, gradualism emphasizes the role of institutions including formal and informal social networks and the application of reforms that take into consideration of local differences. Stark (1991) stresses the evolutionary aspect of the transition process, mentioning that the shift from a planned economy to a new economic system should pass through local experimentation and learning. The

\footnotetext{
${ }^{7}$ Proponents of "shock therapy" approach represent neo-liberal school of thought, and economists such as Lawrence Summers and Stanley Fisher (Fischer, Summers, and Nordhaus 1992), Nellis (Nellis and Shirley 1992; Nellis 1999), Peter Murrell (Murrell and Wang 1993), and Sachs (Zinnes, Eilat, and Sachs 2001).
} 
disadvantage of mass privatization is that it creates opportunities for market exchange, but in a context that has no established legal system to regulate, monitor or enforce market contracts (Spicer, McDermott, and Kogut 2000). The absence of a legal infrastructure created through rapid privatization makes market solutions and coordination problems particularly costly (McDermott 2007; Spicer, McDermott, and Kogut 2000). The lack of formal institutional mechanisms (e.g., functioning regulatory framework, banking system) to support an interpersonal market exchange in postsocialist economies makes the role of informal agreements and relations even more important, leading many firms to pursue network strategies for growth in this environment (Stark 1996).

This has relevance to our study because it explains how radical reforms and the speed of implementation left individuals in a vacuum - individuals and economic agents could not understand what to believe in and how to behave. The chaos caused by the destruction of an old system without having a well-established new system in place led firms and individuals to experiment and to copy each other; this caused the mutation of various behaviors. This context describes the environment of Armenian firms that were placed in the market without any knowledge of how markets work, and no formal tools with which to examine reality or to participate in market exchange.

The previous literature identified four factors that are important parts of the explanation of the different outcomes of transitional countries. These are: the initial conditions, the speed of transition reforms, mass vs. gradual privatization, and ownership of newly privatized firms (locals vs. foreign).

Woo, Parker, and Sachs (1997) argue that difference in initial conditions determines the outcome of transition. They point out that private property developed in the agricultural sector in China and the decentralized nature of governance allowed for different policy options compared to Russia's case; hence, China had less rigidities within the socialist system, which allowed it to have better macroeconomic outcomes. Indeed, the lack of private property in the USSR created a totally different mentality, and even when almost everyone had some portion of state property (due to voucher privatization), they still did not know how to behave with the new property. An ideological shift from a common property to private or individual property system needs time in order for certain entrepreneurial behaviors to adjust. ${ }^{8}$ Woodruff (1999) shows, for instance, that even though rapid monetary policies were applied, money was still not the primary currency of economic transactions in Russia; rather, a barter system was widely used. Studying the cases of the Czech Republic and Russia, Kogut and Spicer (2002) argue that mass privatization did not facilitate the creation of transparent markets, as it was not followed by efficient secondary trading institutions. With the lack of foreign ownership, the learning process of local agents was very slow compared to Central and Eastern European block countries. Privatization programs implemented in former soviet countries were called the insider model, which means that work collectives and managers usually became the owners of state owned plants. Empirical evidence shows that foreign ownership in transition countries was positively

\footnotetext{
${ }^{8}$ Of course some individuals adjust extremely quickly, and they are able to "take advantage" of those who are slower to adjust.
} 
associated with a firm's productivity increase (Zinnes, Eilat, and Sachs 2001; Filatotchev et al. 2003); foreign owners could facilitate faster learning of the best practices, enhance firm's internalization and bring capital inflows. This is an idea that we incorporate into our analysis of Armenia below. Particularly in this context, foreign ownership, and more generally foreign exposure can be an important source of the resources (mental and otherwise) needed to adapt to the new situation.

Retrospective reviews of current economic outcomes of transition countries (e.g., IMF report 2014; Berglof 2015a) ultimately suggest that if countries had implemented a gradual approach (privatization and other reforms) with the participation of foreign investors, the economic actors would have better learning and adaption outcomes, less uncertainty and would be able to make better decisions.

In addition to these four factors, previous studies (e.g., Kogut and Spicer , 2002) have acknowledged the role of social norms and social network in shaping and legitimating the new institutional changes, however there were no studies to our knowledge that conducted cross-country analysis to compare differences of social network among transition economies.

\section{Privatization in Armenia}

The privatization process in Armenia passed through the following main phases: initial (1991-1994), large scale (1995-1998) and case-by-case (1998-2001)(Arakelyan 2005). During the initial phase, the Armenian government sold around $4 \%$ of small firms as an experiment before the Law on Privatization was adopted. The Law on Privatization established the first legal basis for privatization in 1992, with some amendments added in 1993. During the second phase, medium and large enterprises were privatized through privatization vouchers. All citizens received privatization vouchers and could participate in open or closed auctions. However, most of the vouchers were sold in the informal market at 30-40\% of their nominal value (Arakelyan 2005); and 20\% of the state enterprises were given to employees who had worked for at least one year in those firms without any charge. According to the Law, 30\% of the value of firms was given to citizens on the basis of social justice while the rest was privatized by other privatization method such as auctions.

During the period 1994 to $1995,53 \%$ of medium and large enterprises were privatized. By the end of 1997, around 60\% of small enterprises had been privatized and by the end of 1998, the voucher privatization program was over. From 1999 to 2001, the government moved to case-by-case privatization. The most important companies were privatized during this phase, including Yerevan Brandy Company, state shares in commercial banks, and large manufacturing companies. This stage included local investors and foreign investors, mostly from the Armenian diaspora. In general, the actual privatization outcomes compared to predicted outcomes were very low. ${ }^{9}$

\footnotetext{
${ }_{9}$ During the first phases of privatization, due to lack of external participation such as foreign investors, corruption and lack of financial resources in the hands of Armenians, national property was privatized at a price which was significantly below its nominal value. As a result the government did not raise sufficient funds through privatization to invest, or to lend money to the new owners. Therefore the first phase of privatization brought
} 
According to Arakelyan (2005) only the latest privatization phase had positive outcomes, and it contributed to the country's economic growth: in 1999 the GDP growth was $7.2 \%$, exceeding the predictions of only $5 \%$ growth.

The early privatization process took place during the war in Armenia from 1990-1995, when Armenia experienced an economic blockade and a radical drop in industrial output (Manasyan and Jrbashyan, 2004). ${ }^{10}$ The post privatization period for Armenia was characterized as highly unstable, and has continued to be so due in part to its geographic location. As a landlocked country, economic and political isolation from neighboring countries during the war emphasized the vital importance of Armenia's only working road. This road passes through Georgia, and connects Armenian enterprises with external markets, mainly in Europe and Russia. As Armenia does not have direct access to the sea, the Port of Poti and Batumi in Georgia provides sea access. The scarcity of local resources for local production makes Armenian industry highly dependent on imported inputs. Thus political instability in Georgia (which is not rare) creates additional barriers for Armenian firms. In the Soviet period, these issues were managed centrally, and as Armenia held a key role in the larger Soviet industrial complex, access to inputs and export routes were assured. However, in the post privatization period these assurances disappeared, and firms in Armenia were faced not only with institutional but also with political and geographical difficulties.

Although political and economic conditions in Armenia explain the poor outcome of privatization programs in the first two phases, regulatory frameworks and methods of privatization were also changed during the last phase. Ultimately, the last phase of privatization would become more successful, but by that time the majority of state property was already privatized using less effective methods.

\section{Social Networks in Soviet and transition economies}

Social networks are inevitable features of all markets, where actors use them as a mechanism to protect themselves from incomplete information and uncertainty and gain competitive advantage. The role of social networks became more vital in the context of transitional economies than in the context of developed economies: in transition economies actors found themselves in a highly uncertain environment without any prior knowledge of how to navigate in it. The transition process started with the destruction of the old institutions and not well-functioning or a lack of new intuitions, as a result economic agents faced the problem of contract enforcement, access to credit via banks, available and accurate market information. In order to navigate well in this situation, the economic agents were forced to use their social networks by either to forming a new networks or relying on the old ones.

negative outcomes, while only the second stage with case-by-case privatization the government was able to sell the factories at the nominal value.

10 Turkey imposed an economic blockade on Armenia in support of Azerbaijan and closed the common border because of the Armenian occupation of Nagorno-Karabakh and surrounding areas (source:

http://www.newnations.com/headlines/am.php). 
Business was bound to depend on informal networks, as the contract system was not developed. There were no formal rules to regulate the conflict of interests. Absence of formal rules and sanctions limits the opportunities to cooperate with individuals or firms who are not reliable and who are not part of the social network, where social sanctions are stronger, and thus the agents are less likely to behave opportunistically. The informal relations of trust formed in personal networks (friends, acquaintances, and extended family) were the only guarantee one could rely on (Batjargal 2006). Srubar (1994) argues that power of the communist party and a shortage economy created a mechanism for social integration based on social networks. In order to acquire goods and information people had to rely on their personal networks. Basically, social networks provided an alternative method to regulate the distribution system, when formal regulatory devices did not exist and were weak or untrustworthy. This attitude was inherited from the soviet culture, and was widely present during the transition, again emphasizing the importance of social capital in this context.

Ledeneva (1998) studied Russian culture and traced the effects of the soviet system on post-transition Russian social interactions, finding that actors do not change their "soviet mentality". "Soviet mentality" often has a negative connotation — in the literature it generally means lack of enterprise, sticking to old routines, strict hierarchies, and "soviet" way of management (Ledeneva 1998; Lonkila 2010). A countervailing institution was blat. ${ }^{11}$ As one of the ways of using personal networks to obtain goods and information, blat functioned as a distribution system during and after the soviet period (Ledeneva 1998). In her study, Ledeneva revealed that following the economic reforms, blat only covered reciprocity within personal networks but was not relevant either in market-based exchange or in activities oriented toward profit and financial performance. Barter is another example of a market exchange practice that was implemented in the post-soviet reality through informal social relations. Humphery (2000a) mentioned that post-soviet barter was unique because there were no other examples of large economies that relied heavily on barter mechanisms (see Chapter 3 and Seabright 2000). Ivanenko and Mikheyev (2002) concluded that barter appeared as a result of the structural weakness of the soviet system. Companies that were unable to pay suppliers or to pay salaries in cash had to offer goods or raw material or other forms of non-monetary payments. It is important to mention that even though bartering took place between firms, individuals, who relied on their personal networks, arranged the practical deals. Here we can observe the importance of inter-firm links, quite possibly at the board of directors level.

Our conceptual model is developed to establish the relationship between the resources and knowledge that a firm can access through its social networks and its financial performance and innovation. As social capital plays an important role in transition economies by substituting the absence of formal institutions, we were keen to explore what kind of benefits it can bring to a firm. In our study of the role of social networks we discuss the following three main aspects: that social networks can enhance the exchange of economic resources such as financial resources, assets, knowledge; they serve as a mechanisms to help cope with uncertainty caused by transitional reforms;

11 "Blat" means using personal networks as a means to buy products, occupy positions, gain information, etc.. 
and they provide ways for economic actors (e.g., firms, board members) to learn and to transfer knowledge.

Due to an underdeveloped banking system, the absence of alternative financial resources, a lack of external investors and poor state budgets, firms in the post-soviet period faced hard budget constraints. The credibility of many banks was questioned and it was also very difficult to receive financing from banks due to their high interest rates and collateral requirements. From the banks' perspective, studies (Dinnelo 1999; Guseva and Rona-Tas 2001) found that Russian banks failed to calculate the risks, and the only way they could obtain reliable information (on creditworthiness?) was through social networks, which involved trust. To receive loans firms had two options: to use the blat system or social networks; or to obtain a formal loan from a financial institution, which involved significant amounts of collateral (often many multiples of the amount of the loan), and paying high interest rates. Existing formal sectors for financial borrowing did not create favorable conditions for the development of businesses, which was one of the factors that caused entrepreneurs to look for alternative means of funding. The lack of financial institutions induced borrowing between firms and the practice of barter exchange, which again ultimately stressed the importance of social networks. Social networks provided trust, monitoring and sanctioning opportunities for the firms (Coleman, 1990).

One of the important aspects of the role of social networks is the fact that they reduce uncertainty in the surrounding environment. For instance, lack of information causes market uncertainty for firms, and hence constrains their ability to build coherent strategies. But being part of a network may increase access to critical information, as a result it will make smoother the firm's market planning. Salmi (1996) showed that personal interactions between top management of firms in Russia in post-soviet period complement or even substitute for written contracts, especially in a period of greater uncertainty. Furthermore, social networks are important because the speed of the institutional reforms applied in former soviet countries did not create a strong judicial system including commercial legislation which would regulate market exchange. In this situation, the lack of formal institutions supporting economic activity led entrepreneurs to rely more on their networks rather than on the formal regulatory framework; therefore, most economic activities took place through off-market-deals and private negotiations or blat (Spicer, McDermott, and Kogut 2000; Ledeneva 1998).

Besides learning about other firms, and arranging finance as just discussed, organizational learning and innovation was a very important driver for a firm's survival in the transition context. Firms faced a need to change their behavior in accordance with "new" market rules, and also to upgrade their technology and production, which was labeled as obsolete. Firms had to become more competitive and market-oriented or they would be out of business. Managers and executives in post-soviet countries found themselves competing in a new world, where they were at a competitive disadvantage due to their past economic orientation. Under the planned economy the operating environment was predictable and controlled. Risk-taking was strongly discouraged and managers were expected to follow the decisions from the top of political pyramid (Longenecker 2001). Suddenly faced with a very different context, how to learn what behavioural changes to make and how to make them was a serious 
challenge. In that situation, contacts with foreign firms or foreign investors appeared to be an advantage for firms. Foreign investors provided local managers with the knowledge necessary to allow them to learn and adapt faster to new organizational knowledge. For example, O’Brien (2006) examined the President's Program in Russia, a national business education and mentorship program for early career managers that were introduced to promote new management practices in privatized and new established companies. The evaluation of the President's Program showed that individuals who undertook an internship at a foreign firm were more likely to introduce successful reforms within their company (O’Brien, 2006). In a similar manner we assumed that exporting firms have more interactions with foreign firms, and they are more exposed to a new organizational knowledge.

Another challenge that the firms in transition faced was the urgent need for technological upgrades. After markets were opened to foreign products, local firms struggled to keep their organizations alive. When trying to compete in their local markets with foreign firms, or more ambitiously, to expand into foreign markets, local firms had to innovate or exit from the market, as their products were often considered “old-fashioned", obsolete or technologically poorly developed (Baković 2010). Innovation literature emphasizes that linkages and networks are critical for firms to innovate as they act as channels for obtaining adequate and differentiated knowledge (e.g., Cowan and Jonard 2009; Talke, Salomo, and Rost 2010; Arora and Gambardella 1990). Transition countries are not an exception in this regard, and in fact, with the weak institutional setting, and the sudden need for new and different (types of) knowledge, the role of social network becomes more vital. Firms rely highly on their social networks to learn from and monitor each other's behavior, but the learning outcomes may differ due to the type of social networks in which they are embedded. For instance, if a firm is linked with other firms who lack knowledge or are "soviet minded", then the social network may actually constrain learning outcomes of the best practice or new knowledge, while a firm which has ties with exporting firms or foreign firms have higher chances to obtain new knowledge and advance its managerial skills from its network (Spicer, McDermott, and Kogut 2000).

To sum up, we point out that social networks are important for knowledge transfer, learning and innovation. Besides one's network structure, characteristics of one's partners play an important role. If a firm is embedded in "rich" or "knowledgeable" network based on richness and knowledge of its partners, then firm may have better opportunities.

\section{Corporate Change and Board Networks}

One of the important and core processes of institutional restructuring in transition economies was the establishment of corporations, following the countrywide privatization of state owned companies.

One of the specific characteristics of soviet production was that fact that plants in general were larger than in developed countries. After privatization many former stateowned medium-sized and large companies converted to large open joint stock companies. The way that privatization was implemented in post-soviet countries, especially in Russia and Armenia, was that the property rights of those companies were 
transferred to "work collectives" (Kuznetsov and Kuznetsova 1996). As a result, insiders owned the majority of companies, and the managers had more privileged access to both ownership rights and the control of "worker's assets".

Corporate theory emphasizes three important functions of the board: first, boards advise top management, providing advice on firm strategy; second, boards are important for establishing links with the environment such as building organizational legitimacy (Kim 2005) or facilitating access to external resources critical for the firm's success (Kim 2005; Wincent, Anokhin, and Örtqvist 2010); third, they monitor the CEO's activities, ensuring the CEO acts in the firm's best interest (Mizruchi 1983; $\operatorname{Kim} 2005)$.

Literature in this domain supports the argument that the board network is an important means for the firm to access new and complementary resources, knowledge and information. Consequently, more relational and social visions of the board emerged in the literature (Mizruchi 1983; Dicko and Breton 2010; Kim 2005; Wincent, Anokhin, and Örtqvist 2010). Empirical application of social capital theory to boards of directors' personal networks shows that, indeed, the board network is an important type of social capital that provides the firm with a competitive advantage, and positively influences its performance (e.g., Wincent, Anokhin, and Örtqvist 2010; Non and Franses 2007). A recent study by Martin et al. (2015) shows that board networks enable the firms to improve their performance when they are confronted with greater uncertainty. Serving as a mechanism to cope with different type of uncertainties whether firm level, industry level, market level, or macro-economic — it helps the firms to adapt to new and not very favorable conditions, gain access to information and resources, which therefore allows them to be able to perform better compared to the firms with less network embeddedness. The information and resources gained through network ties reduces the firm's dependence on its environment and mitigates the negative consequences of the changes in external conditions (Martin, Gözübüyük, and Becerra 2015). It seems clear from the discussion above that these conditions hold very strongly in transition economies, and thus the role of boards should be very strong there.

The literature has shown that inter-firm networks, and particularly board networks may perform certain functions and give firms access to certain resources or inputs, and personal networks are most likely to be useful in certain types of situations. As argued above, these situations hold in transition economies, so we should expect to see evidence that firms that are able to form and use board networks perform better than those that cannot or do not.

Our empirical approach targets only the population of open-joint stock companies ${ }^{12}$ that were major large companies in soviet Armenia, and the board members that are listed in these companies. Through constructing the network of board members we trace the personal ties that connect firms in the post privatization period, and we analyze whether this network was beneficial for the firms. Various features of the transition context pointed out above suggest that personal contacts and reputation of

12 Open-Joint Stock companies are defined as the companies with more than 50 shareholders (1999-2005). 
the firm's key actors are very important in securing the firm's markets, access to limited state funding and other resources that affect firm performance (Kuznetsov and Kuznetsova 1996). In this situation, board networks ${ }^{13}$ play an important role, as firms faced the need to rely on a trustworthy network in order to have access to assets and resources.

\footnotetext{
${ }^{13}$ In a board network firms are linked to each other if they share at least one board member. In the literature they are also called "interlocked directorates". Some researchers also use "corporate capital" or "board capital" terminology: see (Wincent, Anokhin, and Örtqvist 2010; Talke, Salomo, and Rost 2010).
} 
CHAPTER

STATE OF THE NATIONAL INNOVATION
SYSTEM OF ARMENIA 


\subsection{Introduction}

Successful management of an innovation system can drive the growth of both companies and national economies. At the national level, governments develop instruments and policies to foster science and technology as well the innovative activities of the private sector. Many developing countries face challenges of technological upgrading. To this end, they employ strategies for catching-up with the countries at the technological frontier. Post-Soviet countries, too, have faced significant barriers to upgrading their science and technology. These countries, however, differ from other developing countries by their historical experiences and production system heritage, together with a shared set of difficulties brought on by the collapse of the USSR.

Years of operating under a central planning system and the corresponding lack of "economic incentives for innovativeness" made deep marks on firms, leaving them with slow and rigid behaviour in dealing with market changes. It has taken time for firms to alter their mindset and to develop their understanding of how capitalist markets operate and how to generate higher economic returns under a new system. Many high skilled workers and scientists left these countries, as the early transition often did not provide them any work opportunities and there was high demand for cheap highly skilled specialists in developed countries.

Armenia's transition, which began in the early 1990s, started with an ethnic conflict that ended in 1995. After 1995, the country embarked on its post-war recovery process by developing economic and social policies, which came into effect mostly after 2000. Macroeconomic data confirm that the main transformation processes were in effect after 2000, and in addition the majority of innovation policies were developed in the 2000s (UNECE, 2014). After the war (1991-1995), Armenia faced a problem common to all transition countries: how to integrate into the world economy with an "old fashioned" production system, poor technology and a lack of financial resources for education and science. However, Armenia inherited some advantages from its "soviet" past: high-quality human capital, well developed laboratories and universities for natural sciences, and a diaspora that was eager to invest in the country's economy.

As the thesis also aims to understand innovative performance of firms in this context, this chapter focuses on deepening our understanding of National Innovation System (NIS) characteristics in transition countries and, in particular, to discuss the conditions in which the Armenian NIS is transforming. We review the key historical path dependencies that are particularly important to explain the interplay between the development level of the NIS and the economic development of Armenia?

We begin with a discussion of the NIS approach in transition countries with a focus on the evolutionary aspect. We point out how the initial transition reforms and common historical path dependencies steer the development of NIS in transition countries and continue to affect it. We further our analysis by highlighting the macroeconomic environment, past industrial development and the challenges that Armenia faced during the transformation of its Regional Innovation System, which functioned very much as an integrated part of the USSR Innovation System, into a 
small country's (independent) National Innovation System. We also discuss the innovation governance system in Armenia, which deserves to be a part of this analysis, and is generally seen as an integral part of NIS. In section 4 we discuss learning and networks as an important aspect of the NIS approach, and how they play a crucial role in explaining innovation and economic development in transition countries. Finally, in section 5, we summarize some of the challenges faced in the transformation of the Armenian NIS.

\subsection{National Innovation Systems in Transition Countries}

The National Innovation System (NIS) of a country is an important factor for accelerating a country's growth and competitiveness. The NIS literature has developed since its first conceptualization by List (1841), who introduced it as a national system of political economy; later, Schumpeter (1935), Abramovitz (1986), and others presented it as a science and technology change that explains the economic growth.

Views on NIS specify the role of innovation rooted in the production system, first discussed by Lundvall (1985), and innovation based in the science and technology system by Freeman (1982); this bridges macro and micro perspectives of the innovation system. Another important aspect of the recent NIS approach is the consideration of socioeconomic features of national institutions in knowledge generation and innovation. In the 1980s, the OECD adopted the comprehensive framework of NIS which emphasizes the role of government, firms and research institutions and their interaction in a country's innovative performance. Figure 31shows that the innovation process includes a heterogeneous set of actors (such as government, public and private research organizations, and firms), and their interactions. It also stresses, though that these actors are influenced by country-specific characteristics - institutions, socio-economic context, history etc.

Figure 3-1: National Innovation System

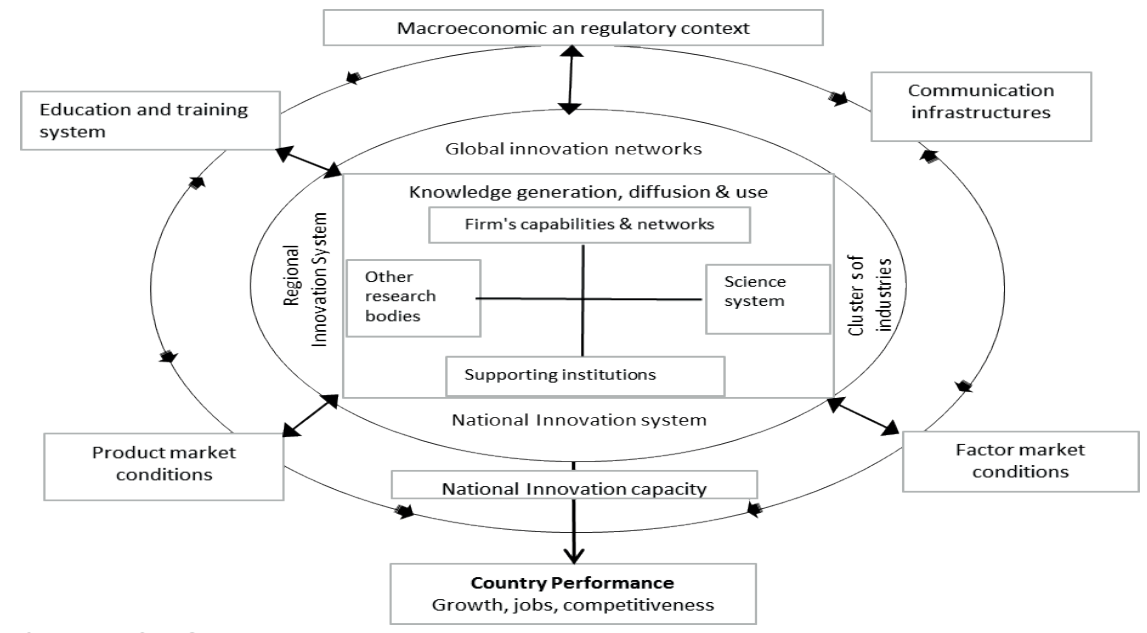

Source: OECD, 1999a 
Most of the early research on the NIS focused on developed countries. Since 2000, however, researchers have turned their attention to the specific nature of NIS in developing countries (Arocena \& Sutz, 2002; Intarakumnerd, Chairatana, \& Tangchitpiboon, 2002), and transition contexts (Kitanovic (2007) and Krammer (2009). Arocena and Sutz (2002) note that the NIS was conceptualized based on empirical evidence from the developed world, and was applied in developing countries as an "ex-ante" concept, with the apparent consequence that, some aspects of the NIS in the southern context are underestimated. These include, for example, knowledge production and knowledge transfer, where interactive learning is a key concept, or collective attitudes, as defined by Putnam's social capital concept, which emphasizes the crucial roles of institutions. If the NIS approach is applied in the context of developing countries, it should incorporate specific characteristics of developing, and perhaps even more so, of transition economies (Arocena \& Sutz, 2000; Kitanovic, 2007). What this idea implies for studying innovation systems in transition economies is developed below.

The post-soviet transition economies possess a number of historically unique characteristics, and have inherited innovation and production systems completely different from those of market economies. A major difference in soviet systems was the extent to which political, social, production and research systems were intertwined. The tight links between them implied that in the Soviet era it was very difficult to make any changes in one part of the system as the heavy linkages would transmit those changes as disruptions to the rest of the system. Naturally, the rest of the system would resist. At a different level, the transition economies generally (with some heterogeneity) inherited very high education levels, and very robust basic research capabilities. In principle this should be setting the stage for high innovative potential, but in practice the organization of the system prevented this potential from being realized. As well, production systems suffered from low productivity, and lagged behind many countries on the technological frontier. The latter feature suggests great potential for a new innovation system, but the former implies that the system is unlikely to evolve naturally to realize it. We see several paradoxes here of this sort where the system seems to contain potential, but at the same time has features blocking that potential. Consequently, Gu (1999) argues that transition economies (compared to developing countries) are more likely to require a direct policy intervention to restructure the countries' innovation systems.

In transition economies, primary policy attention was paid to establishing new political and economic environments via economic liberalization and privatization. Restructuring of enterprises did not receive much consideration (Bakovic, Lazibat, \& Sutic, 2013) because it was assumed that economic agents would intensify innovation in order to adjust to the new competitive environment. However, overall, the course of economic transformation in transition countries proved to be harder and longer than anyone could imagine, partly because the "soviet heritage" was rooted very deeply in the economy and the minds of people.

Building up an innovation system was more challenging than expected for a number of reasons. First, there were no institutions in place to facilitate innovation (e.g. financial sector and regulations). The "learning economy" is a crucial concept within the NIS 
framework, and refers to the ability of a country to absorb new knowledge introduced in the economy. Successful "learning", however, is not based only on absorptive capabilities, but also on the quality of political and social institutions (Lundvall et al., 2002). Second, reforms focused primarily on the privatization of industry and on education and did not attempt to build a new innovation system or to restructure the existing one. To the extent that innovation was even considered, it was believed that innovation would follow naturally from the need to compete. Third, reliance on strong personal linkages was a dominant strategy of doing business in the soviet era, and after the USSR collapsed, highly ranked officials took advantage of these linkages to use their status to navigate the changing environment. This implied great opportunities for short-term personal enrichment through privatization and its immediate aftermath, and these opportunities "crowded out" interest in innovation. Finally, the fact that the new environment inherited parts of a (poorly functioning) system meant that it could not begin with a blank slate. Transformation of the NIS had somehow to deal with the remains of the old system. Parts of the old system disappeared, and were replaced, creating very rapidly new vested interests. This made it very difficult to manipulate the NIS to a better state; even though it had some advantages (such as highly skilled labor) it faced resistance from new and old alike.

\subsubsection{The learning model in the transition context}

Knowledge exchange is particularly important for catching up with technological leaders. Unfortunately, opportunities for knowledge spillovers and knowledge exchange in transition countries are limited. Even when former soviet republics passed large-scale privatization, new owners were still mostly locally based. The lack of foreign ownership prevented local companies from adoption of new strategies. One thing that needs to be learned during the course of a transition is the importance of innovation. In the Soviet system, companies in the USSR had no incentives to innovate in order to improve their production because higher returns were simply taken by the state. After the Soviet Union collapsed, poor innovative outcomes in transition countries were at least partially driven by the persistence of such attitudes and the lack of initiative. But in addition, the lack of foreign ownership, which could have been an easy way to introduce innovation to the mindset of producers, meant that there was no obvious way to learn how and why to innovate. The dominance of local enterprise networks and weak national policies characterizing CIS $^{14}$ as high risk markets for FDI and foreign involvement, as compared to Central and Eastern European countries.

The Lundvall and Johnson (1994) learning model is a highly appropriate depiction of the learning process in the context of transition. According to the model, the learning process includes "creative forgetting" and "low-end forgetting". The difference between "low-end-forgetting" and "creative forgetting" is that the former refers to a type of knowledge, which is destroyed without serving the purpose of technological progress, while the latter serves as a ladder for the creation of new knowledge. To

\footnotetext{
${ }_{14}$ The CIS countries were Armenia, Georgia, Azerbaijan, Russia, Belarus, Ukraine, Moldova, Kirgizstan, Uzbekistan, Tajikistan, Kazakhstan, Turkmenistan.
} 
create new knowledge, transition countries first needed to destroy old knowledge, old habits and routines, and at the same time provide appropriate regulatory frameworks and institutions to support changes in the way new knowledge is created, diffused and used (Kitanovic, 2007). Some of the old knowledge, nevertheless, needs to be retained so that the introduction of new knowledge is successful. "Creative forgetting" requires special institutions that could be created or adapted from the existing ones. Ironically, the path of radical reforms followed in many post-soviet countries did not facilitate creation of legitimate institutions that could support organizational learning. As a result, learning in the transition economies proceeded through the "low-endforgetting" path. The destruction of economic linkages and existing structures happened haphazardly without control or direction by the governmental or other institutions. A remarkable brain drain that characterized most transition countries is, perhaps, the most vivid example of the negative consequences of this "low-end forgetting process". A significant endowment of knowledge at the beginning of market liberalization was often irreversibly lost.

Figure 3-2 presents a conceptual framework in a graphical form, which illustrates the role of actors, inter-linkages, learning, and external environment in the formation of NIS in Armenia and is a slightly modified version of Kitanovic's model.

Figure 3-2: National Innovation System in transitional context

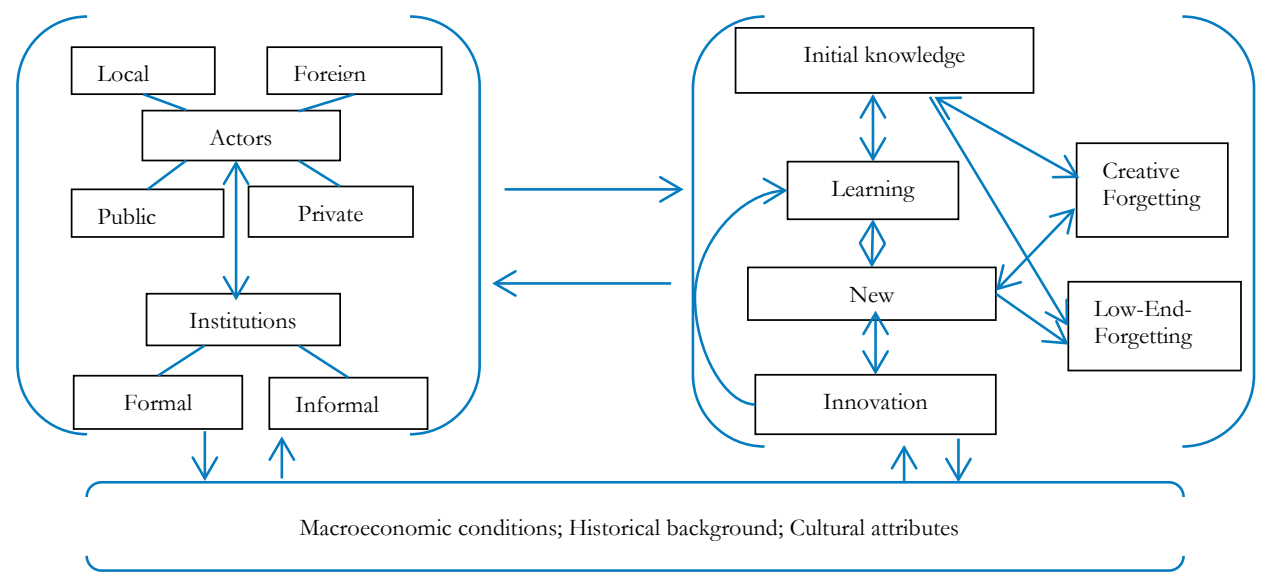

Source: modified from Kitanovic (2007)

Common with other NIS models, the important aspects of this model are that all components of the innovation system interact and shape the emergence of the NIS, and that the learning process is an important factor for explaining the innovation system. Literature on innovation systems shows that the macroeconomic environment plays a crucial role in determining the innovative performance of the country (Arocena and Sutz 2002; Lundvall et al. 2002). State policies can hinder or boost innovation, however global market conditions and historical backgrounds can be as important as the national policies. In the context of transition economies, privatization and old, soviet research and innovation infrastructures impacted the innovation processes. In addition, the absence or the presence of foreign actors, which was mostly determined 
by the privatization policies, also impacted the innovation outcomes in transition economies (Radosevic 2002). The lack of foreign actors in former-Soviet countries resulted the formation of informal local networks.

The transition process, characterized by the replacement of the old planned system with liberalized market and open trade, initiated the disruption of the production chains that existed in the USSR, and dealt a blow to the research and development $(\mathrm{R} \& \mathrm{D})$ system. Because goods produced in the Soviet Union were in general less technologically advanced, they were not competitive in foreign markets. Additionally, rapidly expanding imports made local production unviable and many factories were shut down, leaving thousands of scientists and engineers unemployed. The close integration of production, political, social and innovation systems meant that as large factories that were a part of the soviet R\&D system lost their old markets and production, the national R\&D systems were destroyed. To survive, high-tech industries often shifted their production to low-tech sectors. For example, the Armenian electronic factory Sirius was a leading producer of electronic chips in the USSR; unable to survive the transition as a high-tech enterprise, it switched to making shoes, souvenirs and other products, while thousands of engineers had to find jobs as low-skilled labor in other sectors of the economy. This transition we consider as an example of low-end-forgetting, where existing knowledge instead being upgraded or modified was lost.

It appears that exiting gradually from the old economic and innovation systems inherited from the USSR is crucial for preserving local human capital and R\&D infrastructure in well-functioning shape until it can be modernized (Kitanovic, 2007). In this case learning would follow "creative forgetting" rather "low-end-forgetting". Unfortunately, fast reforms provided blurry vision on potential opportunities both at state, firm and individual levels. As a result of dubious policy choices throughout the transition, many transition countries lost their R\&D potential.

\subsubsection{How small countries could succeed}

Armenia is not only a transition country, it is also a small country. Small countries also have specific concerns regarding to NIS, therefore the perspective on innovative systems presented by Roolaht (2012) appears to be particularly relevant. According to Roolaht (2012), inward FDI and knowledge flows, extensive international collaboration, clear development goals, human and social capital and higher flexibility in policy schemes are the factors crucial for the NIS success in small countries. Perry (2001) shows that in the case of small Nordic countries, shared trust and collective learning stimulate innovation in industries. This study argues that institutions and political environments should address the importance of changing business habits to create more open and trustful interactions between economic actors (Perry 2001). Another important factor that determines the success of a small country is the knowledge production and absorptive capacity (Roolaht 2012; Yalcinkaya, Calantone, and Griffith 2007). This is particularly the case with small countries that are not endowed with rich natural resources, as they can find a niche in a global value chain by providing knowledge skills. Empirical evidence suggest that in small economies, 
innovation policies have limited impact on growth, as they cannot provide a large contribution to global technology development, and have to rely on the absorption of external global knowledge base (Bye, Fahn, and Heggedal 2009; Roolaht 2012). Bye et al. (2009) also highlighted that in a small open economy, the promotion of technological export strategies has proven to be the most efficient, and knowledge transfer and spillovers from abroad enhance country's productivity growth.

To sum up, there are two main aspects that are relevant for the transition of NIS in Armenia. First factors are the specifications of transition processes including privatization and soviet-heritage, and second, it is the size of the country - the case of small Nordic countries shows that even without rich resources countries can still succeed if they have strong human and social capital. But human capital alone without strong public policies, relevant institutions and foreign actors was not enough for successful NIS transition: left to themselves, firms were not able to modernize their production and provide necessary training for the scientific personnel in order to stay up to date on recent technological developments. The former-Soviet republics that were endowed with rich $\mathrm{R} \& \mathrm{D}$ stock failed to transform it into assets and sources for economic growth, transition countries failed (Radosevic (2002)).

\subsection{National Innovation System in Armenia}

The Armenian NIS inherited the legacies of the planned economy, where the dominant linkages were between the central government in Moscow and large combinates (factories) across the USSR (Radosevic 2002). The strong dependence of individual republics on the central government during the USSR became a major barrier to transforming planned economies into market-oriented national innovation systems once those republics gained their independence. This situation is common to all former Soviet countries; they all faced similar challenges (Radosevic 2002), but applied different policies and have different economic opportunities.

In this section we analyze the factors that influence the evolution of the NIS in Armenia.

\subsubsection{Macro Environment}

Armenia is a small open economy with a consolidated ownership structure and a strong Soviet legacy, which means that highly developed R\&D stock is not well related to local industries. After independence, Armenia, like other CIS countries, was paralyzed because Moscow did not provide direction. Lack of experience in the collaboration between R\&D institutes and industries did not facilitate efficient learning and knowledge exchange between these two actors of the NIS in the postindependence period.

In Soviet Armenia, military and defense manufacturing, heavily dependent on inputs from other republics, accounted for 40 per cent of economy (Anderson, 2006). The rest of the Armenian economy, however, was relatively diversified, which was an advantage during the Soviet period, as it gave Armenia an important role in the USSR industrial chain (relative to its size), and allowed an average Armenian citizen to enjoy 
higher standards of living. However, industrial diversity and dependence on production inputs from other countries made Armenia highly vulnerable to the changes after the USSR collapse (Anderson, 2006). Resources, including skilled labor and scientists, were widely spread across various industries and scientific fields. As a small country, Armenia was able to sustain this type of diversity because of the "Big USSR R\&D laboratory"15, where each republic could contribute but also benefit. After the USSR collapsed and its production chains disintegrated, Armenia lost most of its $\mathrm{R} \& \mathrm{D}$ and production resources precisely because it was very diversified for its small size; supporting a wide range of research and production activities whose products were not in demand appeared to be an impossible task.

Armenia's transition experience started with the war with Azerbaijan over the Nagorno-Karabakh region. The consequences were devastating; Armenian economy lost about half of its GDP. But after the war was over in 1994, the country's GDP grew by around 12 per cent per year until 2009. The global financial crisis in 2008 made the Armenian economy contract; and when the growth resumed in 2010, it stayed at only 4 per cent per annum. (See Figure 2-3.)

The transition period also affected allocation of public resources to R\&D. In almost all CIS countries, including Armenia, the early transition was a survival period, and public policies were not directed toward the formation and development of science and innovation policies. Only after 2000 did Armenia experience positive changes in terms of governmental acts and decisions, and an increase in spending on research and science. Before 2000, Armenia spent 0.22 per cent of its GDP on innovations; this number increased to 0.3 per cent of GDP after 2008. Nevertheless, the share of high technology exports in total export remains under 5 per cent.

15 This refers to highly centralized Science and Technology policies, where all the decision were made in Moscow. 
Figure 3-3: Annual GDP Growth

Rate $\%$

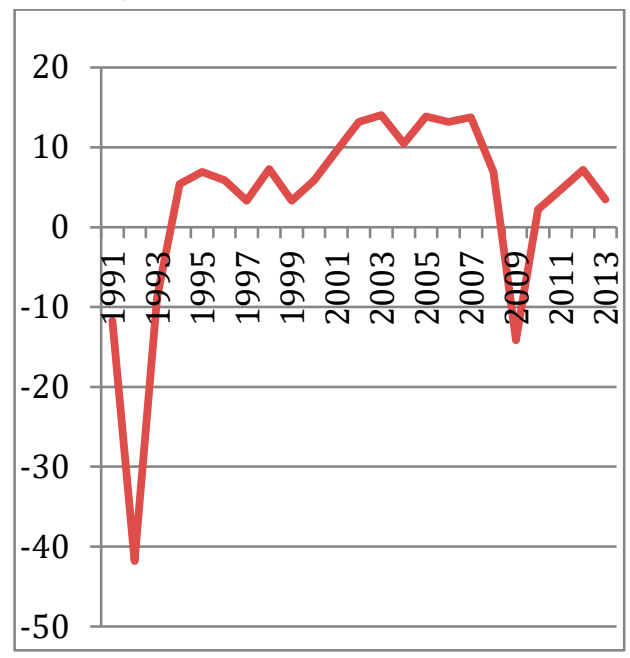

Source: World Bank Data (2013), author's calculation
Figure 3-4: GDP composition

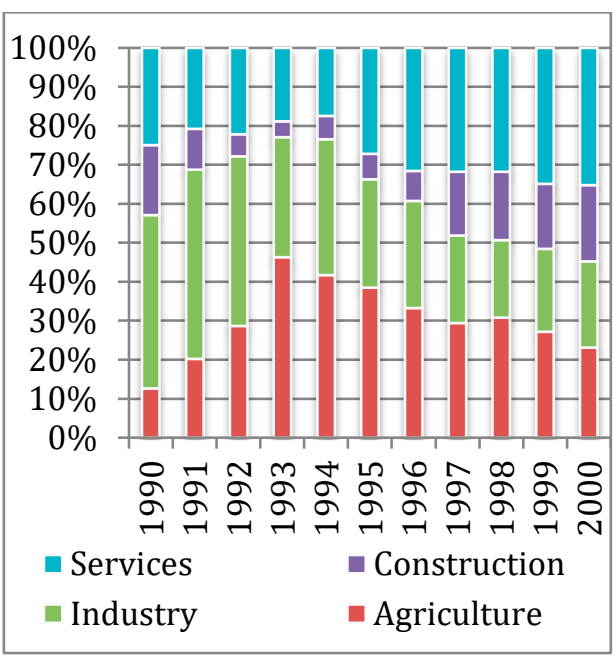

Source: UNDP (2002), author's calculation

Figure 3-4 shows that after the collapse, the contribution of industry to GDP fell, while only agriculture increased. The effect of this radical structural change was profound for the NIS as well. Specialized employees lost their jobs; some became employees of last resort in agriculture, others migrated.

For Armenia with its limited natural resource endowment, human capital appears to be the main competitive advantage (Gevorkyan, 2014). According to the 2013 Human Capital Report (World Economic Forum, 2013), Armenia ranks 60th in terms of education, which places the country above its neighbors. The Armenian business climate, however, is not as favorable as some of its neighbors (World Bank, 2013) but the country enjoys the highest Global Innovation Index rank among its regional peers and is ahead of its many neighbors (including Russia, which is a larger economy and cannot be directly compared to that of Armenia) in terms of innovation linkages. Armenia is also a regional leader in knowledge absorption (Cornell University, INSEAD and WIPO, 2014).

Another important factor for the process of the Armenian transition to a market economy is the role of the diaspora in economic development. Armenia has a sizable diaspora, which exceeds the country's population. The diaspora factor was critical in some areas. For example, during early transition diaspora investors led the way in establishing new business based on foreign direct investment (FDI); linkages between the diaspora and the motherland stimulated scientific and cultural exchange, whereas sizable remittances stimulate domestic demand boosting the economy in general. Some authors, such as Gevorkyan (2014), however, believe that the diaspora effect is not as positive as one might think. According to Gevorkyan, the Armenian diaspora lacks political unity, and the lack of systematic interactions between the Armenian 
government, society and diaspora leads to haphazard effects on country's economic development without significant long-lasting impacts.

The general macro-economic environment in Armenia, as well as factors such as the diaspora and human capital made the Armenian case different from other transition countries. Because Armenia is a small country, the effects of some of the factors described above were amplified in its NIS transition 16. The country was seen as carrying considerable investment risk, which deterred typical foreign investors. However, the diaspora, both for emotional reasons, and perhaps because in general it had better sources of information than other foreigners, had more motivation to invest in the country. The diaspora could also, thereby, serve as a potential source for learning. This is not quite so straightforward, as its positive presence was limited due to the existence of strong local networks, a badly functioning regulatory framework, and corruption. War accompanied by an economic blockade had a very negative effect on the Armenian transition.

\subsubsection{The main strategies regarding the Armenian NIS}

Since 2000, Armenia has introduced several legislative changes to support the formation of a national innovation system. Starting from early 2000, the Armenian economy moved from a survival-oriented phase to a development and innovationoriented phase. Among important policy initiatives in this direction are: the Law on Scientific and Technological Activity adopted in 2000 outlining the main principles for S\&T policies (Khnkoyan 2011); the Law on State Support to Innovation adapted in 2006; the strategy on the Development of Sciences for 2011-2020 in 2010; the government resolution of the Strategy of Export-Led Industrial policies in 2011; and the government resolution on intellectual property in 2011(see full list in UNECE report, 2014). The strategic objectives of export-led policies are to diversify the export portfolio and shift the economy from resource-based to knowledge-intensive industries. However, looking carefully at the content of this strategic view, the development objectives do not integrate academia-industry linkages and small firm innovation with the rest of the innovation system. This presents a striking contrast with other parts of the world where, in Europe in particular, these linkages, and small firm participation were very much central to policy-makers concerns.

The innovation governance system in Armenia is based on three main strategies: Development of Science, Development of Innovation Economy and Export-lead Policy (UNECE report, 2014). The Ministry of Education and partially independent Science Councils are responsible for science and education policies, and industrial development is a priority of the Ministry of Economy. Despite the presence of several important components that should drive the development of the Armenian NIS, the system in place is highly fragmented with lack of systematic collaboration. As a result, industry and academia follow their own strategies without taking into account a holistic view on innovation systems (UNECE, 2014).

\footnotetext{
${ }^{16}$ Some republics also had local conflicts, but in the case of Armenia, the whole country was paralyzed because of the war. Similarly, Armenia's population is only 3 million, but its diaspora is 7 million.
} 
Although these three main strategies are related to the country's innovation system, they did not target common goals; rather, they pulled the Innovation System in different directions (market push from the Ministry of Economy and technological push from NAS) without developing the same vision for the NIS. As an example of the different trajectories that different strategies seem to be following, during our interviews with firms, almost all firms in the IT sector mentioned that after hiring new graduates they spend the first year of their training, as the education system in the universities has not upgraded their curricula to match knowledge requirement of IT firms. ${ }^{17}$

\subsubsection{Research Institutes and Universities}

The R\&D capacity in Armenia is concentrated in research institutes and universities. Most of them either belong to the National Academy of Science or the Ministry of Economy, and they received almost $72 \%$ of their total funding from the state budget in 2008. Armenian exports are mostly dominated by low-tech products such as raw materials and food and beverages. Partly as a consequence, in general local firms have a low innovative capability, which reflects on the firms' incentives to establish collaboration with universities. The "National Competitiveness Report" series shows that for many years Armenia received low scores for university-business research collaboration, and also reports that firms in Armenia rank the quality of research institutes and universities in Armenia quite low (EV Consulting 2012). The only significant actors that are effective in establishing linkages between universities and industry are multinationals. In the IT sector, the presence of multinationals makes favorable changes in university-business collaboration sphere: e.g. Synopsys (a USbased IT company) established R\&D centers in Armenia in close collaboration with universities. Despite the increasing presence of multinationals, though, the linkages between industry and universities are not prevalent in Armenia. Research institutes and the government focus on strategies more irrelevant to the "science push" innovation, while undermining the importance of commercialization for R\&D results. Firms, on the other hand, are small with a local market and have limited view on searching for more innovative ways to increase their productivity.

\subsection{Learning and Innovation}

Throughout this chapter we have mentioned that learning is one of the most important processes of the NIS. In this section we highlight some of the particularities of the learning in transition that is also relevant to the transition of the Armenian NIS.

The brief review suggests that Armenia, being a small and poorly endowed economy (except its high human capital), had limited resources for the learning. Our analysis showed that foreign actors are considered as important agents for transition of new

${ }^{17}$ We have interviewed 200 firms of which more than 20 firms were in IT sector. 
knowledge in transition economies, but their presence was limited due to the insider model $^{18}$, which dominated in CIS countries including Armenia.

The lack of foreign actors affected learning and innovation outcomes in two ways:

- Local networks had a strong role in the learning outcomes

- Local actors had less access to global networks

\subsubsection{Learning through local networks}

In this section we discuss the role of local networks in transitional countries. To our knowledge there are no formal studies that observed inter-firm or personal networks in Armenia. Even though, the "oligarchic"19 connections are the most popular topic in political and economic agenda in Armenia. In the next chapters we study the board network of newly privatized firms (open joint stock companies): our data shows that less than $5 \%$ of board members of these newly privatized companies are listed in more than $60 \%$ of firms ${ }^{20}$, indicating that a small number of people/board members connect majority of privatized firms - this ultimately shows that personal networks play an important role in Armenia.

Previous research showed that there is a difference between industrial networks in the central and eastern European countries and former-USSR republics, particularly Russia (Batjargal, 2000 Radosevic 2002): reviewing various business surveys results, Radosevic (2002) showed that in early transition, firms in Central and Eastern Europe integrated into international industrial networks through foreign actors, trade and production linkages; in contrast, firms in post-soviet countries were more embedded in local networks.

Batjargal (2007) compared Chinese and Russian inter-firm networks, and he found that there is a difference: in both economies networks were important for learning and gaining information in the distorted markets, but Chinese networks were characterized as more homogeneous and cohesive, whereas Russian networks were larger, sparser and more heterogeneous. The difference he explained by cultural aspects: country's traditions, social norms and etc.

Given the challenges that economic actors in Armenia face, global competition and the speed of technological change demand more intense learning from one side; restructuring and adaptation to the new reality from the other side pushes for continuous changes in firms in order to gain accesses to markets, resources and new technology. In this case, those cohesive local networks function as mechanisms to cope with uncertainties, to learn from each other, and to ensure trust and reciprocity. In this context, learning is a result of social cooperation, where "know-who" becomes

\footnotetext{
${ }^{18}$ Insider model is described the privatization where the factory was privatised to its employees by distributing vouchers which indicate that the employee own a share of the factory.

${ }^{19}$ Dominance of personal networks in industry or economy with strong political ties.

${ }^{20}$ Our data consist of around 207 open joint stock companies (is the population), and each firm has on average 6 board member. The "key board members" which were around $5 \%$ of all board members were listed in majority of firms in our database.
} 
an important factor for the access of information and knowledge (Lundvall and Johnson 1994).

Given the studies of other transitional countries with similar preconditions, and interviews with firms, we concluded that learning and economic transformation of the Armenian firms in this setting was based mostly on local experimentation and learning through local networks. This is one reason that we would like to bring strong evidence about how local networks influence learning and innovation in Armenia though examining the board network and firm innovativeness.

Kitanovic (2007) distinguishes four types of learning through social networks. First is the individual learning, without any social interaction. The second is the knowledge acquired through interaction, but with the limited understanding, which will not facilitate further development of the new technology. The third type includes more interactions, but based on feedback rather than commonly created knowledge; and the fourth type is an organized interaction directed toward the creation of a new knowledge, collaborations with universities and collaborative R\&D activities.

In Armenia, firms are challenged to shift toward learning types three and four, however, they still need to change their routines, habits and structures to better adapt to new market economy. The drawback of a slow shift is losing a stock of initial knowledge (see figure 3-2). We have discussed that Armenia inherited strong engineering knowledge stock, which was not employed fully during the transition. The result is that this initial knowledge stock or its major part followed the "low-endforgetting" path.

\subsubsection{Learning through foreign actors}

Studies of socialist countries show that integration of local networks into global networks took place because of presence foreign actors, and that, even though in some cases governments were not able to reinforce innovation policies (Radosevic 2002). Among transitional countries, less successful cases are post-soviet countries, where local networks did not align much with other networks. Whether the local network of firms will integrate or not depends on their nature, capabilities and willingness to restructure their organizations. Unquestionably, lack of foreign actors slows down the process of integration of Armenian firms into the global network, and the embeddedness in networks inherited from the Soviet era further constrain the search of new opportunities. Foreign actors could have been an important channel for learning the best business practices.

Nevertheless, we should also mention that during the learning process, the presence of foreign actors is not a national panacea. Empirical evidence showed that, although foreign actors appeared to be significant factors for the learning in the local context, there were still some limitations. For example, in the study on Vietnamese firms, Ca (1999) concluded that foreign actors were less helpful for technical change and marketing capabilities. Similarly, Mytelka (1992) found that in the case of the textile industry in the Ivory Coast, expatriates were more successful than foreign actors in transferring technological capabilities. Finally, Wignaraja (2003) also shows that in Sri 
Lanka, German firms were more helpful for the utilization of technologies rather than for the development of new technologies, which was undertaken by local actors.

In the case of Armenia, learning from foreign actors and local R\&D depends mostly on collaboration with multinationals, where the only role they can get is to absorb and adapt foreign technology rather than developing new technology or using cheap skilled labor only for outsourcing innovative ideas. The role of multinationals is quite controversial, given the risk of their expansive nature and intention of using local resources. Evidence in developing countries showed that it is typical for local firms to learn and upgrade their knowledge and adapt technologies, but they still fail to learn the main technical change or to develop their independent $\mathrm{R} \& \mathrm{D}$ competence (Ca 1999; Mytelka 1992; Wignaraja 2003). In this context, it is important to mention that although foreign actors are a channel for the post-soviet firms to learn the best practices and new entrepreneurial cultures, the presence of foreign actors alone cannot guarantee positive outcomes. Innovation policies should provide strategies and improved mechanisms for FDI-driven knowledge spillovers (Klochikhin 2013).

\subsubsection{Institutional set-up}

During the last decade, the Armenian government and firms established innovation centers, S\&T parks and free economic zones. However, the efficiency gains from these new institutional arrangements are very low. ${ }^{21}$ One of the reasons for this is that those big projects are financed by external institutional donors, and even though projects themselves intend to establish or promote high tech innovations, they nevertheless fail to facilitate networking with local firms and match their production interests and learning goals. There is a substantial gap between what S\&T parks can provide and what the needs of local firms are.

When we analyze the system of innovation in Armenia we see that even though there are many changes since 2000, including some very positive and ambitious policy initiatives. However, the impression is that those are stand-alone initiatives, and they did not emerge to support existing firms and universities. Slavo Radosevic (2002) argued that in order for S\&T parks and other newly established innovation supporting infrastructures in transition countries to operate as sources of growth, they should support networking as a complementary function of firms and universities. In principle, given the evolutionary nature of "external" and "greenfield" institutions, eventually they will integrate well into the system of innovation in Armenia. However, countries' innovations are rooted in the existing economic structures (Lundvall and Johnson 1994), and learning is both a part of and a result of routine activities (Kitanovic 2007).

Previous research showed that the role of foreign actors and their interventions in the building of market-supporting institutions has had generally positive effects on learning outcomes, particularly in Central and Eastern Europe. In post-soviet countries, although the new market-supporting institutions were "injected" in the beginning of transition, but those institutions needed to be legitimized and integrated

${ }^{21}$ We came to this conclusion from interviews with firms, policy advisors and representatives of industrial unions. 
in the innovation system, and hence learning was mainly done through local personal networks.

\subsection{Conclusion}

This chapter presented a discussion of the state of the Armenian National System of Innovation. It explored the system-level changes by identifying innovation determinants in terms of historical heritage, macro-economic conditions, the role of main actors and networks. It illustrates that the soviet legacy and different patterns of privatization policies affected the transformation of national systems of innovation. We observed and distinguished three main periods for the NIS transformation in Armenia: before 1990, early transition (before 2000) and after 2000. Before 1990, all post-Soviet countries were coordinated by central planning system and were part of USSR innovation system. Early transition was dominated mostly by survival and restructuring strategies. Only after 2000 did Armenia and other transition countries develop policies and strategies to shape specifically their national innovation system. Yet, new innovation policies could not erase the past, and even the establishment of new institutions needed time and further changes to work efficiently.

Inherited from the soviet innovation system, the innovation governance system in Armenia is quite fragmented, which creates additional challenges for industry-academia linkages. Industry-academia linkages that are vital for efficient national innovation systems are the weakest components in the Armenian innovation system. Firms in this situation seek access to external knowledge sources through their personal networks or foreign firms.

One of the main advantages that Armenia inherited from the soviet era was its human capital, but public policies were mostly directed to establish political and economic environments for the firms, and less attention was devoted to training and retraining. As a consequence, high skilled labor remains unemployed in the economy: only a small portion of human capital was employed mostly in IT, and this kept only part of the knowledge stock inside the innovation system.

Current public institutions (e.g., research institutes, universities) and polices do not support firms to overcome shortages in skilled labor in specific niches ${ }^{22}$ and financial resources, and incentivize a strong innovative culture among organizations. The important argument that Radosevic (2002) also brought into the discussion was that the establishment of new institutions that were mostly initiated and supported by western actors did little to deal with the complexities of preexisting institutions. Additionally, those new institutions failed to address the requirements and needs of the local actors. In the short run, the consequences were profound, as they did not operate efficiently.

\footnotetext{
22 Existing skilled labour needed training to update their knowledge and skills, as the industrial structure changed. For example, Armenia had a strong chemical industry with a highly-skilled labour force, but due to foreign competition, and the disappearance of the larger Soviet market, this sector shrank during transition. In the postsoviet era, the ICT sector became the key sector, so chemical engineers while highly skilled, had the wrong skill set for the new industrial structure. Similarly there are strong mathematical research labs but yet those specialists needed training to adapt their knowledge to new companies.
} 
We argue that shortcomings of those new ("greenfield") institutions are reflected into two main directions: first, they destroyed the initial knowledge stock, and second, they failed to integrate firms into S\&T knowledge networks. The major challenges are seen in the lack of collaboration between NIS actors, especially between firms and universities, with firms that have little interest in knowledge acquisition and universities that have little interest in promoting private sector innovation. The aim of this exercise is to gain deeper insight into Armenia's innovation system, innovative performance and macro-environment, all of which affect the firm's innovative performance.

The aim of this chapter is to show the challenges that economic actors in post-soviet period faced: Agents such as firms and universities were left themselves to cope with uncertainty. There was a lack of public policy support that could help actors to transition smoothly and help in general to coordinate interactions among all types of actors. Foreign actors could in principle help to enhance learning and adjustment processes, but there were few such foreign actors. The sectors that developed comparatively well, such as IT sector, is mostly due to foreign companies that employed cheap and high-skilled labor force, and had little interest in, or effect on, learning more generally in the economy. However, universities and research institutes failed to make necessary changes to adjust to the newer industry demand, in general. This mattered because university and industry collaboration are important aspects of National Innovation Systems generally speaking. Thus in chapters 8 and 9 we pay a special attention to it. In this chapter we showed what the industry structure of Armenia was, and what potential it had given its role and development during the soviet period.

We discussed low-end forgetting in the learning process in Armenia, which refers to the processes through which skilled labor, with the exception of a couple of industries remained unemployed. Many large companies that were leading companies in the soviet period had a huge potential to use existing infrastructure and labour force and adjust to a new reality. However, the lack of management skills and understanding of new market challenges played an important role in steering firms toward a future in which this potential was largely unrealized.

In the following chapters we look at the firm-level changes and analyze the factors that affect firms ability to navigate this new and challenging environment. Social networks played an important role, especially given the absence of public policy support. Our goal is to understand what type of social networks/social capital was beneficial for a firm to capitalize on the best opportunities and potential in the transition context. For this reason in the next chapters we analyze the effects of board network of privatized large firms on their financial and innovative performance. 
Part II: Firm Financial Performance

CHAPTER

\section{BOARDS, PERFORMANCE AND SOCIAL \\ CAPITAL}




\subsection{Board Networks and Firm Performance}

Following previous research, our study emphasizes the importance of the board network as a form of social capital, and examines its effects on firm performance (Mizruchi 1983; Larcker, So, and Wang 2013; Dicko and Breton 2010). Board members of companies have an important role in strategic decision-making and can leverage valuable information. They also possess strategic information on a firm's condition and resources, industry trends and macro-level changes, such as new regulatory frameworks, the economic situation in the country etc. The flow of this information through network ties may explain a firm's opportunities and competitive advantage (Larcker, So, and Wang 2013). Previous studies have examined the characteristics of individual board members and find that education, gender and experience of board members is a valuable asset and can provide additional benefits for the firms (Vafeas 1999; Cheng 2008; Guest 2009). For example, firms that included members from financial sectors in their boards appeared to have better access to financial resources and loans and have lower debt ratios (Stearns and Mizruchi 1993). Our focus is not on individual board member characteristics but rather on their interpersonal links.

The links between individual actors in this network are an important channel for information and resource exchange, and embeddedness in social or economic networks may provide opportunities or constraints. Board networks serve as an important channel for inter-organization linkages as they can facilitate knowledge and information transfer, access to useful resources. For instance, Larcker et al. (2013) and Wincent et al. (2010) found that centrality in board networks positively affect firm financial and innovative performance. In financial management literature, determinants of successful firm performance are firm survival (Vafeas 1999), growth (in sales or employees), market value of the firm (Vafeas 1999), over-time variability in accounting performance (Adams, Almeida, and Ferreira 2005; Cheng 2008), Return on Assets (ROA) (Cheng 2008; Guest 2009) and Return on Equity (ROE) (Vafeas 1999; Peng, Buck, and Filatotchev 2003).

In this study, we highlight that the board network plays an especially important role in stabilizing uncertain environments, and serves as a conduit to exchange knowledge and information. The lack of formal institutional mechanisms such as a developed banking sector, a secondary stock market and proper regulations to support interpersonal market exchange makes the role of informal agreements and relations even more important, leading many firms to pursue network strategies to grow in this environment.

This chapter lays out the framework we use to analyse the effects of board networks on firm performance. We follow the stream of literature wherein social networks generally are seen as a source of social capital, and where network content and structure have been found to have a positive influence on firm performance (Zaheer and Bell 2005), managerial performance (Moran 2005), product innovation (Tsai and Ghoshal 1998) and knowledge transfer (Reagans and McEvily 2003). A broad consensus is emerging that social capital is a valuable asset engendered through 
embededdness in social networks (Granovetter 1985), and that its value stems from access to resources available through social ties. One of the unique features that makes social capital different from the other forms of capital such as physical capital or human capital is that it considers the complexity of social contexts in which firms are embedded (Gulati, Nohria, and Zaheer 2000), and argues that ignoring this context in analyzing a firm's behavior and performance can lead to an incomplete picture. Characterized by durable and diverse interpersonal relationships (Bourdieu 1986; Coleman 1988), social capital is tightly bound with the strategy of the firm (Nahapiet and Ghoshal 1998a), but in a different way than other forms of capital.

We begin with a graphical representation of the framework, following which we discuss each of the constituent elements. As part of that discussion we formulate several hypotheses to guide the empirical work in the chapters that follow. Following this discussion we review previous literature relating social capital to firm performance.

\subsection{Theoretical Framework}

Figure 4-1 gives a schematic representation of the framework. The thick lines shows the direct effect of social capital on firm performance, controlled by firm characteristics, and the dashed line shows the interaction effect of network content and structure on firm performance.

Figure 4-1: Conceptual model of social capital and firm performance.

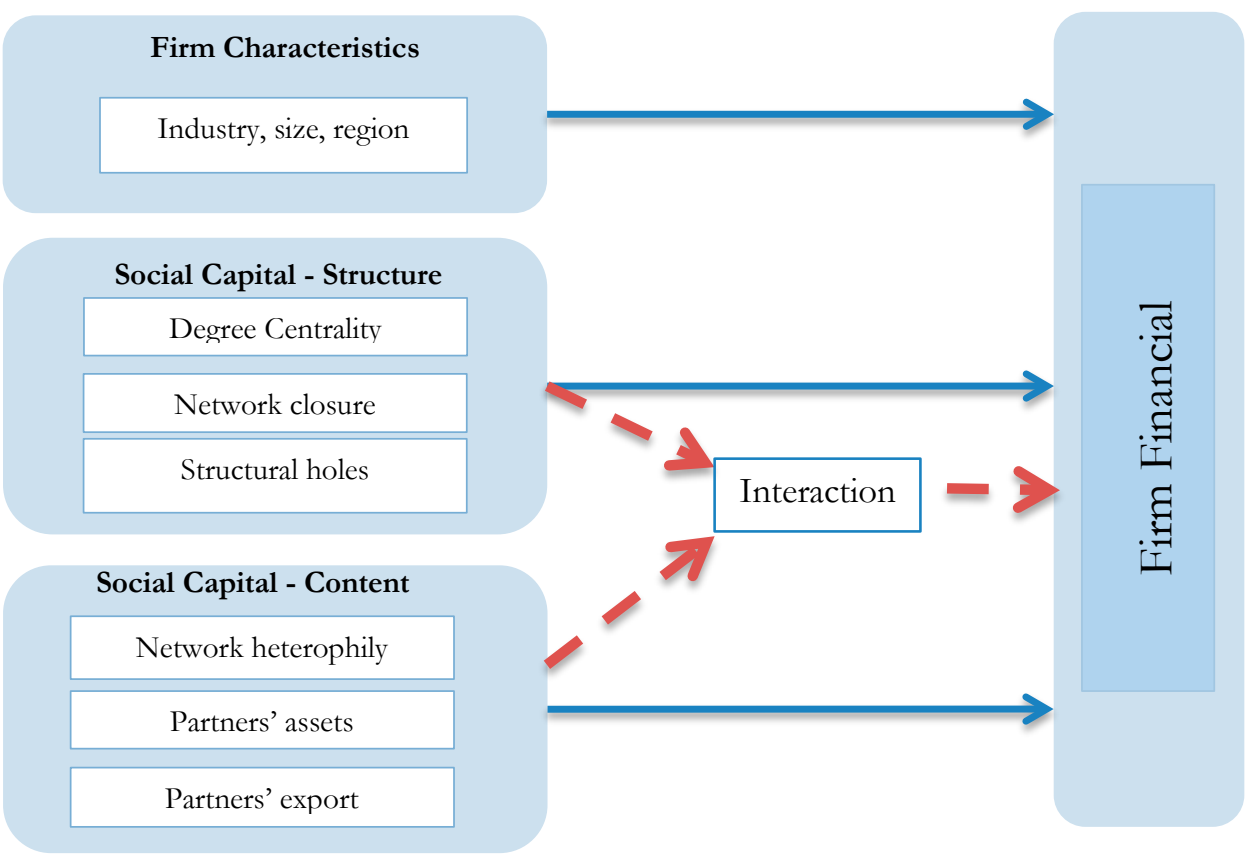


Following the discussion on social capital theory we see social capital as having two central aspects - network structure and content.

1. Social Capital: in this diagram the social capital is captured by the firm's board network.

2. Structural Social Capital: Structural social capital focuses on an actor's structural position in the network. We distinguish three main aspects: centrality of a firm in the board network, network closure and structural holes.

3. Network content we define as the set of alters' characteristics. Each node in the network has a distinctive set of individual characteristics, which gives different qualities to the network in which an actor is embedded. We first define the structural border of an actor's network, and then identify three main aspects of network content: homophily, network resourcefulness (partners' assets) and foreign ties (partners' export-orientation).

4. Firm Characteristics: the firm level characteristics we use as controls for our model. Firm size, firm age, industry and location are widely used in the literature on firm performance (Cheng 2008; Guest 2009)

5. Firm Performance: we use firm performance ${ }^{23}$ as a dependent variable for our empirical model. Numerous normative studies provide empirical evidence of the relationship between social capital and firm performance (Chuang, Huang, and Wu 2013; Larcker, So, and Wang 2013; Zaheer and Bell 2005). Common measures of firm performance in financial management studies are Return on Assets (ROA), Return on Equity (ROE).

In the following subsections we discuss social capital and its dimensions as provided in this framework, the other components of the framework (firm characteristics and firm performance measures) are discussed in the next chapter.

\subsubsection{Social Capital}

Reflecting our evolving understanding of the process of economic growth, the concept of capital has been broadened over time. In early literature, growth was a function of physical capital accumulation. In the 1960s, Schultz (1960) and Becker (1962) introduced the notion of human capital, arguing that physical capital alone left a large part of growth unexplained. In the 1990s, researchers began drawing attention to social context, and how it affects human capital accumulation. Studies on social capital produced evidence to support the proposition that social relations have value, and they complement or constrain other forms of capital (Portes 1998; Baker 1990).

To date, there is no clear consensus among scholars on how to define and measure social capital, and definitions vary depending on context. Some definitions consider social capital at the macro level, indicating that generalized trust and a country's

\footnotetext{
${ }^{23}$ We used this model for measuring both firm financial performance and firm innovation. In this chapter we focus on financial performance. Chapter 9 uses slightly modified version of this model for explaining firm innovation - there we incorporate absorptive capacity in explaining firm innovation.
} 
institutional qualities affect economic outcomes of the country (Dasgupta and Serageldin 2000; Helliwell 1996; Tatsi and Zafar 2011). Some consider social capital at a micro or actor level, where the concept of social capital is defined using networks of relationships, and that those social ties may affect individual performance. For example, studies examined how tangible and intangible resources mobilized through network ties explain firm performance (Baker 1990); product innovation (Tsai and Ghoshal 1998) and the creation and sharing of organizational knowledge (Nahapiet and Ghoshal 1998a).

Our conceptual framework follows the micro tradition, where we investigate the role of social capital in explaining performance of individual firms. The focal points at the individual level are: how individuals/firms invest in social relations and how individuals access and use resources embedded in social networks to generate return (Lin 2002). Individuals possessing extensive and diverse social ties may benefit from the access to and use of differential social resources (Lahiri and Narayanan 2013; Lin 2002). Following this perspective, Flap and Völker (2004) stress the importance of resources mobilized through social networks. They argue that many ties may provide better chances for the focal firm to access resources but if the ties possess only few valuable resources then the value of ties will diminish. In our model, we stress that the position in the network can represent competitive advantage for an actor, particularly if it links the actor to information and others resources which are not accessible to other actors due to their position in the network.

Social capital literature discusses other dimensions of social capital, expanding our understanding of the social context in which actors are embedded. Summarizing the literature, we identify four main dimensions of an individual's social capital: structural - referring to the overall patterns of connections among actors (Burt 2000; Wasserman 1994); relational - referring to the quality of an actor's personal relations (Granovetter 1985); cognitive - referring to how individuals share common language and codes (Nahapiet and Ghoshal 1998a); resourcefulness - referring to the degree to which network ties contain valuable resources (Batjargal 2003).

In our analysis we focus on two main dimensions. The first is network structure, and this dimension is fully overlaps with previous literature. Our second dimension we refer to as "content". For us, "content" includes both aspects of resourcefulness as in previous literature, but we augment this with the degree of homophily or heterophily in a firms set of ties.

To summarize our conceptual approach: first, this study addresses the main debate in the social capital theory: which network structure is better for the actor? This is purely a structural aspect of the social capital. Second, we suggest several measures for network content such as network homophily, partners' assets and export orientation. The main argument here is that network structure does not reveal much about what kind of resources, knowledge and opportunities social networks can provide. In contrast, network content, which reflects the attributes, resources, knowledge that an actor's partners possess provides additional and valuable information on potential use of social capital. Third, this study analyzes complementarity between network structure and content. The main argument is that the utilization of potential resources and 
knowledge available through networks is important. Extending the discussion on this issue, we rephrase this question into "what structure is the best given the attributes of an actor's partners (network content)", and hence we examine the interaction effects of the network structure and content.

\subsubsection{Network Structure:}

In recent years, the firm's network position gained significance in the literature on inter-firm relations and firm performance (Batjargal 2003; Lahiri and Narayanan 2013; Moran 2005; Padula 2008). Social network analysts have created various measures reflecting the firm's position in the network. In this paper we focus on degree centrality, network, closure and structural boles.

Degree Centrality: The competitive advantage of the firm is determined by its ability to establish ties with other firms (Batjargal 2003; Larcker, So, and Wang 2013). The networking strategy of the firm provides access to resources, assets and information that reside outside of firm boundaries, and the ability to establish a high number of ties with other firms increases the likelihood of the firm being an important partner in the network, having access to critical resources, and being able to utilize external knowledge and resources. Firms that have greater degree centrality will have access to a wider variety of resources from different firms, and so higher centrality tends to be associated with innovation and better firm performance (Powell, Koput, and SmithDoerr 1996). Empirical evidence shows that firms with higher degree centrality experience better performance than do non-central firms (Batjargal 2003; Larcker, So, and Wang 2013; Moran 2005; Uzzi 1997). However, managing a large number of connections may bring challenges for the firm (Lahiri and Narayanan 2013). For example, investing time and resources in establishing and maintaining ties with other firms can be quite costly for the focal firm, which may cause diminishing impact of the degree centrality over time and parallel to increasing number of ties.

\section{Hypothesis1. Degree centrality has an inverted U-shaped relationship with firm financial performance.}

Degree centrality can be envisioned as firm investment in terms of establishing interpersonal linkages, which are useful in the markets and can generate positive returns for the firm. However, given the fact that investment into creating more linkages is costly, it may have a sub-linear relationship with the firm's returns.

Network closure vs. structural holes: In network theory the positive or negative effects of social capital have been discussed from two opposing viewpoints in the studies of Coleman and Burt. According to Coleman (1988), dense, highly cohesive networks are the kind of social capital that will most affect a firm's or individual's success. A strong and cohesive tie implies higher trust as well as a greater threat of sanctions in case of deviation. In a closed network, members respect more collective goals, and thus there is more reliability among members. The fear of sanction prevents an actor from deviation of general norms accepted by group members (Coleman 1990).

On the other hand, Burt (1992) emphasized the importance of brokerage links, which may be important for accessing differential resources and information. According to 
Burt, a dense network may constrain an actor's success as they invest time and resources in redundant ties. Focusing on the benefits of social capital in terms of providing new knowledge and opportunities, structural hole theory argues that firms have high level social capital if they are part of a sparse network: firms with a network that is rich in structural holes tend to control information better (Burt 2000; Burt 2004; Granovetter 1985).

The debate between these two opposing traditions is not new. Many studies have explored which structure provides a competitive advantage for the actor. Empirical studies did not provide any universal answer, eventually concluding that both theories are valid, depending on the context.

We should admit that both theories provide insight about how social networks can be advantageous for firms in Armenia. The highly turbulent environment in Armenia that is characterized by a lack of any formal access to information and financial resources, as well as lack of legal enforcement, increases the benefits gained from cohesive ties, which provide reliability and trustworthiness. Firms will be more willing to acquire and share knowledge and products if they have higher monitoring and sanctioning opportunities. The institutional economics perspective emphasizes the fact that an absence of pre-existing market supporting institutional infrastructure leads to more reliance on network resources in order to buffer uncertainty, to reduce transaction and search costs and to gain knowledge and legitimacy (Kogut and Spicer 2000; North 1990; Spicer, McDermott, and Kogut 2000). Research on social embeddedness shows that firms that are operating in a turbulent environment often promote cooperation based on deep social norms and reciprocity. This can be seen, for example, in the cases of Silicon Valley (Saxenian 1996) and Japanese firms networks (Aoki 2013).

Examination of corporate networks in the Hungarian economic transformation showed that cohesive networks were robust and increased chances of survival, but that this did not lead to increases in profitability (Balázs Vedres and Stark 2010; Stark 1991). Of special relevance to our concern is Stark (1991)'s insight that although cohesive ties may be the most efficient "first aid" strategy for firms in transitional countries, this strategy may not fully enable firms to explore and exploit new economic opportunities.

Yet, given the fundamental problem of firm restructuring in post socialist countries, local actors faced another challenge - the old products were obsolete. Firms had an urgent need to experiment with new products, alter existing ones or find an alternative chain of production, which requires finding new markets, new suppliers, financing, etc. The collapse of the USSR is associated not only with a new institutional framework, but also new production and trading schemes. During the period of economic reconstruction and opening new markets (after the USSR's existing production system was effectively shut down), managers needed to expand their networks to understand the rapidly changing context they were trying to navigate. This describes a situation coherent with the arguments of Burt regarding structural holes. Firms in the postSoviet context need new types of information, but are often ignorant even of what kinds of information will be useful. Here access to a variety of information that can be 
assessed and assimilated to make large changes is central to survival. An open network position sounds very desirable.

The structural hole perspective emphasizes the "tie redundancy" aspect - if all actors were connected to each other, then they would circulate the same knowledge (Rost 2011; Uzzi 1996; Martin, Gözübüyük, and Becerra 2015), while the most novel knowledge is generated by divergent ideas (Rost 2011). With the similar arguments, Ahuja (2000), Rodan and Galunic (2006) show that brokerage position is important for firm innovation. Similarly, Rooks et al. (2009) found that structural holes are associated positively with firm performance in entrepreneurial network in Uganda. Martin, Gözübüyük, and Becerra (2015) found that access to differentiated resources through brokerage positions reduces environmental uncertainty for the firm, and hence it affects positively on their performance.

The roots of preferring either of these two structures (dense vs. sparse) lie in the expected outcomes. If the goal of the firm is to maintain and preserve resources or reach higher coordination, than a dense network structure may be better for this goal. But if the firm is looking for new opportunities and new resources, then an open structure may be preferred.

The study of Soda et al. (2004) showed that both structural holes and network closure are essential for an actor's performance. However, they found that these two variables may affect the performance differently given their lag values. Although a position with strong structural holes is positive for current performance, a brokerage position in the past does not influence future firm performance. In contrast, past closure affects future performance positively. This suggests that effects of those two variables differ in terms of durability, suggesting that structural holes provide only current and shortterm benefits, while closure had long-lasting effects (Soda, Usai, and Zaheer 2004). Keeping this aspect in our mind, we will test also the temporal duration effects of network closure and structural holes using several lagged values.

Given the fundamental problem of restructuring the economy, firms in transition economies face the problem of uncertainty and a lack of regulatory framework from one side, and the urgent need for new knowledge and new organizational practices from the other side. Hence, we express our argument in the following Hypotheses.

\section{Hypothesis 2a: Network closure is positively associated with firm's financial performance}

\section{Hypothesis 2b: Ego networks rich with structural holes are positively associated with a firm's financial performance.}

\subsubsection{Network Content}

Our study explores not only whether different positions in the network affect performance but also whether ties to different types of firms affect performance. Thus, we propose variables to capture not only the firm's network position but also the qualities of the networking ties, such as one's network homophily and partners' characteristics. Our study focuses on firm-level analysis, and we consider that the 
properties of the firm's network have an important effect on firm success. A firm's network is defined as the set of actors that the firm interacts with directly (this defines the borders of one's network). The effects of one' network have been studied in both sociology and economics: Marmaos and Sacerdote (2002) showed that in a network providing job information, location and demographic characteristics may explain differences in job search outcomes; Bernard and Jensen (2004) observed that spillover effects from neighboring exporters may increase the probability of exporting; Batjargal (2003) indicated that through heterophilous ties entrepreneurs in Russia have more access to differential resources.

\section{Homophily}

Homophily is a tendency of individuals to interact with others similar to themselves (Golub and Jackson 2012), and it has been documented that similarity has an impact on initiation of partnership between firms, social groups and individuals (Ahuja, Polidoro, and Mitchell 2004; Ibarra 1992). In this study we focus on homophily based on actor attributes such size or industry, rather than on structural homophily which relates to the structural position of an actor in the network.

Prior literature has addressed whether firms partner with similar or dis-similar firms and how that affects performance (Ahuja, Polidoro, and Mitchell 2004; Ibarra 1992; Kim and Higgins 2005; Lobel and Sadler 2013). Findings are inconclusive however. Proponents of homophily argue that firm partnership is more successful when firms collaborate with similar ones - it is easy to establish a connection and trust, which implies reduced search costs (Chung, Singh, and Lee 2000). On the other hand, some emphasize that complementarity of a firm's capabilities is a basis for firm partnership, as firms benefit from access to different resources and knowledge (Gulati, Nohria, and Zaheer 2000; Gilsing, V., et al. 2008; Duysters, 2002).

The literature on learning and information diffusion proposes that actors should find a balance between homophilious and heterophilous links, especially when we talk about diffusion of new knowledge: Golub and Jackson (2012) showed that speed of learning depends on homophily, while Lobel and Sadler (2013) argued that, in sparse networks, homophily may substantially improve social learning; Stuart (1998) found that firms in technological niches tend to collaboration with firms based on knowledge similarity.

In our study we suggest three aspects of network homophily/heterophily: industry, geographic location and firm type. To further the discussion we also suggest using both homophily and heterophily measures: unlike homophily measures, heterophily measures allow for the degree of diversification of links in the network to be captured. Aspects of heterophily are important, in particular, when we have more than two categories in a specific attribute.

Industry Homophily/Heterophily: Batjargal (2003) discussed network heterophily as a survival strategy for entrepreneurs in Russia, and how they benefit from the access to differentiated resources in the transition context: Russian manufacturing firms which were building personal ties across different industries had better access to the financial resources, delivery of different products and barter exchange. Therefore, network heterophily is associated with spreading risks of default in one industry, and this 
reduces the harmful effects of an uncertain situation (Larcker, So, and Wang 2013; Uzzi 1997). On the other hand, firms having more homophilious ties in the same industry will benefit from sharing the same needs, access to inputs, know-how and information, which is relevant to that specific industry. Homophilious ties may permit better communication between firms, can facilitate collusive competitive behavior and can yield economic returns for the firms closely linked with each other (Larcker, So, and Wang 2013). Neither previous empirical findings (e.g., Batjargal 2003; Stark 1996), nor the variety of the problems that Armenian firms faced, indicate the direction of the effects of industry homophily/heterophily on a firm's profitability. Therefore, we argue that a firm's network homophily (industry) has an ambiguous effect on its performance, and we should instead rely on empirical testing.

Homophily based on firm's location: Location has been identified as an important factor not only for a firm's success and performance, but also for inter-firm linkages. Robertson (2013) argues that demographic characteristics may generate strong network connections: economic agents that share demographic characteristics are assumed to share values, knowledge and attitudes, which makes communication easier, and results in stronger network ties. Partner's location homophily may provide certain advantages to the focal firm: for example, a firm connected with other firms in the same region may facilitate better communication, reduction of transaction costs and ease of knowledge transfer.

The location of the firm may have positive external effects such as dense population, high level of urbanization, skilled labor force, and opportunity of reducing risks (Krugman 1993; P. Martin, Mayer, and Mayneris 2011; Puga 2010). Puga (2010), for instance, found that firms are more productive in a large, urban environment. As the previous empirical research found that location is an important factor to explain a firm's performance and success, primarily because financial, material, human and organizational resources are agglomerated, we take this into consideration by specifying the firm's location in the capital city vs. other regions. Yerevan, the capital city of Armenia, is the most populated city in the country: half of the population of the country lives there and $50 \%$ of the business activity is located in the city. Thus, the firm's region variable will capture the effects of population and business density. To summarize, we argue that a firm's location homophily has positive effects on its performance, and that the effect might be stronger if the focal firm and its connection are located in Yerevan.

Firm type homophily: In alliance studies practitioners and scholars give specific importance to the "organizational fit" between connected organizations. This refers to complementarity and compatibility between partner firms (Kale, Singh, and Perlmutter 2000). Complementarity refers to the lack of similarity between partners' core organizational capabilities. Complementarity ensures that partners provide each other with different and valuable resources and capabilities. This creates the opportunity for each firm to learn and to gain new knowledge or resources from the other. Compatibility emphasizes the importance of organizational fit. In order for firms to have a successful partnership first of all they need to be compatible. In organizational literature, compatibility has been assessed by operating strategy, corporate culture and firm size, among other things (Parkhe 1993). Compatibility between collaborating 
firms enables them to capitalize on and learn from the opportunities provided by complementary capabilities of the partnership (Kale, Singh, and Perlmutter 2000). Gilsing et al. (2008) argue that for exploration firms are faced with a dual task: on the one hand, they need to develop heterogeneous ties to access to different type of knowledge and hence potentially to create novel combinations; on the other hand, firms need to be sure that accessing diverse knowledge they will be able to absorb it. This line of argument stressed the importance of balancing novel and diverse sources as well as familiarity and dis-similarity.

We extend this notion of "organizational fit" in the firm's network to the firm types of homophily/heterophily. We classify firms as small and large, and exporting and non-exporting. A small firm has limited resources; hence, to grow and gain higher financial returns, small firms may need to establish links with larger firms (complementarity principle). Social networks are instrumental in creating a bridge between small and large firms (Tung and Wang 2012). In contrast, on the other side exporting provides access to new information, new ways of doing business and new organizational knowledge. If a firm is small and non-exporting, then ties with large enterprises provide them access to resources, and ties with exporting firms enable the smaller firm to learn new organizational knowledge. Additionally, large and exporting firms will benefit from the similar connection (compatibility), as the firm may benefit less from small or non-exporting firms. Therefore, we assume that the firm type homophily will either limit the firm's opportunity to learn and access new resources or will have less impact given the firm's own type.

The discussion on homophily we summarize in the following hypotheses.

Hypothesis 3a: Location homophily of the firm's network has a positive impact on firm financial performance. This effect is stronger if the firms are located in Yerevan.

Hypothesis 3b: Firm type homophily of the firm's network has a positive impact on firm financial performance.

Hypothesis 3c: Industry homophily of the firm's network has a positive impact on firm financial performance.

Heterophilous relationships require more effort because of resource differentials and lack of shared attributes, whereas homophilious ties make interaction less costly. Yet, there might still be a value, as the beterophilous interaction is more efficient if the firms need complimentary recourses or knowledge. The extent to which homophily is valuable for the firm is contingent on the dimension of attributes we are looking at: firm industry; location and firm type.

\section{Network Resourcefulness}

Network resourcefulness captures the financial aspect of one's network ties. Interpretation of this aspect of neighborhoods reflects the context of transition economies: privatized firms in Armenia were facing hard budget constraints for the first time (in a long time) and experienced a lack of access to any financial resources. 
Thus being in a neighborhood with rich financial resources may provide access to alternative financial resources.

Closed networks and embededness in local networks provide firms more opportunities to monitor each other's behavior. Thus, this might serve as a coping mechanism in borrowing financial resources from each other given shortage of formal financing sources, and weak legal institutions. This factor might be highly significant for determining firm performance. In our study we use a variable capturing firm's network resourcefulness, which takes into account not only how many connections a firm has but also the richness of resources, which potentially gives the firm, access to.

\section{Hypothesis 4: The greater the firm's network resourcefulness (partners' assets), the better the firm's financial performance.}

Personal networks were important instruments for actors in transition economies to support and facilitate market exchange. Through personal networks actors take action to maintain and gain valued resources, and individual actors with the ability to access and mobilize the resources through their networks experience greater opportunities to survive and produce higher rates of return.

\section{Foreign Ties}

Firms in Armenia found themselves in a new market environment having no prior knowledge or skills with which to navigate it. In this position, firms that have ties with foreign firm learn and acquire new organizational, and can transfer this knowledge through network ties. These ties could provide new ideas and new knowledge regarding how to navigate a (newly opened) market economy. As we discussed in the introduction, the main specificity of transition countries is the "old" or "soviet" way of doing business. Sometimes firms continue to use the "old" way of business due to a lack of information and motivation to change their behavior. O'Brien (2006) showed that even after the collapse, when there was no coordinator in Moscow, economic agents in Russia still kept a bureaucratic and inflexible attitude - and this is reflected in all areas such as organizational structure, production system, marketing and etc.

Over time, firms in closed networks develop a shared language, codes and mental models (Baum, Shipilov, and Rowley 2003; Nahapiet and Ghoshal 1998a); as a result, information exchange between firms in a network may become mutually reinforcing and more similar (Duysters et al. 2009). This may lead to the firm's overembeddedness in the board member network (Hagerdon, 2008). In this case, ties with foreign firms provide access to knowledge and information outside the local, Armenian context, and presumably from firms that have organizational experience more relevant to the new situation. In addition to other benefits, such as access to foreign markets and knowledge, technologies that in literature are associated with exporting, firms also learn how to change stereotypical soviet behavior, and hence adapt much faster to the market economy (Kikeri, Nellis, and Shirley 1994). Therefore, we argue that firms with more foreign ties (higher partners' export volume) will restructure and adapt to the new environment faster, and hence will have better performance (Pahor, Prašnikar, and Ferligoj 2004; Stark 1991).

The arguments above apply in two senses: direct effects on the exporting firm itself, and indirect effects through the exports of a firm's neighbours in the network. Our 
interest is in the indirect effects since they are the effects that operate through board networks, and we focus there in the econometric analysis. A second reason for that focus is more immediate. A firm that is able to export, must have, to a great extent, already assimilated the sorts of knowledge and information that we discuss here. They have already broken out of the local context and are able to address the operation and organization of the wider, capitalist, economy. Thus we expect there to be little effect (from learning) for previous exporters, but possible scope for those firms that have little export experience themselves, but which are linked to exporters. Thus in the analysis we examine the indirect effects through partners exports, looking at exports of the focal firm only as a control.

We measure the foreign ties of the neighborhood by the total volume of partners' export, which is a continuous variable. Grossman and Helpman (1991) argue that exporting "tangible commodities" facilitates the "exchange of intangible ideas", and in addition, the intensity of trade between two countries is related to the intensity of knowledge spillovers. This provides an insight why exporting firms in Armenia had an opportunity to learn through knowledge spillovers. Given that export intensity is a good measure of a foreign knowledge and best practices, we looked at how the focal firm that is linked with exporting firms may access to this knowledge and benefit. Or in the other words, we measure how knowledgeable is a firm partner. Therefore partners' export intensity captures how knowledgeable is one's network in terms of organizational new knowledge and best practices.

\section{Hypothesis 5: The greater the firm's Foreign Ties (partners' export), the better the firm's financial performance.}

The way privatization was implemented in Armenia limits foreign participation in the ownership structure, which does not provide opportunities for local firms to be exposed to new knowledge related to the new "market economy" paradigm. Actors were placed into the new "market economy" framework without prior knowledge and experience and without knowledge of the "rules of the game"; thus, the only channel to learn is through connections with foreign firms.

\subsubsection{Interactions between Network Structure and Content}

In the previous two sections we argued first that participation in social structures could yield benefits to a firm, and that the firm's position in the network could influence its performance. We argued second that the properties of the firm's neighbours are also important - being well-connected to firms that have no knowledge or resources to offer will be of no value. In this section we argue that there is an interaction between those two sources of (dis)advantage.

Burt's "structural holes" theory argues that disconnected contacts are sources of different resources and information. However, Burt does not address the question of what happens if the broker is connected to two or more groups who have the same resources or knowledge. If this is the case, what would be the value of occupying this position? Rodan and Galunic (2006) point out that network content may provide different outcomes for the same network structure: e.g., structural holes alone without heterogeniety of knowledge are of little benefit for managerial performance. Golub 
and Jackson (2012) showed that homophily for an actor with low degree centrality matters more than it does for an actor with high degree centrality. Similarly, Gilsing et al. (2008) concluded that network structure without other dimensions of network embeddedness, such as technological distance, will not explain the success rate of firms.

We argue therefore, that examination of a firm's performance in a board network is driven in part by the interaction of network structure and content. In making this argument, we draw on Rodan and Galunic (2006)'s approach that the structural view of network exchange must be augmented by observable actual resources, knowledge and attributes possessed by actors; otherwise, considerable variance in outcomes will be unexplained.

We define the following hypotheses to test the complementarity between network structure and content.

Hypothesis 6: Network resourcefulness (partners' assets) and network closure jointly and positively affect firm financial performance.

Hypothesis 7a: Network homophily and network closure jointly and positively influence firm financial performance.

Hypothesis 7b: Network heterophily and network sparseness jointly and positively influence firm financial performance

Hypothesis 8a: Foreign ties (partners' export) and network sparseness jointly and positively influence firm financial performance.

Hypothesis 8b: Foreign ties (partners' export) and network closure jointly and positively influence firm financial performance

Differential returns on social capital emerge because different combinations of network content and network structure may occur for an actor embedded in social networks. Resources embedded in an actor's neighborhood in conjunction with its network structure provide key information to predict how likely an instrumental action is to lead to a better outcome. For each network content, either cohesive or sparse ties may provide better social capital, and available and mobilized resources should be considered valuable if they are supported with an appropriate structure, and only then will they provide benefits for the firms in transitional countries.

In the previous section, we discussed the benefits of certain structures; here we start with a detailed examination of interaction terms between network structure and content. We suggest that each type of network content is associated with a certain network structure that will provide benefits to firms in the network.

For instance, when we consider actors coping with uncertainties, sharing risks or dealing with resource exchange and economic barter, then network cohesiveness combined with network resourcefulness may provide better opportunities for firm performance. Firms in a rich and resourceful neighborhood have higher chances to access financial resources and other possible assets available in the neighborhood. In this neighborhood, firms may benefit from borrowing or bartering as means of production. And in the context of a country where legal infrastructure was not well 
developed, leading to a lack of legal enforcement, firms are forced to rely only on social sanctioning mechanisms. Such a strong sanctioning mechanism allows the firm to monitor others' behaviors and increase trust; as such, it may result in only strong and cohesive personal network. Thus we argue that embeddedness in a cohesive and resourceful network may facilitate better and more effective assets exchange and borrowing between firms.

But, when we discuss the importance of acquiring new knowledge and generating new ideas, then brokerage position combined with foreign ties or network diversity may provide better outcomes. In fact, foreign ties (as indicated by partners' exports) are associated with new organizational knowledge and will have a higher impact if they are combined with structural holes since actors occupying a brokerage position will be more open for new business behavior. Above we discussed "old-minded" firms and that their new business strategies and organizational structures were heavily influenced by soviet culture. We believe that cohesive and dense networks of "old minded" firms have more constraints to changing and adapting new business behavior. Moreover, firms that are over-embedded in this type of neighborhood are discouraged from making some changes, as it considered being a deviation from the rules accepted by the group. So we argue that the potential value of foreign ties may be reduced if it is combined with cohesive networks.

Finally, the third dimension of neighborhood is network homophily. The findings regarding the effects of homophily are quite controversial. Rodan and Galunic (2006) show that heterophily of knowledge strengthens the effect of brokerage position on individual performance. Heterophily is a source of new ideas, more innovative approaches and solutions. On the other hand, the greater the homophily, the less the effort required to communicate and absorb information (Rogers 2003). The exchange of industry level information and resources may be faster and more efficient when firm is connected with similar ones. To sum up, the effect of homophily is ambiguous; however, one common aspect of homophily/heterophily that was discussed in the literature was that the benefits of heterophily in ties were always associated with sparseness of network.

\subsection{Related Studies on Social Capital and Performance}

One of the most prominent issues in social network research is a debate on the relative merits of different network characteristics and their roles in determining individual outcomes. Exploring empirical studies that used social network analysis to construct social capital variables, we found that the community uses different measures for the same social capital concept: e.g., to capture structural holes, studies use betweenness centrality, inverse of network density, or constraint, to capture network closure, clustering coefficient, ego density or two-step-reach. All these alternative measures capture different network structures, and it would be wrong consider the findings of empirical research without paying attention how social capital is measured.

Another important aspect of this section is to summarize studies that examine the relationship between board networks and firm performance. This section lays the groundwork to compare the results of our study with existing literature in this domain; 
therefore attention is paid to measures that previous studies have used to capture different characteristics of board networks and firm performance. However, as the studies utilizing board network data provide limited insights on social capital and firm performance, we complement our literature survey with studies on firm alliances. We summarize the main findings of the studies in this domain in Table 1 (see Appendix A), providing insight on the most frequently used measures of social networks in the context of the board's network, as well as in the context of alliance and other interfirm networks.

Degree centrality: One of the most popular measures of social capital is degree centrality, which captures the number of firms to which the focal firm is connected. Degree centrality in inter-firm networks has been a common measure for the studies in resource dependency theory (Beckman, Haunschild, and Phillips 2004) and studies that consider the network as a source of external resources (Ahuja 2000; Powell, Koput, and Smith-Doerr 1996; G. Martin, Gözübüyük, and Becerra 2015).

Table 1 (see Appendix A) shows that network size or degree centrality is used in the majority of the studies (Non and Franses 2007; Bosma et al. 2004; Batjargal 2007; Watson 2007; Chuang, Huang, and Wu 2013). ${ }^{24}$ In the emerging country context, degree centrality is an important factor in explaining firm performance: for example, Chuang, Huang, and Wu (2013) found that in the Taiwanese high tech-sector, a firm's centrality in the board network increases that firm's knowledge and information on emerging markets. In contrast, in the case of Australia, centrality has been shown to have no significant effect on ROE, but it has significant association with firm survival and growth. This can be explained by the assertion that social networks in general reduce uncertainty in the business environment (G. Martin, Gözübüyük, and Becerra 2015), but they do not always have a significant effect on profitability (Watson 2007). Empirical evidence on board network effects on ROA and ROE is not conclusive: Non and Franses (2007) found that lagged network size has a significant effect on ROA and ROE, and Larcker, So, and Wang (2013) and Ong, Wan, and Ong (2003) also found significant effects on ROA; however, some studies did not find there to be a significant relationship between board network and ROA or ROE (Watson 2007). ${ }^{25}$ A further investigation with Armenian data is therefore undertaken to provide evidence of any relationship between board network and firm performance.

Some studies also tested whether degree centrality has a non-linear relationship, and found that there is inverted U-shaped relationship with degree centrality and firm survival and growth (Watson 2007; Aral, Brynjolfsson, and Alstyne 2007), but not with ROE. The empirical research is very consistent in applying the degree centrality measure, despite the fact that the empirical findings show different effects on firm performance.

However, there is less consistency in the literature in terms of measuring network closure and structural holes.

\footnotetext{
${ }^{24}$ Some studies called it network size.

${ }^{25}$ While some authors might not report if they did not find significant relationship.
} 
Network Closure: Clustering coefficient and ego-network-density (density) are the most widely used network closure measures. These two measures attempt to capture the same ego network structures. ${ }^{26}$ For instance, Moran (2005) used density as a measure of one's network closure. He finds that it had a negative impact on managerial performance. Reagans and McEvily (2003) found that cohesive networks affect the ease of knowledge transfer, especially when we talk about tacit knowledge. Cohesive networks encourage trust, reciprocity and mutual help and interdependency; in this context diffusion of knowledge and information is faster and easier.

Another variable that the literature often uses to capture network cohesiveness is twostep-reach. It calculates the number of ties a firm has through its direct links, though it does not include closure itself. Nevertheless, this measure is still used in the literature as a proxy for network connectedness (Burt 2005; Grigoriou and Rothaermel 2014).

Structural holes: Betweenness centrality was proposed by Freeman (1977), network constraint by Burt (1992) and efficient size by Burt (1995). Betweenness centrality is one of most widely used measures in the literature, and Ahuja (2000), Rodan and Galunic (2006) show that it is positively associated with firm innovative performance. The literature on board networks that we have discussed does not contribute much to the debate between structural holes and network closure. For example, Larcker, So, and Wang (2013) used a z-centrality score for all centrality measures, ${ }^{27}$ although findings suggest that, while centrality in the board network is an important factor explaining firm performance, the composite measure they create to aggregates several types of centrality into one scalar, and thereby loses the ability to distinguish the several factors or mechanisms whereby network position might affect performance. Vedres and Stark (2008) propose the concept of intercohesion (overlapping cohesive groups), ${ }^{28}$ and their findings suggest that intercohesion is more important for group performance than brokerage or cohesiveness alone. The study of the entrepreneurial network in Uganda (Rooks et al. 2009) shows that constraint has a positive but inverted U-shape relationship with innovative performance. Martin, Gözübüyük, and Becerra (2015) used Burt's constraint measure for board networks, and found that it reduces uncertainty in the business environment, but has only a moderating effect on firm performance.

Rodan and Galunic (2006) used (1 - ego density) to measure structural holes, where density is a proxy for network closure, and they found that it has a positive effect on firm performance (obviously implying that ego-density, a measure of network closure, will have a negative effect on performance). Interestingly, they found complementarity between network sparseness and knowledge heterophily.

In this study, we use the most popular measures: betweenness centrality to measure structural hole, and the clustering coefficient for network closure. However, we used

\footnotetext{
${ }^{26}$ There is not universal consensus on the definitions of "density". Much of the general network literature uses it as a global measure, whereas in the management literature, and elsewhere, it is often used as a nod-level statistic. Even there, different authors use different definitions. We discuss more detail the measures in the next Chapter. ${ }^{27}$ They used a measure composed of all centrality measures such as degree centrality, betweenness centrality, and eigenvector centrality.

${ }^{28}$ Intercohesion is a measure that combines structural holes and cohesive networks.
} 
alternative measures such as constraint to test whether they have different effects compared to betweenness centrality.

Network Homophily: Network homophily has been the focus of a number of studies (Chung, Singh, and Lee 2000; Batjargal 2007; Rodan and Galunic 2006; McPherson, Smith-Lovin, and Cook 2001). But consensus has not been reached on the question of whether heterophilous or homophilous networks affect positively individual performance. A study of Russian entrepreneurship reveals that network heterophily was not significant for individual performance (Batjargal 2007), while Chuang et al. (2013) show that a higher degree of industry homophily leads to better access to an industry specific resources and knowledge, and hence improves the firm's performance. Jiang et al. (2010) found that industry diversity in a firm's alliance portfolio has a U-shaped relationship with firm performance; studies in the innovation domain point out the importance of heterogeneity of knowledge, and hence network heterophily is an important factor for performance (Rodan and Galunic 2006; Lee 2010; Jiang, Tao, and Santoro 2010).

Network resourcefulness: Network resourcefulness measures the degree to which network ties contain valuable resources. Batjargal (2007), Koka and Prescott (2002) have studied the resources available through network ties. For example, Batjargal (2007) examined the socioeconomic status of ego's alters, which measures the availability of different types resources through high ranked officials, and did not find it to have a significant effect on firm performance. Interestingly, with a slightly more nuanced analysis he found that actors who were actually utilizing the resources available through these ties have better performances, which confirms the relative explanatory power of the resources available through networks. Koka and Prescott (2002), showed that social networks yield three distinct information benefits: information volume, information richness and information diversity. These are interrelated but very distinct dimensions of social capital, which provide distinct benefits.

\subsection{Conclusion}

This chapter has outlined structural and content dimensions of social capital. By bringing together the structural aspect and the quality of social networks, we set the framework for conceptualization of the role of social capital in explaining a firm's performance. When we consider the structural aspect alone, we assume the firm's access and availability of resources, but to make it explicit we should include the value of the potential resources. At the same time, an actor who initiated action to mobilize the resources available through social networks may be constrained by the network structure, and hence structural effects cannot be ignored in the analysis.

Another important consideration is the how to measure or evaluate the quality of social networks, and what is actually transferred through social networks? Here we discuss some important concepts that can play an important role while considering corporate networks in a transition context: resourcefulness, homophily and heterophily of partners' attributes and foreign ties. This is an attempt to assess different features of partners' attributes, which in fact constitute some aspects of social capital: network 
resourcefulness is an assessment of the firm's partner's financial resources, and foreign ties captures opportunity for learning about best organizational practice and new market opportunities. Homophily, which we disentangle into firm type, location and industry aspects, plays a critical role in two ways: first, it measures the efficiency of knowledge and information transfer; and second, it specifies a partners' skills, capabilities and knowledge.

The value of this conceptual framework lies in its ability to highlight how the structural dimension of social capital and its qualities provide a more refined understanding of firm performance, stressing the complementary features of the structure and content. In the appendix, we provide a summary of studies that have used social capital to explain firm performance. Studies on board networks have used a very limited approach in measuring social capital, and as result various dimensions of social capital have not been very well captured. In contrast, studies on alliances provided richer theoretical and empirical understanding for social capital and its effect on firm performance. Hence, in the literature review part, we heavily rely on alliance studies. However, the most valuable aspect of previous studies on board network, was that they provided strong empirical evidence that the board network plays significant role in explaining firm performance. This discrepancy between the depth of research on alliances and that on boards could be because data on board networks is not easily available.

To enrich our discussion on different dimensions of social capital and their effects on firm performance we also used alliance literature. As we were interested in extending our analysis and applying other dimensions of social capital we looked at studies that utilize various networks such as alliances and entrepreneurial networks. This provided very rich background on our understanding of how social networks may shape, add value or even constrain individual performance. We also paid attention to what measures empirical studies are using, how they operationalize various social capital concepts. For example, some studies used different measures for structural holes or network cohesiveness or network homophily. Before, defining our measures we used a comparative approach across the study, which is reflected in our literature survey. By doing so, we emphasized the importance of looking at the concrete variables that the studies are using. Studies may find different effect of the same social capital dimensions simply because they used different variables or alternative measures. Finally, we also operationalized the propositions into working hypotheses, and the following table suggests how we are going to test them with our data. 
Table 4-1: Empirical hypotheses for estimation of firm performance

\begin{tabular}{|c|c|c|c|}
\hline Hypothesis & $\begin{array}{l}\text { Factors affecting } \\
\text { performance }\end{array}$ & Explanatory variables & $\begin{array}{l}\text { Expected } \\
\text { sign }\end{array}$ \\
\hline \multirow{2}{*}{ H1 } & \multirow{2}{*}{ Centrality } & Degree Centrality & + \\
\hline & & Square of degree centrality & - \\
\hline \multirow{3}{*}{$\begin{array}{c}\mathrm{H} 2 \\
(\mathrm{a}, \mathrm{b})\end{array}$} & Network Closure & $\begin{array}{l}\text { Clustering coefficient, two step } \\
\text { reach }\end{array}$ & $+/-$ \\
\hline & Structural holes & $\begin{array}{l}\text { Betweenness centrality, } \\
\text { constraint }\end{array}$ & $+/-$ \\
\hline & $\begin{array}{l}\text { Location } \\
\text { homophily }\end{array}$ & $\begin{array}{l}\text { Homophily index based on } \\
\text { firms location }\end{array}$ & + \\
\hline \multirow[t]{2}{*}{$\begin{array}{c}\text { H3 } \\
(a, b, c)\end{array}$} & $\begin{array}{l}\text { Firm type } \\
\text { homophily }\end{array}$ & $\begin{array}{l}\text { Homophily or heterophily index } \\
\text { based on firm type }\end{array}$ & $+/-$ \\
\hline & $\begin{array}{l}\text { Industry } \\
\text { homophily } \\
\text { Network }\end{array}$ & $\begin{array}{l}\text { Homophily or heterophily index } \\
\text { (industry) }\end{array}$ & $+/-$ \\
\hline H4 & $\begin{array}{l}\text { resourcefulness/ } \\
\text { Partners' Assets } \\
\text { Foreign }\end{array}$ & Sum of partners' assets & + \\
\hline H5 & $\begin{array}{l}\text { Ties/partners' } \\
\text { export }\end{array}$ & Sum of partners' export volume & + \\
\hline H6 & $\begin{array}{l}\text { Network closure } \\
\text { and partners' } \\
\text { assets }\end{array}$ & $\begin{array}{l}\text { Interaction term of Network } \\
\text { closure and partners' assets }\end{array}$ & + \\
\hline H7a & $\begin{array}{l}\text { Network } \\
\text { homophily and } \\
\text { Network closure }\end{array}$ & $\begin{array}{l}\text { Interaction between network } \\
\text { closure and industry homophily; } \\
\text { Closure and Location } \\
\text { homophily, closure and firm } \\
\text { type homophily }\end{array}$ & + \\
\hline $\mathbf{H} 7 \mathrm{~b}$ & $\begin{array}{l}\text { Network } \\
\text { heterophily and } \\
\text { structural hole }\end{array}$ & $\begin{array}{l}\text { Interaction of heterophily (firm } \\
\text { type or industry) and structural } \\
\text { hole measures }\end{array}$ & + \\
\hline H8a & $\begin{array}{l}\text { Partners' assets } \\
\text { and Structural } \\
\text { hole }\end{array}$ & $\begin{array}{l}\text { Interaction of partners' export } \\
\text { and structural hole measures }\end{array}$ & $+/-$ \\
\hline H8b & $\begin{array}{l}\text { Partners'assets } \\
\text { and Network } \\
\text { closure }\end{array}$ & $\begin{array}{l}\text { Interaction of partners' export } \\
\text { and network closure }\end{array}$ & $+/-$ \\
\hline
\end{tabular}




\section{Appendix A: Literature Review}

Table 1: Summary of empirical findings

\begin{tabular}{|c|c|c|c|c|c|c|}
\hline Study, Year & $\begin{array}{l}\text { Network } \\
\text { type }\end{array}$ & Country & $\begin{array}{l}\text { Firm performance } \\
\text { (Dependent } \\
\text { variable) }\end{array}$ & Social capital (SC) & $\begin{array}{c}\text { Variables } \\
\text { (Independent variables) }\end{array}$ & Findings \\
\hline $\begin{array}{l}\text { (Dicko and } \\
\text { Breton } \\
2010) \\
\end{array}$ & $\begin{array}{c}\text { Board } \\
\text { network }\end{array}$ & Canada & & $\begin{array}{l}\text { Political, economic, } \\
\text { social affiliation }\end{array}$ & $\begin{array}{l}\text { Number of ties in } \\
\text { different networks }\end{array}$ & Only Political social capital was important \\
\hline $\begin{array}{l}\text { (Zaheer } \\
\text { and Bell } \\
2005)\end{array}$ & $\begin{array}{l}\text { Board and } \\
\text { managemen } \\
\text { t network }\end{array}$ & $\begin{array}{l}\text { Canadian } \\
\text { mutual fund } \\
\text { firms }\end{array}$ & $\begin{array}{l}\text { Market share, } \\
\text { firm's } \\
\text { innovativeness }\end{array}$ & $\begin{array}{l}\text { Structural holes, alter } \\
\text { innovativeness }\end{array}$ & $\begin{array}{l}\text { Burt's constraint, alter- } \\
\text { specific redundancy } \\
\text { score, interaction terms }\end{array}$ & $\begin{array}{l}\text { This study found that firm's innovative capabilities and } \\
\text { its network structure both enhance firm performance. }\end{array}$ \\
\hline $\begin{array}{l}\text { (Larcker et } \\
\text { al. 2013) }\end{array}$ & & & $\begin{array}{l}\text { Stock Return, } \\
\text { ROA }\end{array}$ & Network Centrality & $\begin{array}{l}\text { Degree, Closeness, } \\
\text { Betweenness, } \\
\text { Eigenvalue centrality }\end{array}$ & Centrality was important \\
\hline $\begin{array}{c}\text { Chuang } \\
\text { et.al. 2013) }\end{array}$ & $\begin{array}{c}\text { Shareholder } \\
\text { s }\end{array}$ & $\begin{array}{l}\text { Taiwan, } \\
\text { Emerging } \\
\text { Economy }\end{array}$ & & $\begin{array}{l}\text { Social capital and } \\
\text { Depth of SC }\end{array}$ & $\begin{array}{l}\text { Degree centrality, } \\
\text { Industry homophily }\end{array}$ & $\begin{array}{l}\text { They found that Social capital and SC depth has high } \\
\text { impact in general, but it is more significant in high } \\
\text { competitive markets }\end{array}$ \\
\hline $\begin{array}{l}\text { (Non and } \\
\text { Franses } \\
\text { 2007) }\end{array}$ & $\begin{array}{c}\text { Board } \\
\text { network }\end{array}$ & Holland & $\begin{array}{l}\text { Stock return, } \\
\text { ROA, Price- } \\
\text { earnings ratio, } \\
\text { ROE }\end{array}$ & $\begin{array}{l}\text { Number of interlock } \\
\text { directors }\end{array}$ & Network size & $\begin{array}{l}\text { Number of interlocks on stock returns, price-earning } \\
\text { ration and ROA is not significant, but is significant on } \\
\text { price to book ratio and ROE. For ROE only lagged } \\
\text { variables are important Square rot and leaner SC is } \\
\text { significant, U shape is for ROA and max } 3.9 \text { interlock, } \\
\text { ROE is inverted U- shaped on ROE }\end{array}$ \\
\hline $\begin{array}{l}\text { (Vedres } \\
\text { and Stark } \\
2008)\end{array}$ & $\begin{array}{c}\text { Board } \\
\text { network }\end{array}$ & $\begin{array}{l}\text { Hungary, } \\
\text { Transition }\end{array}$ & $\begin{array}{l}\text { Innovative group } \\
\text { performance }\end{array}$ & $\begin{array}{l}\text { Cohesive groups } \\
\text { /intercohesion and } \\
\text { Structural holes }\end{array}$ & $\begin{array}{l}\text { Brokerage, group size, } \\
\text { group homophily }\end{array}$ & $\begin{array}{l}\text { Intercoheison contributes to higher group } \\
\text { performance. }\end{array}$ \\
\hline $\begin{array}{l}\text { (Wincent et } \\
\text { al. 2010b) }\end{array}$ & $\begin{array}{c}\text { Board } \\
\text { network }\end{array}$ & $\begin{array}{l}\text { Sweden, } \\
\text { SMEs }\end{array}$ & $\begin{array}{l}\text { Network } \\
\text { innovative } \\
\text { performance }\end{array}$ & $\begin{array}{l}\text { Board's human and } \\
\text { relational capital }\end{array}$ & $\begin{array}{l}\text { Board's expertise } \\
\text { diversity, network size, } \\
\text { intensity of board's ties }\end{array}$ & $\begin{array}{l}\text { The study finds, that board network diversity of } \\
\text { expertise and education level is important for } \\
\text { innovative performance (total, incremental and radical) } \\
\text { in smaller networks. }\end{array}$ \\
\hline $\begin{array}{l}\text { (Martin et } \\
\text { al. 2015) }\end{array}$ & $\begin{array}{c}\text { Board } \\
\text { network }\end{array}$ & $\begin{array}{c}\text { US } \\
\text { manufacturi } \\
\text { ng } \\
\text { industries }\end{array}$ & $\mathrm{ROA}$ & $\begin{array}{l}\text { Network position, } \\
\text { Structural hole }\end{array}$ & $\begin{array}{l}\text { Degree centrality, } \\
\text { Burt's constraint }\end{array}$ & $\begin{array}{l}\text { This study shows that boards network enable firms to } \\
\text { improve performance when they are confronted with } \\
\text { greater uncertainty. This implies that uncertainty } \\
\text { mediates the board network effect on performance. } \\
\text { (Centrality and constraint has negatively related to } \\
\text { uncertainty) }\end{array}$ \\
\hline
\end{tabular}




\begin{tabular}{|c|c|c|c|c|c|c|}
\hline $\begin{array}{l}\text { (Watson } \\
\text { 2007) }\end{array}$ & $\begin{array}{c}\text { SME } \\
\text { owners }\end{array}$ & Australia & $\begin{array}{l}\text { Survival, growth, } \\
\text { ROE }\end{array}$ & $\begin{array}{l}\text { Informal and formal } \\
\text { Networking }\end{array}$ & $\begin{array}{l}\text { Network size, } \\
\text { intensity, } \\
\text { range(different sources } \\
\text { for networking) }\end{array}$ & $\begin{array}{l}\text { Networking is significant with survival and growth, but } \\
\text { not with ROE, Network intensity is more critical for } \\
\text { survival than network range, and opposite was true for } \\
\text { growth. No significance with ROE, Networking was } \\
\text { equally important for young and old firms, inverted U- } \\
\text { shaped relationship with firm survival and growth, but } \\
\text { not with ROE }\end{array}$ \\
\hline $\begin{array}{l}\text { (Bosma et } \\
\text { al. 2004) }\end{array}$ & $\begin{array}{c}\text { Entreprene } \\
\text { urial }\end{array}$ & Holland & $\begin{array}{l}\text { Profit, Cumulative } \\
\text { employment, } \\
\text { survival }\end{array}$ & $\begin{array}{c}\text { Number of } \\
\text { entrepreneurial, ways } \\
\text { to get information, } \\
\text { emotional support }\end{array}$ & $\begin{array}{l}\text { Network size, Contact } \\
\text { types (general, } \\
\text { commercial, fellow } \\
\text { entrepreneurial), } \\
\text { emotional support } \\
\text { from spouse }\end{array}$ & $\begin{array}{l}\text { Social capital appeared to influence performance. } \\
\text { Commercial information improve all performance } \\
\text { measures, general channels improve survival and } \\
\text { generated employment. Informal Contact with others } \\
\text { improves employment. Emotional support is positive } \\
\text { and significant and provides } 40 \% \text { more chances for } \\
\text { better perform. }\end{array}$ \\
\hline $\begin{array}{l}\text { (Batjargal } \\
2007)\end{array}$ & $\begin{array}{c}\text { Entreprene } \\
\text { urial }\end{array}$ & Russia & $\begin{array}{l}\text { Sales growth, } \\
\text { operating profits } \\
\text { and ROA }\end{array}$ & $\begin{array}{l}\text { Three dimensions of } \\
\text { social capital, strong } \\
\text { and weak ties }\end{array}$ & $\begin{array}{l}\text { Network size, network } \\
\text { heterophily, } \\
\text { resourcefulness }\end{array}$ & $\begin{array}{l}\text { Various dimension of social capital have different } \\
\text { effects on performance. Weak ties are positive to sales } \\
\text { growth, profit margins and ROA the same is true for } \\
\text { resource embeddedness. While Network size and } \\
\text { heterophily have no impact on the firm performance. }\end{array}$ \\
\hline $\begin{array}{l}\text { (Rooks et } \\
\text { al. 2009) }\end{array}$ & $\begin{array}{c}\text { Entreprene } \\
\text { urial }\end{array}$ & Uganda & $\begin{array}{l}\text { Innovative } \\
\text { performance }\end{array}$ & $\begin{array}{l}\text { Constraint, density, } \\
\text { Multiplexity }\end{array}$ & $\begin{array}{l}\text { Constraint, } \\
\text { Multiplexity, Network } \\
\text { size }\end{array}$ & $\begin{array}{l}\text { Constraint and Density have positive effect on } \\
\text { innovative performance, but constraint has inverted- } \\
\text { shaped relationship with performance. }\end{array}$ \\
\hline (Lee 2008) & Alliances & $\begin{array}{c}\text { Global } \\
\text { Technology } \\
\text { sector }\end{array}$ & $\begin{array}{l}\mathrm{Z} \text { score which is a } \\
\text { sum of ROE, } \\
\text { ROE, and others / } \\
\text { Tobin Q }\end{array}$ & $\begin{array}{l}\text { Corporate social } \\
\text { capital is a sum of } \\
\text { intellectual capital, } \\
\text { absorptive capacity } \\
\text { and alliance network }\end{array}$ & Network centrality & $\begin{array}{l}\text { Centrality is positively associated with the firm } \\
\text { performance }\end{array}$ \\
\hline $\begin{array}{c}\text { (Koka and } \\
\text { Prescott } \\
\text { 2002) }\end{array}$ & Alliances & $\begin{array}{c}\text { Steel } \\
\text { industry }\end{array}$ & & $\begin{array}{c}\text { Structural holes, } \\
\text { information richness, } \\
\text { knowledge } \\
\text { heterogeneity }\end{array}$ & $\begin{array}{l}\text { Constraint, nationality } \\
\text { Blau's heterogeneity } \\
\text { index, alliance } \\
\text { experience }\end{array}$ & $\begin{array}{l}\text { Different dimension of social capital impacts } \\
\text { performance differently. Firms vary in terms of } \\
\text { different levels of social capital based their structural } \\
\text { social capital and changes of social capital over the } \\
\text { period. }\end{array}$ \\
\hline $\begin{array}{l}\text { (Jiang et al. } \\
\text { 2010) }\end{array}$ & Alliance & $\begin{array}{l}\text { Multination } \\
\text { als }\end{array}$ & Net profit margins & $\begin{array}{l}\text { Alliance portfolio } \\
\text { heterogeneity }\end{array}$ & $\begin{array}{l}\text { Industry, country and } \\
\text { organizational } \\
\text { heterogeneity }\end{array}$ & $\begin{array}{l}\text { They found mixed results. Industry diversity has a U- } \\
\text { shaped relationship with firm performance, } \\
\text { Organizational diversity showed J-shaped relationship, } \\
\text { functional diversity was found desirable for R\&D, } \\
\text { marketing. Governance diversity was negative. }\end{array}$ \\
\hline
\end{tabular}




\begin{tabular}{|c|c|c|c|c|l|l|}
\hline $\begin{array}{c}\text { Rodan and } \\
\text { Galunic } \\
2006)\end{array}$ & Alliance & Global & $\begin{array}{c}\text { Managerial } \\
\text { performance, } \\
\text { innovativeness }\end{array}$ & $\begin{array}{l}\text { Network size, } \\
\text { structural hole, } \\
\text { knowledge } \\
\text { heterogeneity }\end{array}$ & $\begin{array}{l}\text { Network size, (1- } \\
\text { ensity), } \\
\text { Blaus'heterogeneity } \\
\text { index } \\
\text { Interaction term }\end{array}$ & $\begin{array}{l}\text { Study on managerial performance, shows that network } \\
\text { structure is important, and access to heterogeneous } \\
\text { knowledge is an essential component for the growth of } \\
\text { individual performance and innovativeness. }\end{array}$ \\
\hline $\begin{array}{c}\text { (Ahuja } \\
2000)\end{array}$ & Alliance & $\begin{array}{c}\text { Chemical } \\
\text { industry }\end{array}$ & $\begin{array}{c}\text { Patents/ } \\
\text { Innovative } \\
\text { performance }\end{array}$ & $\begin{array}{c}\text { Direct and indirect } \\
\text { network ties, } \\
\text { Structural holes, } \\
\text { diversity }\end{array}$ & $\begin{array}{l}\text { Entropy measure for } \\
\text { diversity, constraint }\end{array}$ & $\begin{array}{l}\text { Longitudinal study on firm's innovation shows that } \\
\text { increasing structural holes have a negative effect on } \\
\text { firm's innovative performance. }\end{array}$ \\
\hline
\end{tabular}


CHAPTER

EMPIRICAL APPROACH 


\subsection{Introduction}

This is an empirical study of the historical data on Armenian board network, and this chapter introduces the data and the empirical approach we use.

In this chapter we explore the data on Armenian publicly listed companies for the period of 2000-2010, and the constructed the board network for the period of 20002005. This represents a unique contribution to understanding the process of the formation of corporate culture in Armenia, as to date there has been no systematic analysis of large Armenian corporations. First we provide details on data collection and construction of the board member's network, its visualization and network statistics. Then, we discuss how the social capital measures and other variables are constructed.

We also undertake the preliminary analysis of the interrelation between a firm's social capital measures and financial variables. The purpose of this preliminary analysis is to present the background information necessary for the econometric modeling in Chapter 5.

\subsection{Data Collection}

Our data is derived from two main sources. The first source is the board representation data that we collected from paper-based archive data stored in the Central Bank of Armenia for the period of 2000-2005. The second source is firm level data that includes industry, annual employment and financial information for the period of 2000-2010. This was collected from the Revenue Ministry of Armenia. We focused on large companies that became open joint stock companies in 1999 after the large-scale privatization reforms. These were publicly listed companies having more than 50 shareholders and initial capital of 1 million AMD (Armenian currency). They had to report to the Central Bank of Armenia and Stock Exchange about their financial situations, and provide information on their board members and CEOs every year.

\subsubsection{Network Data and Visualization}

The first dataset contains information on those shareholders that possess at least $10 \%$ of a company's shares, board members, balance sheets and financial reports. Our database, which covers all publicly listed companies, includes data on 207 companies. These are the largest industrial firms in soviet Armenia, which were privatized. According to the law on publicly traded companies, they were obliged to report information about board members, major shareholders and their financial information. The above-mentioned criteria for publicly traded companies were changed in 2005, and as a result the number of publicly traded companies shrank from 207 to 50 companies. Therefore, we had access to board members information only for the period of 2000-2005. Based on this database we construct 4 waves of undirected and unweighted network data for 2000, 2001, 2003 and 2005. By using R (igraph package) we extracted a one-mode network from the bipartite graph. In particular, two companies are considered to be linked if they share at least one board member. To 
encode the network, for each year we construct an $\mathrm{M} \times \mathrm{M}$ adjacency matrix $\mathrm{A}$, where $\mathrm{M}$ is a number of companies. Elements of $\mathrm{A}, a_{i j}$, take the value 1 if there is a direct link between $i$ and $j$, that is, if firms $i$ and $j$ have a board member in common, and 0 otherwise. To visualize the network we use UCINET software and network data for four periods (see Figures 1- 4 in Appendix B). ${ }^{29}$

\subsubsection{Financial Data from 2000 to 2010}

Our second data source is collected from the Ministry of Revenue and the Ministry of Economy. These data document annual firm level financial variables such as profit, equity, labor, sales etc. We trace the financial information of the firms present in the first dataset, and as a result we construct panel data for the targeted firms for the period 2000 to 2010 (see Appendix C). This period was selected as joint stock companies were created in 1999 indicating the major shift from state owned companies to private ownership, and 2010 is the period when we undertook the collection of data.

\subsection{Variables and Descriptive Statistics}

\subsubsection{Network Characteristics}

In our empirical analysis we focus on firms and their partners' network position as well as their attributes such as financial resources, firm type and industry to explain how they affect a firm's performance. Our key explanatory variables are constructed using UCINET software (Borgatti, Everett, and Freeman 2002). The use and selection of these particular network measures follows other studies that have indicated the relevance of those measures in explaining firm's performance.

We applied the following measures of social capital:

\section{Degree Centrality}

Degree centrality measures a node's connectedness, and is defined as the number of direct links with other nodes.

$$
d_{i}=\sum_{j \neq i} a_{i j}
$$

where $a_{i j}$ denotes the link between firm $i$ and $j$, and higher degree, $d_{i}$, indicates that a firm is connected with more firms.

\section{Network Closure}

To capture network closure we used the following measures:

Clustering Coefficient - Clust $t_{i}$ of a node $i$ is defined as

\footnotetext{
${ }^{29} \mathrm{We}$ also constructed a weighted matrix, where the link weight, $a_{i j}$, is equal to number of board members shared between firms $i$ and $j$.
} 


$$
\text { Clust }_{i}=\frac{2 g_{i}}{d_{i}\left(d_{i}-1\right)}
$$

Let $N_{i}$ be $i$ 's neighborhood, where $d_{i}$ is the size of the neighborhood, and $g_{i}$ is the number of connected pairs between all neighbors of $i$. Intuitively, it measures the extent to which one's friends are also friends of each other.

TwoStepReach - is the number of nodes that ego is linked through the third node. Defining $a_{i j}^{2}$ as the element $i, j$ of the square of the adjacency matrix, $\mathrm{A}^{2}$, we can define two-step reach as

$$
\text { Step }_{i}=\sum_{j \neq i} \min \left(a_{i j}^{2}, \mathbf{1}\right)
$$

where 1 is the MxM matrix of $1 \mathrm{~s}$, and $\min$ is the element-wise minimum. TwoStepReach measures the number of nodes that a focal actor is connected through its direct connections (friend of friend). A higher value of STEP indicates a higher level of cohesion for the node.

\section{Structural Holes}

We use the following measures:

Betweenness Centrality - which measures how important a node is in connecting other nodes (Larcker, So, and Wang 2013). It shows how many shortest paths occur between the focal firm and other firms.

$$
\text { Betweeness }_{i}=\sum_{j \neq i} \frac{b_{i k j} / b_{k j}}{(n-1)(n-2) / 2}
$$

where $b_{i k j}$ is the number of shortest paths between $k$ and $j$ that node $i$ lies on and $b_{k j}$ is the total number of shortest paths between nodes $k$ and $j$.

Constraint - Burt's constraint measures how a firm is strongly constrained by its partners (Burt, 1992).

$$
\text { Const }_{i}=\sum_{j \neq i}\left(p_{i j}+\sum_{q \in V_{i}} p_{i q} p_{q j}\right)^{2}
$$

where Const $_{i}$ is a measure of constraint of node $i, V_{i}$ is defines as $i$ s ego network, $p_{i j}$ is the proportion of $i$ s network spent on contact $j$ directly, and $\sum_{q \in V_{i}} p_{i q} p_{q j}$ measures $i$ s network spent on $j$ indirectly. The constraint measure varies from 0 to 2 , and measures the extent to which $i$ s network time and energy is spent on $j$ directly or indirectly. For undirected network $p_{i j}=\frac{e_{i j}}{\sum e_{i q}}$ where variable $e_{i q}$ measures the strength of connection from ego to contact $q$. In unweighted network $p_{i j}$ varies from 
zero to one. To measure a firm's structural hole access, we subtracted constraint measure from 2, as a result it will show lack of redundancy in one's network. ${ }^{30}$ Higher values of these measures imply that a firm has a less constrained position in the network, and hence has more brokering opportunities. For firms without ties, we assigned the largest integer. The idea of the constraints is important because it points out that an actor who has many redundant ties may lose freedom of action, rather than gaining benefits.

\section{Network Content}

\section{Homophily}

We use UCINET to calculate Homophilous ties for each firm based on three main categories: Industry, Region and Firm type. For each category we use several measures of homophily generated by UCINET. For any attribute that we are interested in we can partition the set of nodes into those that hold the attribute, subset $E$, and those that do not, subset $\bar{E}$.

PctHomoph - Homophily of an actor $i$ is the ratio of the number of ties actor $i$ has with actors that share the same attributes, to the total number of ties of an actor $i$.

$$
\operatorname{Hom}_{i}=\frac{\sum_{j \in E} a_{i j}}{d_{i}} .
$$

The sum counts those ties of $i$ that are to nodes that also possess the attribute, and $d_{i}$ is is degree.

EI Index. - is the measure of homophily of an actor $i$, which equals $i$ s number of links with actors belonging to another group minus the number of links within $i$ s own group category, divided by the $i$ s degree.

$$
E I H_{i}=\frac{\sum_{q \in \bar{E}} a_{i q}-\sum_{j \in E} a_{i j}}{d_{i}}
$$

where the first sum counts the number of ties $i$ has to nodes not possessing the attribute, and the second to nodes that do.

This homophily measure can range from -1 to 1 , where -1 shows perfect homophily and 1 perfect heterophily.

\section{Heterophily}

Blau's measure of heterophily examines the heterogeneity of the actor's ties in a certain category, which provides insight on an actor's diversification strategy. Two homophily measures discussed earlier are more appropriate when we consider dichotomous attributes such as gender (female or male) or, as in this study, as a regional variable (whether a firm is located in the capital city or outside of it). However in our study, we also use the variables of industry and firm type. These variables have 4 and 9

${ }^{30}$ Following the approach that was developed by Martin et al. (2015) and Rooks et al. (2009). 
categories respectively. The heterophily measure provides richer information on how diverse actors in terms of firm type or industry are distributed in an ego-network.

\section{Blau's Heterogeneity Index}

$$
H T_{i}=1-\sum_{g=1}^{G}\left(f_{i g}\right)^{2}
$$

where $G$ is a total number categories for a certain attribute (e.g. industry sectors) indexed by $g$, and $f_{i g}$ is the proportion of the ties of firm $i$ to other firms in category $g: f_{i g}=\frac{u_{i g}}{\sum_{g=1}^{G} u_{i g}}$, where $u_{i g}$ is the number of links from firm $i$ to firms in category $g$.

This measure can range from 0 to 1 , where low values show that an actor's ties are concentrated in a single category, and in the case of 0 it is complete concentration. Actors evenly spreading their connections among all categories will have higher scores.

To sum up, in our study we analyze the effect of homophily/heterophily based on industry, location and firm type.

a. Industry homophily - shows how homophilous are ego's alters, based on the industry in which they operate; we have 9 industries.

b. Regional homophily - indicates homophilous ties based on the firm's location. The location variable is a dummy, which shows whether the firm is located in the capital city or in another region.

c. Firm type homophily - we divided firms into four categories:

1. Small and exporting firms

2. Small and not-exporting firms

3. Large and exporting firms

4. Large and not exporting firms

\section{Network Resourcefulness}

The measure of the network resourcefulness of a firm is a sum of its partners' assets, which captures the resource embeddedness of a firm. To calculate this variable we use network structure and information on assets per firm.

$$
R_{i}=\sum_{j \neq i} a_{i j} r_{j}
$$

where $a_{i j}$ is an element of an $A$ adjacency matrix, $r_{j}$ measures assets possessed by firm $j$. In the empirical analysis we use also the average value of resourcefulness, which 
is $R_{i}$ divided by $i$ s degree centrality. A higher value of resourcefulness indicates that firm $i$ has access to richer resources. By using average $R_{i}$ we control for network size.

\section{Foreign Ties}

The measure of a firm's Foreign Ties is the sum of partners' export volume, which captures the intensity of the connection with foreign firms. To calculate this variable we use network structure and information on export volume per firm.

$$
M_{i}=\sum_{j \neq i} a_{i j} h_{j}
$$

where, $h_{j}$ is firm $j$ 's export volume.

We also used the average value, which is $M_{i}$ divided by $i$ s network size. A higher value of foreign ties indicates that firm $i$ has better access to modern knowledge or new organizational knowledge.

\subsubsection{Firm characteristics}

\section{Control Variables}

Firm size, measured by the log of the number of employees or total assets. We used annual book value of the total assets.

Firm industry is a dummy variable, which takes 1 if the firm is operating in manufacturing and 0 otherwise.

Previous year's sales measured by the lagged value of log sales (book value of annual sales)

Region dummy is equal to 1 if the firm is registered in Yerevan (the capital of Armenia), and equals 0 otherwise. $50 \%$ of the economic activities of the country are conducted in Yerevan.

\section{Firm Performance}

Return on Assets (ROA) - Return on Assets is the ratio of net profit on total assets for each year. It measures the efficiency of total assets in generating net profit, which refers to the number of Armenian drams (AMD) in net profit produced for every 1 AMD in Total Assets.

Return on Equity (ROE) - Return on Equity is the ratio of net profit on equity calculated for each year. Similarly it measures the efficiency of equity in generating net profit before tax.

\subsubsection{Descriptive statistics}

Network variables: The dataset includes corporate network data for the periods of 2000, 2001, 2003 and 2005. In this section we reveal network measures for these four periods. Table 5-1 reports the degree distribution in percentages for the years of 2000, 
2001, 2003 and 2005. Percentage of isolates (when degree centrality is equal 1) fluctuates over the years: in 2000 it counted $47 \%$, in 2001 the number fell to $25.3 \%$, and in 2003 rose again to 53\% (the highest proportion for isolates for the Armenian board network), and in 2005 it reduced to $21 \%$. Firms that were linked to more than 6 firms occurred in 2000 and 2005, where the highest degree centrality was 13 but only for one firm.

Table 5-1: Distribution of degree centrality in percentage

\begin{tabular}{|c|cccc|}
\hline Degree Centrality & 2000 & 2001 & 2003 & 2005 \\
\hline Isolates & 46.9 & 25.3 & 53.0 & 21.3 \\
1 & 25.0 & 26.3 & 16.9 & 27.9 \\
2 & 7.3 & 19.4 & 14.2 & 20.8 \\
3 & 6.3 & 12.4 & 9.3 & 11.5 \\
4 & 3.6 & 8.1 & 3.8 & 8.7 \\
5 & 2.6 & 3.8 & 2.2 & 1.6 \\
6 & 0.5 & 2.2 & 0.6 & 1.6 \\
7 & 4.2 & 2.7 & & 0.6 \\
8 & 1.0 & & & 2.2 \\
9 & 2.6 & & & 1.1 \\
10 & & & & 1.1 \\
12 & & & 100 & 1.1 \\
14 & 100 & & & 0.6 \\
\hline Total & & & & 100 \\
\hline
\end{tabular}

Average degree centrality was 1.82 in 2000 and it increased to 3.2 for 2005 (see Table 2 Appendix B). As many real-world networks, this boards network shows that small number of firms are highly connected, and many firms have few connections. However, the proportion of isolates falls after the initial year (after privatization). We have many missing observations for 2003, and we can assume that high proportion of isolates is because of them.

Table 5-2 shows the evolution of our network statistics over time (Correlations between the variables is shown in Table 2 in appendix B). What we observe is that the network was increasing in density, suggesting that that firms were becoming aware that to re-create the social connections that drove the soviet economy, they had to link to other firms. Boards network was one mechanism they used. Constraint and clustering show little change over the period, which suggests that firms' networking efforts were focused more on degree than on the local structures. This may be quite reasonable: manipulating local structures demands a quite sophisticated understanding of network effects, and an equally sophisticated ability to address them. It seems reasonable that the first, and simplest network attribute to address is driven by a firms simple desire to be connected. 
Two-step reach sees a dramatic increase over the period. ${ }^{31}$ One explanation is that peripheral firms or isolates tried to make connections with more central firms, even through non-direct connections. After privatization (2000), when the economic actors were established, they had an opportunity to observe who the central firms are. Very often, central firms are the ones who had strong political and economic connections, making them particularly important partners. This sort of preferential attachment will produce a rapid increase in two-step reach.

We note that 2003 appears to be out of trend in terms of density. There are two possible explanations. One is that after a first flurry of network formation, firms learned that not all connections are equally valuable, and a sort of shakeout took place around 2003. So the network became less dense as firms shed non-useful connections and slowly was re-built. The second explanation is simply that reporting was not as routine in the early years. Initially, in order for privatization to happen firms, and thus their boards, had to be carefully registered. So data for 2000 and 2001 are relatively complete. One can easily imagine, though, that the process of reporting was not wellestablished early on, and that firms were not complete in their reports in early years after transition. Thus the data 2003 may simply be missing observations. We do several robustness checks, presented in appendix D (Tables 4 and 5) against this possibility.

Table 5-2: Summary Statistics of Network Variables by each year

\begin{tabular}{|c|c|c|c|c|c|c|}
\hline \multicolumn{7}{|c|}{ Panel A: Sample Average by year } \\
\hline Year & Degree & Betweeness & Constraint & 2step reach & $\begin{array}{c}\text { Clustering } \\
\text { Coefficient }\end{array}$ & Density \\
\hline 2000 & 1.82 & 0.82 & 0.89 & 1.92 & 0.24 & 0.004 \\
\hline 2001 & 2.85 & 1.62 & 0.9 & 3.6 & 0.22 & 0.010 \\
\hline 2003 & 2.05 & 2.05 & 0.93 & 3.7 & 0.36 & 0.008 \\
\hline 2005 & 3.2 & 2.73 & 0.89 & 5.25 & 0.24 & 0.012 \\
\hline All & 2.48 & 1.805 & 0.9025 & 3.6175 & 0.265 & 0.0085 \\
\hline
\end{tabular}

Firm attributes and network content: Figure 1 in Appendix $C$ shows that $8.1 \%$ of firms are operating in the agro-food production sector, while the chemical and wood production sectors only contribute $2.86 \%$ of large corporations. The largest number of firms in our data lies in the metallurgy sector, $28.1 \%$, followed by the service sector, $20 \%$. We also classify firms into four firm type categories, and figure 2 (Appendix C) reports that small and non-exporting firms are the largest group, but that this slightly fluctuates during our study period of 2000-2010. The second largest group is made up of small and exporting firms counting 20 firms in total for 2000, with the number increasing to around 50 in 2002 and 2005. We also see some interesting dynamics among large and exporting firms, which shows less than 10 firms in 2000 and increases in 2003 to almost 20 firms. Large and non-exporting firms have decreased since 2000,

\footnotetext{
${ }^{31}$ In our analysis we have to keep isolates, as otherwise we will have selection bias. An isolated firm is effectively in a closed network and thus has no access to structural holes. In this case constraint will take the value 0 , which is the same as density. On the other hand, isolates, as firms not connected to any other firm, are free from social pressure or regulation, hence their score for constraint or any variable for network closure can be the highest integer. However, to control the effect of isolates we used a dummy variable; this is a widely used practice for the studies where isolates cannot be removed from the analysis.
} 
though the number was never above 20 firms according to annual statistics. Since, 2000 the exporting opportunities for the economic agents have increased. The reason was the country's macroeconomic, political and geographical situation. During the war, followed by the economic blocked; opportunities for any economic activities were very low. After the war (1997), the country passed several political and economic reforms, which had positive effects - political stability brought more investments and FDI, opening roads with the external world reduced transportation costs. All these improvements encouraged firms to export.

Table 3 Appendix B shows that on average firm type homophily and region homophily are higher than industry homophily. It also shows that in 2001 on average connected firms showed higher firm type homophily (0.7); for region homophily the highest was in 2003 (0.53). Industry heterophily was between the range of $0.66-0.59$ for EI index, and in the case of Blau's measure, which reflects balanced heterophily, it was lowest (0.24) in 2000 and highest (0.34) in 2005.

This suggests that Armenian firms prefer to diversify their ties across industries, but in terms of firm type and location, they tend to connect with similar ones. Geographical proximity is perhaps not so surprising, given that $50 \%$ of economy is located in Yerevan. But proximity in terms of firm organization type is important for firms in Armenia to be able to successfully collaborate, even at the board level. This is consistent with Boschma (2005), who highlighted the importance of geographic proximity combined with organizational and cognitive proximities in facilitating interactive learning.

Firms' partners' assets and foreign ties (export volume): Panel B in Table 3 (Appendix B) shows annual statistics for the connected firms, the total resources held by a firm's neighbours. Yearly statistics show that the average neighborhood in 2000 represented 9188350000 AMD in assets and 80294000 AMD in export volume. For comparison we included panel C (Table 3 in appendix B), which gives the firms' average assets and exports, and in 2000 an average firm possessed 3062760000 AMD assets and the export volume was 23750000 AMD. We can see that on average firms are endowed with much fewer resources than its neighborhood, as we would expect. In contrast, neighborhood may provide access to much larger resources. Moreover, on average one partner contributes more than an average firm possesses - e.g. statistics for 2003 reveal that one partner contributed 395191000 AMD for export volume and 4632153000 AMD assets while on average firms possessed 3621040000 AMD assets and exported 351750000 AMD. Table 1 (see appendix C) reports that $73.6 \%$ of Armenian corporations are in non-manufacturing sector, and 53.8\% are located outside of capital city.

This shows that the board network of Armenia has features of the "friendship paradox" described by Feld in 1991, where he found that the average number of friends that a person in the network has is lower compared to the average number of friends that his/her friends had. ${ }^{32}$ This phenomenon is also translated to the average

${ }^{32}$ https://www.technologyreview.com/s/523566/how-the-friendship-paradox-makes-your-friends-better-thanyou-are/ 
wealth/happiness that friends of friends possess. This paradox arises because the degree distribution is a power law, indicating that only a small number of people have lots of friends. And this small group of people causes the paradox - significantly increases the average number of friends of friends. Similarly, this small group of people possessed higher level of wealth, which is reflected on the average wealth of one's friends. This carries over directly to partners' assets - firms with considerable assets (or exports) are attractive as partners so firms with more assets will tend to have more partners. Those high-asset/high-degree firms will raise the average of "partners' assets and export".

Firm financial performance and explanatory variables: Figure 1 shows the distribution of ROA and ROE for each industry category, and Figure 5-2 reports distribution of log exports among exporting firms for each industry for the period of 2000-2010. It shows that firms in all industries perform better in terms of ROE than ROA. Even though these two measures are related, but they measure different type of organizational efficiency. The highest median we observe is in categories 4 and 6 (chemical industry and metallurgy), and the lowest median for ROE is reported in the agro and food sectors. Figure 5-3, which reveals the distribution of ROA and ROE over our study period, shows that there is less fluctuation in ROE than in ROA. Correlation Table 2 (Appendix B) shows that constraint has a negative and strong correlation with ROA and two-step-reach, while for ROE among structural measures betweenness centrality has the highest correlation at 0.11 . From overall correlation we see that both cohesiveness and sparseness are positively correlated with performance measures though we find differences in their magnitudes.

Figure 5-1: ROA and ROE by Industry

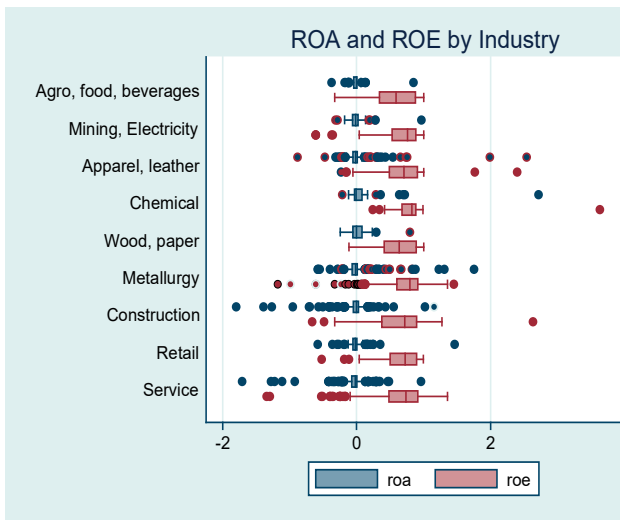

Figure 5-2: Export by Industry

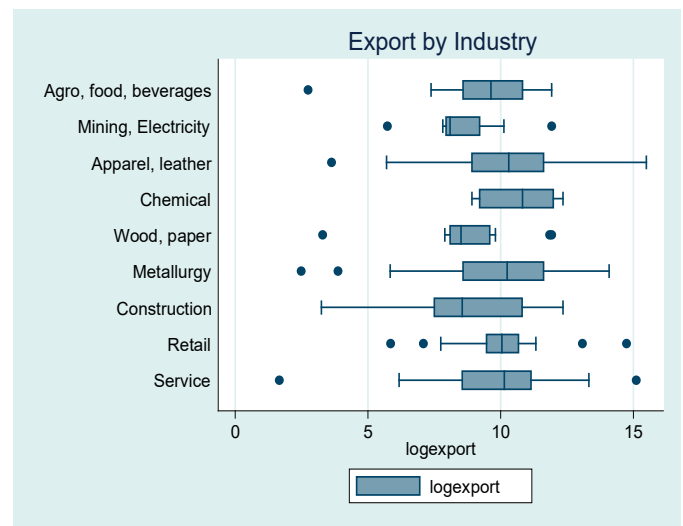


Figure 5-3: ROA and ROE

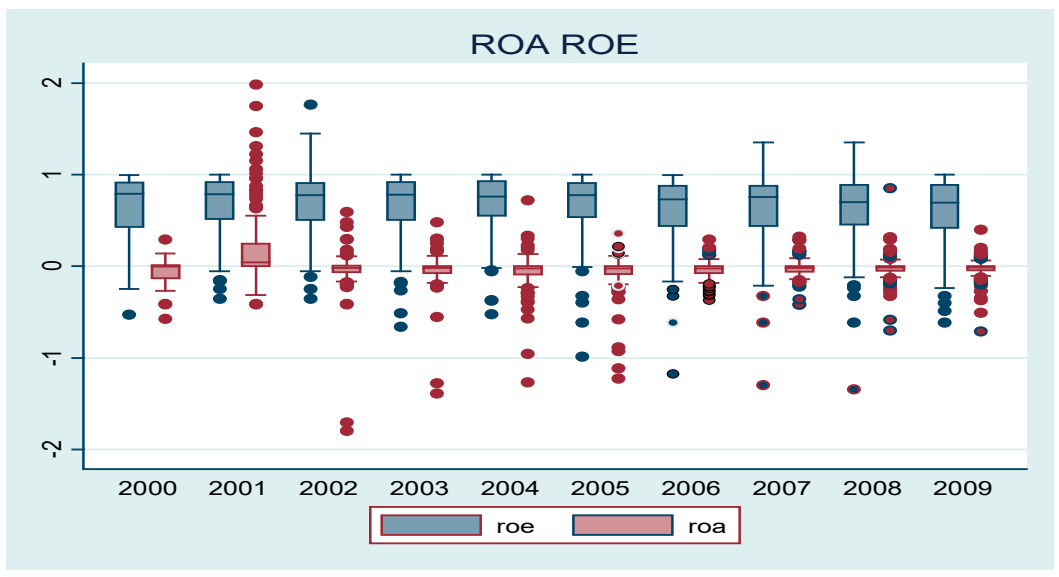

Figure 2 reveals that among exporters (more than 10\% of their sales), the highest median is for the chemical industry. The textile and metallurgy sectors are second in terms of high export volumes. Mining, energy and water sectors have the lowest export volumes; however, if we only considered mining firms, the results would be different.

\subsection{Conclusion}

This chapter presents details on measures and variables, which are constructed for estimation model as well as their descriptive statistics. Additionally, it also discusses the econometric models applied for the analysis of the firm performance. In the previous chapter we reviewed the empirical literature, and selected the most common measures of social capital such as betweenness centrality, constraint and efficient size for capturing structural holes, and density, clustering coefficient and two-step-reach for measuring network cohesion. In this chapter we showed how we measured those variables (equations), and their application to the data.

In this study the concepts of network homophily, resourcefulness and foreign ties were discussed with the availability of data on the firm partner's attributes. The summary statistics show that in terms of network resourcefulness and foreign ties partners may provide strong advantage to the firms. Summary statistics reveal that on average firms are poorer in terms of available assets than the average partner contributes to their network, which ultimately may suggest that partners may serve as additional sources for financial means, assets and other resources. Regarding the question of whether Armenian corporations share board members with similar firms or not, we examine this issue in three different dimensions. Interestingly, the results show that firms are more likely to pursue similarity towards location and firm type, but prefer to connect with firms in different industries. The data also reveals that firms show better performance in terms of ROE, while in terms of ROA firms are less profitable. It shows also that larger firms tend to export more. 


\section{Appendix B: Corporate Network}

Network Visualization ${ }^{33}$

Figure 1: Network 2000

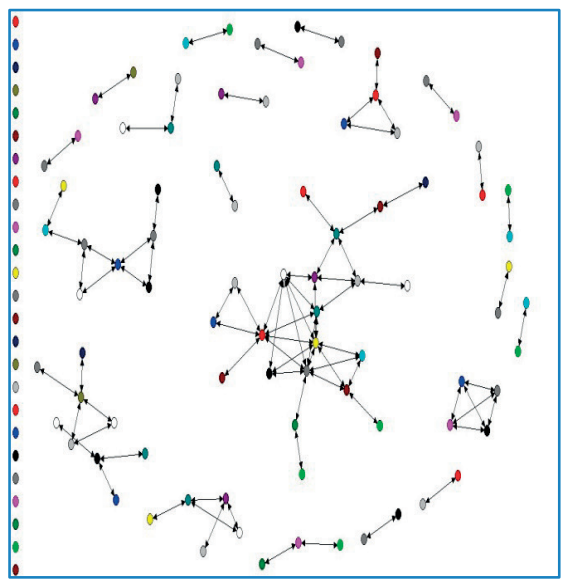

Figure 2: Network 2001

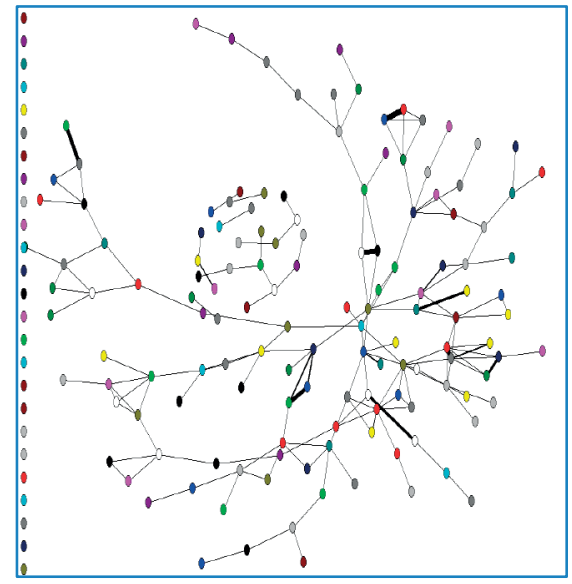

Figure 3: Network 2003

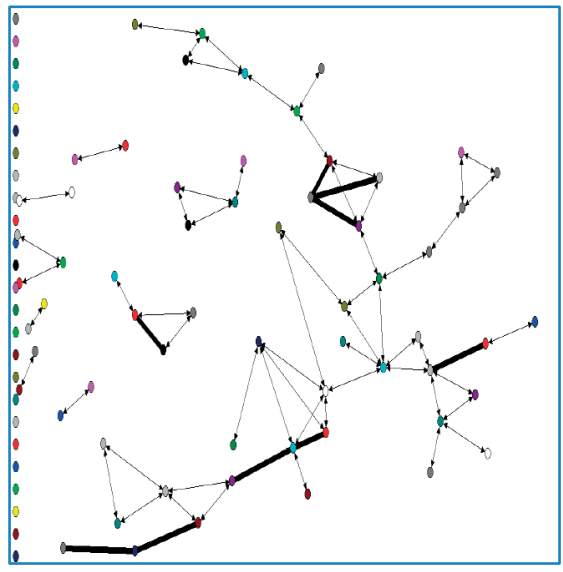

Figure 4: Network 2005

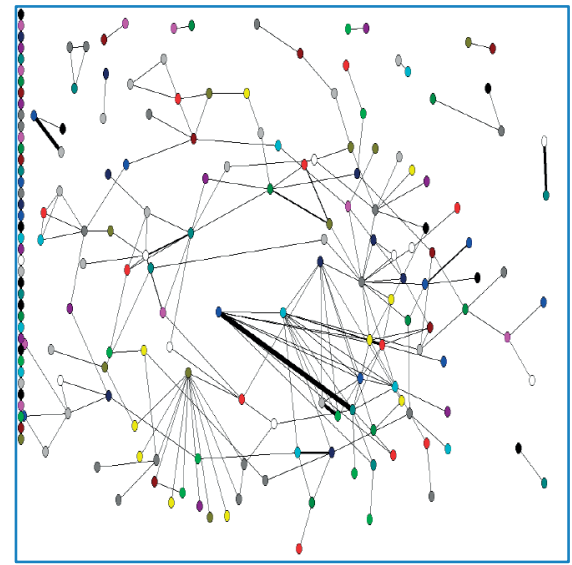

${ }^{33}$ For visualization we have used the weighted network data, where the thickness of links is proportional to the number of board member two firms share. 
Figure 5: Frequency distribution of Degree centrality

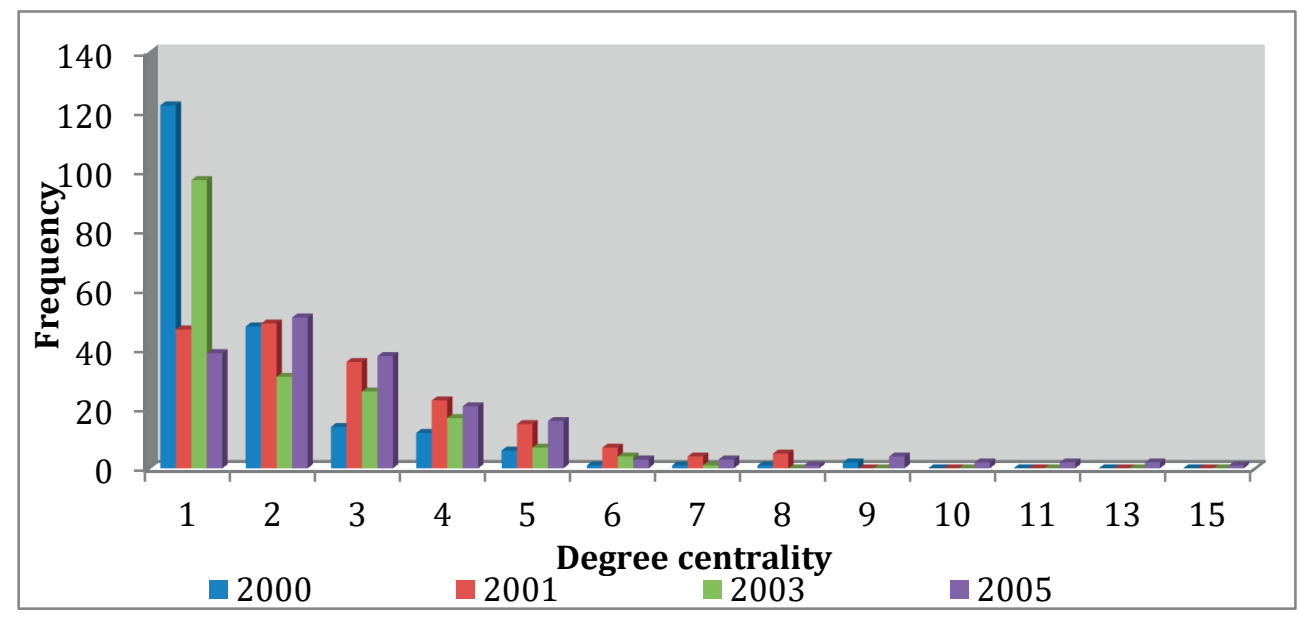

Table 1: Percentage of firms by industry category and degree centrality. ${ }^{34}$

\begin{tabular}{|l|cccc|cccc|cccc|}
\hline & \multicolumn{4}{|c|}{ Isolates } & \multicolumn{3}{c|}{ Degree centrality less than 5 } & \multicolumn{3}{c|}{ Degree centrality above 5 } \\
\cline { 2 - 12 } Year & 2000 & 2001 & 2003 & 2005 & 2000 & 2001 & 2003 & 2005 & 2000 & 2001 & 2003 & 2005 \\
\hline \hline $\begin{array}{l}\text { Agro, food, } \\
\text { beverages }\end{array}$ & 10.3 & 6.7 & 7.5 & 5.3 & 5.7 & 4.6 & 8.7 & 8.2 & 20 & 3.6 & 2 & 3.2 \\
$\begin{array}{l}\text { Mining, energy, } \\
\text { water }\end{array}$ & 2.6 & 8.9 & 6 & 0 & 5.7 & 1.5 & 2.9 & 2.7 & 10 & 0 & 11.1 & 3.2 \\
$\begin{array}{l}\text { Apparel, leather, } \\
\text { textiles }\end{array}$ & 15.5 & 20 & 11.9 & 18.4 & 8.6 & 15.4 & 13.6 & 17.8 & 20 & 17.9 & 11.1 & 12.9 \\
$\begin{array}{l}\text { Chemicals } \\
\text { Wood, paper, }\end{array}$ & 4.3 & 4.4 & 4.5 & 2.6 & 0 & 0 & 1.9 & 2.7 & 0 & 3.6 & 0 & 3.2 \\
$\begin{array}{l}\text { non-metal } \\
\text { materials }\end{array}$ & 5.2 & 4.4 & 7.5 & 2.6 & 2.9 & 4.6 & 1.9 & 4.1 & 0 & 3.6 & 11.1 & 3.2 \\
$\begin{array}{l}\text { Metallurgy, } \\
\text { machinery, }\end{array}$ & 27.6 & 15.6 & 19.4 & 26.3 & 14.3 & 27.7 & 27.2 & 27.4 & 0 & 42.9 & 22.2 & 35.5 \\
$\begin{array}{l}\text { Construction and } \\
\text { transport }\end{array}$ & 12.9 & 20 & 14.9 & 13.2 & 20 & 15.4 & 16.5 & 12.3 & 10 & 14.3 & 22.2 & 19.4 \\
$\begin{array}{l}\text { Retailing } \\
\text { Service }\end{array}$ & 2.6 & 4.4 & 4.5 & 10.5 & 5.7 & 7.7 & 6.8 & 2.7 & 20 & 7.1 & 22.2 & 3.2 \\
\end{tabular}

${ }^{34}$ Numbers are in percentage 
Table 2: Summary Statistics of Network Variables by each year Panel A contains correlations of the network measures of Degree centrality, Betweeness centrality, Constraint Two-step reach, Clustering Coefficient 35 and firm performance.

\begin{tabular}{c|ccccccc}
\hline & Panel A: Pearson Correlations & & & & & \\
\hline & ROA & ROE & Degree & Betweeness & Constraint & $\begin{array}{r}\text { 2step } \\
\text { reach }\end{array}$ & $\begin{array}{c}\text { Clustering } \\
\text { Coefficient }\end{array}$ \\
\hline \hline ROA & 1 & & & & & & \\
ROE & 0.08 & 1 & & & & & \\
Degree & 0.16 & 0.1 & 1 & & & & \\
Betweeness & 0.08 & 0.12 & $0.275^{*}$ & 1 & & & \\
Constraint & -0.21 & -0.04 & $-0.79^{*}$ & $-0.5^{*}$ & 1 & & \\
2step reach & 0.1 & 0.06 & $0.89^{*}$ & $0.12^{*}$ & $-0.66^{*}$ & 1 & \\
Clustering & & & & & & & \\
Coefficient & 0.08 & 0.55 & $0.4^{*}$ & 0.067 & $-0.289^{*}$ & $0.35^{*}$ & 1
\end{tabular}

Table 3: Descriptive statistics

Panel A, B and C report descriptive statistics of Neighborhood variables.

Panel A: Sample Average by year for Homophily / Heterophily Measures 36

\begin{tabular}{cccc|cc|ccc}
\hline \multicolumn{4}{c|}{ Industry } & \multicolumn{3}{c|}{ Region } & \multicolumn{3}{c}{ Firm type } \\
\hline Year & $\begin{array}{c}\text { industry } \\
\text { pct } \\
\text { homoph } \\
\text { ilous }\end{array}$ & $\begin{array}{c}\text { indus } \\
\text { try E- } \\
\text { I } \\
\text { index }\end{array}$ & $\begin{array}{c}\text { Heter } \\
\text { ophily }\end{array}$ & $\begin{array}{c}\text { region pct } \\
\text { homophil } \\
\text { ous }\end{array}$ & $\begin{array}{c}\text { region } \\
\text { E-I } \\
\text { index }\end{array}$ & $\begin{array}{c}\text { firm type } \\
\text { pct_homop } \\
\text { hilous }\end{array}$ & $\begin{array}{c}\text { firm } \\
\text { type } \\
\text { E-I } \\
\text { index }\end{array}$ & $\begin{array}{c}\text { heterop } \\
\text { hily }\end{array}$ \\
\hline \hline 2000 & 0.161 & 0.679 & 0.243 & 0.508 & -0.016 & 0.536 & -0.071 & 0.130 \\
2001 & 0.154 & 0.664 & 0.287 & 0.445 & 0.081 & 0.701 & -0.401 & 0.139 \\
2003 & 0.171 & 0.657 & 0.302 & 0.529 & -0.058 & 0.482 & 0.036 & 0.160 \\
2005 & 0.155 & 0.689 & 0.343 & 0.443 & 0.107 & 0.519 & -0.038 & 0.180 \\
& & & & & & & &
\end{tabular}

Panel B: Partners' export and partners' assets by year. ${ }^{37}$

\begin{tabular}{ccccc}
\hline Year & $\begin{array}{c}\text { Partners' } \\
\text { Export } \\
\text { (average) }\end{array}$ & $\begin{array}{c}\text { Partners' } \\
\text { export } \\
\text { (sum) }\end{array}$ & $\begin{array}{c}\text { Partners' } \\
\text { assets } \\
\text { (average) }\end{array}$ & $\begin{array}{c}\text { Partners } \\
\text { 'assets } \\
\text { (sum) }\end{array}$ \\
\cline { 2 - 5 } 2000 & 6179.7 & 8029.4 & 544714.5 & 918351 \\
2001 & 2085.0 & 7741.8 & 314822.3 & 768101.1 \\
2003 & 39519.1 & 178027.8 & 463215.3 & 1228435.0 \\
2005 & 24257.0 & 78179.9 & 536751.7 & 1195162.0 \\
\hline All & 18010 & 67995 & 464876 & 1027512 \\
\hline
\end{tabular}

Panel C: Average for Assets and Exports of individual firms. 38

\begin{tabular}{ccc}
\hline Year & Assets & Export \\
& & \\
\cline { 2 - 3 } 2000 & 306276 & 2375 \\
2001 & 317453 & 2412 \\
2003 & 362104 & 35175 \\
2005 & 503871 & 34131 \\
\hline All & 372426 & 18523 \\
\hline
\end{tabular}

\footnotetext{
$35 *$ shows 0.01 level of significance.

${ }^{36}$ We calculated average values among connected firms

${ }^{37}$ Numbers are in 10000 AMD

${ }^{38}$ Calculated for all firms
} 


\section{Appendix C: Description of the firms' financial data}

Table 1: Summary statistics for firm's financial data

Panel A: Sample statistics for Industry Dummy

Number of firms

Non-Manufacturing

Manufacturing

Total
145

52

211

\section{Panel B: Region}

Number of firms

Outside of capital

city

106

Capital city/

Yerevan

Total

100

53.8

Percentage

100

Table 2: Correlation

Panel A contains the correlation of firm's financial and size measures. We used log values for number of employees, total annual assets and export volume.

\begin{tabular}{|c|c|c|c|c|c|c|c|c|}
\hline & $\mathrm{ROE}$ & $\mathrm{ROA}$ & $\begin{array}{l}\text { Region } \\
\text { dummy }\end{array}$ & $\begin{array}{l}\text { Industry } \\
\text { dummy }\end{array}$ & $\begin{array}{c}\log (\mathrm{N} \\
\text { employees) }\end{array}$ & $\begin{array}{c}\log \\
\text { (assets) } \\
\end{array}$ & Log (sales) & $\begin{array}{c}\log \\
\text { (export) } \\
\end{array}$ \\
\hline ROE & $\overline{1}$ & & & & & & & \\
\hline $\mathrm{ROA}$ & 0.0511 & 1 & & & & & & \\
\hline Region dummy & 0.055 & -0.045 & 1 & & & & & \\
\hline Industry dummy & -0.0559 & 0.005 & 0.017 & 1 & & & & \\
\hline Log (employment) & -0.021 & -0.009 & $0.284^{*}$ & $-0.064 *$ & 1 & & & \\
\hline Log (assets) & -0.052 & 0.050 & $0.1675^{*}$ & 0.017 & $0.464 *$ & 1 & & \\
\hline $\log$ (sales) & -0.029 & 0.040 & $0.1444 *$ & -0.014 & $0.632 *$ & $0.51 *$ & 1 & \\
\hline Log (export) & 0.009 & -0.017 & $0.1533^{*}$ & -0.035 & $0.473 *$ & $0.241 *$ & $0.328^{*}$ & 1 \\
\hline
\end{tabular}




\section{Appendix C: Description of firm's financial data}

Figure 1: Frequency and percentage of firms for each industry

The figure below displays the distribution of firms in each industry sector. Industry is constant over time period of 2000-2010 for our sample firms. First measure is a number a firms operating in each of 9 industry sector, second measure is a percentage.

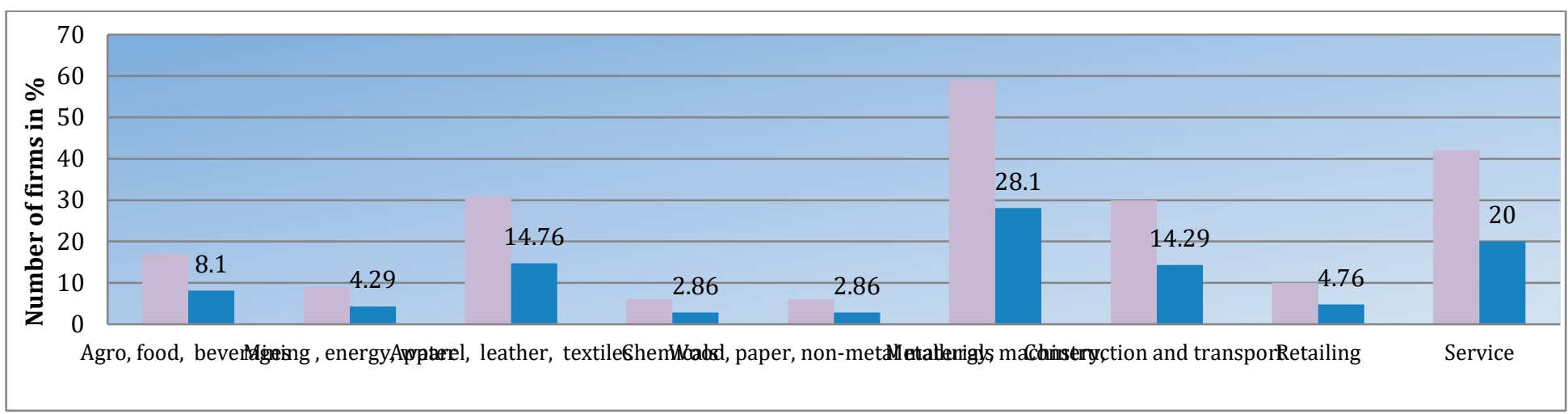


Figure 2: The firm type distribution

This figure shows the number and percentage of firms operating in 4 categories of firms for the period of 2000-2010. We classified firms based on their size and export volume. Firms are divided into small and large size, and exporting and non-exporting firms ${ }^{39}$.

Frequency statistics by firm type and year

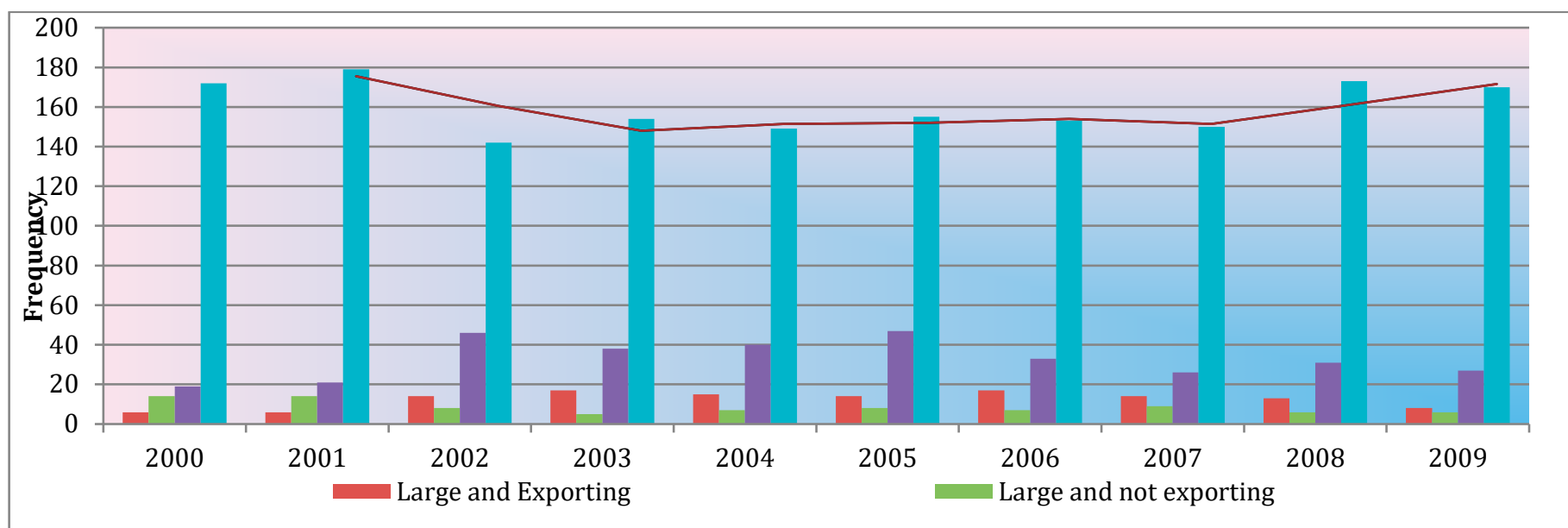

${ }^{39}$ Small firms are defined firms which employ less than 100 employees. Exporting firm are the firms, which export more than 10 percent of their total sales. 
Figure 3: Log (employment) and ROA

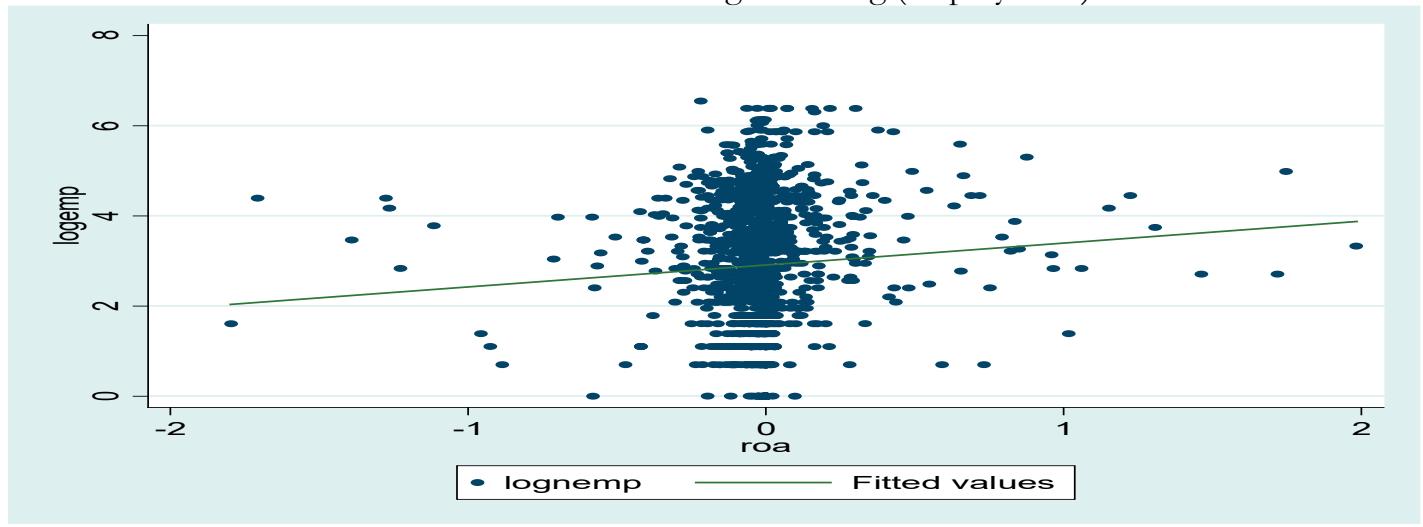

Figure 4: Log (employment) and ROE

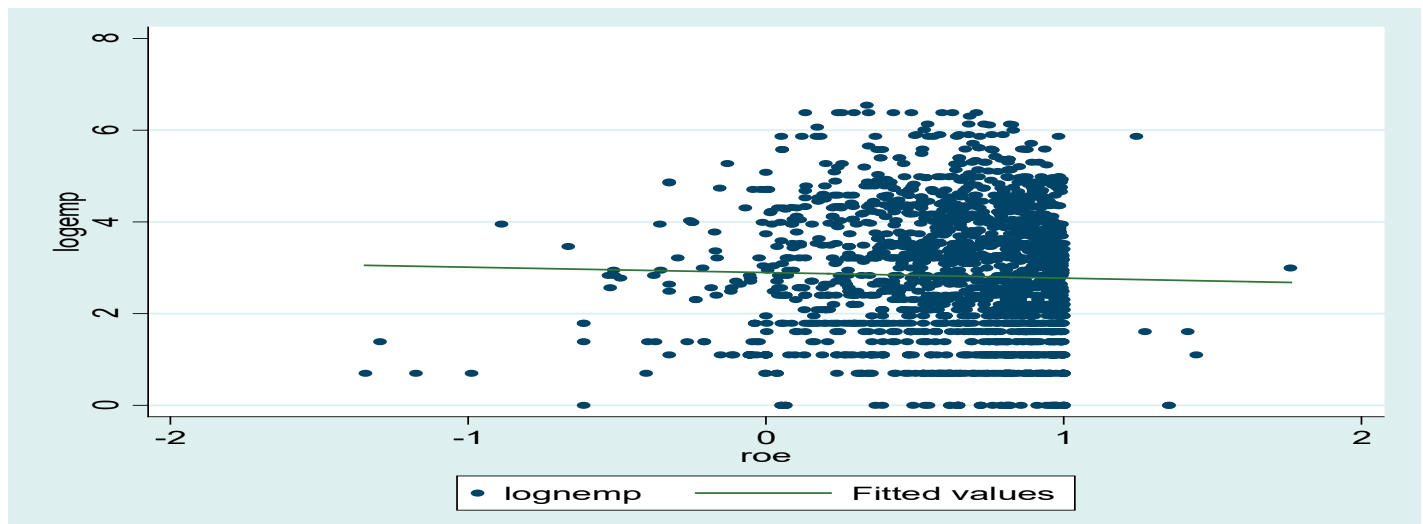


CHAPTER

\section{ECONOMETRIC EVIDIENCE: ESTIMATION MODELS AND RESULTS}




\subsection{Introduction}

In this chapter we discuss the results from the econometric analysis and draw conclusions by applying social capital theory in explaining firm financial performance in the context of a transition economy - Armenia. One of the most important aspects of this study is that we explore firms that were formed as a result of the largest reforms implemented in Armenia, which was privatization of large state owned companies, and following this privatization, the formation of new corporate firms. The establishment of corporations was a huge institutional change for a country with 70 years of planned economy experience. In 1999, for the first time, large firms in Armenia became publicly listed companies under the new corporate law, and 220 firms were selected into this category. Our data reflects the "destiny" of those firms for the period of 2000-2010.

Corporate networks have long traditions in developed countries; however, they are new to transition countries. Hence while the literature on corporate governance has discussed the role of boards and their networks on firm performance in the context of developed economies with well-established corporate cultures, this remains less explored for the transition country context.

The network of board members is a form of social network, and it can serve as conduit for inter-organizational support. Board members linking companies may serve as a channel for the exchange of information, provide access to different resources (Larcker, So, and Wang 2013), and hence bring competitive advantage to the firms. Following the literature in this domain, which shows consistently that a firm's position in the board network helps to explain its performance (Larcker, So, and Wang 2013; Dicko and Breton 2010; Non and Franses 2007), the current study extends empirical analysis in two main aspects: first, it explores the role of board networks in the transition context, and second, it applies wider characteristics of social capital such as network resourcefulness, foreign ties and homophily, as well as taking into account their complementary effects.

Our empirical analysis follows the analytical structure of Chapter 4, where we developed propositions according to the main dimensions of social capital: structural, network content and the complementarity of these two dimensions. In Chapter 4, we discussed the empirical approach and variables; in this chapter we discuss the empirical methodology, specifically the panel data models, which are applied for the estimation of a firm's financial performance, and present the regression results. The first section provides an explanation of the estimation models, and describes additional conditions for testing the hypotheses. Following this framework we first estimate the impact of the structural dimension of the social capital on firm performance, then the effects of network content, and in the third part we test for interaction effects.

To do the analysis, variables capturing the firms' network position, their partners' network position and attributes, and the firms' financial performance were operationalized. The explanatory variables are constructed using UCINET software (Borgatti, Everett, and Freeman 2002). Multiple regression analyses were used to identify the explanatory power of network variables for the selected firm's 
performance. This stepwise analysis is aimed at identifying the expected improvement in explanatory power with each network measure with different lagged values. Fixed Effects (FE) and Random Effects (RE) models were used for the estimation.

The remainder of this chapter is organized as follows: section 2 discusses the results from econometric models testing the hypotheses related to the structural dimension of the social capital and impact of network quality on firm performance, section 3 shows the results on testing moderating effects of network structure and network content; section 4 discusses the robustness check, and section 5 concludes the chapter.

\subsection{Estimation models}

\subsubsection{Estimation of Firm Performance}

The literature has argued that social capital, built through board networks among other ways, is an asset for a firm, and we have argued that this is especially so in a transition economy such as Armenia. An important challenge for this sort of estimation is the endogeneity of the link formation that lies behind a firm's social capital. To address this issue we use the framework of financial performance developed by Roberts and Dowling (2002), which used a one period lag of a firm's reputation to control for this endogeneity. Though their original framework was designed for a firm's reputation we believe that this conceptual approach can model the relationship of the social capital and firm performance in time. In our context social capital arises as members of the board of one firm join the board of another firm. This is an active decision on the part of board members, both in terms of invitations to join, and accepting such invitations. Past firm performance may affect a board member's decision to accept such an invitation. Firms with better past performance will be more attractive from a board member's perspective. On the other hand, firms with better social capital also possess a huge advantage for the firm, and hence they perform better. In this context the causation is not clear, and one way to control for it is to use lagged values for social capital variables (Cameron and Trivedi 2005).

\subsubsection{Panel Data Models}

Prior research has documented the wide-ranging effects of network ties on the behavior of both individuals and organizations (Knoke and Yang 2007; Powell, Koput, and Smith-Doerr 1996; Moran 2005; Gulati, Nohria, and Zaheer 2000). To focus on boards of directors: Dicko and Breton (2010) empirically examined the effect of board network on a firm's ROA, while Zaheer and Bell (2005) used the firm's network structure to explain firm performance measured by market share. These studies used a common empirical strategy, namely selected methods for a short panel, meaning that the data on many individual units and short time periods (10 years) (Cameron et al., 2010), which capture both variation over individual units and time. Compared to cross-sectional data methods, the standard errors of panel-data estimators need to be adjusted, as they are not independent of previous periods. We have applied two different models - fixed effect (FE) and random effect (RE) models. FE explores the relationship between independent and dependent variables within a firm, considering 
that each firm has its own individual characteristics that influence the dependent variable. FE models assumed that there are time-invariant characteristics that are unique to the firm and should not be correlated with other firm level characteristics. In contrast, the RE model assumes that the variation across units is random but still uncorrelated with the independent variables. The general estimation model to measure firm performance is

$y_{i t}=\beta_{0}+\sum_{g=1}^{G} \beta_{g} X_{i t}+\sum_{w=1}^{W} \beta_{w} Z_{i t-b}+u_{i t}$

where $y_{i t}$ is firm performance and $X$ is a group of variables indicating firm characteristics, and finally $\boldsymbol{Z}_{i t \boldsymbol{b}}$ are network characteristics. We have different financial performance measures, and we estimate the impact of social capital on firm performance separately for each performance variable.

We tested the consistency of the FE and RE estimators by applying the Hausman test.

\subsubsection{Testing complementarity between network structure and content}

In the third part of our analysis we test the complementarity of two social capital dimensions -network structure and network content, where the main variables are network closure and structural holes from the structural perspectives, and firm tie homophily, partner's assets and exports from the content side. Literature in the field of industrial organization has shown than there is a complementarity between different organizational strategies of a firm (Arora 1996; Arora and Gambardella 1990; Belderbos, Carree, and Lokshin 2006; Cimoli, Hofman, and Mulder 2010). To test complementarity, we examine the cross derivative of two variables, following the approach suggested by Belderbos et al. (2006). We include interaction terms in our regression model. In standard management literature, the interaction term between two dimensions will indicate that resources moderate network effects, yet here we will look for the complementarity using standard approaches to test joint significance of two variables (Belderbos et al. 2006).

Let us consider that variables $\mathrm{x}$ and $\mathrm{z}$ are complementary for the firm's performance and that the model is the reduced form of the real model we use in our empirical estimation.

$\pi_{i}=\beta_{0}+\beta_{1} x_{i}+\beta_{2} z_{i}+u_{i}$

where $\pi_{i}$ is a firm performance, $\beta_{1}$ and $\beta_{2}$ are the marginal effects of $\mathrm{x}$ and $\mathrm{z}$ on the firm performance such that

$\frac{\partial \pi_{i}}{\partial x_{i}}=\frac{\partial E\left(\pi_{i} / x_{i,} z_{i,}\right)}{x_{i}}=\beta_{1}$ 


$$
\frac{\partial \pi_{i}}{\partial z_{i}}=\frac{\partial E\left(\pi_{i} / x_{i,} z_{i,}\right)}{z_{i}}=\beta_{2}
$$

When we include interaction terms of two variables in the regression model,

$$
\pi_{i}=\beta_{0}+\beta_{1} x_{i}+\beta_{2} z_{i}+\beta_{3} x_{i} z_{i}+u_{i}
$$

then the marginal effect of one variable on firm performance is a linear function of the other explanatory variable, such that

$$
\begin{aligned}
& \frac{\partial \pi_{i}}{\partial x_{i}}=\frac{\partial E\left(\pi_{i} / x_{i,} z_{i,}\right)}{x_{i}}=\beta_{1}+\beta_{3} z_{i} \\
& \frac{\partial \pi_{i}}{\partial z_{i}}=\frac{\partial E\left(\pi_{i} / x_{i,} z_{i,}\right)}{z_{i}}=\beta_{2}+\beta_{3} x_{i}
\end{aligned}
$$

When $\beta_{3}>0$ this implies that marginal effects of each variable are positive, given that $x$ and $z$ both are positive numbers, and the presence of two dimensions simultaneously leads to higher performance rates rather than when two strategies are used separately.

\subsection{Effects of Network Structure and Content on Firm Performance}

We follow our analytical approach and first present hypotheses on structural aspects of the social capital, then network content. Table 6-1 gives the regression results for both dimensions of social capital and their interaction terms. Following our theoretical approach we used step-by-step approach, adding each social capital variable at a time and then adding interactions terms.

Hypothesis tests are conducted for each of the two firm performance measures, ROA and ROE. Four control variables for the firm's region, industry, previous year sales and previous year size were included; note that we use a dummy variable for region and industry and the logarithm of number of employees and sales for size. In addition to the main results, we also conducted tests using alternative measures for network closure, structural holes and network homophily/hetrophily, which we discuss as a part of our robustness checks.

Our data provide the opportunity to test present and past effects of social capital on firm performance, and we extended our analysis by regressing different lagged values of social capital measures - i.e., we used models with one, two or three years lagged social capital measures. For our analysis from present to 4 years, lagged values of key variables were also used. The results show that network variables were significant for all years lagged including 4-year lags. However, the limitation of the data did not allow us to include different lags simultaneously. Therefore, we estimate the effects of each year lagged values separately. We used random and fixed effect generalized least square regressions, and conducted a Hausman test to select between these two models. Hausman test results are shown for each model, indicating that random effects models 
are preferred. Another reason to report random effects was to see the marginal effect of time invariant variables. All the models with different lagged values and parameters are tested, and we reported the results for 3 years lags. Table 6-1 shows the results of selected models for estimation of network structure and network content variables, and the models with all interaction terms. We first obtained estimates for network structure and network content. Then we used step-by-step estimation of interactive variables. Details of the step-by-step inclusion of the network variables are reported in the Appendix (see Tables 2 and 3). 
Table 6-1: Results: Network Structure and Network Content: ${ }^{40}$

\begin{tabular}{|c|c|c|c|c|c|c|}
\hline & $\begin{array}{l}\text { ROA } \\
\text { Model } 1\end{array}$ & $\begin{array}{c}\text { ROA } \\
\text { Model } 2\end{array}$ & $\begin{array}{c}\text { ROA } \\
\text { Model } 3\end{array}$ & $\begin{array}{c}\text { ROE } \\
\text { Model } 4\end{array}$ & $\begin{array}{c}\text { ROE } \\
\text { Model } 5\end{array}$ & $\begin{array}{c}\text { ROE } \\
\text { Model } 6\end{array}$ \\
\hline Region Dummy & $\begin{array}{l}-\mathbf{- 0 . 1 1 * *} \\
(0.054)\end{array}$ & $\begin{array}{l}-\mathbf{- 0 . 1 1 1 *} \\
(0.062)\end{array}$ & $\begin{array}{c}\mathbf{0 . 0 5} \\
(0.073)\end{array}$ & $\begin{array}{l}\mathbf{0 . 0 1 2} \\
(0.026)\end{array}$ & $\begin{array}{l}\mathbf{0 . 1 3 *} \\
(0.073)\end{array}$ & $\begin{array}{l}\mathbf{0 . 0 3 2} \\
(0.041)\end{array}$ \\
\hline Industry Dummy & $\begin{array}{l}-0.02 \\
(0.03)\end{array}$ & $\begin{array}{l}\mathbf{0 . 0 0 7} \\
(0.07)\end{array}$ & $\begin{array}{l}\mathbf{0 . 1 7 * *} \\
(0.081)\end{array}$ & $\begin{array}{c}-0.11 * * * \\
(0.03)\end{array}$ & $\begin{array}{c}-\mathbf{0 . 0 9 * * *} \\
(0.03\end{array}$ & $\begin{array}{c}-\mathbf{0 . 0 8 1 *} \\
(0.045\end{array}$ \\
\hline Log Empl. & $\begin{array}{c}\mathbf{0 . 0 0 2} \\
(0.024)\end{array}$ & $\begin{array}{c}\mathbf{0 . 0 1 8} \\
(0.029)\end{array}$ & $\begin{array}{l}\mathbf{0 . 0 7 * *} \\
(0.028)\end{array}$ & $\begin{array}{c}\mathbf{0 . 0 3} * * * \\
(0.012)\end{array}$ & $\begin{array}{c}\mathbf{0 . 0 3} * * * \\
(0.012\end{array}$ & $\begin{array}{c}\mathbf{- 0 . 0 2 9 *} \\
0.016\end{array}$ \\
\hline $\log$ Sales & $\begin{array}{l}-\mathbf{0 . 0 0 2} \\
(0.008)\end{array}$ & $\begin{array}{l}-0.006 \\
(0.01)\end{array}$ & $\begin{array}{l}-\mathbf{0 . 0 1 4 *} \\
(0.008)\end{array}$ & $\begin{array}{c}-\mathbf{0 . 0 8 * *} \\
(0.04)\end{array}$ & $\begin{array}{c}-\mathbf{0 . 0 8 * *} \\
0.04\end{array}$ & $\begin{array}{c}-\mathbf{0 . 0 1 * *} \\
0.004\end{array}$ \\
\hline Network variables & & & & & & \\
\hline Degree & $\begin{array}{c}\mathbf{0 . 0 8 3} * * \\
(0.037)\end{array}$ & $\begin{array}{c}\mathbf{0 . 1 9 3} * * \\
(0.087)\end{array}$ & $\begin{array}{l}\mathbf{0 . 1 9 * *} \\
(0.087)\end{array}$ & $\begin{array}{c}\mathbf{0 . 0 5 2} * * \\
(0.026)\end{array}$ & $\begin{array}{c}-\mathbf{- 0 . 0 7 6 *} \\
(0.04)\end{array}$ & $\begin{array}{c}-\mathbf{- 0 . 0 7 6 *} \\
(0.04)\end{array}$ \\
\hline Degree sq. & $\begin{array}{c}-\mathbf{0 . 0 0 7 * *} \\
(0.003)\end{array}$ & $\begin{array}{l}-\mathbf{0 . 0 1 *} \\
(0.006)\end{array}$ & $\begin{array}{l}-\mathbf{0 . 0 1 *} \\
(0.006)\end{array}$ & $\begin{array}{c}-\mathbf{0 . 0 1 0 * *} \\
(0.004)\end{array}$ & $\begin{array}{l}0.004 \\
(0.003)\end{array}$ & $\begin{array}{l}\mathbf{0 . 0 0 4} \\
(0.003)\end{array}$ \\
\hline Clustering coef. & $\begin{array}{r}-\mathbf{0 . 1 0 8} \\
(0.09)\end{array}$ & $\begin{array}{l}\text { 0.111* } \\
(0.057)\end{array}$ & $\begin{array}{l}\mathbf{0 . 1 0 3} \\
(0.286)\end{array}$ & $\begin{array}{l}-\mathbf{0 . 0 1 3} \\
(0.047)\end{array}$ & $\begin{array}{l}-\mathbf{0 . 0 3 9} \\
(0.049)\end{array}$ & $\begin{array}{l}\mathbf{0 . 0 7 *} \\
(0.052)\end{array}$ \\
\hline Between.centr. & $\begin{array}{c}-\mathbf{0 . 0 1 2} * \\
(0.005)\end{array}$ & $\begin{array}{l}\mathbf{- 0 . 0 9} \\
(0.05)\end{array}$ & $\begin{array}{l}-\mathbf{- 0 . 0 0 7} \\
(0.098)\end{array}$ & $\begin{array}{l}-0.04 \\
(0.07)\end{array}$ & $\begin{array}{l}-0.03 \\
(0.07)\end{array}$ & $\begin{array}{l}0.12 * \\
(0.073)\end{array}$ \\
\hline IND heteroph. & & $\begin{array}{l}\mathbf{0 . 4 6 * *} \\
(0.191)\end{array}$ & $\begin{array}{l}\mathbf{0 . 0 3 7} \\
(0.049)\end{array}$ & & $\begin{array}{c}\mathbf{0 . 2 5 * * *} \\
(0.091)\end{array}$ & $\begin{array}{c}\mathbf{0 . 2 2 8 * *} \\
(0.093)\end{array}$ \\
\hline Ftype heter. & & $\begin{array}{c}\mathbf{- 0 . 0 2} \\
(0.202)\end{array}$ & $\begin{array}{c}-\mathbf{0 . 3 9 8 * *} \\
(0.159)\end{array}$ & & $\begin{array}{c}-\mathbf{0 . 1 3 7 *} \\
(0.081)\end{array}$ & $\begin{array}{c}-\mathbf{0 . 2 4 3 * *} \\
(0.117)\end{array}$ \\
\hline Region Homoph. & & $\begin{array}{l}-\mathbf{- 0 . 1} \\
(0.9)\end{array}$ & $\begin{array}{c}-\mathbf{0 . 1 5 1 * *} \\
(0.06)\end{array}$ & & $\begin{array}{l}\mathbf{0 . 0 3 5 *} \\
(0.012)\end{array}$ & $\begin{array}{c}\mathbf{0 . 0 8 7 * *} \\
(0.041)\end{array}$ \\
\hline Partners' assets & & $\begin{array}{c}-\mathbf{0 . 0 0 2} \\
(0.01)\end{array}$ & $\begin{array}{c}\mathbf{0 . 0 1 3} * \boldsymbol{*} \\
(0.007)\end{array}$ & & $\begin{array}{l}\mathbf{0 . 0 1 5 *} \\
(0.008)\end{array}$ & $\begin{array}{l}\mathbf{0 . 0 1 3 *} \\
(0.065)\end{array}$ \\
\hline Partners export & & $\begin{array}{c}-\mathbf{- 0 . 0 2 0 *} \\
(0.012)\end{array}$ & $\begin{array}{c}\mathbf{0 . 0 2 7} * * * \\
(0.007)\end{array}$ & & $\begin{array}{l}\mathbf{0 . 0 0 7} \\
(0.005)\end{array}$ & $\begin{array}{c}\mathbf{0 . 0 1 1} \\
(0.015)\end{array}$ \\
\hline Interactions & & & & & & \\
\hline $\begin{array}{l}\text { Part.Exports } x \\
\text { clust.coef }\end{array}$ & & & $\begin{array}{l}\mathbf{0 . 0 9 *} \\
(0.04)\end{array}$ & & & $\begin{array}{l}\mathbf{- 0 . 2 5 7} \\
(4.046)\end{array}$ \\
\hline IND.hetero $\mathrm{x}$ between & & & $\begin{array}{l}-\mathbf{- 0 . 1 3 *} \\
(0.054)\end{array}$ & & & $\begin{array}{c}-\mathbf{0 . 1 1} * * * \\
(0.02)\end{array}$ \\
\hline FtypeHetero.x between & & & $\begin{array}{c}\mathbf{0 . 1 1} * * * \\
(0.04)\end{array}$ & & & $\begin{array}{c}\mathbf{0 . 0 4 *} \\
(0.017)\end{array}$ \\
\hline Reghomop.x Clust coef & & & $\begin{array}{c}\mathbf{0 . 3 5 9} * * \\
(0.148)\end{array}$ & & & $\begin{array}{l}-\mathbf{0 . 1 1 4} \\
(0.095)\end{array}$ \\
\hline Part. assets x Clust.coef & & & $\begin{array}{l}-\mathbf{0 . 0 2 4} \\
(0.022)\end{array}$ & & & $\begin{array}{l}\mathbf{0 . 1} * \boldsymbol{*} \\
(0.03)\end{array}$ \\
\hline Cons & & $\begin{array}{l}\mathbf{- 0 . 0 9 5} \\
(0.124) \\
\end{array}$ & $\begin{array}{c}\mathbf{0 . 1 3} \\
(0.08) \\
\end{array}$ & & $\begin{array}{c}\mathbf{0 . 7 2 * * *} \\
(0.054) \\
\end{array}$ & $\begin{array}{c}\mathbf{0 . 7 7 2 * * *} \\
(0.063) \\
\end{array}$ \\
\hline Rho & & 0.365 & 0.391 & & 0.661 & 0.423 \\
\hline $\mathrm{N}$ & & 372 & 0.19 & & 544 & 0.1 \\
\hline chi2 & & 18.342 & 30 & & 35.695 & 29.7 \\
\hline Hausman (Prob $>$ Chi_2) & & 0.28 & 0.27 & & 0.13 & 0.15 \\
\hline
\end{tabular}

${ }^{40}$ Note. In this table we use $* * *$ if $\mathrm{P}<0.01, * * \mathrm{P}<0.05, * \mathrm{P}<0.1$, and standard errors in parentheses. 
Model 1-2 and 4-5 in Table 6-1 gives the results of the regression analysis for testing network structure and network content variables. Models include the following variables of interest: degree centrality and its quadratic form, betweenness centrality and clustering coefficient, measures of location, industry and firm type homophily/heterophily, partners' assets and partners' export (foreign ties). Models 3 and 6 reports the results with interaction terms.

Table 6-2: Summary of Marginal effect of Network structural variables when network content variables are at their mean values: ${ }^{41}$ Standard errors in parentheses

\begin{tabular}{|l|l|l|}
\hline Average Marginal effects & ROA & ROE \\
\hline \hline Clustering coefficient & $0.24^{* *}$ & $0.82^{*}$ \\
& $(0.101)$ & $(0.40)$ \\
\hline Betweeness centrality & 0.005 & 0.01 \\
& $(0.012)$ & $(0.012)$ \\
\hline IND heterophily & $0.24^{* *}$ & $0.033^{* *}$ \\
& $(0.10)$ & $(0.014)$ \\
\hline FT heterophily & $-0.35^{* *}$ & $-0.41^{* *}$ \\
& $(.12)$ & $(.172)$ \\
\hline Reg.Homophily & $.12^{*}$ & $0.05^{* *}$ \\
& $(0.078)$ & $(.018)$ \\
\hline Partner assets & $0.011^{*}$ & $0.028^{* *}$ \\
& $(0.006)$ & $(0.014)$ \\
\hline Partner export & $.144^{* *}$ & .011 \\
& $(.066)$ & $(.008)$ \\
\hline
\end{tabular}

We used the calculation of marginal effects for all key network variables. This provide deeper insights on how a key network variable affect firm financial performance, in particular, when its direct effect and interaction terms have opposite signs. In this case, it is hard to tell what the overall effect of the key variable is. But one can only see that if one calculates the marginal effect for every firm (averaging at the end).

\section{Control variables:}

Control variables appear to be significant for Models 3 and 6, showing that they have significant impact on both ROA and ROE. Regional dummy was significant in Model 2 and 5, but when doesn't show significance for Models 3 and 6. Industry dummy and Log employment show significant effect on both ROA and REO, but had opposite signs. This indicates that firms in manufacturing sector have higher ROA than in the other sectors, while in terms of ROE firms perform better if they are not in manufacturing industry. One simple explanation is that of two otherwise equivalent firms, the nonmanufacturing firm has a lower debt/equity ratio. This could be explained by the fact that borrowing opportunities are fewer, and costs higher, for non-manufacturing firm. Log employment has positive effect on returns except in the Model 6; prior year log sales have a negative effect on returns. Supartika and Margaretha (2015) found that sales

\footnotetext{
${ }^{41}$ We used results from 6-1 Table (models with interaction terms) and calculated the effects of key variables given the coefficient of the first variable + coefficient of the interaction term
} 
growth negatively affects a firm's profitability measured by both ROA and ROE, explaining that when sales volume increases, the cost for storage, advertisement and delivery will also increase.

Overall we see that control variables are significant predictors for both ROE and ROA, except for the Region dummy. Additionally, some variables have opposite effects on ROA and ROE. Finding different results for ROA and ROE is consistent with other studies that examine them both: for example Hart and Ahuja (1996) show that an industry dummy was not significant for ROA, but was significant for ROE; Li et al. (2008) found that among Chinese firms firm size is significant and negative for ROA and ROE, but financial leverage was significant and negative for ROA, and significant and positive for ROE, while firm age was a not significant predictor for neither of them.

\section{Network Structure:}

First we tested the Hypothesis 1, which indicates that Degree centrality has a positive and non-linear effect on firm performance. Our results show that having more partners has a positive effect on returns in terms of ROA, but the marginal effect is decreasing: coefficients on degree and degree squared are positive and negative respectively. The coefficient estimates are statistically significant in almost all these regressions, providing support for Hypothesis 1, suggesting that better-connected firms have lower ROA. This finding is consistent with previous empirical literature. However, the models with ROE showed the opposite sign, and didn't support the hypothesis.

Related to Hypothesis $2 \mathrm{a}$ and $\mathrm{b}$, we did not find strong support for either of these opposing hypotheses: coefficients on clustering are positive, and on betweenness are negative in Models 2 and 5. Yet, when we add interaction terms clustering coefficient became non-significant for ROA model, but significant and positive for ROE (Models 3 and 6 in Table 6-1). At the same time, betweenness centrality also became positive and significant for ROE. These results were not what we have expected, and don't support our hypotheses for ROA, but shows that both dense and sparse networks have positive effects on ROE.

We expected to find stronger effect of clustering coefficient, arguing that dense networks may provide a substitute for formal institutions in Armenia. In terms of significance level of clustering coefficient and betweenness centrality, the Model 6 reports positive main effects, suggesting that brokerage position for the firm is as important as dense networks.

\section{Network Content:}

Region homophily shows significant and positive effect on ROE in the Models 5 and 6 in Table 6-1. We used two alternative measures, which showed the same results (homophily PC measure is reported, and the alternative measure is homophily EI index (see in Table 2 in Appendix)). Ties with firms in the same region improve a firm's ROE, but decrease ROA (Models 3 and 6 in Table 6-1). One explanation could be that in addition to board connections, geographic connections improve borrowing opportunities. This would imply that firms with geographically local inter-board 
connections will borrow more than those with distant connections. Holding equity constant, the former group will have higher assets, and so, presumably, higher profits. Roughly speaking, this would imply an increase in return on equity without changing return on assets.

Moreover, we argued that region homophily will have different effects for firms located in Yerevan compared to firms in other regions. To address this we introduced an interaction term between region dummy and region homophily, but it was not significant for either ROA or ROE (we did not report).

The regression results support Hypothesis 3 a partially: our findings confirm that region bomophily is positively associated with firm performance (only ROE). However, our findings do not support the second part of Hypothesis 3a, which argues that the effect of region homophily will be stronger for a firm located in Yerevan. Firm type heterophily appears to have a negative and significant effect on ROE (Model 6 in Table 6-1) and on ROA (Model 3 in Table 6-1). In addition, four firm type dummies were created and incorporated in the estimation models to test whether firm's connections with different type of firms will negatively affect firm performance given its own type. But our results did not show any significant differences among these four groups (we didn't report those models). However, the results support hypothesis $3 \mathrm{~b}$, which states that firm type homophily has a positive impact on firm performance (we selected the model with firm type heterophily).

Industry heterophily, which takes into consideration how balanced ties are with different industries in the firm's network, shows significant and positive effect on both ROE and ROA in all models in Table 6-1, except Model 3 where it has insignificant effect on ROA. Our results provide strong evidence that industry heterophily significantly affects firm performance (for ROE), but it contradicts Hypothesis 3c, which states that ties with firms in the same industry enhances firm's performance.

Hypothesis 4 indicates that resource-rich networks affect firm financial performance, which we tested through including the total value of firms' partners' assets in the model. The results show that partners' assets has positive and significant effect on both ROA and ROE, which strongly support Hypothesis 4.

Hypothesis 5 states that partner's exports, which measures foreign ties of a firm's alters, will affect positively the firm financial performance. The results show that it has significant and positive effect on ROA, and positive but not significant effects on ROE. These results show that, in fact, resource-rich networks help firms to have higher profitability (see Models 3 and 6). Additionally, while foreign ties are associated with new knowledge and best practice, they appear to increase a firm's profitability, and therefore we accept Hypothesis 5.

\subsection{Interaction effects between network structure and content}

In this section we focus on the interaction effects of two main dimensions of social capital - structural social capital and network content. Here we will test the hypotheses developed in chapter 4. 
In the previous section we distinguished two mechanisms - network structure and content - and estimated their respective contributions. In this section, we further our exploration of how these mechanisms work together, and whether we can observe a complementarity between them. Through this exercise we aim to enlarge our understanding of how partners' attributes influence firm performance. Hence, we study two interlinked mechanisms, to understand how much network structure and network content matter.

To test the empirical hypotheses with our data we constructed the following interaction terms:

1. Network closure $\mathrm{x}$ network resourcefulness (partners' assets) (Hypothesis 6)

2. Network closure $\mathrm{x}$ network homophily (region homophily)(Hypothesis 7a)

3. Structural hole $\mathrm{x}$ network heterophily (industry beterophily / ftype beterophily) (Hypothesis 7b)

4. Structural hole $\mathrm{x}$ foreign ties (partners' export) (Hypothesis 8a)

5. Network closure $\mathrm{x}$ foreign ties (partners' export) (Hypothesis 8b)

Our primary interest in this section is the discussion of interaction effects of social capital variables for both ROA and ROE, presented in Model 3 and Model 6 in Table 6-1, while details are provided in Table 3 in the Appendix. We reported only selected results: e.g., interactions with ftype homophily and clusters were not significant, thus we reported only the models with ftype heterophily and structural boles; similarly, the interaction term with partners' exports and network sparseness were not significant in any model, and we reported only partners' export and network closure.

Interaction term with partners' assets and network closure is positive and significant only for ROE in Model 6 which supports Hypothesis 6, while it wasn't significant for ROA. Partners' assets have positive impact and its marginal effect is to increase a firm's $\mathrm{ROE}$ if the firm is also embedded in cohesive networks. The average marginal effect of the partners' assets is also positive and significant for both ROA and ROE (see Table 6-2).

Hypothesis 7 a concerns the importance of network homophily and network closure, suggesting that when firm has both a closed network position and region homophily, there is an additional value, which we tested in Models 3 and 6, using interaction term of clustering coefficient and region homophily. Our results support Hypothesis 7a only for ROA; we didn't find significant effect for ROE (Models 3 and 6 in Table 6-1). Regional homophily has a negative effect on a firm's ROA, but when it is combined with network closure it provides positive benefits to the firm. While, the interaction term wasn't significant for ROA. However, overall marginal effect of region homophily shows positive and significant effects on both ROA and ROE.

Hypothesis $7 \mathrm{~b}$ is a general statement about interaction of network heterophily and network sparseness; therefore we have two different results:

a) When we discuss firm's network heterophily in terms of industry, and then our results reject hypothesis $7 \mathrm{~b}$ indicating that industry heterophily combined with 
network sparseness has a significant and negative effect on firm financial performance. One explanation of this negative coefficient could be that in this period in Armenia relevant knowledge did tend to be largely industry-specific. If so, then firms that do not have a strong core of supporting firms (i.e., firms not having a closed position) do not have the basic foundation on which to build with knowledge acquired from outside. A second explanation could be simply that firms with "only" inter-industry connections have not settled on a focused line of business, and so have been unable to create a core that they can exploit. Unfortunately, our data are not strong enough to differentiate between those two explanations. That said, this result does indicate that even though industry heterophily has a positive effect on firm performance, its effect falls when a firm is embedded in sparse networks. Nonetheless, the average marginal effect of industry heterophily was positive and significant for both ROA and ROE.

b) But when we consider firm type heterophily, our results show that a combination of network heterophily and network sparseness has significant and positive effect on both ROA and ROE (see the interaction term between ftype heterophily and betweennesss centrality in Models 3 and 6. These results support Hypothesis 7b when network heterophily is measured by firm type. We discussed above that the direct effect of, ftype heterophily is significant and negative on both ROA and ROE. However, when firm type hetrophily is combined with structural holes the negative effect of the firm type heterophily falls. Yet, the average marginal effect is still negative for both ROA and ROE.

Related to Hypothesis 8b, the interaction term between partners' exports and network closure is positive and significant only for ROA, and not significant for ROE (see models 3 and 6 in Table 6-1), which supports Hypothesis 8b only for ROA. Ignoring interaction effects, (Models 2 and 5, in Table 6.1) Partner's exports appear to have a negative effect on ROA (and no significant effect on ROE). However, when interaction terms are considered (Models 3 and 6), the effect of partners exports becomes positive, with the marginal effect also being positive (again only for ROA). The interaction term itself is positive (for ROA and insignificant, though negative, for ROE) which suggests that if the firm is embedded in a locally dense neighborhood it gains extra value from its partners' exports.

\subsection{Discussion of Findings}

Overall, we found that degree centrality is positively associated with firm performance, having a sub-linear relation with ROA. In the case of ROE we did not find nonlinearity (except for Model 4 in Table 6-1), though in general there is still a positive relation between degree centrality and ROE. Region Dummy has negative and significant impact on ROA in all Models, but positive and significant impact on ROE. In connection with this, our results also suggest that firms in the manufacturing sector have fewer opportunities to generate higher returns compared to firms in other sectors (industry dummy). These two findings demonstrate that the most profitable sectors are located outside of the main city. E.g., mining sectors contribute significantly to Armenia's GDP, and most of the mining companies are located outside of Yerevan. Prior firm size measured by the logarithm of the number of employees, appears to 
have a positive effect on firm profitability, while previous year sales has a very small but negative impact.

We employed different models to examine the effect of network homophily/heterophily in terms of industry, firm type and location; ${ }^{42}$ as well we estimated the impact of partner's assets (network resourcefulness) and partners' export intensity (foreign ties) on financial performance. Results from the regression model highlight that greater industry diversity can be beneficial for firm performance, while firm type diversity has mixed effects. Industry and firm type diversity capture the learning and resource access benefits caused by the collaboration with firms for a wide range of supporting purposes, while region diversity is costly and add more organizational difficulties. Firm type diversity reflects difficult tensions between firms attempting to maximize their learning from exporting firms and benefiting from the exchange of available resources (large firms), such that, e.g., large non-exporting firms may benefit from exporting firms in order to exploit foreign market opportunities, while small firms may benefit from large firms having access to variety of resources. We expected to have different effects of diversity measures for the different firm types, but our findings do not indicate any significant difference across firm type. In the case of region diversity, more is not necessarily better; indeed, most probably distance between regions creates more challenges and adds costs for efficient exchange of knowledge and resources. Findings related to partners' assets show positive impact as we expected, while exporting intensity of partners has adverse effects: economic returns from learning new organizational knowledge and its application may require time, and also might depend on firm's absorptive capability.

Our main focus, in this section, was testing the significance of interaction terms between network structure and content. Prior research showed that network structure has an important role explaining firm performance (Moran 2005a; Burt 2000). However, closer to our concerns are Rodan and Galunic's (2006) findings, which suggest that an ego network rich with structural holes will most probably benefit if it is combined with knowledge heterogeneity. While we considered this notion in our analysis, we also suggest that there is still value to a closed network structure, and for the exchange of resources, coordination, trust and easier communication resourcefulness and homophilious attributes may indicate better individual performance.

Prior research suggests that the value of a structure depends on context - e.g. network sparseness provides the actor with an advantage when there is a need to acquire new knowledge or broker with different resources. Network closure is advantageous for trust, as it also provides actors with the opportunity to monitor each other and learn tacit knowledge. We argue that actors will exchange resources if there is a high level of trust, and if there is a mechanism to monitor each other. However, it is important to note that the transition context does not provide many formal mechanisms for transparent monitoring of business partners in Armenia; in highly corrupt countries,

\footnotetext{
${ }^{42}$ Heterophily index also shows how balanced are diverse ties in actor's network, and in case of industry heterophily, firms with a highly balanced representation of the partners in the different industry sectors are benefiting from the knowledge and resource variety.
} 
economic agents rely more on informal mechanisms such as reputation, recommendations, etc., rather than on formal legal institutions for market exchange.

This intuition is reflected in Hypothesis 6. Our results show that rich or resourceful partners provide benefits for the focal firm and increase their return on equity, and this effect is increased in more cohesive network structures. Thus, the cohesive network provides background for the better exchange of resources such as financial resources, money borrowing, etc.

Our next set of arguments relates to the tradeoff between diversity and homogeneity. Firms with a diversity of ties have greater access to non-redundant information and knowledge, which have additional value for social capital. However, diversity of knowledge and information may have an adverse effect on firm performance: there is a tradeoff between exploratory learning and exploitative learning (Koka and Prescott 2002). To benefit from social capital we suggest various mechanisms, and we try to empirically examine to what extent homophilious or heterophilous ties can be beneficial. Our results showed that firms located in the same region (regional homophily) and being in a denser network will gain some additional advantage (only for ROE). This may suggest that a firms being strongly connected to other firms in the same region reduces information asymmetry, and have a higher chance to access to the resources that other firms possess, in particular, financial resources. Having preferential access to financial resources increases a firm's profitability. Our results showed that industry diversity combined with network sparseness has a negative and significant effect on firm performance. We found slightly different results for the firm type dimension, where firm type heterophily is negatively correlated with firm performance, but if it is combined with network sparseness then it increases firm profitability.

One of our interests was to test the indirect effect of exports through the firm's network. We anticipated that a firm that is able to export already has assimilated much of this sort of knowledge and so exports directly would not have this sort of knowledge effect. We did test for a relationship between exports of the focal firm and its ROA and ROE. In neither case did exports have a significant effect, so that variable was excluded from the final model. However, we did find that partners' exports have positive impact (significant on ROA but insignificant for ROE). This difference may explain our assumption that partners' export provide new knowledge, which could increase efficiency of organization but doesn't importantly provide access to new and rich financial resources, hence it is significant for ROA but not for ROE. Surprisingly, for foreign ties/partners' export we found that exposure to entirely new knowledge and capabilities is particularly beneficial when it is combined with network closure.

Our results showed that a closed network position is positive for efficiently using its assets, and if this structure is combined with newer organizational knowledge, which is assumed to be shared within the dense network, and only then it is a valuable resource for a firm. It can be argued that foreign (outside) knowledge and business practices are well diffused, and functional in dense rather than sparse networks. Armenian firms that do not have access to foreign markets and experience, because they were blocked from the outside world for 70 years, do not have the ability or willingness to accept 
new organizational knowledge, especially when firms do not have a view on how widely it is acceptable in their network. This may indicate that being closed for many years makes it hard for firms to absorb "modern ideas". When absorptive capacity is low, then dense networks are more beneficial in allowing for ideas to be repeated and accepted by all group members.

This finding brings an interesting discussion in understanding the role of foreign ties and asset-rich partners, showing slightly contrasting effects of interaction terms on ROA and ROE. This may indicate that partners' assets serve rather a better opportunity for borrowing, while partner's exports are a proxy for (or source of) new knowledge, and these two affect ROA and ROE differently. Our findings suggest that partners' assets have a significant impact on ROA and ROE, but also showed that network closure combined with asset-rich partners is significant for ROE but not for ROA, which may ultimately indicates that rich partners influence firm's borrowing opportunities rather than efficiency.

We also have found diverse effect of network closure and structural hole on ROA and ROE. One possible way to interpret these results is to look at the borrowing aspect and forming a debt. A firm in a closed network had higher chances for borrowing from its "friends"; in this case it will form a debt, which will make its ROE higher than its ROA. Higher level of debt may indicate that a firm was not using its assets in the most efficient way, and therefore had very limited opportunities to borrow from the banks, but instead has got recourses from the partner firms. Yet, the negative effect from network closure may be partially offset by the resources that partners have such as being regionally connected and having access to partner's exports, which helps a firm to navigate better in the market economy. At the same time, being closely connected and having rich network provide higher chances for borrowing, and hence increase the firm's ROE. As ROA provides a total return made by the firm, irrespective of the financing source, the social capital plays different roles for ROE, which focus on firm's debt ratio.

\subsection{Robustness Check}

\section{Multicollinearity}

All network variables were standardized, which was necessary to detect and reduce multicollinearity in the model caused by the high correlation between interaction terms and the component variables. Mean-centered variables are widely used in the econometrics literature for the analysis of interaction terms (Allison 1977). Standardized variables show the relative impact on the firm performance measures, interaction terms show moderating effects of two variables on explaining the firm's ROE or ROA. However, under certain conditions they could also indicate the complementarity between network structure and network content. Table 1 in Appendix D shows the correlation between network variables. We reduce the initial correlation between interaction terms and component variables through standardizing network variables. We also reported the models where we used interaction terms separately (see Appendix). 


\section{Endogeneity}

We used several methods to check the robustness of our results. First, we tested the parameters of the models and goodness of fit. We also controlled the main endogeniety issue by using lagged value of the independent variables, especially controlling for the network effects: all models estimate the effects of past network characteristics on firm performance.

\section{Model Parameters}

To select the most appropriate model, we conducted a Hausman test between random-effects and fixed-effects models. If the $\mathrm{p}$ value of a Hausman test was higher than 0.05 , then we chose random effect models. Most of the models show that Random effect model is well specified (see results in Table 6-3) as well as it allows showing effects of time variant variables. In addition to the Hausman test, we also look at other model parameters such as higher $\mathrm{R}$ square, significant values for $\mathrm{F}$ statistics and Rho. For each model we report the results of $\mathrm{F}$ test statistics (Wald Chi_2), which indicates that all of the coefficients in the models are different than zero (when probability Chi-2 $<0.05$ ). In all reported models chi_sq tests are significant and support the models.

\section{Alternative measures}

In Chapter 4, we discussed that empirical literature uses various measures to capture the same concept, and we identified a few alternative measures for network closure, sparseness and homophily. We decided to use them in our estimation models to see whether the obtained results vary related to these measures. Our empirical strategy used different a configuration and combination of alternative variables. Most of the estimation models show consistency in obtained results across alternative measures. We found that network closure is not significant, and this holds true for all three measures, as well as sign effects are consistent (not reported). We obtained very similar results for the "structural hole" measures - e.g., betweenness centrality shows positive and significant results, which has been confirmed with constraint. Network homophily/heterophily indices, which measure networks by region, industry and firm type, also show consistent results: e.g., the PC homophily index always shows the opposite sign compared to EI and Blau's heterophily indices in all models and in all categories.

\section{Missing observations for Network 2003?}

One issue of concern in the data was the network in 2003. We have board information for only 130 firms for 2003. This may indicate an actual sparse network for 2003, or it may indicate a missing data problem. To address this, our strategy is to run regressions that a) include actual networks we observe in 2003 b) exclude networks in 2003 and c) impute values for probable missing observations in the 2003 network, and then to compare the results with the ones we reported.

In order to impute missing observations, we constructed two different networks based on two main assumptions. First, we assume that missing firms might have links in 2003 if they had links both in 2001 and 2005. In that case, we input the missing link 
and construct new Network 2003_1. Second, we assume that missing firms have links if there is a link between two firms either in 2003 or 2005, and we construct Network 2003_2. In these two networks, links are inputed only for the firms that are not in our network data for 2003.

Our results are reported separately for ROA and ROE, and we compare with four datasets: first, data with observed network 2003, the second and third datasets used data with constructed networks for 2003, and the fourth, data from the excluded network 2003. The reported results do not show significant differences between different configurations; therefore, we found that regression results with observed network 2003 are robust (see Tables 4 and 5 in Appendix D).

\subsection{Conclusions}

This chapter presents a detailed picture on how social capital effects firm performance in the Armenian transitional context. We developed 8 empirical hypotheses, which have been tested with the data on Armenian corporate networks. In the first part of this chapter, the effects of structural dimension of the social capital were analyzed, providing an in-depth understanding of how the firm's position in the network is important for explaining firm performance. Prior literature has addressed this issue, however we also noticed that different measures of network sparseness and network closure were used while operationalizing the social capital concept, and therefore we decided to incorporate different measures as alternatives to capture structural hole and network closure. This exercise was an important step in selecting and furthering our research using only betweenness centrality and clustering coefficient. Since their correlation with degree centrality was low, we were able to include all of them in our analysis.

This study finds support for the benefit of the network strategies of degree centrality, network closure and structural holes. It appears that firms occupying a central position in the board network have considerable benefits. However connections are also costly, which ultimately suggests that firms should carefully chose partners, as efforts and time invested in linkages eventually will bring diminishing returns. Firms are most likely to profit from centrality in the network, but even if they do, such firms experience increase in a future profitability. However, markets are slow to incorporate this information, and therefore we had discrepancy between effects on ROA and ROE.

Another important finding was that firms in closed networks benefit, perhaps as a result of having more control, monitoring and exchange opportunities. Yet, our empirical evidence doesn't support which of the network structure is beneficial for the firms (network closure vs. structural holes). Indeed, it shows that both structures are important for the firm performance (only for ROE). This finding supports our intuition on transitional economies, where firms need pass through re-structuring in order to adapt to a new and turbulent environment caused by the collapse of the centralized planning system. Market instability and an institutional volatile environment enhance the value of reciprocity ties, as they are credible guarantees for market exchange, at the same time brokerage position also provide firm better opportunities to navigate and access to the resources that others are not able to access. 
In addition to the structural dimension of the social capital, our empirical findings show how a firm's network quality affects its profitability. Despite a widely held belief that firms should invest more in value-creating ties (Moran 2005b), there is little consensus on how to measure the partners' values. Here we suggest using measures for network homophily/heterophily, resourcefulness and foreign ties. These measures capture the knowledge, resources, opportunities and skills that a focal firm may gain from its social ties. Our findings show that industry heterophily has a strong impact on firm performance, indicating that more ties with different industries provide better opportunities for the firm. This finding contributes to the growing literature on knowledge and organization, expanding our understanding of why heterogeneous knowledge is important for firm performance. As we expected, network resourcefulness has a significant and positive impact on firm performance, suggesting that firms embedded in resource-rich networks gain a significant advantage.

One of our surprising results was that ties with exporting firms show a positive effects, and the benefits of foreign ties will increases if it is combined with dense networks. Previous research found that in general the presence of foreign actors in transitional countries brought positive outcomes, yet it has also been emphasized that public policies were likewise important to support learning and cooperation between local and foreign actors (McDermott 2002). For instance, in the Czech Republic, state intervention was able to embrace a participatory restructuring mechanism by sharing some risks and mediating disputes between foreign and local actors, which brought stability (McDermott 2002). Poor governance structure and legal infrastructure, as well as high corruption in Armenia very often did not create beneficial environment for foreign actors. But indirect effect of foreign actors was important for changing the behavior of the local firms, and if the firms are densely connected and can share new organization learning in their network, then it has stronger effect on firm performance.

Another important contribution of this study is that it addressed the question of combination of network structure and content in maximizing the benefits for the firm's network. By parsing apart the influence of network structure and network content, we provide a more comprehensive view of the influence on social capital on firm performance. In this regard, we suggest looking at the interaction terms of the two dimensions of social capital. Our empirical analyses were focused on the extent to which network structure and network content are important for firm performance. Particularly, we found that there is a value of combining certain network structure with certain content such as network heterophily with structural holes, network resourcefulness with network closure, and foreign ties with network closure.

Finally, our findings suggest considerable practical concern for a firm's strategy, and offered insights on what constitutes productive and value-adding social relations. Our study points to the substantial resources and knowledge available through networks that specifically hone in on a precise combination of network structure and content. Knowledge and information spillovers are linked with the notion of social capital formed as a result of inter-organizational linkages (Koka and Prescott 2002), and information that flows through board members is an essential factor in explaining the inter-organizational learning from each other's practices. Our study shows that access to information and capabilities possessed by a firm's partners is differently distributed, 
and that it is a function of firm's own capabilities and knowledge, its network position and structure, and the attributes of the partners.

The main contributions of this chapter are that board sets of measures and novel variables are used in the estimation of the firm performance. It also examined board networks in the transitional context, with the unique and historical data. The review of literature showed that there is a significant lack of evidence of applying deeper social capital analysis in the examination of board networks. If future work continues to support the importance of firm's access and utilization of social capital, the firms may benefit from successfully choosing board members and partner firms. In conclusion, we hope that this work will contribute to further the studies on complementarity of different dimensions of social capital, which will deepen our knowledge on strategic advantages of building and utilizing the social capital. 


\section{Appendix D:}

Table 1: Correlation of network variables and interaction terms: ${ }^{*} \mathrm{p}<0.01$

\begin{tabular}{|c|c|c|c|c|c|c|c|c|c|c|c|c|c|c|c|c|c|c|c|}
\hline & 1 & 2 & 3 & 4 & 5 & 6 & 7 & 8 & 9 & 10 & 11 & 12 & 13 & 14 & 15 & 16 & 17 & 18 & 19 \\
\hline 1. degree & 1 & & & & & & & & & & & & & & & & & & \\
\hline 2.degree2 & $0.33^{*}$ & 1 & & & & & & & & & & & & & & & & & \\
\hline 3.clust & $0.57^{*}$ & $0.24 *$ & 1 & & & & & & & & & & & & & & & & \\
\hline 4. Partners' assets & $0.81 *$ & $0.17^{*}$ & $0.39 *$ & 1 & & & & & & & & & & & & & & & \\
\hline 5. Partners' export & $0.64^{*}$ & $0.25^{*}$ & $0.26^{*}$ & $0.64^{*}$ & 1 & & & & & & & & & & & & & & \\
\hline 6.RegHom & $0.48^{*}$ & 0.09 & $0.19 *$ & $0.49^{*}$ & $0.27^{*}$ & 1 & & & & & & & & & & & & & \\
\hline 7. INDHom & $0.45^{*}$ & 0.08 & $0.31 *$ & $0.45^{*}$ & $0.36^{*}$ & $0.37 *$ & 1 & & & & & & & & & & & & \\
\hline 8. FTT.Hom & $0.54^{*}$ & 0.1 & $0.27^{*}$ & $0.48^{*}$ & -0.01 & $0.33^{*}$ & 0.1 & 1 & & & & & & & & & & & \\
\hline 9.Between & $0.7^{*}$ & $0.36^{*}$ & 0.13 & $0.5^{*}$ & $0.42^{*}$ & $0.34^{*}$ & $0.3^{*}$ & $0.35^{*}$ & 1 & & & & & & & & & & \\
\hline 10. IND_het & $0.84^{*}$ & $0.34 *$ & $0.56^{*}$ & $0.6^{*}$ & $0.47^{*}$ & $0.39 *$ & $0.37^{*}$ & $0.362^{*}$ & $0.7^{*}$ & 1 & & & & & & & & & \\
\hline 11. Ftype_het & $0.66^{*}$ & $0.28^{*}$ & $0.46^{*}$ & $0.53^{*}$ & $0.77^{*}$ & $0.3^{*}$ & $0.47^{*}$ & 0.046 & $0.5^{*}$ & $0.612^{*}$ & 1 & & & & & & & & \\
\hline 12.Region*clust & 0.03 & $0.32 *$ & 0.11 & -0.02 & -0.13 & 0.05 & 0.03 & 0.002 & -0.12 & 0.051 & -0.02 & 1 & & & & & & & \\
\hline 13.INDHm*clust & 0.1 & $0.3^{*}$ & $0.19 *$ & -0.03 & 0.01 & 0.03 & $0.24^{*}$ & -0.028 & -0.1 & 0.123 & 0.1 & $0.36^{*}$ & 1 & & & & & & \\
\hline 14.FtHm*clust & 0.04 & $0.25^{*}$ & $0.16^{*}$ & 0.01 & -0.01 & 0.02 & -0.03 & 0.025 & -0.07 & 0.098 & -0.03 & $0.27^{*}$ & -0.03 & 1 & & & & & \\
\hline 15.Part.assets. ${ }^{*}$ clust & 0.09 & $0.42^{*}$ & $0.22^{*}$ & -0.09 & -0.01 & -0.03 & -0.04 & 0.004 & -0.01 & 0.133 & 0.08 & $0.31 *$ & $0.36^{*}$ & $0.28^{*}$ & 1 & & & & \\
\hline 16.Part.export*clust & 0.12 & $0.37^{*}$ & 0.11 & -0.01 & 0.16 & -0.13 & 0.01 & -0.008 & 0.1 & 0.106 & $0.17^{*}$ & 0.13 & $0.38^{*}$ & -0.09 & $0.56^{*}$ & 1 & & & \\
\hline 17. IND*betw & $0.28^{*}$ & $0.57^{*}$ & -0.02 & $0.17^{*}$ & $0.18^{*}$ & 0.1 & 0.1 & 0.106 & $0.49 *$ & $0.322^{*}$ & $0.21 *$ & 0.09 & $0.25^{*}$ & -0.01 & $0.26^{*}$ & $0.34^{*}$ & 1 & & \\
\hline 18. FTT*betw & $0.21 *$ & $0.43^{*}$ & 0.05 & 0.1 & $0.23 *$ & 0.01 & 0.17 & 0.090 & $0.29 *$ & $0.187 *$ & $0.26^{*}$ & 0.03 & 0.09 & $0.25^{*}$ & $0.24 *$ & 0.13 & $0.5^{*}$ & 1 & \\
\hline $\begin{array}{l}\text { 19. Part. } \\
\text { export*betw }\end{array}$ & $0.17 *$ & $0.38^{*}$ & 0.11 & 0.03 & 0.15 & -0.12 & 0.11 & 0.143 & $0.22 *$ & 0.171 & $0.24^{*}$ & 0.06 & 0.15 & 0.14 & $0.23^{*}$ & $0.19^{*}$ & $0.42^{*}$ & $0.77^{*}$ & 1 \\
\hline
\end{tabular}


Table 2: Results: Network Structure and Network Content ${ }^{43}$

\begin{tabular}{|c|c|c|c|c|c|c|c|c|c|c|}
\hline & $\begin{array}{c}\text { ROA } \\
\text { Mod. } 1\end{array}$ & $\begin{array}{c}\text { ROA } \\
\text { Mod. } 2\end{array}$ & $\begin{array}{c}\text { ROA } \\
\text { Mod.3 }\end{array}$ & $\begin{array}{c}\text { ROA } \\
\text { Mod. } 4\end{array}$ & $\begin{array}{c}\text { ROA } \\
\text { Mod } 5\end{array}$ & $\begin{array}{c}\text { ROE } \\
\text { Mod. } 6\end{array}$ & $\begin{array}{c}\text { ROE } \\
\text { Mod. } 7\end{array}$ & $\begin{array}{c}\text { ROE } \\
\text { Mod.8 }\end{array}$ & $\begin{array}{c}\text { ROE } \\
\text { Mod. } 9\end{array}$ & $\begin{array}{c}\text { ROE } \\
\text { Mod.10 }\end{array}$ \\
\hline \multirow{2}{*}{$\begin{array}{l}\text { Region } \\
\text { Dummy }\end{array}$} & $-0.105^{*}$ & $-0.11 * *$ & $-0.117 *$ & $-0.116^{*}$ & $-0.11 *$ & 0.098* & 0.012 & 0.014 & 0.015 & $0.13 *$ \\
\hline & $(0.054)$ & $(0.054)$ & $(0.061)$ & $(0.061)$ & $(0.06)$ & $(0.055)$ & $(0.026)$ & $(0.026)$ & $(0.026)$ & $(0.07)$ \\
\hline \multirow{2}{*}{$\begin{array}{l}\text { Industry } \\
\text { Dummy }\end{array}$} & 0.05 & -0.02 & -0.03 & -0.02 & 0.007 & $-0.12 * *$ & $-0.1 * * *$ & $-0.1 * * *$ & $-0.1 * * *$ & $-0.1 * * *$ \\
\hline & $(0.03)$ & $(0.03)$ & $(0.09)$ & $(0.07)$ & $(0.07)$ & $(0.051)$ & $(0.03)$ & $(0.03)$ & $(0.03)$ & $(0.03)$ \\
\hline $\begin{array}{l}\text { Log } \\
\text { Empl. }\end{array}$ & 0.003 & 0.002 & 0.014 & 0.014 & 0.018 & $0.084 *$ & $0.03 * * *$ & $0.04 * * *$ & $0.04 * * *$ & $0.03 * * *$ \\
\hline $\log$ Sales & $\begin{array}{l}(0.024) \\
\mathbf{- 0 . 0 0 2} \\
(0.008)\end{array}$ & $\begin{array}{l}(0.024) \\
\mathbf{- 0 . 0 0 2} \\
(0.008)\end{array}$ & $\begin{array}{c}(0.029) \\
\mathbf{- 0 . 0 0 5} \\
(0.01)\end{array}$ & $\begin{array}{c}(0.029) \\
-\mathbf{- 0 . 0 0 5} \\
(0.01)\end{array}$ & $\begin{array}{c}(0.03) \\
-\mathbf{0 . 0 0 6} \\
(0.01)\end{array}$ & $\begin{array}{c}(0.048) \\
\mathbf{- 0 . 0 9} \\
(0.07)\end{array}$ & $\begin{array}{c}(0.012) \\
\mathbf{- 0 . 0 8 * *} \\
(0.04)\end{array}$ & $\begin{array}{c}(0.012) \\
\mathbf{- 0 . 0 8 * *} \\
(0.04)\end{array}$ & $\begin{array}{c}(0.012) \\
\mathbf{- 0 . 0 8 * *} \\
(0.04)\end{array}$ & $\begin{array}{c}(0.012) \\
-\mathbf{0 . 0 8} * * \\
(0.04)\end{array}$ \\
\hline \multicolumn{11}{|c|}{ Network Structure } \\
\hline Degree & $\begin{array}{l}\mathbf{0 . 0 6 1 *} \\
(0.033)\end{array}$ & $\begin{array}{l}\mathbf{0 . 0 8 * *} \\
(0.037)\end{array}$ & $\begin{array}{c}\mathbf{0 . 1 6 5 * *} \\
(0.066)\end{array}$ & $\begin{array}{l}\mathbf{0 . 1 9 * *} \\
(0.087)\end{array}$ & $\begin{array}{r}\mathbf{0 . 1 9 * *} \\
(0.09)\end{array}$ & $\begin{array}{l}\mathbf{0 . 0 2 4} \\
(0.03)\end{array}$ & $\begin{array}{c}\mathbf{0 . 0 5 2 * *} \\
(0.026)\end{array}$ & $\begin{array}{l}\mathbf{- 0 . 0 3 1} \\
(0.03)\end{array}$ & $\begin{array}{c}-\mathbf{0 . 0 7 7 *} \\
(0.04)\end{array}$ & $\begin{array}{c}-\mathbf{- 0 . 0 7 6 *} \\
(0.04)\end{array}$ \\
\hline \multirow[t]{2}{*}{$\begin{array}{l}\text { Degree } \\
\text { sq. }\end{array}$} & $-0.01 *$ & $-0.01 * *$ & $-0.01 * *$ & $-0.011^{*}$ & $-0.01 *$ & -0.003 & $-0.01 * *$ & 0.001 & 0.004 & 0.004 \\
\hline & $(0.003)$ & $(0.003)$ & $(0.005)$ & $(0.006)$ & $(0.01)$ & $(0.003)$ & (0.004) & $(0.002)$ & (0.003) & $(0.003)$ \\
\hline \multirow{2}{*}{\multicolumn{2}{|c|}{$\begin{array}{l}\text { Clusterin } \\
\text { g coef. }\end{array}$}} & -0.108 & 0.101 & 0.106 & $0.11 *$ & & -0.013 & -0.034 & -0.041 & -0.039 \\
\hline & & $(0.09)$ & (0.101) & $(0.102)$ & $(0.06)$ & & $(0.047)$ & $(0.049)$ & $(0.049)$ & $(0.049)$ \\
\hline \multirow[t]{2}{*}{$\begin{array}{l}\text { Between. } \\
\text { centr. }\end{array}$} & & $-0.012 *$ & $-0.08 *$ & $-0.09 *$ & -0.09 & & -0.04 & -0.05 & -0.004 & -0.03 \\
\hline & & $(0.005)$ & $(0.02)$ & $(0.02)$ & $(0.05)$ & & $(0.07)$ & (0.07) & $(0.007)$ & $(0.07)$ \\
\hline \multicolumn{11}{|c|}{ Network Content } \\
\hline \multirow[t]{2}{*}{$\begin{array}{l}\text { IND } \\
\text { heteroph }\end{array}$} & & & $0.4 * *$ & $0.42 * *$ & $0.5^{* *}$ & & & $0.2 * *$ & $0.24 * * *$ & $0.25 * * *$ \\
\hline & & & (0.185) & $(0.189)$ & $(0.19)$ & & & $(0.088)$ & $(0.091)$ & (0.091) \\
\hline \multirow[t]{2}{*}{$\begin{array}{l}\text { Ftype } \\
\text { heter. }\end{array}$} & & & -0.245 & $-0.253 *$ & -0.02 & & & -0.079 & -0.07 & $-0.137 *$ \\
\hline & & & $(0.151)$ & $(0.151)$ & $(0.2)$ & & & $(0.067)$ & $(0.067)$ & (0.081) \\
\hline \multicolumn{2}{|c|}{ Region Homoph. } & & $\begin{array}{r}\mathbf{- 0 . 1 0 7} \\
(0.09)\end{array}$ & $\begin{array}{l}-0.09 \\
(0.01)\end{array}$ & $\begin{array}{l}-0.1 \\
(0.01)\end{array}$ & & & $\begin{array}{c}\mathbf{0 . 0 4 4 *} \\
(0.02)\end{array}$ & $\begin{array}{c}\mathbf{0 . 0 2} \\
(0.042)\end{array}$ & $\begin{array}{l}\text { 0.035* } \\
(0.012)\end{array}$ \\
\hline $\begin{array}{l}\text { Partners' } \\
\text { assets }\end{array}$ & & & & $\begin{array}{c}-\mathbf{- 0 . 0 0 5} \\
(0.01)\end{array}$ & $\begin{array}{r}-\mathbf{0 . 0 0 2} \\
(0.02)\end{array}$ & & & & $\begin{array}{l}\mathbf{0 . 0 7 *} \\
(0.04)\end{array}$ & $\begin{array}{l}0.015^{*} \\
(0.08)\end{array}$ \\
\hline $\begin{array}{l}\text { Partners } \\
\text { export }\end{array}$ & & & & & $\begin{array}{c}-\mathbf{0 . 0 2 *} \\
(0.01)\end{array}$ & & & & & $\begin{array}{c}\mathbf{0 . 0 0 7} \\
(0.005)\end{array}$ \\
\hline _cons & 0.01 & -0.004 & -0.064 & -0.085 & -0.095 & $0.7 * * *$ & $0.65 * * *$ & $0.69 * * *$ & $0.72^{* * *}$ & $0.72 * * *$ \\
\hline & 0.1 & $(0.094)$ & $(0.117)$ & $(0.12)$ & $(0.12)$ & $(0.078)$ & $(0.045)$ & $(0.05)$ & $(0.054)$ & $(0.054)$ \\
\hline Rho & 0.4 & 0.868 & 0.712 & 0.642 & 0.365 & 0.868 & 0.683 & 0.661 & 0.065 & 0.661 \\
\hline $\mathrm{N}$ & 423 & 423 & 375 & 375 & 372 & 505 & 546 & 546 & 546 & 544 \\
\hline chi2 & 28 & 21.026 & 35.059 & 29.319 & 18.342 & 28.426 & 23.067 & 29.987 & 33.069 & 35.695 \\
\hline $\begin{array}{l}\text { Hausman } \\
\text { Prob }>\text { Chi_2 }\end{array}$ & 0.1 & 0.14 & 0.07 & 0.45 & 0.28 & 0.13 & 0.14 & 0.15 & 0.16 & 0.13 \\
\hline
\end{tabular}

\footnotetext{
43 This shows the set-by-step approach we used for our econometric modeling. We gradually include each network variable.
} 
Table 3: Regression results with interaction terms ${ }^{44}$

\begin{tabular}{|c|c|c|c|c|c|c|c|c|c|c|c|c|}
\hline & $\begin{array}{l}\text { ROA } \\
\text { Mod1 }\end{array}$ & $\begin{array}{c}\text { ROA } \\
\text { Mod } 2\end{array}$ & $\begin{array}{c}\text { ROA } \\
\text { Mod 3 }\end{array}$ & $\begin{array}{c}\text { ROA } \\
\text { Mod } 4\end{array}$ & $\begin{array}{l}\text { ROA } \\
\text { Mod5 }\end{array}$ & $\begin{array}{c}\text { ROA } \\
\text { Mod } 6\end{array}$ & $\begin{array}{c}\text { ROE } \\
\text { Model } 7\end{array}$ & $\begin{array}{c}\text { ROE } \\
\text { Model } 8\end{array}$ & $\begin{array}{c}\text { ROE } \\
\text { Model } 9\end{array}$ & $\begin{array}{c}\text { ROE } \\
\text { Mod } 10\end{array}$ & $\begin{array}{c}\text { ROE } \\
\text { Mod } 11\end{array}$ & $\begin{array}{c}\text { ROE } \\
\text { Mod } 12\end{array}$ \\
\hline \multirow[t]{2}{*}{ Region D. } & -0.06 & 0.104* & -0.059 & $-0.12 * *$ & $-0.13 * *$ & 0.05 & 0.14* & 0.016 & 0.14* & $0.1 *$ & 0.03* & 0.013 \\
\hline & $(0.06)$ & $(0.06)$ & $(0.042)$ & $(0.055)$ & $(0.055)$ & $(0.073)$ & $(0.077)$ & $(0.026)$ & $(0.073)$ & $(0.073)$ & $(0.073)$ & $(0.026)$ \\
\hline \multirow[t]{2}{*}{ IND D. } & 0.028 & 0.022 & -0.001 & 0.02 & -0.004 & $0.17 * *$ & $-0.09 *$ & $-015^{* *}$ & $-0.073 *$ & $-0.12 *$ & -0.099 & $-0.14 * * *$ \\
\hline & $(0.064)$ & $(0.076)$ & $(0.049)$ & $(0.064)$ & $(0.064)$ & $(0.081)$ & $(0.049)$ & $(0.053)$ & $(0.032)$ & $(0.062)$ & $(0.082)$ & $(0.03)$ \\
\hline \multirow[t]{2}{*}{$\log E m p$} & -0.01 & $0.04 *$ & 0.043 & $0.08 *$ & $0.08 * * *$ & $0.07 * *$ & 0.015 & $0.04 * * *$ & $0.03 * * *$ & 0.025 & 0.029 & $0.035 * *$ \\
\hline & $(0.026)$ & $(0.027)$ & $(0.049)$ & $(0.027)$ & (0.019) & $(0.028)$ & $(0.035)$ & $(0.012)$ & $(0.014)$ & $(0.034)$ & $(0.034)$ & $(0.012)$ \\
\hline \multirow[t]{2}{*}{.logsales } & -0.004 & -0.014 & -0.004 & $-0.02 * *$ & $-0.02 * *$ & $-0.014 *$ & -0.015 & $-0.01 * *$ & -0.01 & -0.011 & -0.011 & $-0.01 * *$ \\
\hline & $(0.008)$ & $(0.016)$ & $(0.006)$ & $(0.007$ & $(0.008)$ & $(0.008)$ & $(0.012)$ & $(0.004)$ & $(0.011)$ & $(0.011)$ & $(0.011)$ & $(0.004)$ \\
\hline \multirow[t]{2}{*}{ Cluster coef. } & $-0.1 * *$ & -0.054 & $0.06^{*}$ & 0.074* & $0.08 * *$ & $0.08 *$ & $0.07 *$ & -0.032 & -0.002 & -0.006 & 0.015 & $-0.03 *$ \\
\hline & $(0.046)$ & $(0.041)$ & $(0.031)$ & $(0.043)$ & $(0.041)$ & $(0.048)$ & $(0.052)$ & $(0.048)$ & $(0.051)$ & $(0.047)$ & $(0.053)$ & $(0.013)$ \\
\hline \multirow[t]{2}{*}{ Betweeness centr. } & 0.024 & $0.11 * *$ & -0.08 & -0.054 & -0.044 & 0.052 & 0.01 & $0.096 * *$ & $0.15^{* * *}$ & $0.11 *$ & $0.12 *$ & 0.036 \\
\hline & $(0.047)$ & $(0.041)$ & $(0.071)$ & $(0.049)$ & $(0.045)$ & $(0.043)$ & $(0.05)$ & $(0.039)$ & $(0.048)$ & $(0.054)$ & $(0.073)$ & $(0.025)$ \\
\hline \multirow[t]{2}{*}{ Partners assets } & 0.024 & 0.036 & 0.032 & 0.032 & 0.035 & 0.059 & $0.024 *$ & 0.036 & $0.04 *$ & $0.13 *$ & $0.13 *$ & $0.013^{*}$ \\
\hline & $(0.047)$ & $(0.043)$ & $(0.042)$ & $(0.054)$ & $(0.053)$ & $(0.043)$ & $(0.012)$ & $(0.026)$ & $(0.019)$ & $(0.07)$ & $(0.071)$ & $(0.065)$ \\
\hline \multirow[t]{2}{*}{ Partners Export } & $-0.11 *$ & 0.03 & -0.05 & $-0.099 *$ & $-0.07 *$ & $-0.10^{*}$ & 0.03 & 0.028 & -0.015 & 0.01 & 0.006 & 0.012 \\
\hline & $(0.059)$ & $(0.028)$ & $(0.28)$ & $(0.057)$ & $(0.042)$ & $(0.59)$ & $(0.052)$ & $(0.017)$ & $(0.046)$ & $(0.051)$ & $(0.051)$ & $(0.016)$ \\
\hline \multirow[t]{2}{*}{ Region Homophily } & 0.027 & -0.028 & -0.022 & -0.028 & -0.027 & 0.007 & $0.1^{*}$ & 0.026 & 0.03 & 0.028 & -0.026 & 0.009 \\
\hline & $(0.033)$ & $(0.041)$ & $(0.025)$ & $(0.033)$ & $(0.032)$ & $(0.031)$ & $(0.048)$ & $(0.036)$ & $(0.045)$ & $(0.045)$ & $(0.045)$ & $(0.016)$ \\
\hline \multirow[t]{2}{*}{ Industry heterophily } & 0.019 & $0.13 * *$ & 0.066 & $0.13 * *$ & $0.14 * *$ & 0.037 & 0.084 & $0.12 *$ & $0.1 *$ & $0.11 * *$ & $0.2^{* * *}$ & $0.14 * *$ \\
\hline & $(0.06)$ & $(0.056)$ & $(0.043)$ & $(0.059)$ & $(0.056)$ & $(0.049)$ & $(0.081)$ & $(0.062)$ & $(0.055)$ & $(0.06)$ & $(0.075)$ & $(0.07)$ \\
\hline \multirow{2}{*}{ Ftype homophily } & & $0.05 *$ & $0.05 *$ & & & & $0.34 * *$ & & $0.09 * *$ & & & $0.05 *$ \\
\hline & & $(0.028)$ & $(0.028)$ & & & & $(0.16)$ & & $(0.036)$ & & & $(0.027)$ \\
\hline Ftype heterophily & $\begin{array}{l}-\mathbf{0 . 0 8 *} \\
(0.044)\end{array}$ & & & $\begin{array}{l}-0.1 * * \\
(0.048)\end{array}$ & $\begin{array}{l}-\mathbf{0 . 0 8} * \\
(0.045)\end{array}$ & $\begin{array}{c}\mathbf{0 . 0 3 5} \\
(0.043)\end{array}$ & & $\begin{array}{c}\mathbf{- 0 . 1 0 9 *} \\
(0.063)\end{array}$ & & $\begin{array}{r}-\mathbf{0 . 0 2 3} \\
(0.056)\end{array}$ & $\begin{array}{c}-\mathbf{0 . 0 1 1} \\
(0.056)\end{array}$ & \\
\hline Part.Exports x clust.coef & $\begin{array}{c}\mathbf{0 . 0 9} * * * \\
(0.029)\end{array}$ & & & & & & $\begin{array}{c}\mathbf{0 . 0 2 5} \\
(0.031)\end{array}$ & & & & & \\
\hline IND.hetero $\mathrm{x}$ between & & $\begin{array}{l}-\mathbf{0 . 1}{ }^{*} \\
(0.07)\end{array}$ & & & & & & $\begin{array}{c}-\mathbf{0 . 1} * \boldsymbol{*} * \boldsymbol{*} \\
(0.02)\end{array}$ & & & & \\
\hline Ftypehom.x clust.coef & & & $\begin{array}{l}-\mathbf{- 0 . 0 2} \\
(0.02)\end{array}$ & & & & & & $\begin{array}{c}\mathbf{0 . 0 1 2} \\
(0.041)\end{array}$ & & & \\
\hline
\end{tabular}

${ }^{44}$ Duo to multicollinearity issue we first include one interaction at a time, and then report the model with all network variables and interactions. Main cofficinet are bolded, and standard errors are bellow. 


\begin{tabular}{|c|c|c|c|c|c|c|c|c|c|c|c|c|}
\hline FtypeHetero.x between & & & & $\begin{array}{c}\mathbf{0 . 1} \text { **** } \\
(0.04)\end{array}$ & & & & & & $\begin{array}{c}\mathbf{0 . 0 4} * \\
(0.017)\end{array}$ & & \\
\hline Reghomop.x Clust coef & & & & & $\begin{array}{c}\mathbf{0 . 0 2 4} \\
(0.023)\end{array}$ & & & & & & $\begin{array}{c}\mathbf{0 . 0 2} \\
(0.039)\end{array}$ & \\
\hline Part. assets x Clust.coef & & & & & & $\begin{array}{c}\mathbf{0 . 0 1} \\
(0.04)\end{array}$ & & & & & & $\begin{array}{c}\mathbf{0 . 1} \boldsymbol{*} * \\
(0.034)\end{array}$ \\
\hline -cons & $\begin{array}{c}\mathbf{0 . 1 5 *} \\
(0.082) \\
\end{array}$ & $\begin{array}{l}\mathbf{0 . 1 2 * *} \\
(0.057) \\
\end{array}$ & $\begin{array}{l}\mathbf{0 . 1 2 * *} \\
(0.057) \\
\end{array}$ & $\begin{array}{l}\mathbf{0 . 1 3 *} \\
(0.08) \\
\end{array}$ & $\begin{array}{l}\mathbf{0 . 1 3 *} \\
(0.08) \\
\end{array}$ & $\begin{array}{c}\mathbf{- 0 . 2 8 * * *} \\
(0.098) \\
\end{array}$ & $\begin{array}{c}\mathbf{0 . 6 7} * * * \\
(0.103) \\
\end{array}$ & $\begin{array}{c}\mathbf{0 . 6 7} * * * \\
(0.037) \\
\end{array}$ & $\begin{array}{c}\mathbf{0 . 6 4} * * \boldsymbol{*} \\
(0.102) \\
\end{array}$ & $\begin{array}{c}\mathbf{0 . 6 4} * * \boldsymbol{*} \\
(0.102) \\
\end{array}$ & $\begin{array}{c}\mathbf{0 . 6 4 * * *} \\
(0.103) \\
\end{array}$ & $\begin{array}{c}\mathbf{0 . 6 6} * * * \\
(0.039) \\
\end{array}$ \\
\hline$\overline{\mathrm{N}}$ & 352 & 353 & 353 & 351 & 351 & 351 & 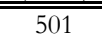 & $\overline{546}$ & 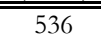 & 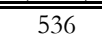 & 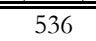 & 544 \\
\hline $\mathrm{r} 2$ & 0.19 & 0.24 & 0.2 & 0.13 & 0.22 & 0.19 & 0.14 & 0.12 & 0.18 & 0.11 & 0.13 & 0.1 \\
\hline chi2 & 17.55 & 14.45 & 15.324 & 16.66 & 18.16 & 26.19 & 25.85 & 29.81 & 23.51 & 23.48 & 24.33 & 33.44 \\
\hline
\end{tabular}


Table 4: Results for ROA models testing missing values in Network 2003

\begin{tabular}{|c|c|c|c|c|c|c|c|c|c|c|c|c|c|c|c|c|}
\hline \multicolumn{17}{|c|}{ ROA models } \\
\hline & \multicolumn{4}{|c|}{ With Observed Network 2003} & \multicolumn{4}{|c|}{ With Network 2003_1 } & \multicolumn{4}{|c|}{ With Network 2003_2 } & \multicolumn{4}{|c|}{ Without Network 2003} \\
\hline Social & Model & Model & Model & Model & Model & Model & Model & Model & Model & Model & Model & Model & Model & Model & Model & Model \\
\hline Capital & 1 & 2 & 3 & 4 & 1 & 2 & 3 & 4 & 1 & 2 & 3 & 4 & 1 & 2 & 3 & 4 \\
\hline Degree & $0.08 * *$ & $0.16 * *$ & $0.2^{* *}$ & $0.2 * *$ & $0.07 * *$ & $0.12 *$ & 0.119 & 0.117 & 0.036 & 0.029 & 0.009 & 0.056 & 0.076 & $0.2 * *$ & $0.23 * *$ & $0.2 *$ \\
\hline & $(0.04)$ & $(0.06)$ & $(0.08)$ & $(0.08)$ & $(0.03)$ & $(0.06)$ & $(0.09)$ & -0.086 & $(0.03)$ & $(0.05)$ & $(0.06)$ & $(0.06)$ & $(0.04)$ & $(0.09)$ & $(0.11)$ & (0.11) \\
\hline Degree & $-0.01 * *$ & $-0.01 * *$ & $-0.01 *$ & $-0.01 *$ & -0.01 & -0.01 & -0.01 & -0.01 & -0.01 & 0.001 & 0.002 & -0.001 & -0.01 & $-0.02 *$ & $-0.02 *$ & -0.01 \\
\hline & $(0.00)$ & $(0.00)$ & $(0.01)$ & $(0.01)$ & $(0.004)$ & $(0.01)$ & $(0.01)$ & $(0.01)$ & $(0.01)$ & $(0.01)$ & $(0.01)$ & $(0.01)$ & $(0.01)$ & $(0.01)$ & $(0.01)$ & $(0.01)$ \\
\hline $\begin{array}{l}\text { Clustering } \\
\text { coef. }\end{array}$ & -0.11 & 0.101 & 0.106 & $0.11^{*}$ & -0.109 & 0.083 & 0.069 & 0.069 & -0.05 & 0.068 & 0.053 & 0.081 & -0.102 & 0.18 & 0.187 & $0.185 *$ \\
\hline & $(0.09)$ & $(0.1)$ & $(0.1)$ & $(0.06)$ & $(0.082)$ & $(0.1)$ & $(0.11)$ & $(0.11)$ & $(0.06)$ & $(0.09)$ & $(0.09)$ & $(0.092)$ & $(0.12)$ & (0.13) & $(0.13)$ & $(0.73)$ \\
\hline $\begin{array}{l}\text { Between.c } \\
\text { entr. }\end{array}$ & $-0.01 *$ & $-0.08 *$ & $-0.09 *$ & -0.09 & -0.05 & -0.06 & -0.01 & -0.01 & 0.004 & -0.01 & -0.01 & -0.01 & -0.013 & -0.009 & -0.01 & -0.01 \\
\hline & $(0.01)$ & $(0.02)$ & $(0.02)$ & $(0.05)$ & $(0.01)$ & $(0.01)$ & $(0.01)$ & $(0.01)$ & 0.003 & $(0.005$ & 0.005 & 0.005 & $(0.02)$ & $(0.02)$ & $(0.02)$ & $(0.02)$ \\
\hline $\begin{array}{l}\text { IND } \\
\text { heteroph }\end{array}$ & & $0.4^{* *}$ & $0.42 * *$ & $0.46^{* *}$ & & -0.29 & -0.28 & -0.29 & & -0.102 & -0.101 & -0.215 & & $0.49 * *$ & $0.51 * *$ & $0.53 * *$ \\
\hline & & $(0.19)$ & $(0.19)$ & $(0.19)$ & & $(0.18)$ & $(0.18)$ & $(0.18)$ & & $(0.15)$ & $(0.15)$ & $(0.16)$ & & $(0.23)$ & $(0.24)$ & $(0.24)$ \\
\hline $\begin{array}{l}\text { Ftype } \\
\text { heter. }\end{array}$ & & -0.25 & $-0.25 *$ & -0.02 & & -0.2 & -0.197 & -0.197 & & -0.12 & -0.113 & 0.002 & & -0.226 & -0.231 & -0.021 \\
\hline & & $(0.15)$ & $(0.15)$ & $(0.2)$ & & $(0.15)$ & $(0.15)$ & $(0.15)$ & & $(0.15)$ & $(0.15)$ & $(0.16)$ & & $(0.18)$ & $(0.18)$ & $(0.25)$ \\
\hline $\begin{array}{l}\text { Region } \\
\text { Homoph }\end{array}$ & & -0.1 & -0.09 & -0.1 & & -0.131 & -0.119 & -0.12 & & -0.104 & -0.111 & -0.134 & & -0.156 & -0.137 & -0.148 \\
\hline & & $(0.09)$ & $(0.09)$ & $(0.097)$ & & $(0.09)$ & (0.1) & $(0.1)$ & & $(0.09)$ & $(0.1)$ & $(0.1)$ & & $(0.11)$ & $(0.12)$ & $(0.12)$ \\
\hline $\begin{array}{l}\text { Partners` } \\
\text { assets }\end{array}$ & & & -0.005 & -0.002 & & & -0.001 & 0.003 & & & 0.005 & 0.005 & & & -0.005 & -0.003 \\
\hline & & & $(0.01)$ & $(0.01)$ & & & $(0.01)$ & $(0.01)$ & & & $(0.01)$ & $(0.01)$ & & & $(0.012)$ & $(0.01)$ \\
\hline $\begin{array}{l}\text { Partners } \\
\text { export }\end{array}$ & & & & $-0.02 *$ & & & & -0.011 & & & & $-0.1 * *$ & & & & -0.019 \\
\hline & & & & $(-0.01)$ & & & & $(0.02)$ & & & & $(0.01)$ & & & & $(0.02)$ \\
\hline _cons & $\begin{array}{l}\mathbf{- 0 . 0 0 4} \\
(0.09) \\
\end{array}$ & $\begin{array}{c}\mathbf{- 0 . 0 6 4} \\
(0.12) \\
\end{array}$ & $\begin{array}{c}-\mathbf{- 0 . 0 8 5} \\
(0.12) \\
\end{array}$ & $\begin{array}{c}-\mathbf{- 0 . 0 9 5} \\
(0.12) \\
\end{array}$ & $\begin{array}{l}-\mathbf{- 0 . 0 1 9} \\
(0.08) \\
\end{array}$ & $\begin{array}{l}\mathbf{0 . 0 0 1} \\
(0.11) \\
\end{array}$ & $\begin{array}{l}\mathbf{- 0 . 0 1} \\
(0.12) \\
\end{array}$ & $\begin{array}{l}\mathbf{- 0 . 0 0 1} \\
(0.12) \\
\end{array}$ & $\begin{array}{l}\mathbf{0 . 0 3 1} \\
(0.08) \\
\end{array}$ & $\begin{array}{c}\mathbf{0 . 1 1 7} \\
(0.1) \\
\end{array}$ & $\begin{array}{c}\mathbf{0 . 1 1 5} \\
(0.1) \\
\end{array}$ & $\begin{array}{l}\mathbf{0 . 0 6 1} \\
(0.11) \\
\end{array}$ & $\begin{array}{l}\mathbf{0 . 0 4 6} \\
(0.13)\end{array}$ & $\begin{array}{l}\mathbf{- 0 . 0 3 5} \\
(0.16) \\
\end{array}$ & $\begin{array}{c}\mathbf{- 0 . 0 5 4} \\
(0.16) \\
\end{array}$ & $\begin{array}{c}\mathbf{- 0 . 0 5 3} \\
(0.16) \\
\end{array}$ \\
\hline $\begin{array}{l}\mathrm{N} \\
\text { chi2 }\end{array}$ & $\begin{array}{c}423 \\
21.03 \\
\end{array}$ & $\begin{array}{c}375 \\
35.06 \\
\end{array}$ & $\begin{array}{c}375 \\
29.32 \\
\end{array}$ & $\begin{array}{c}372 \\
18.35 \\
\end{array}$ & $\begin{array}{c}425 \\
19.81 \\
\end{array}$ & $\begin{array}{c}405 \\
13.14 \\
\end{array}$ & $\begin{array}{c}386 \\
11.94 \\
\end{array}$ & $\begin{array}{l}377 \\
12.1 \\
\end{array}$ & $\begin{array}{l}425 \\
15.9 \\
\end{array}$ & $\begin{array}{l}405 \\
11.4 \\
\end{array}$ & $\begin{array}{c}386 \\
10.66 \\
\end{array}$ & $\begin{array}{c}377 \\
15.33 \\
\end{array}$ & $\begin{array}{c}273 \\
15.54 \\
\end{array}$ & $\begin{array}{c}289 \\
22.79 \\
\end{array}$ & $\begin{array}{c}289 \\
22.96 \\
\end{array}$ & $\begin{array}{c}287 \\
24.54 \\
\end{array}$ \\
\hline
\end{tabular}


Table 5: Results for ROE models testing missing values in Network 2003

\begin{tabular}{|c|c|c|c|c|c|c|c|c|c|c|c|c|c|c|c|c|}
\hline \multicolumn{17}{|c|}{ ROE models } \\
\hline & \multicolumn{4}{|c|}{ With Observed Network 2003} & \multicolumn{4}{|c|}{ With Network 2003_1 } & \multicolumn{4}{|c|}{ With Network 2003_2 } & \multicolumn{4}{|c|}{ Without Network 2003} \\
\hline $\begin{array}{l}\text { Social } \\
\text { Capital } \\
\end{array}$ & Model 1 & $\begin{array}{c}\text { Model } \\
2\end{array}$ & $\begin{array}{c}\text { Mode } \\
13\end{array}$ & $\begin{array}{c}\text { Model } \\
4\end{array}$ & $\begin{array}{c}\text { Model } \\
1\end{array}$ & $\begin{array}{c}\text { Model } \\
2\end{array}$ & $\begin{array}{l}\text { Mod } \\
\text { el } 3\end{array}$ & $\begin{array}{c}\text { Model } \\
4\end{array}$ & $\begin{array}{c}\text { Model } \\
1\end{array}$ & $\begin{array}{c}\text { Model } \\
2\end{array}$ & $\begin{array}{c}\text { Model } \\
3\end{array}$ & $\begin{array}{c}\text { Model } \\
4\end{array}$ & $\begin{array}{c}\text { Mode } \\
11\end{array}$ & $\begin{array}{c}\text { Model } \\
2\end{array}$ & $\begin{array}{c}\text { Model } \\
3\end{array}$ & $\begin{array}{c}\text { Model } \\
4\end{array}$ \\
\hline \multirow[t]{2}{*}{ Degree } & $0.05 * *$ & -0.03 & $-0.08 *$ & $-0.08 *$ & 0.01 & -0.05 & $-0.1 * *$ & $-0.1 * *$ & 0.011 & -0.017 & -0.044 & $-0.06 *$ & 0.026 & -0.036 & $-0.1 * *$ & $-0.1 * *$ \\
\hline & $(0.02)$ & $(0.03)$ & $(0.04$ & -0.04 & -0.019 & -0.029 & -0.04 & -0.04 & -0.016 & -0.022 & -0.028 & -0.03 & -0.02 & -0.034 & -0.044 & -0.044 \\
\hline \multirow[t]{2}{*}{ Degree sq. } & $-0.01 * *$ & 0.001 & 0.004 & 0.004 & -0.001 & 0.003 & 0.005 & 0.005 & -0.001 & 0.001 & 0.002 & 0.003 & -0.01 & 0.001 & 0.006 & 0.005 \\
\hline & -0.004 & -0.002 & -0.003 & -0.003 & -0.003 & -0.003 & -0.01 & -0.003 & -0.002 & -0.002 & -0.002 & -0.002 & -0.01 & -0.003 & -0.004 & -0.004 \\
\hline \multirow{2}{*}{$\begin{array}{l}\text { Clustering } \\
\text { coef. }\end{array}$} & -0.013 & -0.034 & -0.041 & -0.039 & 0.02 & -0.018 & -0.03 & -0.025 & -0.048 & -0.054 & -0.058 & -0.065 & -0.01 & -0.038 & -0.051 & -0.046 \\
\hline & -0.047 & -0.049 & -0.049 & -0.049 & -0.05 & -0.054 & -0.05 & -0.054 & -0.041 & -0.046 & -0.046 & -0.046 & -0.05 & -0.06 & -0.05 & -0.057 \\
\hline \multirow[t]{2}{*}{$\begin{array}{l}\text { Between.c } \\
\text { entr. }\end{array}$} & -0.04 & -0.05 & -0.004 & -0.03 & 0.001 & -0.001 & -0.01 & -0.002 & 0.001 & 0.001 & 0.001 & 0.001 & 0.004 & 0 & -0.002 & -0.002 \\
\hline & -0.07 & -0.07 & -0.007 & -0.07 & -0.006 & -0.006 & -0.01 & -0.006 & -0.002 & -0.002 & -0.002 & -0.002 & -0.01 & -0.01 & -0.01 & -0.01 \\
\hline \multirow{2}{*}{$\begin{array}{l}\text { IND } \\
\text { heteroph }\end{array}$} & & $0.2^{* *}$ & $0.2 * * *$ & $0.3 * * *$ & & $0.2^{* *}$ & $0.2^{* *}$ & $0.2^{* *}$ & & $0.16 * *$ & $0.16 * *$ & $\begin{array}{c}0.19 * * \\
*\end{array}$ & & $0.2^{* *}$ & $0.3 * * *$ & $0.3 * * *$ \\
\hline & & -0.088 & -0.091 & -0.091 & & -0.084 & -0.08 & -0.08 & & -0.068 & -0.068 & -0.072 & & -0.093 & -0.096 & -0.097 \\
\hline \multirow[t]{2}{*}{$\begin{array}{l}\text { Ftype } \\
\text { heter. }\end{array}$} & & -0.079 & -0.07 & $-0.14 *$ & & -0.071 & -0.07 & -0.069 & & -0.084 & -0.085 & -0.107 & & -0.028 & -0.02 & -0.095 \\
\hline & & -0.067 & -0.067 & -0.081 & & -0.066 & -0.07 & -0.066 & & -0.064 & -0.064 & -0.066 & & -0.07 & -0.07 & -0.085 \\
\hline \multirow{2}{*}{$\begin{array}{l}\text { Region } \\
\text { Homoph }\end{array}$} & & $0.04 *$ & 0.02 & $0.04 *$ & & $0.07 *$ & 0.034 & 0.035 & & 0.045 & 0.01 & 0.016 & & 0.053 & 0.023 & 0.031 \\
\hline & & -0.02 & -0.042 & -0.012 & & -0.04 & -0.04 & -0.043 & & -0.038 & -0.042 & -0.042 & & -0.042 & -0.04 & -0.044 \\
\hline \multirow[t]{2}{*}{$\begin{array}{l}\text { Partners` } \\
\text { asstes }\end{array}$} & & & $0.01 *$ & $0.02^{*}$ & & & 0.06 & 0.06 & & & $0.007^{*}$ & 0.016 & & & $\begin{array}{c}0.009 * \\
*\end{array}$ & $0.017 *$ \\
\hline & & & -0.004 & -0.008 & & & -0.04 & -0.04 & & & -0.004 & -0.014 & & & -0.004 & -0.04 \\
\hline \multirow{2}{*}{$\begin{array}{l}\text { Partners } \\
\text { export }\end{array}$} & & & & 0.007 & & & & 0.002 & & & & 0.004 & & & & 0.008 \\
\hline & & & & -0.005 & & & & 0.001 & & & & -0.003 & & & & -0.005 \\
\hline \multirow[t]{2}{*}{ _cons } & $0.7 * * *$ & $0.7 * * *$ & $0.7 * * *$ & $0.7 * * *$ & $0.7 * * *$ & $0.7 * * *$ & $\begin{array}{c}0.7 * * \\
*\end{array}$ & $0.72 * * *$ & $0.6 * * *$ & $0.7 * * *$ & $0.7 * * *$ & $0.7 * * *$ & $\begin{array}{c}0.6^{* *} \\
*\end{array}$ & $\begin{array}{c}0.67 * * \\
*\end{array}$ & $\begin{array}{c}0.71 * * \\
*\end{array}$ & $\begin{array}{c}0.71 * * \\
*\end{array}$ \\
\hline & -0.045 & -0.05 & -0.054 & -0.054 & -0.042 & -0.05 & -0.05 & -0.053 & -0.042 & -0.045 & -0.046 & -0.047 & -0.05 & -0.054 & -0.057 & -0.057 \\
\hline$\overline{\mathrm{N}}$ & 546 & 546 & 546 & 544 & 613 & 546 & 538 & 537 & 613 & 546 & 538 & 537 & 4440 & 4440 & 440 & 439 \\
\hline chi2 & 23.07 & 29.99 & 33.07 & 35.69 & 22.9 & 31.14 & 31.39 & 31.57 & 24.197 & 30.68 & 32.42 & 34.38 & 24.12 & 31.44 & 36.19 & 39.06 \\
\hline
\end{tabular}


Part III: Firm Innovation

CHAPTER

\section{FIRM INNOVATION: INNOVATION SURVEY \\ RESULTS}




\subsection{Introduction}

This chapter reports the methodology and the results of an Innovation and Collaboration Survey conducted among Armenian firms. The survey design and the development of the questionnaire are crucial aspects of this research that aimed to construct various new measures and extract information on firm innovativeness. To our knowledge this was the first firm-level innovation survey conducted in Armenia. ${ }^{45}$ During the pilot and questionnaire design stage we have collaborated with the Ministry of Economy and the AM Partners consulting company under the framework of the World Bank project on "Innovation Readiness Survey in Armenia".

The main research interest of this study is to measure the effect of social capital (board network) on firm performance and innovation. Part 2 (Chapters 4-6) is focused on conceptualization and estimation of social capital effects on firm financial performance, where we used ten year panel data to collect data on firm financial performance. As data related to the firm's innovation were not available for Armenia, we needed to initiate our own innovation survey. We went beyond our initial research questions, and developed instruments for conducting the first Innovation and Collaboration Surveys in Armenia, which is critical for a country that prioritizes a knowledge-based-economy approach.

Chapter 2 in Part 1 laid the groundwork for understanding the transition of the Armenian Innovation System from a planned to a market economy, and described the macro environment. In contrast, Part 3, which includes Chapters 7, 8 and 9, focuses on firm level innovation. Chapter 7 discusses the survey questionnaire and collection of the data, and Chapter 8 presents descriptive analysis of the survey data. Chapter 8 mainly focuses on extending our conceptual framework and testing our hypotheses relating firm innovation and board networks. The firms that we focused on are the same privatized open joint stock companies that we studied in Part 2. We conducted the survey among those firms (Chapters 8 and 9). We discuss details on sampling in the survey implementation part (see section 7.4).

The development of the survey instruments was one of the most challenging parts of this study. We examined various questionnaires established both for developed and developing countries, and concluded that Community Innovation Survey (CIS) type questionnaires are most appropriate for this study; however, some changes have been made. The questionnaire design and the actual survey implementation were very distinct: first, we knew that Armenian firms in general operate poorly and are not familiar with an innovative culture; second we were not sure how many firms, from our initial selection (1999), survived to the time of the survey implementation. Given these constraints, we decided to develop the questionnaire based on the responses of the leading companies in the country. Therefore, the survey implementation passed through two main phases:

${ }^{45}$ Only in 2012 and 2013 World Enterprise Survey added Innovation Module Questions for their regular questionnaires in Armenia. 
1. Interviews with leading companies and revision of the questionnaire

2. Interviews with previously selected companies (our target companies)

In both cases the survey was conducted using face-to-face interviews.

In Section 2 we discuss the survey instrumentation. Section 3 presents the questionnaire design (see Appendix $G$ for the full questionnaire) and Section 4 provides the phases of the survey implementation. This survey used structured questionnaires as a data collection instrument. Though the survey was cross-sectional, we also included retrospective questions, in order to have information on the firm's dynamics for the period 2000-2010. We conducted face-to-face interviews with the top management of the firms. This multiple data collection technique greatly enhanced the response rate. Section 5 gives some insights on how we can improve the survey methodology considering Armenian firms' specificities, and firm expectations from the survey. The final section draws conclusions from the survey instrumentation and interprets the responses in light of the country's innovation system.

\subsection{Instrumentation}

Innovation is a complex process that involves various actors. Our approach looks at the firm's innovation as a comprehensive phenomenon, and considers the role of different components in the innovation process. Following the Oslo Manual's recommendations we also emphasize the role of firms' linkages with other actors and institutions in the innovation process, as well as considering innovation in industries that are not R\&D intensive (OECD 2005). In our questionnaire we focused only on product and process innovation, and we did not develop questions targeting organizational and marketing innovation. The reason for this decision was that even though those aspects of innovation are very important they were situated beyond our research interests. Hence, we limited our agenda to the firm's product and process innovation.

Our survey covers all the industries in Armenia; therefore we were challenged to develop a questionnaire that would accommodate a broad range of industries including high and low technology industries. Continuing traditions developed in the Oslo manual, this survey provides indicators for innovation output such as the introduction of new products or processes, and whether those innovative outputs are new to the market or to the firm. Further, it also includes questions related to innovation expenditures such as personnel training, motivation schemes, etc., and hence, does not limit the concept to only $R \& D$ expenditures. The survey also provides information about the way innovation proceeds: the sources of knowledge, linkages, search for partners, role of the government and barriers for innovation.

Data collected from Community Innovation Surveys are subjective in nature as they depend on the judgments and knowledge of the respondents. In some cases respondents may over-evaluate the importance and the value of a new product, and sometimes they understand "innovation" in the context of technological innovation, therefore underestimating the value of their new products. 
Previously we have mentioned that Armenian firms vary in terms of their understanding of "innovation culture", which is reflected in the survey results. First, as there is a need to explain the questions and concepts, interviewers should talk more about the context and conceptual framework of innovation, and what the concept of "innovation" actually means. Second, some firms operate very poorly in terms of any kind of innovative activities, and informal components dominate; therefore it is hard for the respondents to provide precise answers on R\&D teams and expenses.

The questionnaire is designed for firms operating in the formal sector, and those who are engaged in formal innovative activities. In order to test the questionnaire we selected 40 leading companies in Armenia. We selected two firms for each industry located in Yerevan, and the rest from other regions. The first stage of testing the survey instrument provided us the opportunity to have a more realistic view of the difficulty of the questions, and whether they were suitable for all industries. Based on the survey and interview results, we revised the questionnaire.

\subsection{Questionnaire design}

The questionnaire includes five main parts:

Part A - Firm structure and characteristics, and markets

Part B - Innovative performance such as product and process innovations

Part C- Innovative and R\&D activities and expenditures

Part D- Cooperation and Collaboration

Part E - External environment such as economic and innovative environment, institutional fragility, constraints on innovation

The order of different topics in the questionnaire was designed in a format to achieve the most accurate and useful information. We put some questions at the end of the questionnaire such as information about their sales and turnover because firms were very reluctant to share this type of information in the beginning of the interview. There was a better chance to receive answers to these questions after gaining their trust in the rest of the questions. In total the questionnaire covers 9 sections, where Part A corresponds to section 1 and 13, Part B is covered by section 2 and 3, Part C is associated with section 4 and 5, Part D with section 6, Part E with section 7 and, finally, Part F includes section 8, 9 10, 11 and 12.

The data collected through the survey provides both quantitative and qualitative indicators for innovation. The questionnaire combined closed and open questions: ranking, multiple choice or descriptive e.g. detail description of the innovative products. However, the focus of the study is to collect cross-sectional data with some retrospective questions (incorporating questions for past 10 years period) for the application of the quantitative methods.

Section A - Firm's structure and characteristics, and markets 
The objective of the first part is to collect background information about the firms and the markets in which they operate. The size and economic activity of the firm provide initial understanding about its performance. This part also includes information about the firm's major markets. The following questions are included in this part:

Q1.1 General Information about the firm

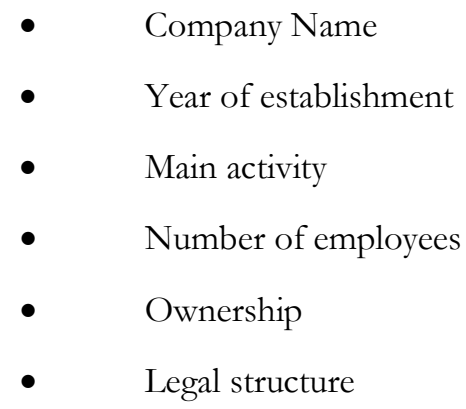

Year of establishment is the year when the firm was privatized. Firm ownership includes information about whether the firm has foreign, local or state participation. Legal structure specifies the firm's current status, as even though our initial selection was based on Open Joint stock companies, we do expect some changes mainly because our selection was based on the firm's status in 2005 .

Q1.2 Whether the firm is a part of an enterprise group.

Q1.3 Information on geographic location of the firm's markets; in this question we distinguish 6 main categories: Armenia, USA and Canada, CIS and Russia, European countries Middle East and the rest.

Q1.4 Firm's largest geographic markets for sales in 2008, 2009 and 2010.

Q1.5 Distinguish firms into two "innovators" and "non-innovators."

Q13.1 Total turnover for 2008, 2009, 2010

Q13.2 Number of employees in 2008, 2009, 2010

Part B - Innovative performance such as product and process innovations.

In this section questions collect information on the firm's innovative performance. The questionnaire uses the broad definition of "innovation" as identified in the Oslo Manual (2005), but it only focuses on product and process innovations. To capture the firm's innovative performance we use the indicator of how many new or significantly improved products or production methods occurred for the study period. It is important to make a distinction between product and process innovation, although in some cases it was hard to find a border between them. We group questions separately for product and process innovations, and follow Oslo Manual's guidelines for their definitions.

Another indicator for the firm's innovative performance is the degree of innovativeness. The Oslo Manual (2005) defines three degree of "newness" in the 
following ways: first degree is an entry level innovation when technologies embodied in the new product are new to the firm, second degree measures newness by its application in the market, and the third degree is when innovation refers to new to the world. A first-degree product or the process innovation may already have been in the market and used by other firms, but it must be the first time it is used by the firm. Second-degree innovation is "new to the market" when the firm first develops the process or product that no other firm has produced or applies in that specific market. This indicator also helps to identify market leaders and adopters. The third dimension is the world level innovation, when a firm is the first to introduce the innovation for all markets indicating that this innovation has greater impact than "new to the market" innovation. In our questionnaire we capture the degree of innovation by asking whether it is new to the firm or market, then it also includes the option to specify whether this refers to the Armenian or foreign market.

This section also includes retrospective questions, which ask about the frequency of the firm's innovative performance in preceding years. We have excluded questions on patents, because patenting was not a popular strategy for firms in Armenia. In the pilot stage when we interviewed the leading firms, questions on patents were included in the questionnaire. However, survey results show that even leading firms in Armenia do not have patents, nor did they apply for patents. Before revising the new questionnaire we have requested information at the National Patent Office in Armenia. According to them, only a few state universities have applied for and were granted patents, and in general firms do not apply for patents.

Q 2.1 Number of new or significantly improved products and services for the period of 2008-2010.

Q2.2 Provides information on the firm's innovative inputs for each product or service innovation, as well measures the intensity of the innovation. Firms could develop new products or services based on their own capabilities or through collaboration or external knowledge. Firm's product or service innovation intensity is measured by indicating whether the innovation was new to the firm or to the market.

Q2.3 Percentage of sales from new or improved products and services from 2008 to 2010

Q2.4 Indicates the frequency of firm's innovative activities for the period of 20002010. We have no prior information about firm's innovative activities, and this retrospective question provides some insight on whether the firm was innovative or not in the previous years.

Q3.1 Number of new or significantly improved productions or methods for the period of 2008-2010.

Q3.2 Firms' capabilities for developing process innovation, and the degree of innovativeness (new to the market or new to the firm).

Q3.3 Collects retrospective information on the frequency of the firm's innovativeness over the past 10 years.

Part C - Innovative activities and R\&D and expenditures 
This section aims to gather information on types of innovation activities firms engage in and the kind of resources they use for innovation. Innovation activities include capital purchases, external or in-house $R \& D$ activities and the availability of human resources; these indicate how well the firm can absorb new knowledge and innovate. This section provides quantitative measures on innovation expenditures and identifies the factors that enhance the firm's ability to innovate. This is important because it captures the firm's strategy to develop resources and which activities to initiate in order to have a higher innovative performance. The quantitative measures on expenditure along with output measures may also help to calculate returns to innovation activities. This section facilitates the examination of the firm's in-house resources such as its $\mathrm{R} \& \mathrm{D}$ team.

Q4.1 Asks for precise information about expenditures for innovation activities such as R\&D, capital purchases, investment in new knowledge, training of personnel and financial and commercial steps.

Q4.2 Asks details about personal training and how it is financed.

Q4.3 Information on public financial support during 2008-2010.

Q5.1-3 Details about R\&D types and spending for 2008, 2009 and 2010.

Q5.4 Size of the R\&D team.

Part D - Cooperation and Collaboration, Sources of Information

Collaboration is an important part of innovative activities, and therefore we paid particular attention to type of actors, and geographic location. This section of the questionnaire provides the basis of the firm's networking strategy. Linkages are an important source for information and knowledge. The character of the collaborations and linkages created by the firm may provide the firm with new resources, knowledge and technology as well with business practices. Collaborative partners may vary; they can be other firms, suppliers, clients, universities and public research institutes. They can also vary by their geographic location. Content of collaboration may also be different: R\&D collaboration, knowledge networks, internship, and training. The information provided by this section identifies how transfer of knowledge and technology take place, what are the main sources of knowledge and technology flows for the firm, and what strategies the firm used to find or select partners.

Q6.1 Collects data on board member for 2008-2010 (if the firm is still OJSC).

Q6.2 Distinguishes the type of collaboration into collaboration with other firms, supplier, clients, commercial labs and R\&D institutes, universities and government or public research institutes, and then it asks the geographic location of the partner.

Q6.4 Collects information on the type of collaboration with partners in Armenia and abroad and includes a separate set of questions for collaboration with universities.

Q.7.1 Asks questions on the importance of certain sources of information:

- Internal 
- Market

- Institutional

- Other, such as conferences, scientific journals and professional associations.

Part E - External environment such as economic and innovative environment, institutional fragility

This last section of the questionnaire collects data on the importance of innovation, external factors that influence the firm's decision to innovate and factors that hampered innovation in Armenia from the perspectives of the firm. There are a number of macroeconomic factors that determine the incentives to innovate in developing countries such as lack of human capital, availability of finance, macroeconomic uncertainty, and lack of legal regulations. Armenia is characterized by its small local market, which affects things in two ways: first, a lack of competition and the dominance of large companies drains innovative potential, and second, the less developed market infrastructure reduces the incentives to innovate on a world scale, which in turn may affect the interpretation of "new to the market" innovation as referring to that which is new to the Armenian market. This section collects data on whether the firm is aware of or benefiting from any public policies aiming to increase innovative potential in Armenia. Protection of innovation is also an important aspect for the examination of the innovative environment for the firms in Armenia. This is still a very weak institution in Armenia, and may discourage a firm from innovating.

Q8.1 Asks about the objectives to develop products or process innovation for the period of 2008-2010

Q9.1 Asks which methods the firm used to protect the innovation.

Q10.1 Asks about ongoing innovation projects.

Q11.1 External factors hampering the innovation.

Q.12.1Reasons for not innovating.

\subsection{Survey Implementation}

The implementation of the questionnaires was carried out in March 2011 for the pilot survey and September 2011-June 2012 for the countrywide survey. The pilot phase was designed for a small sample of firms, and it aimed, mainly, to test the questionnaire. The implementation of the countrywide survey took longer, because we were collecting updated information on firms' new locations and addresses (our target firms were publicly listed companies from 1999 to 2005). The seasonal aspect was another challenge for the survey implementation: some regions in Armenia are difficult to access in the late autumn and winter period and higher response rates required faceto face interviews. Therefore, we adjusted our interviews to take place during a more convenient period.

Telephone contact was the first step in organizing and conducting interviews. Most of the time, managers or CEOs of the companies agreed to accept the interviews, but 
sometimes they also requested to view the questionnaire beforehand. After the main interview, a call back phase was also implemented in order to pursue a completed questionnaire. The coding of variables was done at the end.

\section{Phase 1: Pilot Survey}

In total, 40 face-to-face interviews were implemented for the pilot stage. As the main objective of the pilot stage was to develop the questionnaire, two leading companies from each sector were selected. We mentioned earlier that for this stage we contributed to the World Bank's project on "Armenian Enterprise Innovation Readiness Survey". The final report of the project gives details. In this chapter we will only highlight important points, and why this phase was important for our research. In total 41 firms were selected and only 4 refused to participate in the survey.

1. Mining and quarrying

2. Agro, food and beverage production

3. Apparel, garment and leather

4. Manufacture of chemicals, chemical products

5. Manufacture of machinery and equipment

6. Manufacture of wood products

7. Construction

8. Manufacturing of the pharmaceuticals

9. Science and research organizations

This sample provided us with an opportunity to test the survey instrument among most successful firms, covering all industries in Armenia, so that based on the results we could conclude whether the survey instrument was suitable for all industries and covered all relevant information on firm innovative activities.

During this phase special attention was paid to the smoothness of the answers. Some questions turned out to be difficult for respondents. Most of the firms did not have details on $\mathrm{R} \& \mathrm{D}$ teams and expenditure; it was very hard to extract this information. Some firms were very reluctant to answer the questions of the firm's turnover and number of employees. They also suspected that the interviewers might represent their competitors or share the information with them. In addition, we should acknowledge that the meaning of the innovation is understood differently in the developing countries. The majority of the firms are not in the technology frontier, and sometimes, minor innovation or imitation was perceived as a major innovation for the firm. And sometimes firms understood innovation only as a narrow and "technological" concept; as a result they underestimated their innovative capacity by comparing themselves with world leaders. We discussed already the "subjective" character of the innovation survey data; however it is important to mention that this was the first innovation survey in Armenia, and the interviewers' explanations on survey concepts and questions are an important aspect for consideration. Hence, proper training of interviewers was essential for the successful survey implementation. For the 
countrywide survey, five interviewers were trained to conduct the interviews. The average interview length was 40-80 min.

\section{Phase 2: Countrywide Survey}

After revision of the questionnaire, we started the countrywide survey. There were two main considerations for the organization of the survey: the first factor is related to the supplementary databases that we have collected. The first database was based on archive materials for the period of 2000-2005, which provides the list of the OJSCs we were interested in studying. The second database contains information on the firm's finance and location for 2000-2010. These two databases played an essential part in the selection of the firms for interviews. The second factor is the seasonal aspect: the geographic specification of some regions during winter, holidays and the tax reporting periods for financial year were the main constraints for conducting interviews in time. ${ }^{46}$

\section{Phase 3: Coding of the variables}

This phase started after the collection and correction of all questionnaires. We have coded 100 variables and created a glossary of definitions of all variables (see Appendix $\mathrm{G})$ that includes count, date, binary, categorical variables, in some cases also descriptive text.

\section{Phase 4: The data}

It was a challenging process to make a final selection of the firms for this survey. The initial aim of this research was to trace the "destiny" of the companies that were privatized and announced as publicly listed companies. However, this criterion has changed since 2005, and we used alternative ways to find information on those firms. ${ }^{47}$ First, we selected the firms from the latest database on publicly listed companies in 2005. Second, we updated the data on those firms from the new dataset that was available from Revenue Ministry. The second database enabled us to update information on firms' locations and addresses. We selected 221 firms from the 2005 list; however, we could find only 200 firms, and only 192 responded to our questionnaire (21 firms from our initial sample were closed in 2010 and two firms refused to participate in the survey).

Data cleaning was done and the firms were contacted to clarify missing data and mistakes. The analysis of the survey data is provided in Chapter 8.

\footnotetext{
46 Armenia is a mountainous country, so during the winter roads are closed and some regions are not accessible; August, the end of December and the beginning of January are holidays or vacation periods, and usually it is hard to arrange appointments during these times.

${ }^{47}$ See "Law on Securities Market" in 2007.
} 


\subsection{Lessons we learn through first Innovation survey in Armenia}

\subsubsection{Instrumentation and Interviews}

We chose a Community Innovation type survey to collect information on firm level innovation. Our prior investigation which included meeting with almost all key stakeholders in Armenia related to innovation, industrial and science policies showed that there were no established innovation-related surveys in Armenia until 2010-2011. The World Bank had intended to add an innovation module to their enterprise survey, and therefore they launched the "Innovation Readiness Survey in Armenia" pilot project to test and develop instruments to study firm level innovation. As a result, the additional module of questions was added to the Enterprise Survey questionnaire in 2012.

Many questions in our questionnaire partially overlap with the World Bank's Innovation Readiness Survey; however, some important questions were only included in our survey: especially the part on collaborations, which was initiated to cover our research interests. Another difference between our survey and the World Bank's survey is the target firms: in our case, we targeted specific companies to construct longitudinal data, while the World Bank's survey focused on leading companies and the IT sector. Incorporating the results of the pilot and the countrywide survey, the final results provide sufficient interviews to represent all industry sectors and generalize the findings. In addition, this survey developed an instrument for better understanding the firm Innovation in Armenia.

Why did we choose a CIS type survey? One of the main reasons was to apply a survey instrument that can provide comparability of data across countries. The problem of comparability of the data for CIS has been addressed by many researchers (Gault 2015), and statistical offices responsible for CIS implementation have gradually improved survey methodology and questions to make data more comparable. Our departure point was the examination of the most recent CIS questionnaires at the time of the questionnaire design ${ }^{48}$ that will allow the data to be made more comparable with the results of other CIS surveys implemented in other countries. Our goal was to contribute to the development of the survey methodology in Armenia for the collection of countywide quantitative data on firm innovation. But in doing so, we should also acknowledge that self-reporting innovation surveys are very subjective in nature. To minimize or at least to understand what type of bias can occur, we also implemented cognitive interviews as a part of survey. ${ }^{49}$ The goal of cognitive testing is to ensure that the respondent understood the questions, and is able to provide valid answers.

\footnotetext{
${ }^{48}$ We have used all available questionnaires in 2010, including the draft of upcoming surveys. We paid special attention to CIS type questionnaires designed for developing countries such as the South African National Innovation survey 2005. We also reviewed the questions used by researchers at UNU-MERIT (e.g. Biotech Firm's Survey in Argentine [2008] by Lilia Stubrin, Survey of ICT firms in Pakistan by A.B Qazi)

${ }^{49}$ Guide to conduct cognitive interviews of survey questionnaires, A. van Cruysen and A. Arundel, 2010 UNUMERIT
} 


\subsubsection{The Concept of Novelty}

Innovation surveys were new to Armenia, and the interpretation of the concept of innovation varies from one person to another. This might be also the case in other countries, ${ }^{50}$ but what we found in Armenia can be interpreted from the perspective of a transition country. During the soviet era, Armenia was a highly industrial country with a large proportion of scientists and many research institutes. In general, fundamental sciences were very developed in post-soviet countries (it is not surprising that after the collapse many famous physicists and chemists were employed in the best universities in developed countries), but surprisingly the level of applied science and production was far behind the technological frontier. After the collapse, countries were challenged to modify their production and survive in a new environment. Most of the people in Armenia are aware of, and have capabilities to understand, knowledge at the frontier, but have limited capabilities to apply and produce at that level. As a consequence, they have very a technological or "narrow" view on the concept of innovation. For example, respondents might report no innovation based on the fact that they did not apply for a patent. By contrast, there are some managers or CEOs that have limited knowledge on their firm's production and technology level, despite owning the firm; these types of people tend to exaggerate the level of novelty. To sum up, we had a wide spectrum of cognitive characteristics of the respondents: from very scientifically oriented to not at all knowledgeable about the actual technology existing in their market.

There were several ways we controlled for the cognitive characteristics of the respondent in order to ensure that we received accurate answer to each questions:

First, the interviewer needed to explain the broader concept of innovation: very often, we asked them to describe their production or product and by asking supportive questions, the respondent was able to identify the level of novelty of the changes. A. Arundel et al. (see Gault 2014, Chapter 4) analyze the open question in CIS and conclude that $35.3 \%$ of non-innovators describe valid innovations.

Second, we asked questions about whether they participate in conferences or international exhibitions, in which markets they operate (if it is foreign, then they are likely have better knowledge about existing technology in their industry). These questions could indicate how well the respondent (and the firm) was aware of the existing technology, especially if they report new to market innovation.

Third, we used multiple respondents for the firms. Very often we first communicated with the CEO and then the CEO indicated the person who was more suitable for this survey. The position of the respondent usually depended on the organizational structure. CEOs sometimes were the most efficient person for our questionnaire, but in general it was hard to set up meeting for one hour with the CEOs, especially in large companies. On the other hand, large companies are well organized, and either the financial manager or head of international department could answer our questions very

\footnotetext{
${ }^{50}$ Crespi and Zuniga (2012) found a higher percentage of innovators in developing countries vs. developed countries, which can be because in developing countries firms perceive incremental innovation as radical.
} 
accurately. Very often, during the interviews when the main respondent was not sure about his/her answer of a certain question, they would ask someone with more competency in that field to answer: e.g., engineers were requested to explain questions on innovation and $\mathrm{R} \& \mathrm{D}$, or chief accountant would answer to provide precise numbers for sales.

\subsubsection{Questions firms do not like}

In general, the response rate was satisfactory, as only 2 firms refused. However, response rates for individual question varied. The reasons for the poor response rate for certain questions are also different. Many studies report that it is very hard to get accurate numbers for R\&D expenditure, and our study was not an exception. One of the reasons could be that in many cases firms do not have a formal R\&D team or well defined $R \& D$ expenditures. Usually $R \& D$ expenditures are considered to be part of the firm's expenditures without clear distinctions, and salaries of scientists and engineers are also part of the expenditures on staff. As a result we have only few firms that have accurate answers - only 5\% firms that report R\&D expenditures provided us with a total amount in drams or in some cases as a percentage of the total turnover.

Firms are very suspicious and not willing to indicate names and firms with whom they collaborate. The survey includes questions on board members (this is usually public information) and on firms with whom they do collaboration. Unfortunately, again only a few firms provided the names of the board members. One of the reasons for their reluctance was that this information might become available to competitors. An interesting point is that they did not trust state agencies for collection of this type of data. We had to emphasize that this study was part of individual research for a university abroad, and to somehow assure them that it is less likely to disseminate this information in Armenia. Firms eagerly answered the "open" questions on their main geographic market, description of product and process innovation, information on engineers and training. But the firms were reluctant to answer "open" questions on their board members and collaborations, particular they avoid specifying the name of a partner firm. For closed and structured questions they provided very accurate answers.

One of the limitations of our questionnaire was that we did not include questions about organizational and marketing innovation, and therefore we can only draw parallels with product and process innovation.

\subsection{Conclusion}

This chapter introduces a unique data source on firm innovation reported by Armenian corporations. The results are of relevance both to research on innovative performance of the Armenian private sector and for how the first countrywide innovation survey was applied.

This chapter highlights the importance of survey design and indicator interpretation. The survey instrument was developed based on the EU Community Innovation Survey and the guidelines of the Oslo manual. As it was mentioned, previous studies show that the innovation culture of the country is an important factor that researchers 
should consider while interpreting the results (Gault 2015; Crespi and Zuniga 2012). One of the important aspects of innovation culture is how firms perceive the concept of novelty. As the survey is subject-based, it has subjective bias in the respondents' understanding of the innovation concept. The respondent's interpretation of the concept of novelty may mislead researchers to make a strong conclusion on country's innovative performance: Crespi and Zuniga (2012) found that in developing countries, firms tend to over-evaluate the importance of incremental innovation, reporting them as a radical. As a result, it affects the comparability of innovation survey results across countries. During our interviews, we found that most of the respondents interpreted innovation from the narrow view, reflecting the countries' past industrial development, while we used an open concept of innovation following the Oslo manual. However, there were also respondents that have limited knowledge about state of art technology.

Arundel (2014) analyses survey results through the coding of open-ended questions for the description of innovation, and found that they are important sources to check whether a firm is an innovator or not (Gault 2015, Chapter 4). Throughout our survey we also used open-ended questions, as well as some additional questions to test how the respondents perceived the concept of novelty, and whether they had knowledge about state of art technology used in their respective fields. Well-trained interviewers conducted all interviews, and in this regard, an interviewer was one of the key factors for successful innovation survey. 
CHAPTER

\section{PATTERNS OF INNOVATION OF PRIVATISED FIRMS: SOME INSIGHTS FROM THE FIRST INNOVATION SURVEY IN ARMENIA.}




\subsection{Introduction}

The performance of large privatized firms has been one of the most significant subjects of discussion by researchers and policy makers dealing with corporate change in transition countries. Institutional changes, including corporate governance as well as judicial reforms, the development of financial sectors and the capital market were followed by large-scale privatization in former USSR countries. Specific actions were taken by international donor organizations such as the World Bank, the European Bank of Reconstruction and Development and the United States Agency for International Development to strengthen the business sector by developing a competition policy, business support services, and so on. (Anderson 2006).

The goal of our Firm Innovation Survey is to examine how privatized large firms in Armenia are performing two decades after the collapse of USSR. The selected companies faced intense pressure to restructure, innovate and increase productivity. They faced an urgent need to adopt new technologies and produce new products, as the "soviet" products were labeled "obsolete".

This chapter lays the basis for the econometric analysis in the next chapter, but it will also provide analysis of the survey data, to cover the ground on the relationship between firm characteristics and firm innovative performance. The descriptive statistics of the survey data present a detailed picture of how various measures of innovation are correlated with a firm's industry, turnover, employment, exports and labor productivity. We have looked at empirical studies that used innovation surveys in both developed and developing countries. Comparison with other countries brings insight into how firm innovation in Armenia is different from or similar to other countries.

For the reference point we used several countries' case studies that rely on Innovation survey data (micro-data): a) Reports on Latin American countries and b) Innovation taxonomy of 22 European countries.

Developing countries: ${ }^{51} \mathrm{We}$ used reports and studies on developing countries such as cross-country comparisons in Latin America, which provide a better understanding of how differently or similarly Armenian firms innovate compared to other developing countries. The Latin American region was very quick to apply the first Oslo Manual and conducted its first innovation survey in 1995 (Crespi and Zuñiga 2010). Systematic empirical analysis of firm level data in this region has made a significant contribution in understanding innovativeness of developing countries and its specification compared to OECD countries.

Innovation Taxonomy: ${ }^{52}$ We also used the taxonomy of innovation regimes suggested by Peneder (2010), which analyzed Community Innovation survey from 22 European countries. We modified slightly this approach and apply it to our survey

\footnotetext{
${ }^{51}$ CEPAL (2011). National Innovation Surveys in Latin America: Empirical Evidence and Policy Implication. http://repositorio.cepal.org/handle/11362/3876

52 M. Peneder (2010). Technological Regimes and the Variety of Innovation Behaviour Creating Integrated Taxonomies of Firms and Sectors. WIFO working paper 362/2010
} 
data. This approach provides an opportunity to understand the innovation patterns that are typical for Armenian firms.

The analytical structure of this chapter relies on two main parts A) Taxonomy of innovation patterns and B) factors that correlate with firm innovation and R\&D.

The first part discusses the taxonomy and the main dimensions for our analysis. It follows with data description and detailed discussion for each dimension of the innovation taxonomy. This part provides some detailed information on the sample and compares it with the World Bank's enterprise survey statistics on Armenia to compare some of the features of the selected firms with a representative sample. ${ }^{53}$ It then gives detailed statistics on different dimensions of innovation regimes such as creative vs. adaptive behavior and knowledge accumulation, as well as how these measures are distributed in different industries and across firm sizes. Special attention is also paid to firms' export markets. We also discuss firms' R\&D and non-R\&D innovation activities such as the acquisition of machines, external knowledge and training. Another important dimension for the taxonomy is the analysis of firm linkages and cooperation for innovation; our survey also collects data on firm partners and the purpose of collaboration.

In the second part, we use regression methods to analyze firm characteristics that perform $\mathrm{R} \& \mathrm{D}$ and introduce product or process innovation. The highlight of this section is a multivariate analysis using a probit model to find correlations between firm innovation and firm-specific factors, and the relative importance of innovation capabilities such as R\&D and non-R\&D activities, past innovative performance, etc. These two approaches combined provide a robust view of innovation strategies that Armenian firms use.

\subsection{Taxonomy of Innovation Regimes}

Previous research has made significant efforts to classify national technological/innovation regimes across various countries. Some studies classify innovation regimes based on macro data (e.g., Godinho et al., 2005), some use microdata (e.g., Peneder, 2010). The latter is based on innovation survey data across European countries. We have followed Peneder's approach ${ }^{54}$, which was based on Community Innovation Survey data collected from 22 European countries. Another reason to choose Peneder's study is that his data is comparable to ours, and we will be able to draw some parallels. Our analysis within this section exploits the firm-level data with our Innovation Survey data on Armenian firms, which was designed following the Community Innovation Survey (OECD) type approach.

\footnotetext{
${ }^{53}$ The World Bank Enterprise survey used a weighted sample of all firms in Armenia for their analysis, which provides us with the opportunity to extract countrywide statistics on Armenian firms. In our case we target only privatized companies that were open joint stock companies from 2000-2005.

54 Pender used Community Innovation Survey data from 22 European countries, and divided them into Continental, South and North regions. He classified firms based on heterogeniety of innovation patterns, and then classified countries/regions based on distribution of various type of firms.
} 
The theoretical focus of Peneder (2010)'s approach lies in the distinction between Schumpeter's "creative" and "adaptive" responses, and differences of technological regimes under which the firm operates. He follow's Schumpeter's definition of creative firms, which are firms conducting their own innovation (i.e., firm initiated technological change through creating new products or processes). Peneder referred to "technological regimes" specified by Malerba and Orsenigo (1993), which were analyzed in terms of opportunity and appropriability conditions and the accumulation of knowledge, which together consist the innovating environment of the firms.

Starting with this approach, we modified it to fit it our data, and added other dimensions that are specific to the transition context. We look, for example, at the geographic location of exporting markets, which plays a key role in a firm's learning environment. This is vital, especially when a country is undergoing transition from its old innovation system to a new, market-oriented system. In general, export markets as well as linkages with advanced countries can provide an advantage in learning and adapting advanced technologies or performing technologically sophisticated innovations. But whether this in fact takes place may depend on whether the firm is exporting to leading or lagging regions. In our suggested taxonomy metrics, we also include innovation partners, which include universities and customers, for the related reason that they too can be a source of new technical knowledge. Another important aspect that we tried to address was economic value of innovation in the national innovation system. This particular dimension, we measure through sales growth and labour productivity growth.

We suggest 8 dimensions for the innovation taxonomy. Below we explain in detail each of those dimensions and indicators suggested for analyzing a firm's "innovation modes".

\section{Creativity vs. Adaptability}

Peneder (2010) starts with Schumpeter's distinction of firm responses into "creative" and "adaptive", where he distinguishes between a firm's pro-active behavior (creating and innovating) and adaptive responses to exogenous changes occurred in the market. "Creative" behavior Peneder considers innovation, which is new to the market. While he considers that "adaptive" behavior exists when either a firm introduces firm level innovation both product and/or process innovations, or it did not introduce any technological innovation but may have introduced other types of non-technological innovations such as organizational innovation.

In our approach, we captured these sentiments, and introduced measures applicable to our data. First, we used the following measure for the creative behavior - Innovating product or process, which is new to the market. Second, we identify the following adaptive behaviors: Introducing product or process innovation new to the firm and non-innovators. Noninnovating firms may pursue non-technological innovation, for example they may introduce new organizational strategies (Peneder, 2010). Yet, we did not collect data for other type of non-technological innovations, therefore we use non-innovator group similar to Peneder's study. 


\section{Opportunity}

This dimension indicates the "ease of innovating" given firms' technological readiness, which is measured by the firm's efforts invested in research (Peneder, 2010). Opportunity does not necessarily lead to an innovation; therefore here we consider how much effort a firm is investing to innovate: are there any important resources invested for introducing future innovation such as expenditure on R\&D or acquisition of machinery or rights (e.g., patents, trademarks). We slightly modified the measures that Peneder used, and following other studies on the taxonomy of innovating firms (e.g., Gokhberg et al., 2012), we used a categorical variable that includes types of R\&D and non-R\&D activities such as acquisition of technology that a firm undertakes to prepare for innovation. In this dimension, we distinguish following types of behavior of firm's opportunity to innovate: firms that conduct a) Continuous R\&D; b) In-house $R \& D$; c) External $R \& D$; d) Acquisition of machinery and e) no opportunity. The most sophisticated behavior is when a firm undertakes either continuous $\mathrm{R} \& \mathrm{D}$ or in-house $\mathrm{R} \& \mathrm{D}$, intermediate is when a firm is outsourcing $\mathrm{R} \& \mathrm{D}$, and the least sophisticated strategy is when a firm only invests in acquisition of machinery.

\section{Appropriability}

Peneder (2010) uses appropriability conditions to describe firms' activities to protect their innovations through various IP instruments. Firms that used a combination of various IP instruments are considered as high appropriability firms, while "none" is a category for the firms that do not use any. Appropriability is not relevant for Armenian context: most Armenian firms do not use any IP instruments due to the country's institutional environment. However, we still retain this section in our study, so that our results can be comparable (at the aggregate level at least). We should note that all firms have the same "performance", and will score "no appropriability" on Peneder's scale.

\section{Cumulativeness of Knowledge}

Peneder's "knowledge cumulativeness" refers to the relative importance of internal and external sources of knowledge for creative vs. adaptive firms. As "knowledge cumulativeness" is a very abstract concept, we capture it as a degree of accumulated knowledge of a firm, measuring the extent to which a firm has accumulated a lot of knowledge, possibly by having innovated a lot in the past. And a firm has higher chances to innovate, since it has accumulated a lot of knowledge through previous innovation. Following Peneder's approach exactly we measure the cumulativeness by looking at the importance of external vs. internal resources for innovation that creative and adaptive firms used. IN our schema, a firm has high cumulativeness if a) being creative and mentioning internal sources of knowledge very important; b) being adaptive and mentioning that external sources were more important for creation of new knowledge. Consequently, cumulativeness is low if a) a creative firm mentioned that external knowledge was more important than internal; b) an adaptive firm mentioned that internal resource was more important than external. 


\section{Schumpeterian competition}

In his study, Peneder didn't use firm size as a separate dimension; however we thought it is important to include firm size in discussing a country's innovation mode, especially when it is Armenia's the first innovation survey. Firm size is another important aspect for analyzing heterogeneity of actors in the system. Schumpeter was one of the first to argue that large firms operating in concentrated markets are the main engines of technological innovation. The relationship of firm size and innovation can be seen from two perspectives - R\&D and innovation output. We grouped firms into large, medium and small sizes, and looked at the distribution of innovative firms in these three groups.

\section{Sectoral classification}

This dimension looks at the sectoral level, and is simply a categorization of sectors according to firm innovation measured by both innovation input and output perspective. Slightly diverting from Peneder's (2003) approach ${ }^{55}$, we looked at the distribution of firm innovation/R\&D across industry sectors. We use a standard 9industry sectoral structure, describing sectors according to the aggregate degree of innovativeness of the constituent firms. This permits us to characterize sectors by the extent to which the firms in them are innovating in terms of introducing product or process innovation or conducting $\mathrm{R} \& \mathrm{D}$ activities.

This dimension is an important component of the national innovation system, especially when contrasting developed and developing countries, given that innovative patterns in sectoral distributions might be quite different.

\section{Export markets}

In addition to Pender's approach, we add this dimension to address the specification of transition context. We look at the geographic location of exporting markets, which has an important effect on how the Armenian national innovation system works. Exports become vital, especially when the country is undergoing transition from an old innovation system to a new, market-oriented system. As we discussed earlier, the Armenian national innovation system inherited soviet connections, which was reflected in its export markets - the main exporting markets are former-soviet (CIS) countries, which is likely not to provide either strong innovation incentives or knowledge or information conducive to modernizing products and processes. In contrast, firms exporting to advanced countries will have more incentives to acquire new knowledge or technology, and depending on the structure of the export relationships, possibly also have access to knowledge and competence that will facilitate adoption or innovation of new technologies and practices. We distinguish export markets by three regions - CIS (former soviet), Middle East and West (North America and Europe).

\footnotetext{
${ }^{55}$ Peneder (2003) classifies sectors according to four innovation type. Given our small sample size we used only two - Innovation and R\&D intensity dimensions.
} 


\section{Cooperation and Linkages}

Even though this aspect was not included in Peneder's analysis, but many reports analyzing national innovation systems (e.g., Annual report on Global Innovation Index, Garrido and Padilla 2011) discuss cooperation and linkages as an important factor for explaining innovation. The existing literature recognizes the importance of cooperation and linkages in technical change, and sees innovation as a collective outcome of interactions (Kline and Rosenberg 1986; Lundvall and Johnson 1994). Collaboration with suppliers, users, competitors, universities and research institutes enhances a firm's motivation and ability to innovate. Through cooperation, firms benefit from more efficient $R \& D$ investments, access to external resources, sharing costs, fostering knowledge transfer, etc. (Garrido and Padilla 2011). The importance of users or customers is well-recognized in developing new products and services (Gault 2015; Von Hippel 1986; Von Hippel 1994). Universities and research institutes also serve as important sources for a firm's innovation, as they develop basic and strategic research, which can successfully contribute to industrial innovation. It is also important to distinguish between local and foreign partners, especially for developing countries - collaboration with foreign partners provides access to knowledge that either does not exist or is poorly developed in the resident country. Through our survey we collect information about firm's partners, their types and whether they are local or foreign.

\subsection{Applying the taxonomy on the survey data}

Before addressing our Armenian data with this taxonomy, we briefly discuss the general properties of the data and the sample.

\subsubsection{Sample and representativeness}

The selection of the firms for the final sample was based on the database of publicly listed companies in Armenia gathered by the Central Bank. The number of firms for the period 2000-2005 was 224. ${ }^{56}$ Before starting our survey we updated the information on those firms using a database obtained from Ministry of Revenue. According to this database, 21 firms of the initial sample were not operating in 2010, therefore the number of targeted firms was reduced to 203, of which 192 responded to our survey. During the period of 2005-2010 some of those firms changed their legal status $-83.25 \%$ of the surveyed firms were still open joint stock companies, $10.47 \%$ were limited liability companies, and $6.28 \%$ were closed joint stock companies.

The majority of responding firms (96.8\%) do not belong to any enterprise group, while $1.6 \%$ belong to a group which has a head office in Armenia, $1.04 \%$ of firms report

\footnotetext{
56 According to the initial Law on Publicly Listed companies, which was from 1999-2005, companies were considered publicly listed open joint stock companies if they had more than 50 shareholders and the initial capital of $1 \mathrm{mln}$ AMD. These companies had to report to the Central Bank of Armenia about their financial situation, and provide information on Boards and CEO every year. After 2005 the Law was modified, and as a result number of companies reduced.
} 
having a head office in CIS countries and $0.5 \%$ of firms have a head office in EU countries.

Firm Size: Our sample consists of 48\% small firms (1-19 employees), 32\% medium size (20-99), and 20\% large firms (100 and above) (see Table 8-1). The average firm size of the selected firms in 2010 is 74.8 employees with standard deviation of 132.67 .57

To understand how our sample is similar to or different from the total population of Armenian firms, we used the data of the World Enterprise Survey, which represents a weighted sample of all firms in Armenia. We found that our sample has a very similar distribution of firm size to that of the Enterprise Survey data (2009), which indicates that our sample is representative. One comment: in our sample, the proportion of larger firms is somewhat higher than in the random sample. We also notice the apparent reduction of large firms in between the two WB surveys, which could be a result of the 2009 economic crisis.

Table 8-1: Firm size distribution

\begin{tabular}{|l|l|l|l|}
\hline Firm size & Our survey (2010) & WB survey $(2009)$ & WB survey $(2013)$ \\
\hline Small & $48 \%$ & $53 \%$ & $46 \%$ \\
\hline Medium & $32 \%$ & $32 \%$ & $38 \%$ \\
\hline Large & $20 \%$ & $15 \%$ & $13 \%$ \\
\hline
\end{tabular}

\subsubsection{Creativity and Adaptability}

\section{Product and Process Innovation}

To measure innovative output we used only product and process innovation. ${ }^{58}$ In our sample, $47 \%$ of firms reported to have either product or process innovation between 2008 and 2010, and among the innovators almost 90\% reported to have at least one product innovation, very few reported service innovation, and about $60 \%$ report process innovation. Nearly $43 \%$ of all surveyed firms are product innovators, $27 \%$ are process innovators, and 60\% report both types. A cross country comparison in Latin America showed that on average $63 \%$ of firms have product innovation, and the leader is Argentina with around 75\% innovators (Waheed 2012b). Furthermore, among EU countries, Germany has the highest proportion of innovative firms $(79 \%)$, but Dutch firms report only 45\%, and UK firms report only 46\% (Gault 2015). One of the reasons that Latin American countries might show higher innovation rates is the perception of novelty (Crespi and Zuniga 2012). In general most of the innovation

\footnotetext{
${ }^{57}$ Defining small, medium and large firms we divert from standard OECD definitions because Armenian firms in general are smaller, partly because the economy is small. The World Bank uses the same definition for Armenian firms.

${ }^{58} \mathrm{~A}$ firm is innovative if it has at least one product or process innovation
} 
survey results across countries and regions show that the proportion of product innovators is higher than process innovators, and this is a case with Armenian firms. ${ }^{59}$

Table 8-2: Distribution of innovating firms

\begin{tabular}{|l|cc|}
\hline Innovation type & Number of firms & Percentage \\
\hline Product & 80 & 87.9 \\
Service & 3 & 3.3 \\
Process & 52 & 57.1 \\
\hline \hline Number of Innovating firms & 91 & 100 \\
\hline
\end{tabular}

\section{Degree of Innovativeness: "New to the market" or "New to the firm" Innovations}

Peneder uses creative firms to distinguish the firms that performed new to the market innovation. While, in his definition adaptive firms are those that perform new to the firm innovation. Following to this approach we also look at the Armenian data. With regard to degree of innovativeness, only a quarter of innovating firms developed new to the market and the rest of the innovating firms have new to the firm innovation (see Figure 8-1. Figure 8-2 revels that $61 \%$ of new to the market innovations were new to external markets, and had they been introduced in countries on the technological frontier, then they could have been world-class innovations.

\footnotetext{
${ }^{59}$ Waheed (2012) reports that in Bangladesh product innovators (33.1\%) are less than process innovators $(44.9 \%)$, which is an exception from other developing country statistics. Moreover, this study found that process innovation has a higher effect on firm's productivity than product innovation, explaining that process innovation effects the reduction of the production cost and increase the efficiency, while a consumer might be more reluctant for new products.
} 
Figure 8-1: New to the market vs. new to the firm innovations

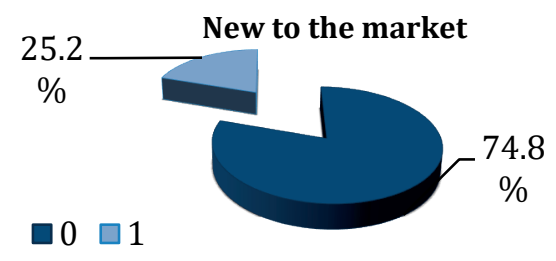

Figure 8-2: New to foreign market vs. new to the local market

New to Foreign market

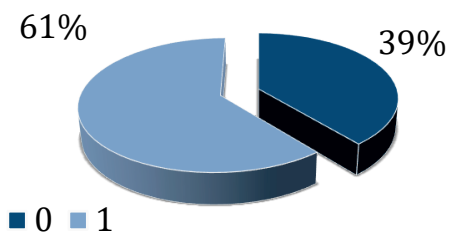


At first glance this might appear very surprising given that Armenia has very low ranks in terms of quality of research institutes (106 among 148 countries), and annual $0.2 \%$ GERD indicator (see Competitiveness report 2011-2012). However, the private sector performs relatively well according to the UNECE 2014 report. Armenia's scores are very high in terms of technological and organizational capabilities of firms, and showed higher numbers than Eastern European and Central Asian averages in categories such as internationally recognized quality certification (7\% above average), technology licensed from foreign companies (20\% above), own website $(13.8 \%$ above), using email for client/supplier communication ( $8 \%$ above). Where Armenia appears to lag is in having annual financial statements reviewed by external auditors (16\% below average) (see UNECE report, 2014). Interestingly, the main foreign markets were reported to be post-soviet countries. To sum up, from our survey it is hard to conclude whether new two foreign market innovations were world-class innovations or not. But the country's general statistics show that technological capabilities of private sector in Armenia are ranked relatively high in the Eastern Europe and Central Asian regions.

\subsubsection{Opportunity}

The comparative study of $27 \mathrm{EU}$ member states found that non R\&D innovators are more likely to have process innovation than R\&D performing firms, which is explained by the fact that there are more possibilities for developing process innovation without R\&D than there are for product innovation (Arundel, Bordoy, and Kanerva 2008). Arundel et al. (2008) claims that even though there are some differences between $\mathrm{R} \& \mathrm{D}$ and non-R\&D firms in terms of their innovative output, non- R\&D firms are also engaged in developing both product and process innovations and the difference is not too large.

Following the Oslo Manual, we break down innovation input activities: in-house $\mathrm{R} \& \mathrm{D}$, acquisition of external $\mathrm{R} \& \mathrm{D}$, acquisition of machinery and equipment, acquisition of external knowledge, training for innovative activities and market introduction. Our survey results show that around $84 \%$ of firms with innovative output reported that they had invested in at least one of the above-mentioned activities.

The majority of innovative firms reported expenditure on acquisition of machinery (78\%), and in-house $\mathrm{R} \& \mathrm{D}$ is the second important type of innovative activities performed by Armenian corporations (37.4). Among those, only 25.3\% of innovative firms are engaged in continuous R\&D activities and more than 30\% of firms report expenditures on market introduction, training and acquisition of external knowledge. 
Figure 8-3: Distribution of $R \& D$ and non-R\&D activities among innovative firms (in \%)

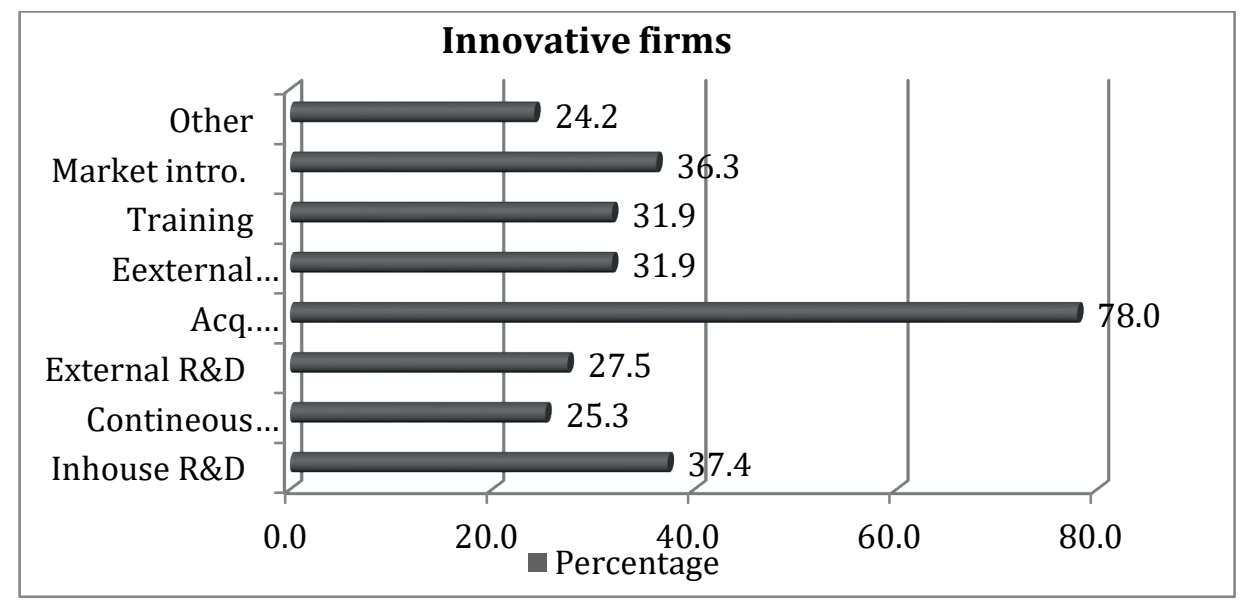

The literature on low-tech innovations identifies four main methods that do not require R\&D: technology adoption, minor modification of products and processes, imitation and combination of existing knowledge (Arundel, Bordoy, and Kanerva 2008; Som and Kirner 2014). Similar to our results, Evangelista and Mastrostefano (2006) found that the acquisition of machinery is the most common innovative activity that firms perform. Training or skills upgrading is another popular innovative activity, performed by $31.9 \%$ of innovating firms in our survey. Only $3 \%$ of non-R\&D performing firms provide training. Among R\&D performing firms, all firms that have external R\&D mentioned that they have provided training, while only $30 \%$ of in-house R\&D performers provide training. We have a very similar picture for the acquisition of external knowledge, as almost all firms who provide training report acquisition of external knowledge. Around 13\% of non-R\&D innovators report expenditures on market introduction of innovations, whereas only $30 \%$ of in-house R\&D performers and all firms with external R\&D report expenditures in this category.

\subsubsection{Knowledge cumulativeness}

In the innovation taxonomy, knowledge cumulativeness is another important dimension, which shows the level of cumulativeness of knowledge but looking at the importance of external vs. internal sources of knowledge for the creation of new knowledge across creative and adaptive firms. We have slightly modified this measure to adjust to our data, and distinguish:

- High cumulativeness: the percentage of creative firms that report Internal and continuous $\mathrm{R} \& \mathrm{D}$, and the percentage of adaptive firms reporting external R\&D. According to Peneder, creative firms are "new to market innovators"

- Low cumulativeness: the percentage of creative firms that report external $\mathrm{R} \& \mathrm{D}$ and, the percentage of adaptive firms reporting external R\&D. Adaptive behavior is related to "new to the firm" innovation. 
The table below shows the distribution of innovative firms conducting External or Internal $\mathrm{R} \& \mathrm{D}$ by creative and adaptive groups. This indicates that $31.8 \%$ of innovative firms are operating in high cumulativeness regime, and $14.2 \%$ are in low cumulativeness.

Table 8-3: The percentage of innovative firms conducting either internal or external R\&D

\begin{tabular}{|lcc|}
\hline Cumulativeness & Creative & Adaptive \\
\hline External R\&D & $6.6 \%$ & $22 \%$ \\
Internal R\&D & $9.8 \%$ & $7.6 \%$ \\
\hline
\end{tabular}

\subsubsection{Schumpeterian competition}

The relationship of firm size and innovation has been the interest of an academic community both from theoretical and empirical perspective. In his early work, Schumpeter (1934) suggests that small firms with an entrepreneurial spirit are the most important sources of information, but later he argues that large firms that have accumulated knowledge are the ones who actually possess enough resources for R\&D laboratories. In general, researchers find a positive relationship between innovative activities and firm size. E.g., Waheed (2012) shows that employment had a significant and positive impact on R\&D and product innovation in developing country context.

Firm size and Innovation output: Table 8-4 gives a breakdown of innovating and non-innovating firms by firm size. The firm size distributions of the two subpopulations — innovators and non-innovators — are very similar. However, when dividing (not partitioning ${ }^{60}$ ) the innovators into new to the market and new to the firm, we see a significant difference in size distribution. Producers of new to the market innovations are much more likely to be large firms.

Table 8-4: Distribution of firm size and innovation / R\&D for the period of 20002010

\begin{tabular}{|l|c|c|c|c|c|}
\hline Firm size & $\begin{array}{c}\text { Non- } \\
\text { Innovators }\end{array}$ & Innovators & $\begin{array}{c}\text { New to } \\
\text { market }\end{array}$ & $\begin{array}{c}\text { New to } \\
\text { firm }\end{array}$ & R\&D \\
\hline \hline Small & $56 \%$ & $40 \%$ & $6 \%$ & $46 \%$ & $28 \%$ \\
\hline Medium & $30 \%$ & $34 \%$ & $22 \%$ & $33 \%$ & $40 \%$ \\
\hline Large & $14 \%$ & $26 \%$ & $72 \%$ & $21 \%$ & $32 \%$ \\
\hline Sample & \multicolumn{2}{|c|}{ All firms } & \multicolumn{2}{c|}{ Innovators } & $\begin{array}{c}\text { All R\&D } \\
\text { performers }\end{array}$ \\
\hline
\end{tabular}

Radical innovation is important for a firm's competitive advantage by providing temporary monopolistic position or even creating new markets, as well as by

${ }^{60}$ The same firm may appear both as a new to the market firm and as a new to the firm. 
enhancing the opportunities for Armenian firms to enter new foreign markets. However, radical innovations are costly and characterized with higher risks. Incremental innovations, on the other hand, are more attractive for the firms, as they are less costly, but still can provide firms with a competitive advantage by either reducing the cost of production or creating new product differentiations (Barbosa, Faria, and Eiriz 2013). As we mentioned earlier, radical innovations require stronger research capabilities, and they are generally costly, therefore among innovators $72 \%$ of new to the market innovations were introduced by large firms, whereas small firms provide the modest numbers $(6 \%)$ (see Table $8-4)$. An opposite picture can be seen in the category of incremental innovations (new to the firm), where small firms contributed the most with $46 \%$, medium contributed $33 \%$ and large firms contributed $21 \%$.

Firm size and R\&D: In terms of firm size, $40 \%$ of R\&D performers are medium size firms, $32 \%$ are large firms and $28 \%$ are small firms (see Table 8-4. However, it is worth mentioning that half of the large firms report R\&D expenditure, whereas only $18 \%$ of small firms are among R\&D performers. In fact, all firms engaged in continuous or external $\mathrm{R} \& \mathrm{D}$ are innovators, and firms with occasional R\&D performance are less likely to innovate.

Our data reveals that performing $\mathrm{R} \& \mathrm{D}$ is more relevant to large and medium sized firms. Yet, R\&D is an important factor for increasing the likelihood for firm innovation. We would expect that the percentage of large firms performing $R \& D$ will be higher than medium size Firms. One explanation could be that large state owned firms might have a slower strategy to adapt and aggressively innovate, which speaks more about their strategic management decisions.

\subsubsection{Sectoral Innovation}

Sectoral distribution in terms of innovation output: Another aspect of the explanation of the heterogeneity of a firm's innovative activities is industry specific characteristics. Industry specific features may explain firms' innovative behavior, and it is revealed in Figure 8-4.

Sectors where innovating firms dominate are agro-food, chemicals, retail and possibly apparel-leather. Service and construction are dominated by non-innovators, whereas the remaining sectors are relatively split between firms that innovate and firms that do not. 
Figure 8-4: Proportion of innovating and non-innovating firms by industry (in \%)

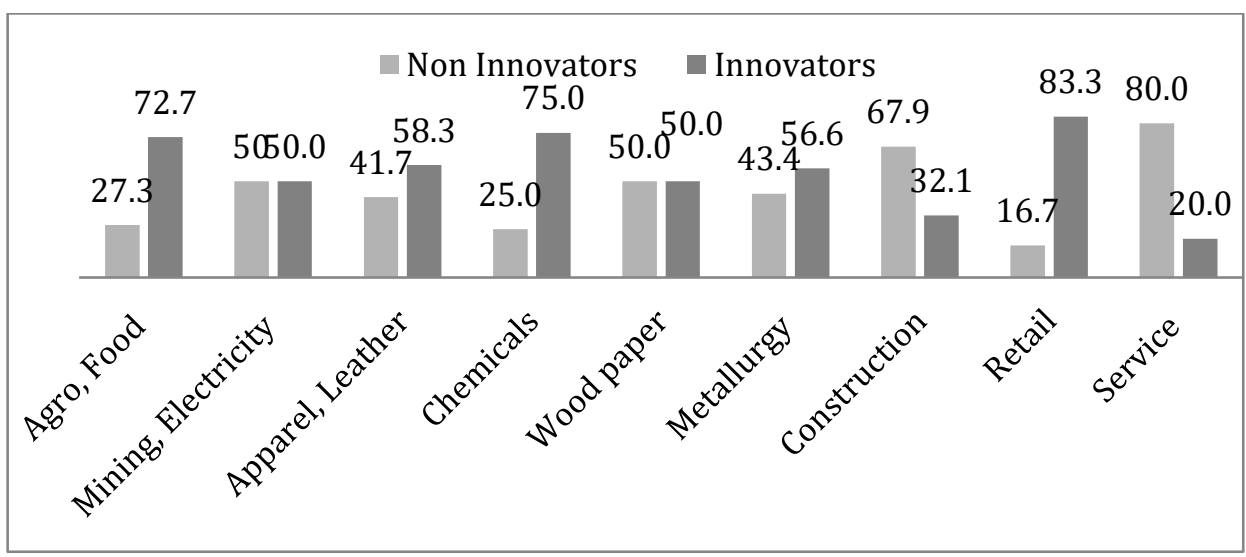

Our data shows that innovation rates vary across industries though we should mention that some industries in our dataset have only few firms included. Therefore we also looked at sectoral contribution to innovating and non-innovating groups. Over $36 \%$ of innovating firms are from the metallurgy sector, $17 \%$ the apparel sector and $11 \%$ the construction sector. But at the same time, the metallurgy sector also has a large proportion in the non-innovating group. Other sectors that are heavily present in the non-innovating group are services (33\% of innovating firms are in services), construction $(20 \%)$, and apparel sector $(11 \%)$. Other sectors each contribute less than $10 \%$ of innovating firms.

Sectorial distribution in terms of R\&D: We used binomial variable to capture firm's $R \& D$ performance, which takes one if a firm perform $R \& D$ - a firm either reports an $\mathrm{R} \& \mathrm{D}$ expenditure or indicates the type of $\mathrm{R} \& \mathrm{D}$ they had performed. Comparing the sectors, metallurgy is the most R\&D intense, with 36\% of metallurgy firm reporting that they do formal R\&D. The least intense is agro-food, wherein only $3 \%$ of firms report that they do R\&D.

\subsubsection{Geographic markets}

The vast majority of firms in our survey operate in the domestic market. Table 5 presents the distribution of firms according to their main markets, where "main market" is defined as the market in which firms have more than $70 \%$ of their sales. In 2008, 2009 and 2010 the main geographic markets for almost 90\% of firms were local markets. The second important geographic region for the Armenian firms is CIS countries (Union of Former Soviet Republics), and mostly Russia (8\%). 
Table 8-5: Largest geographic markets in percentages (2008-2010)

\begin{tabular}{|lccc|}
\hline Main Geographic Market & 2008 & 2009 & 2010 \\
\hline Armenia & 88.4 & 88.6 & 89.2 \\
USA and Canada & 1.1 & 1.1 & 1.1 \\
CIS & 8.4 & 8.2 & 8.1 \\
EU & 1.6 & 1.6 & 1.1 \\
Middle East & 0.5 & 0.5 & 0.5 \\
\hline \hline Total & 100 & 100 & 100 \\
\hline
\end{tabular}

In addition, to their main geographic markets, firms were asked to indicate their export markets (note there is a distinction between firm's main geographic market and its export market). An "export" market is a market where the firm introduces at least 10\% of its total sales. Therefore, our statistics on exporting are different from the main geographic market: a firm that reports its main market as Armenia can also report other countries for export. Almost $8 \%$ of firms export to US and Canada, $6 \%$ to the EU, $40 \%$ to CIS countries, and 20\% to Middle Eastern countries.

In general, our data reveals that firms are predominantly local market oriented, and CIS countries are the second most popular destination. Firms in the wood and paper sector, retail and service have chosen only local markets for the period of 2008-2010.

\subsubsection{Linkages and cooperation}

One aim of this survey was to collect data on firms' collaboration and linkages; therefore, the questionnaire distinguishes partners by private and public, as well as by local and foreign (see Figure 8-8). We also added open-ended questions, specifying which co-operation partner was valuable and why the firm chose to co-operate. Among the most popular factors that drive cooperative behavior are: access to foreign experience, consultancy, lack of production means, access to new technologies, direct investment and access to financial means, foreign specialist and new foreign markets.

Figure 8-5 presents the innovation partners reported by the firms in the survey, broken down by type of partner and geographic location. It is important to note that only firms who have innovated responded to this question, so these responses can be seen to indicate innovation partners. Surprisingly, none of the respondents mentioned partners in USA and Canada or the Middle East as important for innovation partners. The most commonly reported partners are local universities, followed by EU suppliers and local customers. Local competitors and local government research institutes are also common partners. It is worth pointing out that the university partnerships are mostly made up of student internships and vocational training. As we expected, none of the firms indicated foreign University and public research institutes for innovation cooperation. 
Figure 8-5: Type of innovation cooperation partner by location ${ }^{61}$

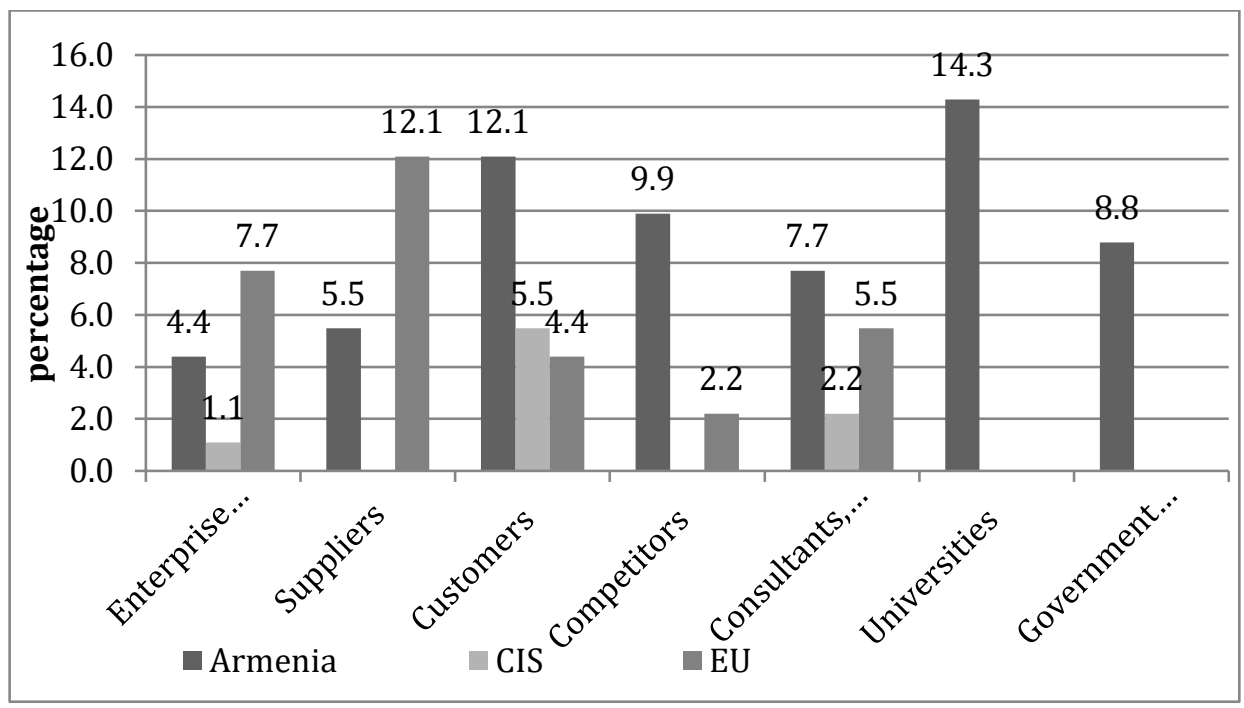

In fact, poor collaboration among surveyed firms confirms countrywide statistics: Armenia is ranked $111^{\text {th }}$ in the category of innovation linkages by the Global Innovation Index (GII) in 2011. In the category of knowledge workers and knowledge absorption, Armenia ranked $67^{\text {th }}$, but in university-industry collaboration $-113^{\text {th }}$, state cluster development $-102^{\text {nd }}$, and in terms of scientific output - $41^{\text {st }}$, which might be because of high-level in-house R\&D activities among firms.

To understand better the sources of knowledge for the firms in our sample, we asked questions about how they chose partners. The most common purpose for the selection of a partner was commercialization: nearly $15 \%$ firms reported commercialization, and 5\% reported R\&D for private actors both local and foreign. On the question of how firms learn about the firms for cooperation they answered "market" (10\%) for local partners and "market" again for foreign firms ( $8 \%) .8 \%$ of firms indicate previous experience for selection of local partners, and $7 \%$ for foreign partners. Less than $2 \%$ report choosing a local partner through the Internet, though a slightly higher percentage (around 5\%) found foreign actors through Internet. ${ }^{62}$ This suggests that collaboration among Armenian firms is a matter of building trust. Even though firms mentioned that they need collaboration to have access to foreign experience and markets, they are nevertheless reluctant to choose firms outside of their "market knowledge" or reputation.

To sum up, our results show that suppliers, customers and universities are the most important partners for innovating firms; however, only $5 \%$ of innovating firms collaborate to develop new product or process innovation. During our interviews,

\footnotetext{
${ }^{61}$ The population who answered this question in the survey is just the firms who said that they had done innovation in the past 3 years

62 "Foreign partners" refers to firms from abroad - question 6.4.2 in our questionnaire.
} 
many firms mentioned that universities do not provide the necessary education and training, and as a result firms spend around one year training new graduates. Under central planning, the industry and university linkages were very strong; we were expecting to observe deeper collaboration between university and large privatized firm in the current stage of transition. The reason for modest university-industry collaboration also includes that firms adapt new technologies and utilize new knowledge faster in contrast to universities, which suffers from poor financing $(0.2 \%$ of GDP goes for country level R\&D), and hence cannot upgrade existing technology (e.g., poorly equipped laboratories). Another observation about university-industry collaboration is that surveyed firms did not mention any collaboration with foreign universities or research institutes.

\subsubsection{Summary of finding from Taxonomy exercise}

Our main findings are summarized in Table 8-6, which shows the dominating "innovation modes" in the Armenian National Innovation System. In his study, Peneder grouped countries into continental, north and south regions. While looking at the distribution of firms by classification type in each of these groups, we could draw some parallels. Although we were not able to use the same indicators for all innovation types, it can still provide some valuable insights. For instance, the percentage of firms with high creativity is higher than in continental and north Europe. For noninnovators Armenia's results stand between 46\% non-innovators in continental Europe, and $56 \%$ in the north. In terms of technological opportunity, Armenian firms perform similarly to firms in continental Europe where $28 \%$ firms perform in-house $\mathrm{R} \& \mathrm{D}$ as compared to $26 \%$ in Armenia. In regard to acquisition of technology as an important strategy for innovation, Armenians perform similarly to other developing countries. For instance, one study in Russia showed that almost $68 \%$ of firms used acquisition of machinery and equipment compared to $78 \%$ in Armenia (Gokhberg et al., 2016).

Armenia stands between continental (45.69\%) and north Europe (56\%) in terms of percentage of firms innovating without cumulative knowledge, and performs similarly to continental Europe $(31.41 \%)$ in terms of high cumulativeness, while low cumulativeness level of Armenian firms $(14.2 \%)$ is close to southern Europe $(14.39 \%)$.

The survey showed that most of the firms doing R\&D are medium size firms $(40 \%)$, and slightly fewer are large (32\%). This is consistent with the observation that $34 \%$ of innovators are medium-sized firms, and $26 \%$ are large.

Another important dimension is whether innovation leads to the firm growth or not. Our results show that Armenian firms that introduce new to the market innovation significantly improve labour productivity and create more employments compared to non-innovators, while there is no significant difference in sales growth between innovators and non-innovators (See figure Figures 1-4 in the appendix and Table 2). In terms of labor productivity, ANNOVA test results show that there is a significant difference between non-innovators and innovators that introduce new to the market innovation. 
As we discussed earlier, Armenian national innovation inherited soviet connections, which was reflected in developing export markets - main exporting market are formersoviet (CIS) countries, whereas only 14\% of firms export to the advanced market such as USA and Europe. Patterns of usage of the information sources, which represent another dimension of innovation strategy, shows that university, EU suppliers and local customers, are the most important source for innovation.

Table 8-6: Taxonomy

\begin{tabular}{|c|c|c|}
\hline Innovation mode & Indicators & Armenia \\
\hline 1a. Creative & $\begin{array}{l}\text { Innovations with new to the } \\
\text { market }\end{array}$ & $13 \%$ \\
\hline 1b. Adaptive & $\begin{array}{l}\text { Innovation new to the firm } \\
\text { Non-innovators }\end{array}$ & $\begin{array}{l}47 \% \\
50 \%\end{array}$ \\
\hline 2. Opportunity & $\begin{array}{l}\text { Continuous R\&D } \\
\text { In-house R\&D } \\
\text { External R\&D } \\
\text { Acquisition of machinery } \\
\text { Non }\end{array}$ & $\begin{array}{l}10.9 \% \\
26 \% \\
15 \% \\
78 \% \\
48 \% \\
\end{array}$ \\
\hline 3. Appropriability & None & $100 \%$ \\
\hline 4. Cumulativeness & $\begin{array}{l}\text { High: } \\
\text { Low: } \\
\text { Non }\end{array}$ & $\begin{array}{l}31.8 \% \\
14.2 \% \\
54 \%\end{array}$ \\
\hline $\begin{array}{l}\text { 5. Shumpeterian } \\
\text { competition }\end{array}$ & $\begin{array}{l}\text { Large } \\
\text { Medium } \\
\text { Small }\end{array}$ & $\begin{array}{l}\text { Innov. } \\
26 \% \\
34 \% \\
40 \%\end{array}$ \\
\hline 6. Sectorial classification & $\begin{array}{l}\text { High innovation intensive } \\
\text { sectors } \\
\text { High R\&D intensive sectors }\end{array}$ & $\begin{array}{l}\text { Chemical, Food, Retail } \\
\text { Metallurgy }\end{array}$ \\
\hline 7. Export markets & $\begin{array}{l}\text { CIS } \\
\text { Middle east } \\
\text { West }\end{array}$ & $\begin{array}{l}40 \% \\
20 \% \\
14 \% \\
\end{array}$ \\
\hline 8. Linkages and partners & $\begin{array}{l}\text { Universities } \\
\text { Local customers } \\
\text { Foreign supplier }\end{array}$ & $\begin{array}{l}14.3 \% \\
12.1 \% \\
12.1 \% \\
\end{array}$ \\
\hline
\end{tabular}

\subsection{Factors that are correlated with firm R\&D and innovation}

The taxonomic exercise provides valuable information on the type of innovation modes prevailing in Armenia, however to deepen our understanding on the characteristics of innovative firms we conducted multivariate regression analysis. In this supplementary analysis, we run several regression models to test the relevance of some important factors. We should emphasize that at this point we make no attempt to extract causal relations; we are only looking for the correlation of variables with firm innovation or R\&D. 


\subsubsection{Testing probability that a firm performs R\&D}

To have a better understanding about the characteristics of firms that perform R\&D, we used a probit model, which measures the likelihood of a firm's R\&D (bivariate variable) by certain firm characteristics. A negative coefficient shows a lower probability that the firm performs R\&D.

Table 7 contains the results. It shows that the number of employees is positively associated with firm R\&D performance, and this is significant both in reduced and extended models. ${ }^{63}$ If the firm is exporting then it is more likely that it will perform $\mathrm{R} \& \mathrm{D}$, but this variable (dummy) is not significant when industry dummies were added. This is not surprising as some industries are more export-oriented than others. Empirical evidence of 14 Latin American countries showed that exporting increases the likelihood of positive R\&D decision (Waheed 2012b). We added a dummy variable for US and EU main markets, but it was insignificant.

${ }^{63}$ We also used quadratic form of firm size, but it was not significant. 
Table 8-7: Probability of performing R\&D: Probit model; dependent variable: R\&D Dummy

\begin{tabular}{|c|c|c|c|c|}
\hline Variables & Model1 & Model2 & Model3 & Model4 \\
\hline Ln(employ) ${ }^{64}$ & $\begin{array}{c}\mathbf{0 . 3 1 2} * * * \\
(0.072)\end{array}$ & $\begin{array}{c}\mathbf{0 . 3 2 5} * * * \\
(0.079)\end{array}$ & $\begin{array}{c}\mathbf{0 . 3 0 5} * * * \\
(0.088)\end{array}$ & $\begin{array}{c}\mathbf{0 . 2 8 9} * * * \\
(0.089)\end{array}$ \\
\hline Exporter & $\begin{array}{l}\mathbf{0 . 4 4 8 * *} \\
(0.213)\end{array}$ & $\begin{array}{l}\mathbf{0 . 2 9 4} \\
(0.23)\end{array}$ & $\begin{array}{c}\mathbf{0 . 2 8 5} \\
(0.237)\end{array}$ & $\begin{array}{c}\mathbf{0 . 1 7 3} \\
(0.247)\end{array}$ \\
\hline OJSC & $\begin{array}{c}\mathbf{1 . 0 8 3} \boldsymbol{*} * \boldsymbol{*} \\
(0.315)\end{array}$ & $\begin{array}{c}\mathbf{0 . 7 9 7} * * \\
(0.358)\end{array}$ & $\begin{array}{l}\mathbf{0 . 6 2 2} * \\
(0.368)\end{array}$ & $\begin{array}{c}\mathbf{0 . 6} \\
(0.371)\end{array}$ \\
\hline Mining, Electricity & & $\begin{array}{c}\mathbf{0 . 4 3 9} \\
(0.439)\end{array}$ & $\begin{array}{c}\mathbf{0 . 4 8 8} \\
(0.447)\end{array}$ & $\begin{array}{c}\mathbf{0 . 5 4 2} \\
(0.451)\end{array}$ \\
\hline Apparel, Leather & & $\begin{array}{l}\mathbf{0 . 8 5} \\
(0.56)\end{array}$ & $\begin{array}{c}\mathbf{0 . 8 5 7} \\
(0.572)\end{array}$ & $\begin{array}{c}\mathbf{0 . 7 6 8} \\
(0.597)\end{array}$ \\
\hline Chemicals & & $\begin{array}{l}\mathbf{0 . 8 4 5 *} \\
(0.488)\end{array}$ & $\begin{array}{l}\mathbf{0 . 9 6 6 *} \\
(0.497)\end{array}$ & $\begin{array}{c}\mathbf{0 . 9 9 6 * *} \\
(0.5)\end{array}$ \\
\hline Wood paper & & $\begin{array}{l}1.291 \\
(0.86)\end{array}$ & $\begin{array}{l}1.531 * \\
(0.902)\end{array}$ & $\begin{array}{l}1.551 * \\
(0.935)\end{array}$ \\
\hline Metallurgy & & $\begin{array}{c}\mathbf{0 . 9 5 2} \\
(0.786)\end{array}$ & $\begin{array}{c}\mathbf{0 . 8 8 9} \\
(0.782)\end{array}$ & $\begin{array}{c}\mathbf{0 . 9 1 3} \\
(0.804)\end{array}$ \\
\hline Construction & & $\begin{array}{c}\mathbf{0 . 5 2 1} \\
(0.414)\end{array}$ & $\begin{array}{c}\mathbf{0 . 6 3 5} \\
(0.428)\end{array}$ & $\begin{array}{c}\mathbf{0 . 7 0 2} \\
(0.435)\end{array}$ \\
\hline Retail & & $\begin{array}{c}\mathbf{0 . 0 4 7} \\
(0.468)\end{array}$ & $\begin{array}{l}-\mathbf{0 . 0 3 1} \\
(0.479)\end{array}$ & $\begin{array}{c}\mathbf{0 . 0 6 1} \\
(0.478)\end{array}$ \\
\hline IND8 & & $\begin{array}{c}\mathbf{0 . 5 4 9} \\
(0.645)\end{array}$ & $\begin{array}{c}\mathbf{0 . 5 6 2} \\
(0.671)\end{array}$ & $\begin{array}{c}\mathbf{0 . 5 3} \\
(0.685)\end{array}$ \\
\hline lnsales 2008 & & & $\begin{array}{c}-\mathbf{1 . 0 5 3} * * \\
(0.49)\end{array}$ & $\begin{array}{c}-1.093 * * \\
(0.511)\end{array}$ \\
\hline lnsales 2009 & & & $\begin{array}{c}\mathbf{0 . 0 2 1} \\
(0.434)\end{array}$ & $\begin{array}{c}\mathbf{0 . 0 6 1} \\
(0.458)\end{array}$ \\
\hline lnsales 2010 & & & $\begin{array}{c}\mathbf{1 . 0 3 4} * * \\
(0.413)\end{array}$ & $\begin{array}{l}1.03 * * \\
(0.425)\end{array}$ \\
\hline product_freq & & & & $\begin{array}{c}\mathbf{0 . 3 3 1} * * \\
(0.143)\end{array}$ \\
\hline process_freq & & & & $\begin{array}{l}-\mathbf{0 . 1 9 5} \\
(0.187)\end{array}$ \\
\hline Cons & $-2.619 * * *$ & $-2.827 * * *$ & $-2.851 * * *$ & $-2.936 * * *$ \\
\hline Rho & $(0.447)$ & $(0.517)$ & $(0.531)$ & $(0.535)$ \\
\hline $\mathrm{N}$ & 192 & 192 & 192 & 192 \\
\hline
\end{tabular}

We also tested the effect of the firm's legal status, which shows that open joint stock companies (variable OJSC) are more likely to perform R\&D than closed joint stock companies or LLCs. Firms in the chemical and wood industry are more likely to perform $\mathrm{R} \& \mathrm{D}$, but there is no significant difference between other sectors and a reference category (agro, food and beverages industry).

Previous research indicates competition as noticeable stimulus for firm R\&D (Tang 2006; Waheed 2012b). We did not have precise measures for the firm's competitive

\footnotetext{
${ }^{64}$ Inemploy - log of numbered of employees; product_freq - is dummy for frequent product innovators in past , process_freq -dummy for frequent process innovators in previous years, we used Agro, food and beverage industry as a reference group, ${ }^{*} \mathrm{p}<0.1,{ }^{* *} \mathrm{p}<0.05,{ }^{* * *} \mathrm{p}<0.001$; the probability of chi 2 of all models is high 0.000
} 
environment, but larger sales can partially be used to indicate the firm's relative importance compared to other firms. However, the results show that annual sales have different impacts on R\&D: sales in 2008 have a negative effect on firms' R\&D, but sales in 2010 have had a positive effect. These results suggest that the financial crisis may have had an effect on firm decisions to engage R\&D for the period 2008-2010. Moreover, after the crisis, sales in 2010 are positively associated with R\&D performance.

Firms' past innovativeness (see Table 8-8) ${ }^{65}$ also drives firms to invest in R\&D activities; however, only firms with frequent product innovation in the past 10 years perform R\&D, 66 while frequency in introducing process innovation was not significant. This result is consistent with previous studies, where product innovators perform R\&D more often compared to process innovators (Arundel, Bordoy, and Kanerva 2008). Previous research found that the firm's age is also correlated with R\&D activities (Waheed 2012b). Instead of the firm's age (all surveyed firms are privatized at the same time), we tested past innovativeness as a proxy for knowledge accumulation, which shows the consistent result that it has a positive association with $\mathrm{R} \& \mathrm{D}$ (frequent product innovators vs. frequent process innovators).

\subsubsection{Testing the probability that a firm introduces product or process innovation}

We also use multivariate analysis to examine the relationship between the firm's characteristics, non-R\&D innovation activities and the firm's product or process innovation (with a dependent dummy variable, which takes 1 if the firm innovated and 0 otherwise, see Table 8-8). Results show that firm size, past product innovation frequency, acquisition of external knowledge and machinery are significantly correlated with the likelihood to innovate. Our results show that coefficient of past innovative frequency is bigger for firm innovation compared to the coefficient in the R\&D model (see tables 8-7 and 8-8). We didn't include R\&D dummy in the Innovation model, as all the firms performing R\&D were innovator. Yet, we were interested how non-R\&D innovation activities are correlated to firm innovation, showing that firms past innovative frequency, acquisition of knowledge and machinery are also important for firm innovation.

Compared to the baseline industry, Agro food and beverages, firms are more likely to innovate in the metallurgy and retail industries; other industries do not perform differently in terms of innovation output. The exporter dummy was not significant for firm innovation, therefore in model 3 and 4 we introduced main market USA, Canada and EU in 2008, 2009 and 2010 instead of the export dummy. It shows that firms

\footnotetext{
65 The survey included questions referring the past innovation frequency, where $34.3 \%$ of all firms are frequent product innovators, and among the firms reporting innovative performance for the period $2008-2010,70.33 \%$ are frequent product innovators in the past 10 years, and only 13\% of innovators in 2008-2010 are frequent process innovators (see Table 7-3). Firms that reported new to the market innovation for the period of 2008-2010 only $43 \%$ are frequent innovators, $34 \%$ innovate at least once a year compared to firm level innovations - $79 \%$ of which innovate more than once a year.

${ }^{66}$ If a firm introduces product or process innovation more than every year during 2000-2008.
} 
reporting their main market as USA, Canada and EU in 2008 were less likely to introduce innovation for period 2008-2010. It might be that firms that export to the EU and USA are those who were heavily affected by financial crisis.

Table 8-8: Probability of the firm to introduce product or process innovation

Probit model with Innovation Dummy as a dependent variable

\begin{tabular}{|c|c|c|c|c|}
\hline Variables & Model1 & Model2 & Model3 & Model4 \\
\hline "Ln(employ) & $\begin{array}{c}\mathbf{0 . 3 1 1} \text { **** } \\
(0.09)\end{array}$ & $\begin{array}{c}\mathbf{0 . 2 9 2} * * * \\
(0.104)\end{array}$ & $\begin{array}{c}\mathbf{0 . 2 8 9 * * *} \\
(0.112)\end{array}$ & $\begin{array}{c}\mathbf{0 . 4 4 2} \boldsymbol{*} * \\
(0.205\end{array}$ \\
\hline product_freq & $\begin{array}{c}2.743 * * * \\
(0.306)\end{array}$ & $\begin{array}{c}\mathbf{2 . 7 5 0} * * * \\
(0.316)\end{array}$ & $\begin{array}{c}\mathbf{2 . 9 5 8} * * * \\
(0.372)\end{array}$ & $\begin{array}{c}2.629 * * * \\
(0.76\end{array}$ \\
\hline process_freq & $\begin{array}{c}-\mathbf{0 . 9 2 6 * * *} \\
(0.267)\end{array}$ & $\begin{array}{c}-\mathbf{0 . 9 5 5} * * * \\
(0.273)\end{array}$ & $\begin{array}{c}-1.035 * * * \\
(0.314)\end{array}$ & $\begin{array}{c}-1.019 * \\
(0.587)\end{array}$ \\
\hline OJSC & & $\begin{array}{c}\mathbf{- 0 . 2 1} \\
(0.389)\end{array}$ & $\begin{array}{l}-\mathbf{- 0 . 6 2 1} \\
(0.53)\end{array}$ & $\begin{array}{l}-\mathbf{- 0 . 2 9 3} \\
(0.811)\end{array}$ \\
\hline Exporter & & $\begin{array}{l}-\mathbf{0 . 0 2 9} \\
(0.308)\end{array}$ & & \\
\hline main_US_EU8 & & & $\begin{array}{c}-3.741 * * * \\
(1.383)\end{array}$ & $\begin{array}{c}\mathbf{- 3 . 9 5 1 * * *} \\
(1.416)\end{array}$ \\
\hline main_US_EU9 & & & $\begin{array}{l}-3.471 \\
(2.752)\end{array}$ & $\begin{array}{l}-0.332 \\
(3.974)\end{array}$ \\
\hline main_US_EU10 & & & $\begin{array}{c}3.819 \\
(1.758)\end{array}$ & $\begin{array}{l}2.309 \\
(3.975)\end{array}$ \\
\hline Metallurgy & & & $\begin{array}{c}\mathbf{0 . 3 5 5} \\
(0.586)\end{array}$ & $\begin{array}{l}1.911 * \\
(1.129)\end{array}$ \\
\hline Retail & & & $\begin{array}{c}\mathbf{0 . 9 4 7} \\
(1.039)\end{array}$ & $\begin{array}{l}\text { 2.626* } \\
(1.415)\end{array}$ \\
\hline Training & & & & $\begin{array}{c}-4.537 \\
(773.12)\end{array}$ \\
\hline External knowledge & & & & $\begin{array}{l}2.296 * \\
(1.346)\end{array}$ \\
\hline Acquisition of Machinery & & & & $\begin{array}{c}2.98 * * * \\
(0.73)\end{array}$ \\
\hline Market Introduction & & & & $\begin{array}{c}2.732 \\
(773.1)\end{array}$ \\
\hline Cons & $-2.179 * * *$ & $-1.935^{* * *}$ & $-1.588 * *$ & $-4.285 * * *$ \\
\hline Rho & $(0.37)$ & $(0.581)$ & $(0.637)$ & $(1.502)$ \\
\hline $\mathrm{N}$ & 192 & 192 & 192 & 192 \\
\hline
\end{tabular}

The probit model regression results suggest that firms that conduct continuous inhouse $\mathrm{R} \& \mathrm{D}$ or carry out external $\mathrm{R} \& \mathrm{D}^{67}$ are more likely to innovate; however, among non R\&D activities, the acquisition of machinery and external knowledge provides firms with strong capabilities for innovation. They (Tables 8-7 and 8-8) also show that a firm's past product innovation experience increases the likelihood of engaging in $\mathrm{R} \& \mathrm{D}$ or introducing innovation; in contrast, past process innovation (frequency) is either was not significant or had a negative correlation. Among exporting firms the likelihood of engaging in R\&D is very high, however firm export does not appear to be correlated with the probability to innovate, unless its main market in 2008 was US,

${ }^{67}$ We introduced in-house $\mathrm{R} \& \mathrm{D}$ and external $\mathrm{R} \& \mathrm{D}$ dummy variables in the model, but they were dropped because all the cases were perfectly defined (all R\&D performers were innovators). 
Canada or EU. In terms of the industry sector, the chemical industry was significant for a firm's R\&D, but for innovation output metallurgy and retail are more important (compared with reference category). The firm's legal structure was significant only for $\mathrm{R} \& \mathrm{D}$, showing that firms with open shareholding (open joint stock companies) are more likely to carry out $\mathrm{R} \& \mathrm{D}$, but there is no significant difference in terms of innovation output.

In this section we would like to discuss the factors that are correlated with either produce or process innovation (see Table 8-9). Our data shows that $60 \%$ of Product innovators, are also introduced process innovation. Firm size, measured by the logarithm of employment, was insignificant for both process and product innovation (even in the reduced model), while being an exporter is positively correlated with the likelihood of introducing process and product innovation. Interestingly, there are some differences with innovation input activities: process innovation is insignificantly correlated with R\&D performance (as we might expect, given results of other studies), but acquisition of external knowledge and expenditure on market introduction are significant. By contrast, $\mathrm{R} \& \mathrm{D}$ performance is significant for product innovation, but acquisition of external knowledge and market introduction are not significant. However, acquisition of machinery is significant for both product and process innovation. 
Table 8-9: The probit model with Innovation as a dependent variable dependent variable

\begin{tabular}{|c|c|c|}
\hline Innovation (dummy) & Process Innovation & Product Innovation \\
\hline \multirow[t]{2}{*}{ Exporter } & $1.06 * * *$ & $0.953 * * *$ \\
\hline & $(0.413)$ & $(0.366)$ \\
\hline \multirow[t]{2}{*}{ Training } & 0.505 & -1.719 \\
\hline & $(0.901)$ & $(1.586)$ \\
\hline \multirow[t]{2}{*}{ External knowledge } & $1.445 * *$ & 0.444 \\
\hline & $(0.712)$ & $(0.698)$ \\
\hline \multirow[t]{2}{*}{ Acquisition of Machin } & $4.46 * * *$ & $3.32 * * *$ \\
\hline & $(0.717)$ & (0.449) \\
\hline \multirow[t]{2}{*}{ Market Introduction } & $-3.348 * * *$ & 1.07 \\
\hline & (1.025) & (1.547) \\
\hline \multirow[t]{2}{*}{ R\&D_dummy } & 0.441 & $0.826 * *$ \\
\hline & $(0.424)$ & $(0.389)$ \\
\hline \multirow[t]{2}{*}{ lnsales 2008} & 0.437 & 0.682 \\
\hline & (0.441) & (0.428) \\
\hline \multirow[t]{2}{*}{ lnsales 2009} & 0.265 & 0.182 \\
\hline & (0.458) & $(0.452)$ \\
\hline \multirow[t]{2}{*}{ lnsales 2010} & $-0.66 * * *$ & $-0.82 * * *$ \\
\hline & $(0.211)$ & $(0.296)$ \\
\hline \multirow[t]{2}{*}{ lnlabor2008 } & 0.505 & -0.148 \\
\hline & $(0.573)$ & $(0.625)$ \\
\hline \multirow[t]{2}{*}{ Inlabor2009 } & -1.829 & -1.819 \\
\hline & (1.422) & (1.407) \\
\hline \multirow[t]{2}{*}{ lnlabor2010 } & 1.443 & 2.12 \\
\hline & $(1.36)$ & (1.401) \\
\hline \multirow[t]{2}{*}{ _cons } & $-2.83 * * *$ & $-2.71 * * *$ \\
\hline & -0.544 & -0.476 \\
\hline pr2 & 0.71 & 0.67 \\
\hline $\mathrm{N}$ & 192 & 192 \\
\hline
\end{tabular}

Studies in this domain argue that innovations involve dynamic increasing returns (Gault 2015; Malerba and Orsenigo 1996). Experience in innovation is associated with learning effects and accumulation of knowledge stock, which increases the probability of innovation in the following period. Increasing returns from innovation also include extension of market power, more financial means and a larger set of technological opportunities (Gault 2015). Both product and process innovation can have an effect on market expansion. If the innovator is a first mover and launches a radically new product then it gains a monopoly power, and can gain returns either by increasing sales or price or both. Process innovation often reduces the production costs. This suggests that there will eventually be a price reduction in competitive markets, which will lead to gaining more returns by increasing sales. The probit model shows that sales in 2008 are positively associated with both product and process innovation, but sales in 2010 had a negative correlation, which perhaps can be explained by the financial crisis. However, our model cannot address the causality. 


\subsection{Conclusion}

This chapter analyses the data we collected in the first innovation survey in Armenia. Our main research interest is to trace large firms that were privatized in 1999, and were open joint stock companies with more than 50 shareholders. In the turbulent transitional environment, firms had to pass through tough restructuring and modernization in order to survive. It was an intriguing question how innovative these firms are, as in soviet years they were the industry leaders.

The chapter also considered the potential of micro-level innovation taxonomy to organize evidence of prevailing innovation strategies in the national innovation system of Armenia. Applying Peneder's approach for the case of Armenia demonstrated considerable robustness of the micro-level trends constructed from the firm-level classification exercise. Our analysis showed the distribution of the particular type of innovation behavior reflecting the incentives within the socio-economic environment and the accumulated capabilities for the development. The observed innovation modes allowed expanding our knowledge on national innovation system of Armenia. Firmlevel taxonomies prove to be a valuable instrument for diagnostics of popular innovation modes (Gokhberg et al., 2016), and helping to better understand the components of Innovation system and governance architecture. This exercise also allowed us to compare the case of Armenia with the other European countries. One important implication of this approach is that it provides policy intelligence in understanding the type of innovative firms, their needs and stage of innovation, which will help better targeting and providing necessary support. Unlike using the standard approach of identifying firm needs by industry or size classifications, this approach takes into consideration multiple factors that could determine firm needs in innovation space.

This chapter also provided the extended knowledge base for understating the factors that are relevant for the firm decision to innovate or perform R\&D. Multivariate regressions were carried out to understand the characteristics of firms carrying out innovation and R\&D.

The survey results reveal that almost half of the firms introduce product or process innovation: half of innovators introduce process innovation, and $60 \%$ of firms have both product and process innovation. Surveyed firms are predominantly incremental innovators, and only a quarter of innovating firms introduce new-to-the-market innovation. Multivariate analysis also confirms that firm size (measured by number of employees) significantly increases the likelihood of a firm to introduce innovation. Moreover, large firms introduced $72 \%$ of radical innovations.

Firm size is also positively correlated with the firm's R\&D performance. Our analysis also shows that although continuous and external R\&D are highly correlated with innovation, nevertheless other innovative activities such as acquisition of machinery and external knowledge are also important and increase the likelihood to innovate. In general, R\&D performing firms have higher innovative capabilities; however, other studies in this domain found that in other economies non-R\&D performing firms also introduce high rates of innovation, which indicates that firms without $R \& D$ 
performance should not be excluded from the "innovators" group (Arundel et al. 2008).

In terms of sectoral modes, similar to Latin American countries, Armenia's patterns of industry specialization are more oriented to low-tech sectors. This type of specialization does not facilitate intensive interactions for technological innovations.

Our questionnaire includes some retrospective questions targeting past innovative experience. We observe that innovative firms are operating mostly in Schumpeterian creative accumulation domain, ${ }^{68}$ such that the generation of new knowledge builds on existing knowledge of incumbent firms, which is consistent with previous findings: Malerba and Orsenigo (1996) and Cefis and Orsenigo (2001) both observed that incumbents play the dominant role in sectors with stable innovation patterns, and Klepper (2002) shows that old and large firms have higher chances to survive in the industry.

The probit regression shows that firms reporting their main geographic market as USA, Canada and the EU in 2008 are less likely to perform innovation. This could contradict our expectations, as we introduced a dummy for the developed country expecting that operating in a technologically advanced market would enhance a firm's innovation. However, this negative effect can be seen a consequence of the financial crisis. Indeed, many firms, especially in ICT sector, report that demand for their production and services has radically shrunk, especially those exporting or collaborating with firms in USA and the EU.

This chapter also briefly explores the cooperative behavior of innovative firms, in which "innovation cooperation" refers to the broader concept rather than R\&D cooperation. The stream of literature on empirical evidence on collaboration for innovation activities used Innovation Surveys to provide insight on motivation and drivers for firm's collaborations. Given the importance of linkages in the National Innovation System, this section sheds light on the similarities and differences in cooperative behavior of Armenian firms and other countries, such as some Latin American countries. Local actors play an important role in a firm's decision to innovate: local competitors, consultants, universities and research institutes contribute highly for innovative collaboration. Nevertheless, foreign suppliers and enterprise groups are important players for the innovation system in Armenia.

The survey found that only a small number of innovators are able to regularly produce new products and services, which are competitive at the both national and international market. Yet, among regular innovators there are still a significant number of firms that didn't consistently invest in $R \& D$, which will ensure that firms are developing strong innovative capabilities.

The most distinctive feature of the Armenian National system is the prevalence of technology adopters who concentrate their resources on acquisition of machinery or external knowledge. For innovation, this group usually does not rely on their own resources. A lack of strategic innovators and reliance on external knowledge suggests

${ }^{68}$ Gault (2015) discuss the approaches used in two Schumpeterian domains. 
that changing from an "adopting innovation" mode to a creative mode will be a challenging task. In Armenia we still observe that the most popular firm strategy is the adoption-based modernization, within which a considerable portion of technology adoption is carried out by the firm. In a sense this may be consistent with national policy: our survey results also show that there are no state programs supporting firms in their innovative activities. Adoption will work as a strategy for economies that are in a pure catch-up mode, at least for a time. But to move from a laggard catching up to a globally competitive economy, Armenia's National Innovation System needs to encourage more creative innovators and the diffusion of their practices. One of the noticeable differences with other European countries was that in Armenia novel knowledge tends to be created in isolation and without turning it into formalized IP outcomes. This behavior reflects both country's innovation culture and a lack of incentives due to a weak IP institutional environment. A lack of IP regulations and standardization practices may well have been (and continue to be) impeding the diffusion of novelties and best practices within the country, which also slowed down transition processes.

Based on our findings some policy conclusion can be drawn. The most general policy advice could be that public programs may consider supporting an entrepreneurial mode/destructive innovation mode and strengthen start-up and small firm ecosystem in the innovation landscape. Many countries have adopted policies to strengthen startup ecosystem, which is considered as one of the important drivers of innovation (e.g., Grimaldi et al., 2011). Government policies can support the development of an entrepreneurial ecosystem in Armenia, and by doing this; it will help to reduce practices left over from the Soviet system that hamper firm innovation.

Another important factor is the lack of $R \& D$ incentives among Armenian firms. As $\mathrm{R} \& \mathrm{D}$ performance is highly correlated with firm innovation in many countries, policies also encourage $R \& D$ expenditure or $R \& D$ collaboration for small firms. This behavior may shift Armenian firms further from an old Soviet system. Government can play a strong role in creating incentives for firms in including start-up to focus more on $R \& D$ activities. The analysis also showed that encouraging new to the market innovation may affect labor productivity. As non-R\&D innovative activities such as investment in machinery and acquisition of knowledge appeared to be strongly correlated to firm innovation, innovation policies should also look at encouraging programs and funding enhancing technological adaption stage of firms.

It is important to recognize that Armenia's innovation transition is in a mode of modernization, and even though keeping technological adoption as an important component of the firm's innovation strategy is necessary, there is a need for the policies that will strengthen and shift the national innovation system to a creative mode. 


\section{Appendix D: Survey Results}

Table 1: Distribution of firms main geographic market across industries

\begin{tabular}{|c|c|c|c|c|c|c|c|c|c|c|c|c|c|}
\hline \multirow[b]{2}{*}{ Industry/ Year } & \multicolumn{3}{|c|}{ Armenia } & \multicolumn{3}{|c|}{ US \& Canada } & \multicolumn{3}{|c|}{ CIS } & \multicolumn{2}{|c|}{ EU } & \multicolumn{2}{|c|}{ Middle East } \\
\hline & 2010 & 2009 & 2008 & 2010 & 2009 & 2008 & 2010 & 2009 & 2008 & 2010 & 2009 & 2008 & 2008 \\
\hline Agro, Food & 4.0 & 4.0 & 4.5 & & & & 1.7 & 1.7 & 1.1 & & & & \\
\hline Mining, Electricity & 4.6 & 4.6 & 4.5 & & & & 0.6 & 0.6 & 0.6 & 0.6 & 0.6 & 0.6 & \\
\hline Apparel, Leather & 11.0 & 10.9 & 11.7 & 1.1 & 1.1 & 0.6 & & 0.6 & 1.1 & & & & \\
\hline Chemicals & 1.2 & 0.6 & 1.7 & & & & 0.6 & 1.1 & 0.6 & & & & \\
\hline Wood paper & 2.3 & 2.3 & 2.2 & & & & & & & & & & \\
\hline Metallurgy & 25.4 & 25.3 & 24.6 & & & 0.6 & 4.0 & 4.0 & 3.9 & & & 0.6 & \\
\hline Construction & 15.0 & 14.9 & 14.5 & & & & 0.6 & & & 0.6 & 1.1 & 0.6 & 0.6 \\
\hline Retail & 3.5 & 3.4 & 3.4 & & & & & & & & & & \\
\hline Service & 23.1 & 23.0 & 22.3 & & & & & & & & & & \\
\hline Total & 90.2 & 89.1 & 89.4 & 1.1 & 1.1 & 1.1 & 7.5 & 8.0 & 7.3 & 1.2 & 1.7 & 1.7 & 0.6 \\
\hline
\end{tabular}

Table 2 : ANOVA comparison of Mean across firms ${ }^{69}$

\begin{tabular}{|c|c|c|c|c|c|c|c|c|}
\hline & \multicolumn{2}{|c|}{ Non-innovating } & \multicolumn{2}{|c|}{ New to the market } & \multicolumn{2}{|c|}{ New to the firm } & Ftest & sig. \\
\hline Labour productivity 2008 & $\begin{array}{c}\text { Mean } \\
2196.9\end{array}$ & $\begin{array}{c}\text { Std. Dev. } \\
11013.5\end{array}$ & $\begin{array}{l}\text { Mean } \\
6301.5\end{array}$ & $\begin{array}{c}\text { Std. Dev. } \\
11826.3\end{array}$ & $\begin{array}{c}\text { Mean } \\
1064.5\end{array}$ & $\begin{array}{c}\text { Std. Dev. } \\
3199.2\end{array}$ & 2.65 & 0.07 \\
\hline Labour productivity 2009 & 2291.4 & 11400.9 & 7311.9 & 14891.5 & 1496.9 & 5004.9 & 2.74 & 0.06 \\
\hline Labour productivity 2010 & 2520.3 & 13818.7 & 6855.8 & 13187.3 & 966.2 & 2823.1 & 2.24 & 0.10 \\
\hline
\end{tabular}

${ }^{69}$ Labour productivity is measured by Total sales (in 10000AMD) per employee 
Figure 1: The distribution of total sales growth rates 2008-2009

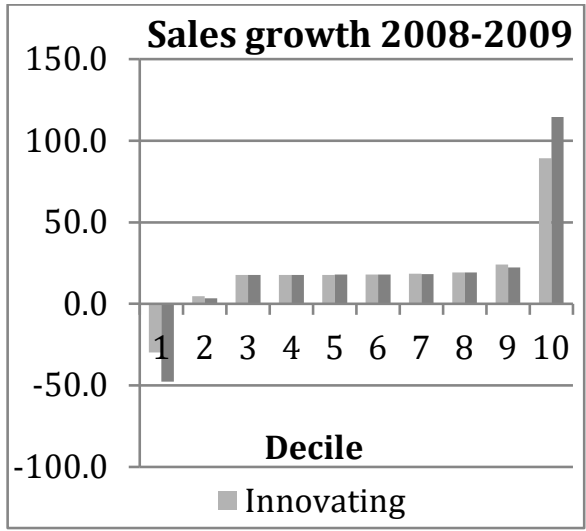

Figure 3: Employment growth rates 2008-2009

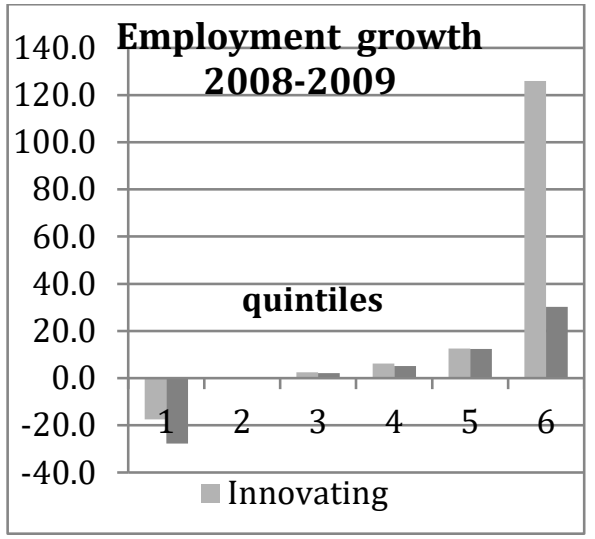

Figure 2: The distribution of total sales growth rates 2009-2010

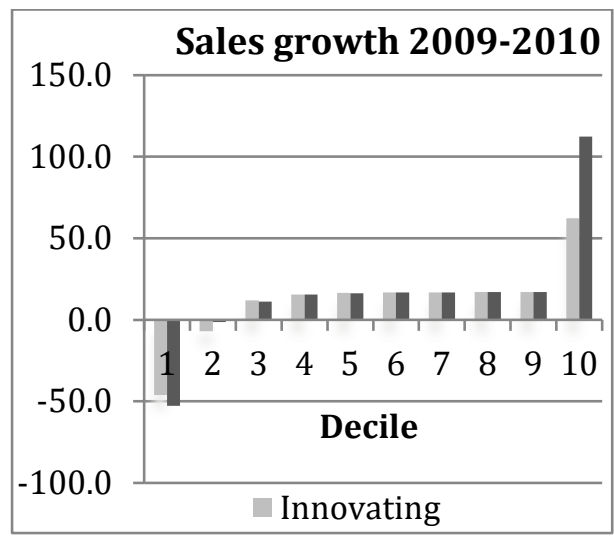

Figure 4: Employment growth rates 2009-2010 70

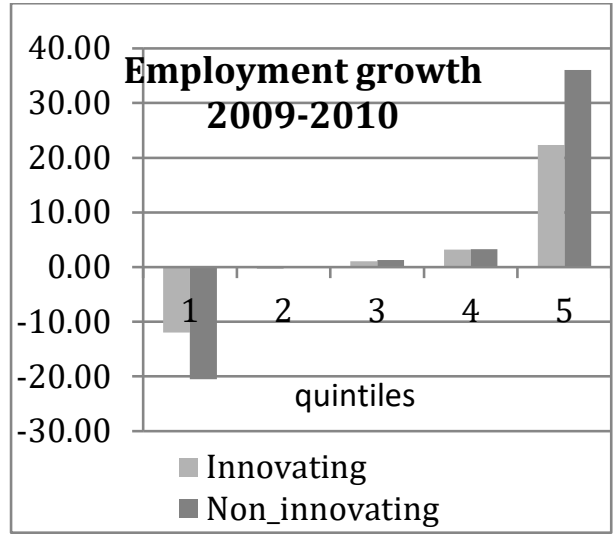

\footnotetext{
70 The numbers for second quintile are: Innovating -0.04 ; non- innovating -0.1
} 
CHAPTER

THE IMPACT OF SOCIAL CAPITAL ON INNOVATION PERFORMANCE 


\subsection{Introduction}

There is a continuing interest in how ownership change and corporate governance of privatized firms influence performance and innovation in transition economies. Many newly privatized firms faced an urgent need to restructure and modernize both management and the production process.

As demonstrated in the review presented in Chapters 2 and 3, strong personal ties play a vital role in facilitating economic exchange, and are likely to affect firm performance and survival (Batjargal 2003; Stark and Bruszt 1998). In this context personal networks provide rich and trusted information that was not readily accessible in the public sphere. Such ties may facilitate access to resources that are critical for firm survival and growth (Kiss and Danis 2010). Our understanding of how personal networks affect firm innovativeness is incomplete. In consideration of this gap in the literature, we develop a framework for deepening our knowledge of how firms in transition economies innovate, and what is the role of network ties in a firm's learning and knowledge transfer processes.

One of the important networks that we are able to examine is the network of board members of around 200 Armenian open joint stock companies. Previous literature has highlighted the importance of board networks, and their role in improving firms' innovative performance (Wincent, Anokhin, and Örtqvist 2010; Vedres and Stark 2008; Martin, Gözübüyük, and Becerra 2015; Mizruchi 1983). A typical finding is that of, Wincent et al. (2010) who found that diversity in characteristics of board members such as education and experience is important for innovation. This study adds a deeper understanding of the role of board network on innovation applying social capital theory (e.g., analyzing interrelationship of social capital structure and content).

The analytical part of this chapter uses the framework we developed in Chapter 4. Here, we also acknowledge the importance for a firm's innovation of accessing and utilizing social capital. As a result, hypotheses in this chapter were drawn from three streams of research: social capital theory, transition economics and firm innovation. Social capital theory focuses on the strategy of firms that access and mobilize resources through utilizing personal network ties (Coleman 1987; Burt 2000; Nahapiet and Ghoshal 1998), while the literature on transition countries emphasizes the role of changes in the political, social and economic system that facilitate (or necessitate) certain organizational behaviors (Stark 1991; Ledeneva 1998; Batjargal 2003; Stark and Bruszt 1998; Berglöf, Thadden, and Ernst-Ludwig 1999), and firm innovativeness literature highlights the role of national innovation systems, path dependence and inter-linkages between actors (Arocena and Sutz 2002; Acs and Audretsch 2003; Lundvall et al. 2002; Radosevic 2002).

This chapter makes several contributions: first, we expand the discussion on the role of the board network on firm innovation into the transition context. Here, the interest is that firms were embedded in strong personal ties in order to survive. At the same time, firms might benefit more if they search for new sources of knowledge and better organizational practice, which might be obtained if they establish linkages with foreign firms or firms outside their existing contacts. Embeddedness in an old board network 
might constrain a firm's ability to extract new knowledge from the new business environment.

Second, prior research on other dimensions of social capital such as network content is mostly discussed in the context of firm alliances. In this study we extend the scope of this stream of research by applying it to the board network. This approach deepens our understanding of the mechanisms through which a board network influences innovative performance. Knowledge transfer is an important driver for firm's innovation and can provide a competitive advantage to the firm. In this regard, this chapter used several measures to capture the board network quality and resources, which contributes to the discussion of the role of board network in firm innovation.

Third, this chapter also explores the effects of interaction between network structure, such as network density and structural holes, and network content, such as actors' network homophily, partners' assets and foreign ties. Similarly to Chapter 6 here we also test the complementarity between certain network structures and qualities.

This study employs three different datasets: the innovation survey data for the period 2008-2010, board members network data in 2005 and firms' financial variables for the period 2000-2010. The combination of these databases enables us to employ a cross sectional design using firms' past network variables, which gives us some control over the endogeneity of firm's network and innovative performance.

We elaborate the theoretical foundations of key hypotheses in section two. Section three provides details on methodology and data collection, and section four reports the result of econometric analysis. The final section discusses the main finding and set concluding remarks.

\subsection{Conceptual framework and hypotheses}

The role of board networks in explaining firm financial performance we discussed in Chapter 4, and in this chapter we extend it to firm innovation. Drawing our arguments from previous literature we only emphasize the aspect of social capital that matters specifically for innovation and learning.

The resource-based theory highlights that board members are useful in providing access to different resources (Salancik and Pfeffer 1978). Scarcity of resources and lack of technical skills encourages collaboration among firms through board members, since collaboration reduces cost, improves quality and forms a base for further collaboration (Uddin 2012). Prior research has established that being connected in board networks enhances organization learning (Uddin 2012) and information sharing (Cooper and Slagmulder 2004), facilitates higher trust (Su and Zhang 2008), reduces uncertainty (Martin, Gözübüyük, and Becerra 2015), and, most importantly for this chapter, increases the chances to innovate (Wincent, Anokhin, and Örtqvist 2010). All this is to say that social capital is important for innovation, as it is for financial performance. In both cases, network connections are used for gathering information (technology, knowledge, competences) that the firm does not have in house. Much of the argumentation of Chapter 4 applies directly here in the innovation setting, as issues regarding, for example open versus closed positions are very similar. Thus we do not 
repeat the arguments of chapter 4, instead jumping straight to hypotheses where appropriate.

As we have shown in the Chapters 2 and 3, firms in Armenia had to restructure and upgrade a production process, which means that in order to survive they faced an urgent need to innovate. But in general, these firms had limited resources and knowledge. One way to overcome this limitation is to use board members' resource acquisition potential, in a way that board composition should match the firm's needs (Wincent, Anokhin, and Örtqvist 2010). This indicates that the value of the board network will depend on the firm's ability to efficiently utilize board potential.

Comparisons of national innovation surveys between developing and developed countries have found that learning in developing countries happened more in informal cooperation and through personal ties, rather than in formal R\&D collaborations, which are one of the important sources of innovation in developed countries (Arocena and Sutz 2002; Garrido and Padilla 2011; Cimoli, Primi, and Rovira 2011). ${ }^{71}$ Analysis of our innovation survey of Armenia found similar results: ${ }^{72}$ most product and process innovations are developed in-house. Interpreting "in-house" in this transition context we can observe that with regard to "innovation culture", a firm's board members might have a more important role for knowledge transfer and exchange, as they are perceived as internal actors, even though they might be also appointed in other firms. With overlap in board memberships, the boundary between internal and external information can become blurred. While this may make analysis of knowledge flows trickier, it might be good for firm innovative performance. Use of social network analysis is an attempt to address the latter issue by mitigating the former.

Research on firm innovation has demonstrated that new knowledge comes from effective knowledge sharing (Grigoriou and Rothaermel 2014; Uzzi and Lancaster 2003), transfer (W. Tsai and Ghoshal 1998), diffusion (Cowan and Jonard 2009) and recombination (Rodan and Galunic 2006). External knowledge combined with internal knowledge has a strong impact on a firm's innovative performance (Ahuja 2000), and social networks are important mechanisms to provide access to a variety of knowledge and resources from different partners (Lahiri and Narayanan 2013).

To address our main research question of which board network characteristics influence firm innovation, we adapted the conceptual framework developed in chapter 4.

\subsubsection{Structural social capital}

Similarly to Chapter 4, our analysis in this section focuses on distinct dimensions of social capital: network structure and network content. In the structural dimension social capital is represented by network positions and network content measures social

\footnotetext{
${ }^{71}$ Arocena and Sutz (2002) found that industrial innovation is highly informal in Latin American countries, and R\&D activities are not formally articulated with the enterprise strategy. Firms consider the ideas of innovation as internal affairs. The National Innovation System in Latin America is called a "neo-peripheral system of innovation" 72 Chapter 7 discusses the details.
} 
capital from the perspective of the ties quality and actual resources that partners possess.

In previous chapters we have discussed how new ideas were important for firm survival and adaptation to a new environment. In the $2^{\text {nd }}$ part of the thesis, we did not differentiate among different types of "newness" that firm required. In this chapter, we focus specifically on new ideas regarding products and processes. Therefore, most of the arguments can be carried over directly from hypothesis related to technical innovation (e.g., firm's absorptive capacity or introduction of new processes and products). In general hypothesis are similar, thus I will focus on those aspects that are specific to process and product innovation.

The importance of a firm's network position for its performance is well established in the management literature and discussed in Chapter 4. Specific to innovation performance, Tsai (2001) argues that occupying a central position in the network enhances opportunities to produce more innovation, as ties with others provide access to new knowledge. However, we already discussed that this relationship is nonlinear, and an excess of ties has a negative effect (Non and Franses 2007; Watson 2007). Therefore, we suggest the following hypothesis about effects on innovation of firm centrality in the Armenian board network.

\section{Hypothesis 1: A firm's degree centrality has a positive, sub-linear relationship with its innovation performance.}

Drawing a network perspective on organizational learning, Tsai (2001) ${ }^{73}$ emphasizes the firm's capabilities and absorptive capacity in generating new knowledge. Network position provides potential to access new resources and knowledge, and innovation is the firm's ability to generate new knowledge, and hence the mechanism through which the firm accesses resources and knowledge, and the way the firm absorbs them has a significant impact on its innovative performance. The network provides a potential opportunity to access complimentary resources, which are outside of firm's boundaries, but the firm's internal resources and absorptive capacity are also critical for innovation. The Schumpeterian view on innovation emphasizes that innovation involves combination and recombination of existing and new resources available to the firms (Schumpeter 1934). Centrality in the board network first enables the focal firm to access a variety of external knowledge and resources through its partners, but the firm's internal capabilities are critical for novel combinations. In other words social capital becomes effective when the firm is embedded in the network, but most importantly when the firm is also capable to assimilate and use the resources and knowledge possessed by partners. Cohen and Levinthal (1990) used the phrase "absorptive capacity" to identify a firm's internal abilities to assimilate and replicate new knowledge. And as the firms differ according to their "absorptive capacities", we suggest to look at combination of firm's position in the network and its "absorptive" capacity.

\footnotetext{
${ }^{73}$ Here we depart from the analytical framework developed by Tsai (2001), which emphasizes the moderating effect of network centrality and organization unit's absorptive capacity on its innovation and business performance.
} 
One way to measure a firm's absorptive capacity is to look at its past innovation performance. One of the standard measures for absorptive capacity is the firm's R\&D intensity (e.g., Cohen and Levinthal, 1990). We are interested in capturing the accumulation of knowledge over the past years, and frequency of past innovative performance is the most appropriate measure for our study. Firms that innovate more often in the past have signaled that they are able to learn and assimilate new knowledge.

Hypothesis 2a: Firm absorptive capacity (as measured by past innovative performance) is positively associated with a firm's innovative performance.

Hypothesis 2b: Firm absorptive capacity will positively moderate the relationship between firm's network (degree) centrality and firm innovative performance.

In this part we suggest hypotheses to examine the Burt vs. Coleman debate in the context of firm innovation, though we expect that network structure may have different effects on firm innovation than it does on financial performance. Specifically, we expect that structural holes may provide better opportunities for firms to innovate. The access to newer and non-redundant knowledge and information might be more valuable for firm innovation given the context of transition (e.g., urgency of replacing obsolete products, adapting new organizational behavior). In our empirical model we will test both competing hypotheses related the old debate between network closure vs. structural holes.

Hypothesis 3a: Ego network positions rich with structural holes are positively associated with a firm innovative performance.

Hypothesis 3b: Firm's network closure is positively associated with firm innovative performance.

\subsubsection{Network content}

Drawing insights from previous literature, we argue that although network structure plays an important role in explaining individual firm performance, network quality resources, knowledge and information embedded in the network structure enhance firm innovation (Maurer, Bartsch, and Ebers 2011; Tsai and Ghoshal 1998; Batjargal 2003; Rodan and Galunic 2006; Lööf and Heshmati 2002). Here we discuss how a firm's network diversity (heterophily), its partner's assets and partners' exports influence its innovation.

\section{Heterophily}

Prior research has focused on the relationship between board members' characteristics and firm innovative performance (Talke, Salomo, and Rost 2010; Rost 2011). These studies pointed out that diversity of the board in terms of expertise and education level positively affects innovation. Results on the relationship between diversity and innovation are inconclusive. For example, at the individual level, Dahlin et al. (2005) show that diversity among innovation team members has positive effects on creativity, 
novel design and solutions. By contrast, Jiang et al. (2010) found a U-shape relationship between alliance portfolio diversity and innovation, pointing out that highly diverse portfolios provide a wide range of options, resources and knowledge, though at the same time increased diversity increases both complexity and coordination costs.

This chapter focuses on firm network diversity in terms of industry, and we argue that though firms in the same industry may have similar backgrounds and can benefit from sharing knowledge, they are competitors and might have conflicting interests and in fact be involved in learning races. Therefore, firms linked with different industries may benefit from a broad range of differentiated needs, as well as not competing in the same market (Jiang, Tao, and Santoro 2010). The alliance literature considers industry level diversity as a benefit for the firm innovation. This type of network diversity increases likelihood of novel problem solutions, as they suggest more variety and possibilities (Lahiri and Narayanan 2013; Jiang, Tao, and Santoro 2010).

Industry diversity might be crucial for spreading risk across industries: if industry-level shocks occur the firm is better off if it is linked with other industries assuming that a firm will have stronger partner-firms when many firms in the same industry sunk due to the shock. This aspect of diversity highlights the importance of reducing firm's surrounding uncertainty. Stark (1991) and Batjargal (2003) noted that firms in transition economies enter and build complicated networks with other firms where assets and liabilities are "creatively dispersed", and thereby reduce the environmental uncertainties. By reducing the uncertainty, firms would more effectively direct their resources on innovation activities. Studies on transitional countries (e.g., Stark 1991; Greeven and van de Kaa 2014) found that a lack of efficient stabilizing mechanisms implemented by the states forced the firms to seek alternative strategies such as creating alliances and network to reduce environmental uncertainty, and this strategy was "crucial in creating competitive advantage for innovating firms" (Greeven and van de Kaa 2014, pp. 244).

\section{Hypothesis 4a: Higher industry heterophily (diversity) in its ego-network is positively associated with firm innovative performance.}

One of the motivations for firm partnership is access to assets: board networks provide opportunities for exchange of material or tangible resources, and in many cases cooperative interests between banks and borrowers, for instance, can affect the availability and cost of the capital (Uzzi and Gillespie 1999). Ayyagari et al. (2007) found that innovation is higher in firms that have access to finance. Since innovation can be costly, it tends to require outside finance, and hence a rich and resourceful network provides competitive advantage.

Dabla-Norris et al. (2012) found a correlation between effectiveness of innovation activity and development of country's financial system. They have also emphasized that development of the financial sector is crucial for a country's ability to capture the technological spillovers from foreign direct investments. Similarly, Aghion et al. (2004) found that innovative firms are reliant on external financial sources. We discussed 
earlier that in the early transition the finance and banking sectors were not well developed. Compared to developed countries, in the Armenian financial sector many intermediary actors such as investment funds or external investors, are missing, and therefore borrowing is costly, banks and other actors are hesitant to invest in risky and long term projects, but firms may be able to find finance from other (non-bank) firms if they are connected in some way This suggests that since firms with higher partner's assets have access to richer assets and resources, and they may be more likely to innovate.

\section{Hypothesis 4b: Partners' assets positively associates with firm innovative performance.}

Firms in Armenia are less exposed to foreign markets and knowledge, and therefore could not benefit greatly through access to new knowledge, from new markets and better organizational practices. In chapter 4, we discussed how important are foreign ties for the firms, here we expect to see an even stronger effect.

Discussing the positive spillovers from being connected to exporting firms we rely on two main assumptions: a) exporting firm are more likely to be innovative because foreign markets are more competitive; b) exporting firms are more exposed to organization change and adaption of best practices.

A) Introducing their products in external markets, firms ultimately feel pressure to adopt and exercise new practices. Compared to local markets competition in foreign markets is more intense, thus firms face an ultimate need to upgrade their technology and processes, and introduce new products. In general, non-exporting firms have fewer incentives to innovate or innovate less frequently than exporting firms. Innovation demands an effort, and very often success in the local market depends on strong political ties rather than on innovation. In contrast, exporting firms need to introduce competitive products in foreign markets either through product or process innovation.

B) Another advantage that ties to exporting firms provide is transferring new organizational practices. In this study we emphasize the role of an exporting firm that could potentially directly serve as a channel for other connected firms to change their "old style" behavior, and thus become more innovative.

Exporting firms have access to foreign markets and potentially new technologies and understanding of different organizational practices, and thus they represent an important resource in the network for the knowledge transfer and adaption of the "new" behaviour. We expect to see strong effects of partner's exporting on firm innovation.

\section{Hypothesis 4c: Partners' exports (foreign ties) positively associates with innovative performance.}




\subsubsection{Appropriation of social capital: complementarity between network structure and content}

We argue that the combination of certain characteristics of network structure and network content enable more efficient mobilization, assimilation and utilization of resources which accrue to the focal firm by virtue of having a network with a greater extent of structural holes or network closure.

Although most of the arguments supporting the hypothesis development in the chapter 4 are relevant for this chapter, we expect to see some important differences. For example, we argue that network sparseness without knowledge diversity may have very small effects. Here, we emphasize this hypothesis, highlighting that diversity of the knowledge might have a stronger effect on firm innovation than it does on financial performance. In terms of industry diversity, insights from Rodan and Galunic (2006)'s study suggest that diversity is more effective when it is complemented with network sparseness. New ideas emerge when firms are not very close to each other; when well-circulated knowledge has less novel value.

\section{Structural holes, network diversity (industry diversity) and foreign ties (partner-firm exports)}

Networks rich with structural holes offer brokerage opportunities for information and knowledge flow. Yet, what happens if the focal firm actor in a tie that spans a structural hole is also connected to disconnected others who are very similar to each other in terms of information and knowledge? As Burt suggests: "Structural holes are the setting for tertius strategies. Information is the substance" (Burt, 1992: 33). We therefore expect the benefits of structural holes to be more pronounced in the presence of some sort of diversity of knowledge of the disconnected others as well as in presence of structural holes. Thus, measures of industry diversity and partners' exports may interact with structural holes when explaining firm innovation (Rodan and Galunic, 2004), given that generation of new knowledge first requires opportunities to access diverse pools of knowledge (Rost, 2011). Hence, new ideas emerge when disconnected firms are not very similar to the focal firm and contain diverse knowledge. We therefore posit the following hypotheses:

Hypothesis 5a: The interaction of network diversity (industry diversity) and structural holes will be positively related to firm innovation.

Hypothesis 5b: The interaction of foreign ties (partner's exports) and extent of structural holes will be positively related to firm innovation.

\section{Network closure and network resourcefulness (partners' assets)}

Conversely, the benefits of network closure are more meaningful if the network is resourceful. Network resourcefulness, in terms of partners' assets, stands to benefit the firm due to the potential for exchange of resources; however, such exchange requires higher levels of trust and reciprocity which are more often found within cohesive ties. In transition economies, in which weak institutional frameworks fail to 
establish legal protection, informal rules dominate. Under these conditions, greater firm network density creates a mechanism for collectively monitoring and coordinating exchange. As a result, firm networks with greater network closure establish certain rules and norms and shared practices that can both constrain individual action while at time same time ensuring that firms do not deviate from the common interests. Cohesive networks may provide higher levels of security, due to fears of creating bad reputation and social sanctions, than legal enforcement. In this case, when we talk about sharing and exchange of the financial resources, equipment and any other material and tangible resources, cohesive networks are more efficient because risks of firm deviation, cost of monitoring and protection are minimized. We therefore hypothesize that:

\section{Hypothesis 5c: The interaction between network closure and network resourcefulness (partners' assets) will be positively related to firm innovation.}

\subsection{Methodology}

\subsubsection{Data}

This study used firm financial and innovation survey data (see Chapter 7), as well as the board representation data (see Chapter 4). For our analysis we only used board network in 2005 and firm level data, which includes industry, annual employment and financial information for the period 2000-2010. These datasets were subsequently combined, and we constructed a cross sectional dataset for this study, where we used only board network data in 2005 to measure its effect on firm's innovativeness in 2008-2010. In total we have data on 192 firms, who also participated in the survey. 26 firms that were in our initial list did not operate in 2011, only 2 firms refused to participate in the survey. Face-to-face interviews were conducted during the innovation survey with participation of top managers that provided an assessment of firm's innovative activities.

\subsubsection{Variables}

\section{Firm innovative performance}

To measure innovative performance we focus on product or service and process innovations: a firm is innovative if it introduced either a new product or service, or a new process (or both) between 2008 and 2010. New product or service is defined as those that were either or significantly improved. Process innovation is defined as significantly improved methods of production or deliver, and includes significant changes in techniques and software. ${ }^{74}$ We distinguish between new to the firm and new to the market innovations.

\footnotetext{
${ }^{74}$ To define Process or product innovation we follow OSLO manual (2005).
} 


\section{Dependent Variables}

Firm Innovative performance is a dummy variable that takes 1 if a firm introduced at least one product service or process innovation between 2008-2010, and 0 for noninnovative firms.

Ordered Innovative performance is categorical variable, which takes 0 for noninnovative firms, 1 if a firm introduced new to firm innovation (incremental innovation), and 2 if firm introduced new to market innovation (radical innovation).

\section{Network structure}

To test our hypotheses about the effect of its network position on a firm's innovative performance, we used degree centrality, constraint/betweeness centrality and clustering coefficient measures for the analysis in this chapter. We have already discussed how we calculate and construct the network in Chapters 4 and 5 . The procedure is the same, but we only used the network variables of the year 2005, and in this chapter we use only one measure for "structural hole". We use Burt's constraint measure, and for the robustness check we use betwenness centrality. With binary data betweeness centrality measures the firm's favored position to the extent that the focal firm falls on the geodesic paths between other pairs of firms in the network. Higher value of betweeness centrality show that more firms depend on the focal firm to make connections with other firms (Batjargal 2003).

To capture network closure we used the local clustering coefficient measure, which assess the number of triples among ego's contacts as a proportion of all possible ties (Galunic and Moran 2000). Higher the value of clustering coefficient, which ranges from 0 to 1 , indicate that more of ego's contacts interact with each other.

\section{Network content}

To assess network content we use 3 main measures network diversity (heterophily), network resourcefulness (Batjargal 2003) and foreign ties (see Chapter 4).

First, the diversity of a firm's ties is based on industry. We used UCINET to calculate Blau's heterophily measure, which take into consideration how balanced are all possible categories are represented in firm's network.

Industry heterophily shows ties with alters based on 9 possible industries. It ranges from 0 to 1 , where low values or approaching zero values show that firm's ties are concentrated in a single category, and in case of 0 it is complete concentration. Actors evenly spreading their connection across industries will have higher scores.

Network resourcefulness measures the sum of partners' assets (total assets that connected firms possess), which captures the resource embeddedness of a firm. We used the logarithm of network resourcefulness. Higher values indicate that ego's network is richer, and the focal firm has access to more alters' resources.

Foreign Ties measures the sum of partners' export volume, which captures the intensity of the connection with foreign firms, and we assume that connection with foreign 
business partner may provide a firm access to new knowledge. Higher value indicates that the focal firm has better access to modern or new organizational knowledge.

\section{Firm level characteristics}

Empirical literature widely uses firm size, age industry and location variables to control for firm level hetrogeniety (e.g., Wu 2008; Mors 2010; Thorgren, Wincent, and Boter 2012):

\section{Control Variables}

Firm size is measured by Log value of the number of Employees.

Firm's industry - We also used industry dummies to capture the technological opportunities: in the absence of direct measure this is widely used practice (Mairesse and Mohnen 2010).

Region dummy equals 1 if firm is registered in Yerevan, and 0 otherwise.

Firm absorptive capacity ${ }^{75}$ shows information on firm's innovation frequency in the past (retrospective survey question). This is dummy variable, and it takes 1 if the firm has introduced innovation more than once per year during the period 2000-2008, and otherwise it takes 0 .

Sales show total annual sales for years 2008, 2009, 2010, we also used average sales for the period 2008-2010.

University dummy indicates 1 if the firm collaborated with Universities, and 0 otherwise.

\subsubsection{Econometric models}

We used the binary outcome probit model to estimate the impact of social capital on the probability that the firm innovates. The binary probit model for innovation is written:

$$
\begin{gathered}
y_{i}^{*}=\dot{x}_{i} \beta+u_{i} \\
i=1, \ldots, N
\end{gathered}
$$

\footnotetext{
${ }^{75}$ In the original work, Cohen \& Levinthal use R\&D expenditure to capture the absorptive capacity. There were two main reasons I had to deviate from this approach: a) R\&D expenditure data was very difficult to collect- the majority of firms could not specify the exact R\&D expenditure. This is based on the country's accounting system, which does not reflect well the innovation aspect. b) many developing countries have many non-R\&D performing innovators. Armenia was not an exception, as we saw in the chapter 8, acquisition of machinery is also highly correlated with innovation. c) Empirical literature also presents evidence that the frequency of past innovation increases the probability of firm's future innovation (see Labeaga J. M., E. Martínez-Ros (2002) and W. Smolny (2003).

Given these conditions, we thought that R\&D expenditure may not capture the absorptive capacity of Armenian firms, instead, firms that innovated frequently in the past are signaling about their high-level absorptive capacity.
} 
Where $u_{i}$ are unobserved effects and $\dot{x}_{i}$ is the set of explanatory variables: the latent variables, the propensity to innovate $y_{i}^{*}$ is not observed. What is observed is the realization of firm introduces innovation or not.

$$
y_{i}^{*}=\left\{\begin{array}{l}
1 \text { if innovation occured } \\
0 \text { if no innovation }
\end{array}\right.
$$

To capture the difference between radical and incremental innovation, we used an ordered probit model on the innovation variable, which now has three outcomes:

$$
y_{i}^{*}=\left\{\begin{array}{l}
2 \text { if innovation is radical } \\
1 \text { if innovation is incremental } \\
0 \text { if no innovation }
\end{array}\right.
$$

The generalized ordered probit model is appropriate when polychotomous dependent variables have a natural order, but the distance between the intervals is not scaled (Barbosa, Faria, and Eiriz 2013).

The parameter of interest $(\beta)$ should be read considering of the fact that our data is cross sectional, and so does not provide the opportunity to measure causal effects of explanatory variables, but rather captures correlation where a causal effect is one possible interpretation. To control partially the potential endogeneity problems we used lagged values of network variables.

To avoid high multicollinearity between main effects and interaction terms the explanatory variables were standardized following the econometrics literature (Allison 1977). ${ }^{76}$

\subsection{Results}

Table 9-1 presents the descriptive statistics and correlation among the main variables. Social capital measures in general are highly correlated, and in some case correlation is higher than 0.7. To avoid multicollinialy in our model we first measure the contribution of each social capital variable in the model (see Table 9-2). We also used step-by step approach which includes social capital variables in the model at a time. These models are reported in the appendix (See Tables 1 and 2). In case of interaction terms, we standardize variables first and then estimate their relative impact. We report marginal effects calculated at mean values of the variables for the models $1-5$, but we also report the main coefficients of the probit estimation for the model with interaction terms (see Model 6 - Table 9-2). The reason is that we were interested in reporting the marginal effects of the main social capital variables from the nonrestricted model 6. For interpretation of the interaction terms we use model 6 . Estimates of control variables are included in model 1 (see Table 9-2). Industry dummies are included, and the reference category is agricultural food and beverage

\footnotetext{
${ }^{76}$ We first standardize a random variable that is normally distributed by subtracting the mean from each value. As a result all values of a variable are centered at the origin. Subsequent tests were conducted and indicate that multicollinearity is not the issue.
} 
production. Only service sector has significant effects (effects of other industries were not significant and we did not report). Estimates of absorptive capacity (innovation frequency) and variables of social capital are introduced in models from 2-5, where model 5 includes all the network variables (see Table 9-2).

Our results (Model 6 Table 9-2) provide support for hypotheses 1, 3a, 4a, 4b and 4c which were testing the impact of network structural and content variables. Our results confirm that Degree centrality has positive but non-linear impact on firm innovation (Hypothesis 1). Hypothesis 2a predicts that a firm's absorptive capacity measured by frequency of innovation is positively associated with the firm's probability to innovate, and our results support it. Hypothesis 2 a suggests that firm absorptive capacity has a positive impact on firm innovation, and our results support that. In terms of hypotheses $3 \mathrm{a}$ and $\mathrm{b}$, our results show that structural holes are a better structure for a firm to innovate. As a robustness check we used a second measures for structural hole - betweeness centrality (we did not report), and it also appears to have a positive and significant effect on firm's innovation (hypothesis 3a). In contrast, hypothesis $3 \mathrm{~b}$ predicts that network closure positively correlates with firm's innovation, but in our results network closure measured by the clustering coefficient has a negative and significant effect (-0.87), contradicting the hypothesis. The effect of industry heterophily is positive and significant in model 6 (Table 9-2), providing support for hypothesis 4a. Network resourcefulness measured by partner's assets is also positive and significant, and if we double resourcefulness than it will increase the probability of the firm innovating by 3\% (hypothesis 4b). Our model supports Hypothesis 4c showing that foreign ties measured by partner's export volume has positive and significant effect on firm's probability to innovate. And if a firm's partner's export volume increases twice it will increase firm's probability to innovate by $12 \%$.

Models 5 and 6 report the results with interaction terms. Our results supported Hypothesis $2 \mathrm{~b}$ which suggests that an interaction term between firm absorptive capacity and degree centrality will increase firm innovation. The estimates indicate that effect of firm's innovative frequency and degree centrality are positive and significant, and they have strong complementary effects.

Hypothesis 5a which suggests that the interaction term between firm's industry heterophily and structural hole has a positive effect on firm innovation, was supported by our results - the coefficient of the interaction terms was positive and significant.

Our results supports Hypothesis 5c, which predicts that the interaction term of clustering coefficient and partners' assets will have a positive effect on the probability to innovate. Our results show that interaction between partner's export and constraint is positive but not significant. Hypothesis 5b predicts that interaction effect of partners' export and structural holes is positive; yet we didn't find a strong support. 
Table 9-1: Correlation matrix

\begin{tabular}{|c|c|c|c|c|c|c|c|c|c|c|c|c|c|c|c|}
\hline & & Mean & S.D. & 1 & 2 & 3 & 4 & 5 & 6 & 7 & 8 & 9 & 10 & 11 & 12 \\
\hline 1 & Firm Innovation & 0.47 & 0.5 & 1 & & & & & & & & & & & \\
\hline 2 & Log(employment) & 3.08 & 1.71 & $0.26^{*}$ & 1 & & & & & & & & & & \\
\hline 3 & University dummy & 0.07 & 0.25 & $0.24^{*}$ & $0.36^{*}$ & 1 & & & & & & & & & \\
\hline 4 & Average sales & 3.92 & 5.02 & $0.15^{*}$ & $0.5^{*}$ & $-0.1^{*}$ & 1 & & & & & & & & \\
\hline 5 & Firm absorptive capacity & 0.27 & 0.44 & $0.72 *$ & -0.01 & 0.02 & $0.23 *$ & 1 & & & & & & & \\
\hline 6 & Degree centrality & 3.2 & 2.46 & $0.25^{*}$ & $0.08^{*}$ & $0.17^{*}$ & $0.23 *$ & $0.11^{*}$ & 1 & & & & & & \\
\hline 7 & Degree centrality squared & 16.22 & 30.53 & $0.16^{*}$ & 0.04 & $0.14^{*}$ & $0.22 *$ & $0.13^{*}$ & $0.94 *$ & 1 & & & & & \\
\hline 8 & Clustering coef. & 0.19 & 0.33 & 0.02 & $0.13^{*}$ & -0.02 & $0.08^{*}$ & 0.03 & $0.3^{*}$ & $0.17^{*}$ & 1 & & & & \\
\hline 9 & Constraint & 1.11 & 0.11 & $0.28^{*}$ & $0.09 *$ & $0.21 *$ & $0.15^{*}$ & $0.07^{*}$ & $0.81 *$ & $0.74^{*}$ & $0.46^{*}$ & 1 & & & \\
\hline 10 & IND diversity & 0.27 & 0.3 & $0.26^{*}$ & $0.06 *$ & $0.16^{*}$ & $0.1^{*}$ & 0.04 & $0.73 *$ & $0.54^{*}$ & $0.48^{*}$ & $0.8^{*}$ & 1 & & \\
\hline 11 & Partners' assets & 10.02 & 5.63 & $0.26^{*}$ & $0.05^{*}$ & $0.15^{*}$ & $0.19 *$ & 0.05 & $0.56^{*}$ & $0.36^{*}$ & $0.32 *$ & $0.55^{*}$ & $0.53^{*}$ & 1 & \\
\hline 12 & Partners' exports & 3.57 & 5.04 & $0.22 *$ & 0.04 & $0.08^{*}$ & $0.12 *$ & 0.04 & $0.55^{*}$ & $0.47^{*}$ & $0.33^{*}$ & $0.53^{*}$ & $0.43^{*}$ & $0.47^{*}$ & 1 \\
\hline
\end{tabular}


Table 9-2: Results of probit models (marginal effects at mean of variables) ${ }^{77}$

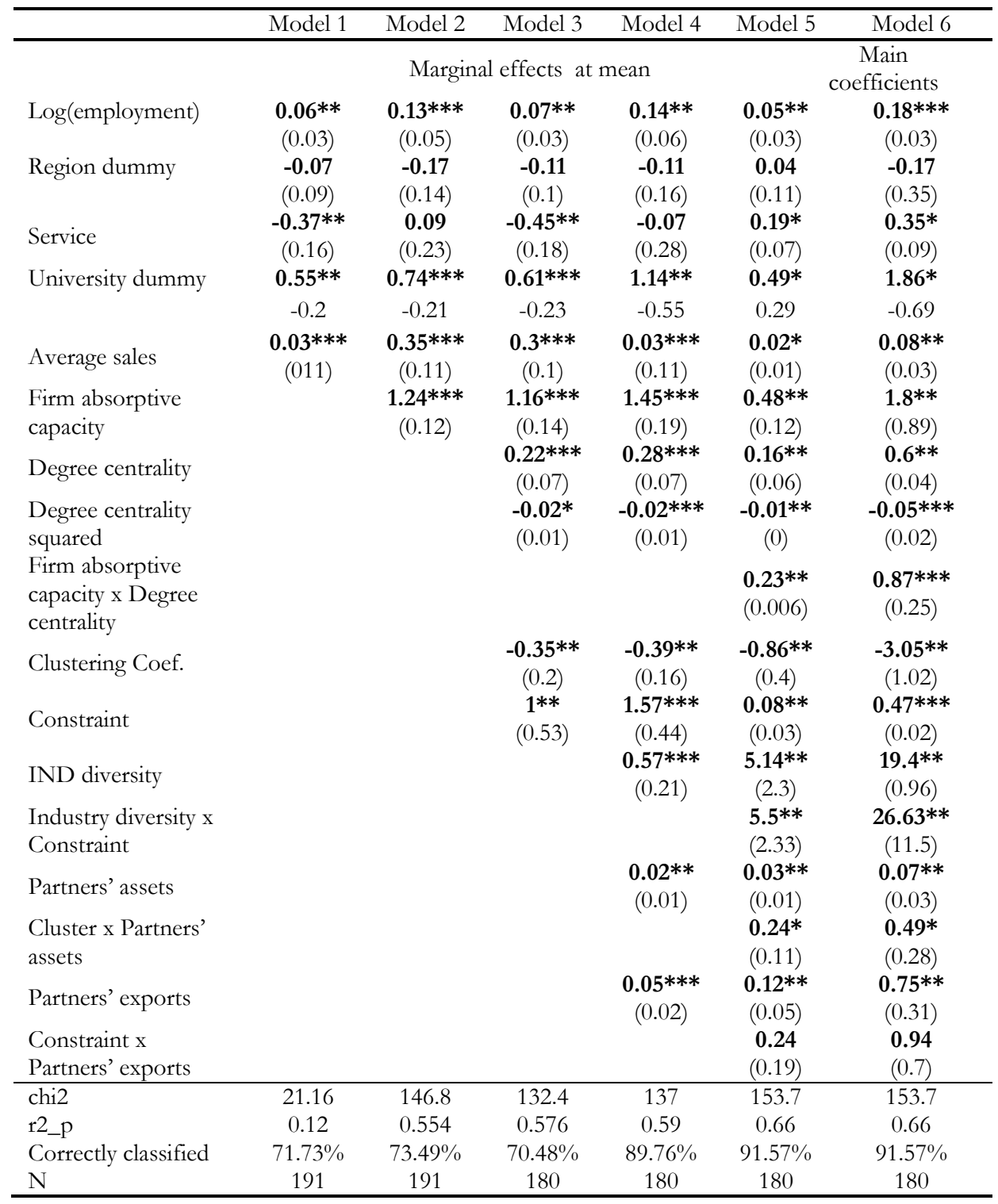

In addition to the probit model we also used an ordered probit. In this case the innovation variable is ordered, taking the values 0 for non-innovators, 1 for new to the firm and 2 for new to the market innovators. The results are reported in appendix F (Table 3), and confirm the findings of the probit model. The results were very similar,

\footnotetext{
${ }^{77}$ For Models 1-5, we reported marginal effect calculated after probit regression, for Model 6 we reported only the coefficients obtained in probit regression as the marginal effects of interaction terms doesn't have explanatory power.
} 
(even the of magnitude of the coefficients), however one important difference is that with the ordered dependent variable the chemical industry becomes a highly significant predictor.

\section{Endogeneity}

The effect of Board network on firm innovation could results for endogenous reasons. One of the main concerns for the endogeneity could be a reverse causality issue, as more innovative firms might attract more established directors with more connections. To mitigate the reveres causality concerns, we used past network characteristics (2005) to estimate effects on a firm's probability to innovate (in 2008-2010). In the empirical literature, using lagged values of social capital variables is a very usual technique to control for reveres causality. In terms of timing effect, both theory and empirical findings did not indicate how far past network characteristics affect firm's performance. Our findings shows that network characteristics in 2005 have significant effects on firm's innovative performance for the period of 2008-2010.

\section{Goodness of fit and prediction}

To assess overall model fit we reported the likelihood ratio chi-squared statistics and pseudo R squared. Table 9-2 reports chi-square for each model. The significance level of all our models for chi-square is in the acceptable range $(\mathrm{p}<0.001)$, and indicates an acceptable fit.

Pseudo R-squared measure attempts to mimic the R-squared measure of linear regression model (Cameron and Trivedi 2005), and it reports fitted log-likelihood value. This measure suggests the level of improvement of the full model (model with predictors) compared to intercept model. Similar to R-squared in linear model it ranges from lower (0) to upper (1) bounds. Higher pseudo R-squared indicate the model with greater likelihood. In all our models pseudo R-squared is higher than 0.6.

We also used goodness of fit measure based on percentage of correctly specified values, which compares fitted and actual values (see Table 9-2). In our model percentage of correctly specified values varied from $71 \%$ to $91 \%$. Especially highly specified are models with all social capital variables (model 5 and 6 in Table 9-2). We have also looked at the ratios of correctly specified observation for both outcomes. And in all models for both outcomes ratios of misspecified observations are very low (not reported).

\subsection{Discussion of results and conclusion}

At the beginning of this chapter we discussed that position in the board network and partner's attributes contributes to firm's innovative performance. We focus on two main dimensions of social capital, network structure and network content. In addition we suggest that the right combination of certain network structure with content will provide higher benefits for the firms. There are discussions in the literature of the view that structure and content will interact in determining innovative performance, but as yet there is not a large body of empirical work that addresses it. Our results provide 
strong support the conjecture found in the literature that network position interacts with network content.

First, our findings indicate that centrality in board network exerted non-linear effects on firm's innovativeness. We further the discussion of Reagans and McEvily (2003), which suggest that centrality in network is beneficial when the firm has higher absorptive capacity, and we found that past innovative performance positively moderates network centrality and significantly increases a firm's probability to innovate.

Second, our findings clearly show that network sparseness has a strong positive effect on innovative performance consistent with prior research (Burt 2000; Rodan and Galunic 2006). According to our results, firms that combine industry heterophily and network sparseness in their board network access more diverse knowledge and resources, and have higher chances to innovate. This finding is aligned with Rodan and Galunic (2006), which shows that knowledge diversity and network sparseness generates novel knowledge. Knowledge diversity is more likely to come from structural holes, but network sparseness alone does not provide benefits for the firm innovativeness. Social capital theory very often assumes that benefits of network sparseness are access to more diverse knowledge and information; however it is wrong to confound sparseness with benefits of access to diverse knowledge and resources (Rodan and Galunic 2006). Our results show that network sparseness has a stronger effect with the presence of industry heterophily.

Third, our findings support our predictions that network resourcefulness (partner's assets) and foreign ties (partners' export) are important in the context of transitional economies to explain firm's innovativeness. Moreover, the question that we address, which network structure is the best for mobilization and actualization of qualities of firm's network, leads us to the conclusion that network sparseness combined with knowledge heterophily (industry heterophily) and network closure combined with rich assets generate higher advantages for firm's innovativeness. To test hypothesis $5 \mathrm{~b}$ we used interaction term between structural holes and partners' export, but it doesn't yield significant results.

Though we did not find any evidence that foreign ties (partners' assets) are more beneficial when it is combined with network structure, but yet our results strongly support that firm's having ties with export oriented firms has higher probability to innovate, regardless of the network position of the focal firm.

\section{Conclusion}

This study contributes to the literature on board networks by explaining the relationship between board network and innovative performance in a transition country context. It adds empirical evidence to the discussion of organizational diversity, network structure and resources, knowledge and information embedded in social ties. Some prior studies show that diversity can constrain firm's collaborations and serve as a potential source of conflicts, it make more difficult the exchange of information (Goerzen and Beamish 2005; Chatman et al. 1998), but some studies found that diversity had a positive impact on innovation through facilitating more 
efficient problem solving for the groups and providing new perspectives (Rodan and Galunic 2006; Dahlin, Weingart, and Hinds 2005). This study measures diversity from the industry perspective, suggesting that experience from different industries can contribute to creation of new knowledge; and may also serve as a coping mechanism for industry level shocks and eliminate potential competition between the firms in the same industry.

This research also followed the longstanding debate in social capital theory, and contrasted the two alternative views of network closure and structural holes. Our analyses show that sparseness in the board network offers more information and control benefits important for innovation such as access to new knowledge and resources. We further the discussion of network structure, as we suggested first to measure the quality of partners (network content), and second, to explore more in the direction of the combination of network structure and content. Our intent was to examine mechanisms by which actors can better mobilize and utilize the potential resources available through networks.

The findings, in particular, point out that network structure matters, but structure alone cannot explain the benefits of social capital. What is also important is both the actor's absorptive capacity to exploit further the information, the knowledge available through network ties, and the quality of the actor's network.

This research has several limitations that are important for the empirical results. First, we have collected data of firm's innovation only for one period, which does not allow us to use more robust models such as panel data models. Second, we discuss the context of transitional countries, but eventually we collected data only on Armenia. It would be very important to continue the analysis in other countries, so we can compare the role of board network in explaining firm's innovativeness. The limitation we have faced is that board network data was available only until 2005 . We tried to collect data through the survey, but information on personal data has been very challenging. Another limitation of the study is that we used one-mode projection of the board network data, and hence we did not include board members' in our analysis, and again the reason was limitation of the more detail data on board members. 


\section{Appendix E: Results of probit and ordered probit models}

Table 1: Results of probit models (marginal effects at mean of variables)

\begin{tabular}{|c|c|c|c|c|c|c|c|c|c|}
\hline & $\begin{array}{c}\text { Model } \\
1 \\
\end{array}$ & $\begin{array}{c}\text { Model } \\
2 \\
\end{array}$ & $\begin{array}{c}\text { Model } \\
3 \\
\end{array}$ & $\begin{array}{c}\text { Model } \\
4 \\
\end{array}$ & $\begin{array}{c}\text { Model } \\
5 \\
\end{array}$ & $\begin{array}{c}\text { Model } \\
6 \\
\end{array}$ & $\begin{array}{c}\text { Model } \\
7 \\
\end{array}$ & $\begin{array}{c}\text { Model } \\
8 \\
\end{array}$ & Model 9 \\
\hline \multirow{3}{*}{$\begin{array}{l}\text { Log(employ } \\
\text { ment) }\end{array}$} & \multicolumn{9}{|c|}{ Marginal effects at mean } \\
\hline & $0.01 * *$ & $0.1 * * *$ & $0.08 * *$ & $0.07^{* *}$ & $0.07 * *$ & $0.07 * *$ & $0.1 * * *$ & $0.1 * * *$ & $0.2 * * *$ \\
\hline & $(0.03)$ & $(0.05)$ & $(0.03)$ & $(0.03)$ & $(0.04)$ & $(0.03)$ & $(0.05)$ & $(0.05)$ & $(0.05)$ \\
\hline \multirow[t]{2}{*}{$\begin{array}{l}\text { Region } \\
\text { dummy }\end{array}$} & -0.07 & -0.17 & -0.12 & -0.14 & -0.13 & -0.11 & -0.13 & -0.14 & -0.18 \\
\hline & $(0.09)$ & $(0.14)$ & $(0.1)$ & $(0.1)$ & $(0.1)$ & $(0.1)$ & $(0.15)$ & $(0.15)$ & $(0.15)$ \\
\hline \multirow[t]{2}{*}{ Service } & $-0.4 * *$ & 0.09 & $-0.4 * *$ & $-0.5^{* *}$ & $-0.5^{* *}$ & $-0.5 * *$ & 0.05 & 0.03 & -0.1 \\
\hline & $(0.16)$ & $(0.23)$ & $(0.18)$ & $(0.18)$ & $(0.19)$ & $(0.18)$ & $(0.24)$ & $(0.23)$ & $(0.25)$ \\
\hline \multirow[t]{2}{*}{$\begin{array}{l}\text { University } \\
\text { dummy }\end{array}$} & $0.5 * * *$ & $0.7 * * *$ & $0.6 * * *$ & $0.54 * *$ & $0.6 * * *$ & $0.6 * * *$ & $0.6 * * *$ & $0.6 * * *$ & $0.7 * * *$ \\
\hline & $(0.20)$ & $(0.21)$ & $(0.21)$ & $(0.21)$ & $(0.22)$ & $(0.23)$ & $(0.24)$ & $(0.21)$ & $(0.23)$ \\
\hline \multirow{2}{*}{$\begin{array}{l}\text { Average } \\
\text { sales }\end{array}$} & 0.07 & $0.4 * * *$ & $0.3 * * *$ & $0.3 * * *$ & $0.3 * * *$ & $0.3 * * *$ & $0.3 * * *$ & $0.3 * * *$ & $0.3 * * *$ \\
\hline & $(0.08)$ & $(0.11)$ & $(0.1)$ & $(0.1)$ & $(0.1)$ & $(0.1)$ & $(0.1)$ & $(0.1)$ & $(0.09)$ \\
\hline \multirow[t]{2}{*}{$\begin{array}{l}\text { Absorptive } \\
\text { capacity }\end{array}$} & & $1.3 * * *$ & $1.1 * * *$ & $1.2^{* * *}$ & $1.2 * * *$ & $1.2 * * *$ & $1.4 * * *$ & $1.2 * * *$ & $1.2 * * *$ \\
\hline & & $(0.12)$ & $(0.13)$ & $(0.14)$ & $(0.14)$ & $(0.14)$ & $(0.2)$ & $(0.18)$ & $(0.15)$ \\
\hline \multirow[t]{2}{*}{ Degree } & & & $0.1 * *$ & $0.2 * * *$ & $0.3 * * *$ & $0.2 * * *$ & $0.3 * * *$ & $0.3 * * *$ & $0.3 * * *$ \\
\hline & & & $(0.02)$ & $(0.06)$ & $(0.07)$ & $(0.07)$ & $(0.07)$ & $(0.07)$ & $(0.07)$ \\
\hline \multirow[t]{2}{*}{ Degree_sq. } & & & & $-.01 * * *$ & $-0.02 *$ & $-0.02 *$ & $-0.02 *$ & $-0.02 *$ & $-.02 * * *$ \\
\hline & & & & $(0)$ & $(0.01)$ & $(0.01)$ & $(0.01)$ & $(0.01)$ & $(0.01)$ \\
\hline \multirow[t]{2}{*}{$\begin{array}{l}\text { Cluster. } \\
\text { Coef. }\end{array}$} & & & & & -0.31 & $-0.4 * *$ & $-0.4 * *$ & $-0.4 * *$ & $-0.4 * *$ \\
\hline & & & & & $(0.16)$ & $(0.2)$ & $(0.21)$ & $(0.21)$ & $(0.16)$ \\
\hline \multirow[t]{2}{*}{ Constraint } & & & & & & $1 * *$ & $0.78 * *$ & $0.74 * *$ & $1.6 * * *$ \\
\hline & & & & & & $(0.53)$ & $(0.24)$ & $(0.26)$ & $(0.44)$ \\
\hline \multirow[t]{2}{*}{$\begin{array}{l}\text { IND } \\
\text { diversity }\end{array}$} & & & & & & & 0.16 & $0.28 * *$ & $0.57 * *$ \\
\hline & & & & & & & $(0.2)$ & $(0.14)$ & $(0.25)$ \\
\hline \multirow[t]{2}{*}{$\begin{array}{l}\text { Partners' } \\
\text { assets }\end{array}$} & & & & & & & & $0.01 * *$ & $0.02 * *$ \\
\hline & & & & & & & & $(0.005)$ & $(0.01)$ \\
\hline Partners' & & & & & & & & & $.05 * * *$ \\
\hline export & & & & & & & & & $(0.02)$ \\
\hline chi2 & 21.16 & 146.8 & 121.4 & 12976 & 131.8 & 132.4 & 132.6 & 132.7 & 137 \\
\hline r2_p & 0.12 & 0.554 & 0.562 & 0.56 & 0.57 & 0.576 & 0.578 & 0.58 & 0.59 \\
\hline $\begin{array}{l}\text { Correctly } \\
\text { classified }\end{array}$ & $\begin{array}{c}71.73 \\
\% \\
\end{array}$ & $\begin{array}{c}91.10 \\
\%\end{array}$ & $70.48 \%$ & $71.69 \%$ & $\begin{array}{c}73.49 \\
\% \\
\end{array}$ & $\begin{array}{c}70.48 \\
\% \\
\end{array}$ & $\begin{array}{c}89.76 \\
\%\end{array}$ & $\begin{array}{c}89.16 \\
\% \\
\end{array}$ & $89.76 \%$ \\
\hline
\end{tabular}


Table 2: Regression results with interaction term (Reporting of the main coefficient effects)

\begin{tabular}{|c|c|c|c|c|c|}
\hline & Model 11 & Model 12 & Model 13 & Model 15 & Model 10 \\
\hline & & Main coe & cients & & $\begin{array}{l}\text { Marginal } \\
\text { effects }\end{array}$ \\
\hline \multirow{2}{*}{ Log(employment) } & $0.27 * *$ & $0.26 * *$ & $0.28 * *$ & $0.18 * * *$ & $0.05 * *$ \\
\hline & $(0.12)$ & $(0.12)$ & (0.13) & $(0.03)$ & $(0.03)$ \\
\hline \multirow[t]{2}{*}{ Region dummy } & -0.41 & -0.3 & -0.38 & -0.17 & 0.04 \\
\hline & $(0.4)$ & $(0.39)$ & $(0.38)$ & $(0.35)$ & $(0.11)$ \\
\hline \multirow[t]{2}{*}{ Service } & 1.27 & $2.22 * *$ & $1.62 *$ & $0.35 *$ & $0.19 *$ \\
\hline & $(1.06)$ & $(1.03)$ & $(0.98)$ & $(0.09)$ & $(0.07)$ \\
\hline \multirow[t]{2}{*}{ University dummy } & 1.22 & $1.503 *$ & 0.91 & $1.86^{*}$ & $0.49 *$ \\
\hline & $(0.84)$ & $(0.77)$ & $(0.67)$ & $(0.69)$ & $(0.29)$ \\
\hline \multirow[t]{2}{*}{ Average sales } & 0.03 & $0.08^{*}$ & 0.06 & $0.08 * *$ & $0.02 *$ \\
\hline & $(0.04)$ & $(0.04)$ & $(0.04)$ & $(0.03)$ & $(0.01)$ \\
\hline \multirow[t]{2}{*}{ Absorptive capacity } & $3.15 * * *$ & $3.63 * * *$ & $3.37 * * *$ & $1.8 * *$ & $0.48 * *$ \\
\hline & $(0.51)$ & $(0.53)$ & $(0.51)$ & $(0.89)$ & $(0.12)$ \\
\hline Degree & $\begin{array}{c}\mathbf{0 . 6 6} \boldsymbol{*} * \boldsymbol{*} \\
(0.2)\end{array}$ & $\begin{array}{c}\text { 0.5* } \\
(0.29)\end{array}$ & $\begin{array}{c}\mathbf{0 . 4 9} \\
(0.17 * *\end{array}$ & $\begin{array}{c}\mathbf{0 . 2 7} * * \\
(0.14)\end{array}$ & $\begin{array}{c}\mathbf{0 . 1 6 * *} \\
(0.06)\end{array}$ \\
\hline \multirow[t]{2}{*}{ Degree_sq. } & $-0.06 * * *$ & $-0.08 * * *$ & $-0.06 * * *$ & $-0.05 * * *$ & $-0.01 * *$ \\
\hline & $(0.02)$ & $(0.03)$ & $(0.02)$ & $(0.02)$ & $(0)$ \\
\hline \multirow[t]{2}{*}{ Cluster. Coef. } & $-1.46^{*}$ & $-1.46^{*}$ & $-1.46^{*}$ & $-3.05 * *$ & $-0.86 * *$ \\
\hline & $(0.8)$ & $(0.8)$ & $(0.6)$ & $(1.02)$ & $(0.4)$ \\
\hline \multirow[t]{2}{*}{ Constraint } & 4.71 & -5.31 & -5.31 & $0.47 * * *$ & $0.08 * *$ \\
\hline & $(5.26)$ & $(5.53)$ & $(5.53)$ & $(0.02)$ & $(0.03$ \\
\hline \multirow[t]{2}{*}{ Industry diversity } & $19.4 * *$ & $19.4 * *$ & $19.4^{* *}$ & $19.4 * *$ & $5.14 * *$ \\
\hline & $(0.96)$ & $(0.96)$ & $(0.96)$ & $(0.96)$ & $(2.3)$ \\
\hline \multirow[t]{2}{*}{ Partners' assets } & $0.07 * *$ & $0.07 * *$ & $0.07 * *$ & $0.07 * *$ & $0.03 * *$ \\
\hline & $(0.03)$ & $(0.03)$ & $(0.03)$ & $(0.03)$ & $(0.01)$ \\
\hline \multirow[t]{2}{*}{ Partners' exports } & $0.1 * *$ & $0.75 * *$ & $0.1 * *$ & $0.75 * *$ & $0.12 * *$ \\
\hline & $(0.05)$ & $(0.31)$ & $(0.05)$ & $(0.31)$ & $(0.05)$ \\
\hline \multirow[t]{2}{*}{ Absorp. capacity x degree } & $0.144 * * *$ & $0.144 * * *$ & $0.144 * * *$ & $0.144 * * *$ & $0.23 * *$ \\
\hline & $(0.05)$ & $(0.05)$ & $(0.05)$ & $(0.05)$ & $(0.06)$ \\
\hline Industry_diversity.x & & $26.63 * *$ & $26.63 * *$ & $26.63 * *$ & $5.5^{* *}$ \\
\hline Constraint & & (11.5) & (11.5) & (11.5) & $(2.3)$ \\
\hline Clustering coef.x Partners' & & & $0.49 *$ & $0.49 *$ & $0.24 *$ \\
\hline assets & & & $(0.28)$ & $(0.28)$ & $(0.11)$ \\
\hline \multirow{2}{*}{ Contsraint x Partn.export } & & & & 0.94 & 0.24 \\
\hline & & & & $(0.7)$ & $(0.19)$ \\
\hline \multirow[t]{2}{*}{ Const. } & $-3.03 * * *$ & $-1.35 * *$ & -0.67 & -0.41 & $-1.35 * *$ \\
\hline & $(0.81)$ & $(0.64)$ & $(0.54)$ & $(0.54)$ & $(0.64)$ \\
\hline chi2 & 138.3 & 148.2 & 145.9 & 149.6 & 149.6 \\
\hline r2_p & 0.60 & 0.64 & 0.63 & 0.65 & 0.65 \\
\hline Correctly specified & $90.36 \%$ & $90.36 \%$ & $89.76 \%$ & $90.36 \%$ & $90.36 \%$ \\
\hline $\mathrm{N}$ & 180 & 180 & 180 & 180 & 180 \\
\hline
\end{tabular}

Table 3: Results of ordered probit models: Results of ordered probit model (reporting main coefficient effects) (Innovative performance is ranked) 


\begin{tabular}{|c|c|c|c|c|}
\hline Ranked Innovation & Model 1 & Model 2 & Model 3 & Model 4 \\
\hline & & Main coef & & \\
\hline \multirow[t]{2}{*}{ Log(employment) } & 0.013 & 0.035 & 0.022 & 0.035 \\
\hline & $(0.065)$ & $(0.077)$ & $(0.078)$ & $(0.083)$ \\
\hline \multirow[t]{2}{*}{ Region dummy } & -0.020 & -0.048 & -0.004 & 0.031 \\
\hline & $(0.187)$ & $(0.223)$ & $(0.234)$ & $(0.24)$ \\
\hline \multirow[t]{2}{*}{ Service } & $-0.473 * *$ & 0.068 & 0.004 & 0.093 \\
\hline & $(0.218)$ & $(0.269)$ & $(0.276)$ & $(0.28)$ \\
\hline \multirow[t]{2}{*}{ University dummy } & $1.84 * * *$ & $2.096 * * *$ & $0.085^{* * *}$ & $2.36 * * *$ \\
\hline & (0.391) & (0.433) & $(0.022)$ & $(0.46)$ \\
\hline \multirow[t]{2}{*}{ Average sales } & $0.039 * *$ & $0.084 * * *$ & $2.145 * * *$ & $0.09 * * *$ \\
\hline & $(0.018)$ & $(0.022)$ & $(0.447)$ & $(0.02)$ \\
\hline \multirow{2}{*}{ Absorptive capacity } & & $1.755 * * *$ & $1.778 * * *$ & $2.17 * * *$ \\
\hline & & $(0.235)$ & $(0.241)$ & $(0.4)$ \\
\hline \multirow[t]{2}{*}{ Degree } & & $0.306 * *$ & $0.556 *$ & $0.75^{* *}$ \\
\hline & & (0.130) & (0.331) & $(0.34)$ \\
\hline \multirow{2}{*}{ Degree_sq. } & & $-0.019 *$ & $-0.035 * *$ & $-0.04 * *$ \\
\hline & & (0.011) & (0.018) & $(0.02)$ \\
\hline \multirow[t]{2}{*}{ Cluster. Coef. } & & & $-0.42 * *$ & -0.19 \\
\hline & & & $(0.17)$ & $(0.413)$ \\
\hline \multirow[t]{2}{*}{ Constraint } & & & 0.286 & 5.31 \\
\hline & & & $(3.202)$ & $(5.13)$ \\
\hline \multirow[t]{2}{*}{ Industry diversity } & & & -0.615 & $13.6 * *$ \\
\hline & & & $(0.682)$ & $(5.92)$ \\
\hline \multirow{2}{*}{ Partners' assets } & & & -0.027 & $0.07 * *$ \\
\hline & & & $(0.031)$ & $(0.035)$ \\
\hline \multirow[t]{2}{*}{ Partners' exports } & & & $0.046 *$ & $0.516 *$ \\
\hline & & & $(0.027)$ & $(0.276)$ \\
\hline \multirow[t]{2}{*}{ Absorp. capacity $\mathrm{x}$ degree } & & & & 0.069 \\
\hline & & & & $(0.089)$ \\
\hline \multirow[t]{2}{*}{ Industry_diversity.x Constraint } & & & & $16.42 * *$ \\
\hline & & & & $(6.642)$ \\
\hline Clustering coef.x Partners' assets & & & & $0.653 * *$ \\
\hline \multirow{2}{*}{ Constraint x Partn.export } & & & & 0.367 \\
\hline & & & & $(0.389)$ \\
\hline \multirow[t]{2}{*}{ Cut1_cons } & 0.22 & $1.84 * * *$ & 2.265 & 7.997 \\
\hline & $(0.21)$ & $(0.402)$ & (3.409) & (5.383) \\
\hline \multirow[t]{2}{*}{ Cut2_cons } & $1.55^{* * *}$ & $3.58 * * *$ & 4.058 & $9.887 *$ \\
\hline & $(0.23)$ & $(0.45)$ & (3.421) & (5.405) \\
\hline chi2 & 44.3 & 113.37 & 118.82 & 143.4 \\
\hline r2_p & 0.12 & 0.35 & 0.39 & 0.626 \\
\hline $\mathrm{N}$ & 180 & 180 & 180 & 180 \\
\hline
\end{tabular}

\section{Part IV: Conclusion}


CHAPTER

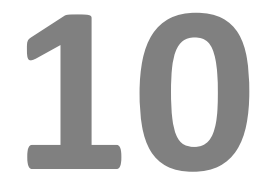

CONCLUDING REMARKS 


\subsection{Main contribution}

In intending to offer a fresh perspective on the dynamics of economic restructuring in transitional economies this study combines an institutional analysis of the process of economic transition and firms' restructuring in Armenia with an in-depth microeconomic analysis of growth and innovation of firms. Here we discuss how in the countries experiencing intensive institutional transformation, the role and effects of social networks on markets differ from the experience of developed countries. In addition, our study is the first analysis of Armenian data constructed through extensive and archival research. In Chapters 1 and 2 we argue that the institutional environment matters in determining opportunities for firms in Armenia, and it is particularly significant if we consider firms' embeddedness in social networks. Social networks serve as a mechanism for firms to cope with and overcome uncertainty of volatile market conditions. Social networks have been used to compensate for the difficulties of market exchange between firms, to access financial resources and to gain information. These networks played an important role in knowledge and skills transfer and diffusion, as well as in the effectiveness with which firms used new knowledge and skills. Firms' embeddedness in their networks had an impact on the way firms, and the whole economy, has restructured.

The institutional aspect shows how the radical reforms combined with inherited soviet past created social institutions: and even though some of these institutions evolve over time, many of them were not functioning well to support a market economy. As a result firms were placed in the markets without sufficient institutional set-up. In this situation the gaps between planned and market economies becomes more evident: lack of finance, practices, technological resources and assets inherited form the soviet period did not support the economic actors' smooth transition to the new reality. Apart from weak institutional framework, another important factor that characterized the Armenian transition was the lack of foreign actors.

The role of foreign actors in transition economies was very important. The evidence shows that foreign-led modernization is more frequent in Central and Eastern European countries (socialist block), than in post-soviet countries (former USSR) (Radosevic and Sadowski 2007). In general Central and Eastern countries are considered as more successful than post-soviet countries, in terms of achieved political and economic development. In those countries firms have had more opportunities to integrate into more developed European markets. In contrast, the insider model of privatization, prevalent in Armenia, as well as lack of political stability in the country, did not attract much FDI. Economic experimentation by local firms leads to the development patterns that in the literature are called domestically-led modernization (Radosevic and Sadowski 2007). The difficulties of Armenian firms to access the stateof the-art technology, lack of finance and past interdependence with soviet production chain, made this process more hazardous. Local firms developed and promoted local capabilities through inter-firm networks.

The importance of networks and linkages we also discussed while analyzing transformation of the National Innovation System in Armenia from USSR's innovation system, reflecting rigidities of its centralized features (Chapter 3). After the collapse, the symbiotic way of functioning within the USSR's innovation system 
created more challenges for a small country like Armenia, which was highly industrialized. The interdependence mechanism that functioned well in the soviet system did not allow local innovation system to transfer into a national innovation system without losing considerable production potential. One of the reasons is that Armenian industry was highly dependent on inputs from other USSR republics. Given internal and external reasons (ethnic war, the collapse, etc.), Armenian firms could hardly survived without the soviet production system. In addition, Armenian economic policies were not specifically targeting restructuring or creating its national innovation system during the early transition. One of Armenia's important advantages was high human capital, which has not been utilized, and as a result over the years it became diminished (the country experienced significant brain drain, aging issues of scientific community, lack of research funds etc.).

Neo-liberal reforms and lack of state policies in promoting the country's innovation system left economic agents alone to find solutions. In this situation pre-existing social networks became the only trustworthy channels with which to observe reality, and to deal with ambiguity and uncertainties arising with the process of economic transformation. The central concern of this study has been to analyze how newly privatized firms were able to utilize the local networks, and what kind of value these networks provided to those firms.

One of the important inter-firm networks, which we examined in this thesis, is the board members network. A board members network refers to the network formed by individual board members who have membership on one or more firm boards. Our aim was to develop a conceptual framework and empirically test the importance of board networks for firm performance and innovation. Chapter 4 explores the influence of board member networks on firm performance and innovation, and presents a conceptual framework for understanding and ultimately predicting the impact of board network features on firms in transitional economies. The study considers these networks as having an intrinsic business value for firms, known in the literature as "social capital".

The thesis proposes that "structural" and "content" attributes of board member networks are key levers underlying the level of social capital presented by these networks for firms. Applying insights from social capital theory, the structural aspect of the social capital emphasizes the role of the firm's position in the network, while network content considers attributes of connected firms or the quality of the network ties that are also significant factors for firm performance and innovation. This study also addresses the topic of how the firms may utilize social capital and which mechanisms are most promising for unlocking the value of the social capital.

\subsection{Empirical Evidence}

Primary Data and Research design: The aim of this study required to design and build an extensive database. Construction of the unique database based on primary and original data enables us to make new evidence-based statements on the role of social networks. We collected and constructed a unique database, which reflects the historical change of large post-soviet firms into private firms. The data on board members was stored in state archives, and we initiated the process of its extraction from the papers 
(converting it into electronic version), and additionally, we acquired supporting data from Ministry of Revenue, which enabled us to construct a panel dataset for 10 years. The first datasets contained the information on 200 firms (Open joint stock companies) for the period 2000-2010, which included data on board members, firm financial data, industry, and other relevant variables. The second database acquired from the Ministry of Revenue provides detailed information on the financial variables of the selected 200 firms (the population of all open joint stock companies). We have constructed 10 years panel data with these two datasets, and used it for the Part II to measure the impact of social capital on firm financial performance. We constructed board networks for four years and generated various social capital variables by using social network analytical software (i.e., Network 2000, 2001, 2003, 2005).

For the Part III, to measure the impact of social capital on firm innovation we have conducted the first firm's innovation survey among selected firms, to obtain information on firms' innovation. We have used the data from the first stage (i.e., panel data for financial performance) and have combined it with the data collected through the innovation survey. For the board network data we only used the Network of 2005 to construct the social capital variables to measure the firm innovation.

Our empirical evidence is based on the examination of the network of board members of privatized large firms, and was presented in Chapters 5,6 and 9. The first part of the analysis focuses on the impact of social capital on firm financial performance measured by the firm's ROA and ROE (Chapters 5 and 6). In the second part (Chapter 9), we estimated the impact of social capital on firm's innovation by applying probit and ordered probit models for our empirical analysis, where independent variables are firm controls and various social capital measures, and the dependent variable was whether the firm has introduced product or process innovation in the surveyed period.

The empirical evidence presented in the thesis shows that social capital embodied in board member networks has a significant impact on firm performance and innovation. A shared board member appears to serve as a channel for transmission of information and knowledge, exchange of resources and assets across firms, which positively affects the firm.

Research Questions: We ask two important questions, which are largely unanswered in the previous literature:

- Do the specific focal firm characteristics interact with board network structure to influence firm performance (innovative performance?)

- Do board network structure and board network content interact to impact firm performance (both firm financial and innovative performance)?

We explore the answers for these main research questions in the context of Armenian transition. The collapse of the USSR was associated not only with a new institutional framework but also new product demand and organizational behavior. During the period of economic transition and opening new markets (the old system of market exchange disappeared), the old product were considered obsolete and firms in Armenian needed access to variety of resources to survive and innovate. On the other hand, the highly turbulent environment in Armenia created a lack of any formal access 
to information and resources, which enhance reliance on trustworthy personal networks to gain access to resources and information.

Findings: One of the interesting findings from our empirical evidence is that the results show that social capital may have differentiated impact on firm financial vs. innovative performance: for example, our results show that network closure is negative for firm innovation, while it has a positive impact on financial performance. Interestingly, for financial performance, our findings suggest that both structural holes and network closure are important. This finding supports our arguments related to the transition economies, where firms need pass through re-structuring in order to adapt to a new and turbulent environment caused by the collapse of the centralized planning system. Market instability and a volatile institutional environment (e.g., underdeveloped banking system, limited access to formal financial support) enhance the value of reciprocal ties, as they are credible guarantees for market exchange. In this case, network closure provides more opportunities for reciprocity. However, at the same time, a brokerage position also provides the firm more opportunities to navigate and to access resources that others are not able to access, which became more important when a firm was seeking new and innovative solutions. Therefore, when we measure firm innovativeness, we see that network closure is an impediment as oppose to brokerage position.

One intriguing question is how the case of Armenian transition differs from other transition economies. In this regard, we looked at the other studies on transition economies.

The case of Hungarian corporate networks showed that cohesive networks increased chances of survival, but that this did not lead to increases in innovativeness (Balázs Vedres and Stark 2010; Stark 1991). Salmi (1996) showed that personal interactions between top management of firms in Russia complement or even substitute written contracts, especially in a period of greater uncertainty, which is coherent with our finding that Armenian firms needed more access to financial resources in order to prosper. Generalizing, financial borrowing and trustworthiness were a "first aid" support mechanism which is more important for firm survival. Existing formal sectors for financial borrowing did not create favorable conditions for the development of businesses, which was one of the reasons that caused entrepreneurs to look for alternative ways for funding. The lack of financial institutions enhanced borrowing between firms and the practice of barter exchange, which ultimately stressed the importance of closed networks. Closed networks provided trust, monitoring and sanctioning opportunities for the firms, and in the environment with no regulatory support firms will borrow and lend only if have sanctioning power. In this scenario, closed network are more favorable for the firms to access to necessary resources. This explanation is also supported by the next findings that rich network content had a positive effect. These findings indicate that financial support (from firms linked through the boards network) was extremely important for a firm's financial performance.

By contrast, considering a firm's creativity and innovativeness, network closure constrains and provides redundant knowledge and information. For firm innovation, our evidence supports Burt's structural hole argument, showing that for innovative 
firms it was essential to access differentiated resources and new knowledge. Although financial resources are important for the firm to innovate, access to new knowledge and new learning opportunities are the key factors.

Our empirical evidence suggests that firms' needs may differ when their goal is either to improve their financial or innovative performance. And social networks are used differently to maximize their opportunities to reach a certain goal. This notion was also supported by Batjargal (2007), when he compares the Chinese and Russian entrepreneurship networks. He found that dense networks in China helped to generate higher revenue growth and were more beneficial for early stage growth. However, tight networks turned into liabilities by blocking the information and resource flows at later stage of development (Batjargal 2007). In contrast, Russian entrepreneurs benefit from structural holes that exposed them to diverse resources and new knowledge, but the cost of monitoring is very high.

In our understanding, structural holes are costly for firms (e.g., they cannot directly control and monitor their behaviour) and don't facilitate higher trust for financial borrowing, and hence have a negative impact on firm financial profitability. An interesting observation was found in the Slovenian corporate ownership network, where Pahor (2009) ${ }^{78}$ shows that in the first period of the transition, corporate networks were characterized by increasing clustering and density, while in the later period, structural holes were more important. This indicates, that over time with the development of external regulatory environment network closure is becoming less efficient, instead, the brokerage position is providing more benefits to the firms.

The third finding that supports this intuition is the effect of the foreign ties on firm financial performance, indicating that foreign ties provide more value in terms of newer organizational knowledge than financial support. Yet our findings showed that foreign and new practices matter more in dense networks, exhibiting network externalities, where the value of new organizational knowledge increases with the number of users. In the transitional context, that suggests that no matter how efficient are new practices, firms will gain more value from adapting them if others adapt and use them, and it seems that dense networks provide more opportunities for the diffusion of those practices. Hence the value of foreign ties increases with network closure.

Armenia is a small economy and firms with strong social ties may easily gain market power and generate profits. Our findings show that when the firm performance is measured by its financial profits, the firm may benefit from the presence of foreign ties and network closure. Yet, these two network strategies do not necessarily lead to being innovative. In order to be innovative, firms must possess different types of resources: in a transition economy, more innovative firms or "non-Soviet-mentality firms" are the ones who took the risk and passed through faster restructuring and organizational changes. In this case, we have found that social networks, or more precisely, structural holes serve as a mechanism to support organizational change and to enable firms to innovate, which might not lead to short-term profitability. This finding may indicate that firms may require different types of social capital given their intention to improve either short-term financial profitability or their innovativeness.

\footnotetext{
${ }^{78}$ See https://emnet.univie.ac.at/uploads/media/Pahor_01.pdf
} 
The thesis also presents measures for assessing board network content (e.g., network diversity, partners' assets and export volume) that are shown through empirical evidence as important in improving financial performance and innovation. This study used different aspects of the firm's network diversity. Our findings showed that industry heterophily has a strong impact on both financial and innovative performance. In a comparative study between Russian and Chinese entrepreneurial networks, Batjargal (2007) showed that homogeneous networks are more efficient in China, while Russian entrepreneurs benefit from heterogeneous networks. The important difference between Chinese and Russian transitions was that Russia went through radical transformation, which is more similar to the Armenian case. In his study on Russian entrepreneurial networks, Batjargal (2003) explained that a firm's connections with different industries provide better opportunities to creatively allocate assets and liabilities in order to reduce the harmful effects of environmental uncertainties. In our findings we observed the importance of accessing different resources, skills and knowledge, which are all highly important for innovation.

Batjargal (2003) also addressed the importance of network resourcefulness among Russian entrepreneurs, but he measured it based on high ranked officials connected to the entrepreneurs. In the context of post-soviet transition personal connection may help a firm to access more resources and opportunities; however he didn't find any significant effect. In our study we use a similar notion, but we measured network resourcefulness based on partner's financial assets, which appeared to have a strong and significant effect on both firm financial and innovative performance.

In regard to joint effects of network structure and content, our findings suggest that indeed two dimensions of social capital have positive effects on firm performance.

Furthermore, we look at the complementarity between firm's centrality and its absorptive capacity. This intuition was based on the previous literature showing that firm absorptive capacity is an important construct for explaining firm innovation, underlining the importance of past innovative performance as an indicator for knowledge accumulation and providing an incumbent firm a competitive advantage to innovate (Schumpeter 1934; Reagans and McEviliy 2003). Our results show that a firm's absorptive capacity (as measured by its past innovative frequency) is important, especially when it complements the firm's connectedness in the board network.

Our results show that explanatory variables including degree centrality and network resourcefulness have different effects on ROA and ROE. This is relatively common outcome: finding different results for ROA and ROE is consistent with other studies that examine them both. For example Hart and Ahuja (1996) show that an industry dummy was not significant for ROA, but was significant for ROE; Li et al. (2008) found that among Chinese firms firm size is significant and negative for ROA and ROE, but financial leverage was significant and negative for ROA but significant and positive for ROE, while firm age was a not significant predictor for either of them. Although these two variables both measure firm profitability, ROA indicates how efficiently a firm manages the use of its assets to generate profit, and ROE measures the profitability of equity investments. But it is also easy to distort this measure - a company can buy its shares and reduce its equity, which will increase ROE. In terms of 
ROA, we find different returns on assets given industry specification. Some industries, such as manufacturing typically use more assets than the software industry, for instance. Our data shows that firms in the manufacturing sector have higher ROA than in the other sectors, while in terms of ROE firms perform better if they are not in manufacturing industry. One simple explanation is that of two otherwise equivalent firms, the non-manufacturing firm has a lower debt/equity ratio. This could be explained by the fact that borrowing opportunities are fewer, and costs higher, for non-manufacturing firm. This intuition is also behind the Region dummy's effect on ROA and ROE (the dummy takes the value of 1 for Yerevan, and Yerevan is home for main economic activities), indicating that borrowing opportunities are likely to be much richer for the firms located in Yerevan vs. outside of the capital city.

One of intriguing questions is why different social capital measures affect differently ROA and ROE. For example, our finding brings an interesting discussion in understanding the role of foreign ties and asset-rich partners. Their differentiated impact on ROA vs. ROE may indicate that partners' assets serve rather a better opportunity for borrowing, while partner's exports are a proxy for (or source of) new knowledge, and these two affect ROA and ROE differently. Our findings suggest that partners' assets have a significant impact on ROA and ROE, but also showed that network closure combined with asset-rich partners is significant for ROE but not for ROA, which may ultimately indicates that rich partners influence firm's borrowing opportunities rather than efficiency.

The differentiated effect of social capital on ROA and ROA we can discuss in two main ways:

1. When a firm has access to additional financing through its social networks

2. How efficiently a firm is using its financial resources

Social network structure and asset-rich friends may indicate that a firm has higher chances to access to additional finical resources. Yet, in order to have higher return it should efficiently use its resources. We have found diverse effects of network closure and structural holes on ROA and ROE. One possible way to interpret these results is to look at the borrowing aspect and forming a debt. A firm in a closed network had higher chances for borrowing from its "friends"; in this case it will form a debt, which will make its ROE higher than its ROA.

Yet, the important question is how a firm is using its financial resources to secure higher profits. If a firm is using its borrowings to produce extra profit then it will have higher ROA than ROE. Our findings shows that network closure had a negative effect on ROA, which means that even a firm may have access to funds it may not necessary use them efficiently. However, when access to funds is combined with other attributes such as partner's export or regional homophily, which may indicate that firm has also access to particular market knowledge, then the firm has high possibilities to invest and utilize its borrowings efficiently. Shortly, the negative effect from network closure may be partially offset by the resources that partners have such as being regionally connected and having access to partner's exports, which helps a firm to navigate better in the market economy. While our finding that being closely connected and having rich network provide higher chances for borrowing, and yet the firm is not generating extra 
profits from its financial resources, then it will impact on the increase of the firm's ROE.

One of our research questions was how different is the impact of the personal network on firm success from developed to developing economies. We have applied social capital theory, which developed the arguments how personal networks are an important source for generating value for the firms, but this theory didn't indicate any differences driven by the countries' contexts. Although we have applied the social capital theory in the transition context, many arguments of its positive effects are applicable to developed economies as well. Indeed, a social network may serve as a powerful tool in all economies. However, there is a difference: in developed economies, where the formal institutions are legitimate for all economic actors, social networks are rather complementing and supporting the efficiency of formal institutions, simply providing some additional value. In contrast, social networks in transition economies are substituting the formal (and not legitimate) institutions, serving sometimes as the only tool to successfully perform in the uncertain environment. The type of social interactions typical for former-Soviet countries such as blat or moy krug (Ledeneva, 2000) have a strong sanctioning and reciprocity features, but are more directed towards short-term survival and profits. Although this type of social network helped firms to generate financial gains in the transition period, they weren't very efficient for firm innovation. Instead, mechanisms through which innovative firms utilize their social capital are more similar to developed countries. This indicates that when we talk about new ideas, knowledge transfer and learning, the firms exhibit networking strategies that are similar to the firms operating in the developed economies.

\subsection{Innovation survey}

When we started our research project there were no firm innovation statistics in Armenia. Another contribution of the thesis therefore is the first firm-level innovation survey for Armenia. The purpose of the innovation survey is to measure the degree of innovativeness at the firm level, as well to measure the efforts of the firms devoted to innovation. Community Innovation Surveys are based on the Oslo Manual guidelines, and are well-established instruments to collect data on firm innovativeness in various countries - both developed and developing countries. We followed this approach, though making some adjustments to local context (Chapter 7). As we were interested in collecting data of firms in all sectors, we chose the instruments that provide data on firm innovation that are comparable across all industries. Another important aim of the survey was the broader understanding of innovation, as Armenian firms in general are not at the technology frontier. Our survey results show that most of the Armenian firms were engaged in firm level innovation, with only a few innovating at the market or world level.

The culture of firm innovation differs in developed and developing economies. Salazar and Holbrook (2004) mention a few characteristics that differentiate between firms in developed and developing countries. In developing countries:

- Firms have more informal organizational setting in carrying out innovation 
- Firms undertake fewer R\&D projects

- Innovation is mainly based on the acquisition of equipment

- Fewer resources are invested in innovation processes and activities

- Fragmented flows of information within national system of innovation

One of the critiques of innovation surveys is that often they do not collect data on how the innovation system works, and are mainly focused on firm innovation. We acknowledge that inter-linkages between actors of National Innovation System are important, and address this issue in the survey: we include questions that cover firm's linkages with other type of actors such as universities and public research institutes. We also asked questions on how firms chose partners and what is the role of a specific type of the partner in the innovation process. Questions on the firm's collaboration cover the important area of learning, and transfer of knowledge and technology between different types of actors in NIS. The insights from the Chapter 2 (e.g., features of Armenian NIS) also were integrated into our analysis of the survey data.

The survey results were compared with other countries such as Latin American and European countries ${ }^{79}$ in Chapter 8, though the main focus of the analysis of the survey data is to identify the factors that are correlated to the firm innovation in Armenia. We carried out multivariate regression to identify significant factors that are correlated with firm innovation and the degree of innovativeness.

Our intention was to depict features of the Armenian National Innovation both from looking at the macro-level changes and reforms (Chapter 2) and utilizing micro-level data to understand firm's innovative mode (chapter 8). Chapter 2 reveals specificities of the Armenian transition context and what type of knowledge production mode was persistent while transitioning from the soviet system to a new system. Given the way the reforms were implemented as well as socio-economic conditions that the country was facing at that time, the country could not utilize its full innovation potential while transitioning to a new system. For example, Armenia was endowed with highly skilled labour which, in general, failed to transfer and update their knowledge and skills to match the demand of new market reality. In a similar way, firms largely failed to change their behavior to adapt to a new reality mostly failing to learn new management styles. In addition, government policies were not addressing the challenges that both firms and people were facing. Largely following neo-liberal shock therapy reforms, which created higher uncertainty without being backed up with necessary institutional and regulatory framework, the country experienced the lost opportunity decades.

Yet, firms and people were trying to survive and innovate. In chapter 8 we looked at the taxonomy of the innovation system from the perspective of persistent innovation mode. The taxonomy exercise showed that the Armenian national system consists mostly of technology adopters, where the firms are mostly innovating though technology adoption and modernization. A lack of strategic and creative innovators suggests that the country is slowing down its catching up processes, and may fall behind on the global scale. One of the noticeable differences with other European

\footnotetext{
${ }^{79}$ Many Latin American countries have long-standing experience in conducting innovation surveys, and provide a good background for comparing their survey results with Armenia's in the context of developing countries
} 
countries was that in Armenia novel knowledge tends to be created in isolation and without turning it into formalized IP outcomes. A lack of IP regulations and standardization practices may well have been (and continue to be) impeding the diffusion of novel ideas and best practices within the country, which also slowed down transition processes.

The analysis of the survey data shows that the firm size (measured by number of employees) significantly increases the likelihood that a firm introduces innovation. Firm size is also positively correlated with firm R\&D performance. Both continuous and external R\&D are highly correlated with firm innovation. However other non$\mathrm{R} \& \mathrm{D}$ activities such as acquisition of machinery and external knowledge are also important and increase the likelihood to innovate. This is consistent with Huang et al. (2010) analysis of 15 European countries, showing that half of the innovative firms use non-R\&D activities. Our findings are also consistent with Mairesse and Mohnen's (2005) study indicating that product innovation compared to process innovation more often involves R\&D, while process innovation often requires participation of external suppliers (von Hippel, 1998) and other non-R\&D activities such as acquisition of machinery and external knowledge.

Another important finding is that Armenian firms are mostly operating in the Schumpeterian creative accumulation domain, ${ }^{80}$ where incumbent firms have higher probability to innovate.

The firm's internationalization, measured by its export performance, is associated positively with the firm's decision to perform R\&D. Chemical firms performed more $\mathrm{R} \& \mathrm{D}$, whereas metallurgy and retail produced more innovations (compared with reference category). The firm's legal structure was significant only for $\mathrm{R} \& \mathrm{D}$, showing that firms with open shareholding (open joint stock companies) are more likely to carry out $\mathrm{R} \& \mathrm{D}$, but there is no significant difference in terms of innovation.

A large stream of empirical research showed that the use of academic knowledge is beneficial for firm innovation and technical change (Acs and Audretsch 2003; Gault 2015; Spector et al. 2013; Veugelers and Cassiman 1999). Consistent with this finding, our data shows that collaboration with universities is a significant factor for firm innovation. The surveyed firms only collaborate with local universities, and very often this collaboration is in terms of training and internships rather that joint R\&D collaborations.

Based on our findings some policy conclusion can be drawn. The most general policy advice was drawn from these following preconditions:

- As firms were left themselves since the transition started, they operate more in a survival mode; even if they do innovate it is not a strategic and long-term decision.

- As our survey showed, many privatized firm innovate more in a Schumpeter's accumulative innovation mode and are mostly in an adaptive rather than creative stage

${ }^{80}$ Gault (2015) discusses the approaches used in two Schumpeterian domains. 
- Given the necessity of minimizing the soviet heritage and securing fast behavioral change among Armenian firms, the creative destruction mode might be more beneficial.

In this case, public programs supporting an entrepreneurial mode and strengthening start-up and small firm ecosystem in the innovation landscape might enable firms to become more creative and globally competitive. Many countries have adopted policies to strengthen the startup ecosystem, which is considered as one of the important drivers of innovation (e.g., Grimaldi et al., 2011). Government policies can support the development of an entrepreneurial ecosystem in Armenia, and by doing this; it will help to reduce practices left over from the Soviet system that hamper firm innovation.

\subsection{Contribution to the social capital literature}

Our contribution to the social capital literature we can summaries in the following main directions:

- Distinguishing financial vs. innovative performance with different results on network structure

- Understanding why there would be different effects of local network structure

- Arguing that effects might be pronounced in transition economies, and in some cases they might differ from the developed economies.

- Showing how network structure interacts with network content, and how this interaction may impact differently firm financial performance and innovation

- Adding to the literature that diversifies network analysis from alliances to boards.

Our finding indicated that network closure and network sparseness may provide different benefits given firm's performance (financial performance vs. innovation). Our discussion incorporates the economic transition context of Armenia in deepening our understanding why board network may have different effects on firm performance depending how we measure it. In addition, our discussion compares why the network role is different from the developed countries (in some cases).

Our analytical framework provides clear distinctions between measuring board network characteristics, content and their interplay in explaining firm performance. And our empirical evidence shows that social capital embodied in firm connectedness has a significant impact on firm performance. Shared board members serve as a channel for transmission of information and knowledge, exchange of resources and assets across firms, which positively affects both their innovativeness and financial performance. Under some circumstances, gaps in connectedness can actually be beneficial for firm performance. For example, if a firms is embedded in a rich network, where its partners possess higher financial resources, it is more likely that the firm will benefit from the borrowing from its partners if the network is more closed, as cohesive network provide higher level trust among its member, they provide monitoring and sanctioning opportunities, especially when the legal infrastructure of the country will not protect the firms. In support of measuring and utilizing social 
capital, we contribute measures for assessing network content and provide empirical evidence how those measure explain the firm performance. We have also find that interaction between network structure and content has significant effects on firm performance (we have already discussed it). In addition, our results show that interaction between firm's degree centrality and firm absorptive capacity a significant effect on firm innovation, which was earlier found by Reagans and McEvily (2003)'s study. We have continued prviding empirical evidience to support this hypothesis also with board network structure.

An issue of how or whom a firm should appoint as a board member, and what is the value of an individual board member for the company is an important topic in corporate governance. One practical application of our findings is to provide better insights in this direction. We show that the value of an individual board members increases if he/she is already connected with other firms. Another important aspect is that there is a certain value of a partner firm's attributes. In line with the studies on importance of boards' compensation, board members education and experience in a certain field, we showed that board members' connectedness has an intrinsic business value for firms.

\subsection{Discussion, Limitations and Future Research}

The role of personal networks in the economy is well recognized; however there are still some debates how and to what extent personal networks may affect firm performance. Management literature has extensively discussed strategic alliances, but board networks have received less attention and very often the external political and economic environment is ignored. With our framework we were able to demonstrate that the interplay between firm, board network and country specific factors all affect firm performance, however further research including sectoral and cross-country analysis would be very fruitful. Empirical findings from other countries will enrich our understanding of the specific features or dimensions of the social capital in various country contexts.

As our main argument was that social capital is easing firm' access to resources or knowledge when the firm is facing institutional or socio-economic uncertainty.

The exclusion of board members' individual characteristics is partially related to the one-mode network approach we applied in this study. We used a one-mode projection of the affiliated network, but in future research, it may be possible to test a two-mode network approach and compare the results. As of yet the literature on social networks does not provide precise answers how reducing two-mode network into one-mode affects the results, and what kind of information we lose in this transformation, or whether the loss is significant.

Discussions related to the importance of the board on a firm's success are important for both policy makers and academic communities. Empirical evidence on how board diversity given different socio-economic, demographic, intellectual backgrounds of the board members may provide additional benefits to a firm, can strongly contribute to this debate. There is an intrinsic value of continuing this line of research for providing stronger empirical evidence by applying social capital theory. Social capital approaches may enrich the research framework. Further research could investigate the joint effects 
of board network and board members characteristics on firm's learning and innovative outcomes. Our approach can be applied to other country contexts, and findings can provide important insight for policymakers in the field of corporate governance, firm's growth and innovation. 


\section{Appendix F: The Survey Questionnaire}

\section{INNOVATION AND FIRM'S COLLABORATIONS SURVEY}

\section{SURVEY QUESTIONNAIRE}

This survey collects information on your enterprise's

Innovations and innovation activities, as well collaborations with other enterprises between 2000 and 2010 inclusive

Name of the company:

Name of the respondent:

Job title:

Phone:

E-mail:

Date:

- An innovation is the introduction of a new or significantly improved product or process by your enterprise.

- The innovation must be new to your enterprise, although it could have been originally developed by other enterprises.

- The questions on innovation activities only refer to product and process innovations.

- $\quad$ Please complete all questions, unless otherwise instructed.

\section{ENTERPRISE}

\subsection{General information about the enterprise}

1.1.1. Name of enterprise

1.1.2. Established on

1.1.3. Address

1.1.4. Postal code

1.1.5. Main activity/industry

1.1.6. Number of employees

1.1.7. Number of engineers/scientists

1.1.8. Ownership:

\begin{tabular}{|c|c|c|c|}
\hline \multicolumn{2}{|c|}{ Private } & Public & Mixed \\
National & $\begin{array}{c}\text { Subsidiary of } \\
\text { foreign company }\end{array}$ & $\square$ & $\square$ \\
\hline$\square$ & $\square$ & $\square$ & $\square$ \\
\hline
\end{tabular}

1.1.9. Legal structure 


\begin{tabular}{|c|c|c|c|c|c|}
\hline Ltd (LLC) & OJSC & CJSC & Cooperative & $\begin{array}{c}\text { Sole } \\
\text { entrepreneur }\end{array}$ & \\
\hline$\square$ & $\square$ & $\square$ & $\square$ & $\square$ & Other $\uparrow$ \\
\hline
\end{tabular}

1.2. In 2010, was your enterprise part of an enterprise group?

A group consists of two or more legally defined enterprises under common ownership. Each enterprise in the group can serve different markets, as with national or regional subsidiaries, or serve different product markets. The head office is also part of an enterprise group.

1.2.1. Yes $\square$, in which country is the head office of your group located?

\subsubsection{No $\square$}

1.3. In which geographic markets did your enterprise sell goods and/or services during the three years 2008 to 2010 ?

\begin{tabular}{|ll|c|c|}
\hline 1.3.1. & $\begin{array}{l}\text { Local / regional within } \\
\text { Armenia }\end{array}$ & Tick a box & Specify country \\
\hline 1.3.2. & USA & $\square$ & \\
\hline 1.3.3. & $\begin{array}{l}\text { Russia and others CIS } \\
\text { countries }\end{array}$ & $\square$ & \\
\hline 1.3.4. & European countries & $\square$ & \\
\hline 1.3.5. $\quad$ Middle East & $\square$ & \\
\hline 1.3.6. & All other countries & $\square$ & \\
\hline
\end{tabular}

1.4. Which of the above mentioned geographic areas was your largest market in terms of turnover between 2008 and 2010 ?

\begin{tabular}{|ll|c|c|}
\hline & $\begin{array}{c}\text { Geographic market } \\
\text { with largest } \\
\text { sales/activity }\end{array}$ & $\begin{array}{c}\text { Share in activity } \\
\text { (\% of sales) }\end{array}$ \\
\hline 1.4 .1$. & Year 2008 & & $\%$ \\
\hline 1.4 .2$. & Year 2009 & & $\%$ \\
\hline 1.4 .3$. & Year 2010 & & \\
\hline
\end{tabular}

1.5. Did your company introduce any product or process innovation between 2008 and 2010?

1.5.1. Yes $\square$

1.5.2. No $\square$, if "No", go to Section 4.

1.5.3. 


\section{PRODUCT (GOOD OR SERVICE) INNOVATION}

\section{Definitions:}

A product innovation is the market introduction of a new or significantly improved good or service with respect to its capabilities, user friendliness, components or subsystems.

- Product innovations (new or improved) must be new to your enterprise, but they do not need to be new to your market.

- Product innovations could have been originally developed by your enterprise or by other enterprises.

- "New to your firm" Your enterprise introduced a new or significantly improved good or service that was already available from your competitors in your market.

- "New to the Market" Your enterprise introduced a new or significantly improved good or service onto your market before your competitors (it may have already available in other markets).

2.1. How many product innovation projects did you have between 2008 and 2010?

2.2. For each product innovation project please fill in below:

\begin{tabular}{|c|c|c|c|c|c|}
\hline $\begin{array}{l}\text { Type } \\
(\operatorname{good}(G) / \\
\text { service(S)) }\end{array}$ & $\begin{array}{l}\text { Name of } \\
\text { product/ } \\
\text { type of } \\
\text { service }\end{array}$ & $\begin{array}{c}\text { Who } \\
\text { developed } \\
\text { this } \\
\text { innovation } \\
\text { (select only } \\
\text { one option) }\end{array}$ & $\begin{array}{l}\text { New to the } \\
\text { market or new } \\
\text { to your firm? } \\
\text { (select only } \\
\text { one option) }\end{array}$ & $\begin{array}{l}\text { Is this } \\
\text { innovation } \\
\text { applied in } \\
\text { Armenian } \\
\text { market or } \\
\text { abroad? }\end{array}$ & $\begin{array}{l}\text { If abroad } \\
\text { - where? }\end{array}$ \\
\hline $\mathrm{G} \square \mathrm{S} \square$ & & $\begin{array}{l}\text { In-house } \\
\text { Cooperati } \\
\text { on } \\
\text { External }\end{array}$ & {$\left[\begin{array}{l}\text { New to } \\
\text { market } \\
\text { New to your } \\
\text { firm }\end{array}\right.$} & $\begin{array}{l}\text { Armenian } \\
\text { market } \\
\text { Abroad }\end{array}$ & \\
\hline
\end{tabular}

2.3. Using the definitions above, please give the percentage of your total turnover during 2010 from:

2.3.1. New or significantly improved goods and services introduced during 2008 to 2010 that were new to your market

2.3.2. New or significantly improved goods and services introduced during 2008 to 2010 that were only new to your firm

2.3.3. Goods and services that were unchanged or only marginally modified during 2008 to 2010 (include the resale of new goods or services purchased from other enterprises) 
2.4 How frequently your enterprise introduce additional good or service innovations:

\begin{tabular}{|ll|c|}
\hline & & Tick a box \\
\hline 2.4 .1 & More than every year & $\square$ \\
\hline 2.4 .2 & At least once a year & $\square$ \\
\hline 2.4 .3 & Every two to three years & $\square$ \\
\hline 2.4 .4 & Every three to five years & $\square$ \\
\hline 2.4 .5 & Once for the period of 2000 to 2010 & $\square$ \\
\hline
\end{tabular}

\section{Process INNOVATION}

\section{Definitions:}

Process innovation is the use of new or significantly improved for the

production or supply of goods and services. The innovation (new or improved) must be new to your enterprise, but it does not need to be new to your industry sector or market. It does not matter if the innovation was originally developed by your enterprise or by other enterprises. Exclude purely organizational innovations such as changes in firm structure or management practice.

\subsection{During the three years 2008 to 2010 did your enterprise introduce:}

\begin{tabular}{|ll|l|l|l|}
\hline 3.1.1. $\begin{array}{l}\text { New or significantly improved methods of } \\
\text { manufacturing or producing goods or services }\end{array}$ & Yes & No & $\begin{array}{c}\text { How } \\
\text { many }\end{array}$ \\
\hline 3.1.2. & $\begin{array}{l}\text { New or significantly improved logistics, delivery or } \\
\text { distribution methods for your inputs, goods or } \\
\text { services }\end{array}$ & $\square$ & $\square$ & \\
\hline 3.1.3. $\begin{array}{l}\text { New or significantly improved supporting activities } \\
\text { for your processes, such as maintenance systems or } \\
\text { operations for purchasing, accounting, or computing }\end{array}$ & $\square$ & $\square$ & \\
\hline
\end{tabular}

\section{If "No" to all, go directly to}

Section 4

3.2. List the new process innovations your company introduced between 20082010 in the following three fields: 
3.2.1. Improved methods of manufacturing or producing goods or services:

\begin{tabular}{|l|l|l|l|l|}
\hline Describe & $\begin{array}{c}\text { Who developed this } \\
\text { innovation mainly } \\
\text { (select only one option) }\end{array}$ & $\begin{array}{c}\text { New to the } \\
\text { market or new to } \\
\text { your firm? } \\
\text { (select only one } \\
\text { option) }\end{array}$ & $\begin{array}{c}\text { Is this innovation } \\
\text { applied in } \\
\text { Armenian market } \\
\text { or abroad? }\end{array}$ & If abroad \\
- where?
\end{tabular}

3.2.2. Improved logistics, delivery or distribution methods for your inputs, goods or services:

\begin{tabular}{|l|l|l|l|l|l|}
\hline Describe & $\begin{array}{c}\text { Who developed this } \\
\text { innovation mainly } \\
\text { (select only one option) }\end{array}$ & $\begin{array}{c}\text { New to market or } \\
\text { new to your firm? } \\
\text { (select only one } \\
\text { option) }\end{array}$ & $\begin{array}{c}\text { Is this innovation } \\
\text { applied in } \\
\text { Armenian market } \\
\text { or abroad? }\end{array}$ & $\begin{array}{l}\text { If abroad } \\
\text { - where? }\end{array}$ \\
\hline & $\begin{array}{l}\text { In-house } \\
\text { Cooperation } \\
\text { External }\end{array}$ & $\square$ & $\begin{array}{l}\text { New to market } \\
\text { New to your }\end{array}$ & $\square$ & $\begin{array}{l}\text { Armenian } \\
\text { firm }\end{array}$ \\
Abrket
\end{tabular}

3.2.3. Improved supporting activities for your processes, such as maintenance systems or operations for purchasing, accounting, or computing:

\begin{tabular}{|c|c|c|c|c|}
\hline Describe & $\begin{array}{l}\text { Who developed this } \\
\text { innovation mainly } \\
\text { (select only one option) }\end{array}$ & $\begin{array}{l}\text { New to the } \\
\text { market or new to } \\
\text { your firm? } \\
\text { (select only one } \\
\text { option) }\end{array}$ & $\begin{array}{l}\text { Is this innovation } \\
\text { applied in } \\
\text { Armenian market } \\
\text { or abroad? }\end{array}$ & $\begin{array}{l}\text { If abroad } \\
\text { - where? }\end{array}$ \\
\hline & $\begin{array}{l}\text { In-house } \\
\text { Cooperation } \\
\text { External }\end{array}$ & $\begin{array}{l}\text { New to market } \square \\
\text { New to your } \\
\text { firm }\end{array}$ & $\begin{array}{l}\text { Armenian } \\
\text { market } \\
\text { Abroad }\end{array}$ & \\
\hline
\end{tabular}

3.3 How frequently your enterprise introduce additional good or service innovations:

\begin{tabular}{|ll|c|}
\hline & & Tick a box \\
\hline 3.3 .1 & More than every year & $\square$ \\
\hline 3.3 .2 & At least once a year & $\square$ \\
\hline 3.3 .3 & Every two to three years & $\square$ \\
\hline 3.3 .4 & Every three to five years & $\square$ \\
\hline 3.3 .5 & Once for the period of 2000 to 2010 & $\square$ \\
\hline
\end{tabular}




\section{INNOVATION ACTIVITIES AND EXPENDITURES FOR PROCESS AND PRODUCT INNOVATIONS}

\subsection{During the three years of 2008 to 2010 , did your enterprise engage in the following innovation activities:}

\begin{tabular}{|c|c|c|}
\hline & & \\
\hline & Yes, amount in AMD & No \\
\hline $\begin{array}{l}\text { 4.1.1. In-house R\&D: } \\
\text { Creative work undertaken within your enterprise to increase the } \\
\text { stock of knowledge for developing new and improved products } \\
\text { and processes } \\
\text { (include software development in-house that meets this } \\
\text { requirement) }\end{array}$ & $\square \_$AMD & $\square$ \\
\hline If yes, did your enterprise perform R\&D during 2008 to 2010 : & & \\
\hline $\begin{array}{l}\text { Continuously (your enterprise has permanent R\&D staff } \quad \square \\
\text { in-house) }\end{array}$ & & \\
\hline Occasionally (as needed only) & & \\
\hline $\begin{array}{l}\text { 4.1.2. External R\&D: } \\
\text { Same activities as above, but performed by other enterprises } \\
\text { (including other enterprises or subsidiaries within your group) or } \\
\text { by public or private research organizations and purchased by your } \\
\text { enterprise }\end{array}$ & AMD & $\square$ \\
\hline $\begin{array}{l}\text { 4.1.3. Acquisition of machinery, equipment and software: } \\
\text { Acquisition of advanced machinery, equipment and computer } \\
\text { hardware or software to produce new or significantly improved } \\
\text { products and processes }\end{array}$ & AMD & $\square$ \\
\hline $\begin{array}{l}\text { 4.1.4. Acquisition of external knowledge: } \\
\text { Purchase or licensing of patents and non-patented inventions, } \\
\text { know-how, and other types of knowledge from other enterprises } \\
\text { or organizations for the development of new or significantly } \\
\text { improved products and processes }\end{array}$ & AMD & 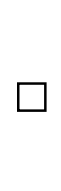 \\
\hline $\begin{array}{l}\text { 4.1.5. Training for innovative activities: } \\
\text { Internal or external training for your personnel specifically for the } \\
\text { development and/or introduction of new or significantly } \\
\text { improved products and processes }\end{array}$ & AMD & $\square$ \\
\hline $\begin{array}{l}\text { 4.1.6. Market introduction of innovations: } \\
\text { Activities for the market introduction of your new or significantly } \\
\text { improved goods and services, including market research and } \\
\text { launch advertising }\end{array}$ & AMD & $\square$ \\
\hline $\begin{array}{l}\text { 4.1.7. Other: } \\
\text { Other activities to implement new or significantly improved } \\
\text { products and processes such as feasibility studies, testing, routine } \\
\text { software development, tooling up, industrial engineering, etc. }\end{array}$ & $\square$ & \\
\hline
\end{tabular}


If "No" to Questions 4.1.1 and 4.1.2, go directly to Section 6

4.2. Does your company provide trainings to your employees?

4.2.1. If "Yes", please describe:

\begin{tabular}{|c|c|c|l|l|}
\hline Describe & $\begin{array}{c}\text { In which area is } \\
\text { it? }\end{array}$ & $\begin{array}{c}\text { Is it regular } \\
\text { or } \\
\text { occasional? }\end{array}$ & \multicolumn{1}{|c|}{$\begin{array}{c}\text { How is it } \\
\text { financed? }\end{array}$} & $\begin{array}{c}\text { Where do } \\
\text { your trainers } \\
\text { from? }\end{array}$ \\
\hline & & $\begin{array}{l}\text { Regular } \square \\
\text { Irregular }\end{array} \square$ & $\begin{array}{l}\text { Internal } \\
\text { External }\end{array} \square$ & $\begin{array}{l}\text { Internal } \\
\text { External } \square\end{array}$ \\
\hline
\end{tabular}

4.2.2. If "No", please state which kind of trainings would you like to get?

4.3. During the three years 2008 to 2010 , did your enterprise receive any public financial support for innovation activities from the following sources?

\begin{tabular}{|ll|c|c|}
\hline 4.3.1. & Funds from government (loans, grants, etc.) & Yes & No \\
\hline 4.3.2. & Funds from financial companies (bank loans, venture capital, etc.) & $\square$ & $\square$ \\
\hline 4.3.3. $\quad \begin{array}{l}\text { Funds from supranational and international organizations (EU, } \\
\text { etc.) }\end{array}$ & $\square$ & $\square$ \\
\hline 4.3.4. $\quad \begin{array}{l}\text { Funds from related companies (subsidiary or associated } \\
\text { companies) }\end{array}$ & $\square$ & $\square$ \\
\hline 4.3.5. $\quad$ Funds from other (non-financial) enterprises & $\square$ & $\square$ \\
\hline 4.3.6. $\quad$ Other sources & $\square$ & $\square$ \\
\hline
\end{tabular}

\section{R\&D ACTIVITIES}

\section{Definition:}

Research and experimental development comprises creative work undertaken on a systematic basis in order to increase the stock of knowledge. Any activity classified as R\&D is characterized by originality. Investigation is a primary objective.

5.1. Do you conduct regular $R \& D$ activities in your company?

\begin{tabular}{|c|c|c|c|}
\hline Yes, intensively & Yes, regularly & Rarely & No \\
$\square$ & $\square$ & $\square$ & $\square$ \\
\hline
\end{tabular}

5.2. Do you cooperate with $R \& D$ institutions?

\begin{tabular}{|c|c|c|c|}
\hline Yes, intensively & Yes, regularly & Rarely & No \\
$\square$ & $\square$ & $\square$ & $\square$ \\
\hline If "yes", which institutions & & \\
\end{tabular}


5.3. What was the total amount spent on $R \& D$ by your company between 2008 and 2010?

\begin{tabular}{|r|r|r|}
\hline 2008 & 2009 & 2010 \\
\hline AMD & AMD & AMD \\
\hline
\end{tabular}

\subsection{Size of the $R \& D$ team:}

5.4.1. What is the total number of scientists and engineers working in your company?

5.4.2. Can you provide the breakdown by category (Ex. Software developer, Biologist, Mathematician, Mechanical engineer, Physicist, Civil Engineer, Telco engineer....)

\subsubsection{1.}

5.4.2.2.

\subsection{Involvement in $R \& D$ activities:}

5.5.1. What number of scientists and engineers are permanently engaged in $R \& D$ activities?

5.5.2. Are there any inventors working at your company?

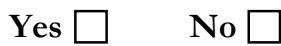

$$
\begin{array}{ll}
\text { 5.5.2.1. } & \text { If "Yes", how many? } \\
\text { 5.5.2.2. } & \text { If "Yes", in which field? }
\end{array}
$$

5.5.3. What is your employees' motivation to innovate?

\section{COOPERATION AND COLLABORATIONS}

\section{Definition:}

With which institutions did your enterprise set up collaborations/ cooperation alliances since 2000. Mention the most significant collaboration agreement. Please, consider all possible sorts of partners such as firs, universities, research institutes and others:

\subsection{Does you enterprise have board of directors? $\quad$ Yes $\square \quad$ No $\square$}

6.1.1 If "Yes", how many?

6.1.2 Please list the names of board members

\begin{tabular}{|c|c|c|c|c|}
\hline $\begin{array}{c}\text { Name and Surname } \\
\text { of board directors/ } \\
\text { owners }\end{array}$ & $\begin{array}{c}\text { Shares of the } \\
\text { company (\%) }\end{array}$ & Year & Nationality & $\begin{array}{c}\text { If abroad - } \\
\text { where? }\end{array}$ \\
\hline & & & & \\
\hline
\end{tabular}


6.2 Please indicate the type of innovation co-operation partner by location

\begin{tabular}{|c|c|c|c|c|c|c|c|c|c|c|c|}
\hline \multicolumn{2}{|c|}{ Type of co-operation partner } & \multirow{2}{*}{$\begin{array}{c}\text { Armenia } \\
\square\end{array}$} & \multirow{2}{*}{$\begin{array}{r}\text { USA } \\
\square\end{array}$} & \multirow{2}{*}{$\begin{array}{c}\text { Russia, } \\
\text { other CIS } \\
\text { countries } \\
\square\end{array}$} & \multirow[t]{2}{*}{$\begin{array}{l}\text { Specify the } \\
\text { countries }\end{array}$} & \multirow{2}{*}{$\begin{array}{c}\begin{array}{c}\text { European } \\
\text { countries }\end{array} \\
\square\end{array}$} & \multirow[t]{2}{*}{$\begin{array}{l}\text { Specify the } \\
\text { countries }\end{array}$} & \multirow{2}{*}{$\begin{array}{c}\text { Middle } \\
\text { East } \\
\square\end{array}$} & \multirow[t]{2}{*}{$\begin{array}{l}\text { Specify the } \\
\text { countries }\end{array}$} & \multirow{2}{*}{$\begin{array}{c}\begin{array}{c}\text { Other } \\
\text { countries }\end{array} \\
\square\end{array}$} & \multirow[t]{2}{*}{$\begin{array}{l}\text { Specify the } \\
\text { countries }\end{array}$} \\
\hline 6.2 .1 & $\begin{array}{l}\text { Other enterprises within } \\
\text { your enterprise group }\end{array}$ & & & & & & & & & & \\
\hline 6.2.2 & $\begin{array}{l}\text { Suppliers of equipment, } \\
\text { materials, components, } \\
\text { or software }\end{array}$ & $\square$ & $\square$ & $\square$ & & $\square$ & & $\square$ & & $\square$ & \\
\hline 6.2 .3 & Clients or customers & $\square$ & $\square$ & $\square$ & & $\square$ & & $\square$ & & $\square$ & \\
\hline 6.2.4 & $\begin{array}{l}\text { Competitors or other } \\
\text { enterprises in your sector }\end{array}$ & $\square$ & $\square$ & $\square$ & & $\square$ & & $\square$ & & $\square$ & \\
\hline 6.2 .5 & $\begin{array}{l}\text { Consultants, commercial } \\
\text { labs, or private R\&D } \\
\text { institutes }\end{array}$ & $\square$ & $\square$ & $\square$ & & $\square$ & & $\square$ & & $\square$ & \\
\hline 6.2.6 & $\begin{array}{l}\text { Universities or other } \\
\text { higher education } \\
\text { institutions }\end{array}$ & $\square$ & $\square$ & $\square$ & & $\square$ & & $\square$ & & $\square$ & \\
\hline 6.2 .7 & $\begin{array}{l}\text { Government or public } \\
\text { research institutes }\end{array}$ & $\square$ & $\square$ & $\square$ & & $\square$ & & $\square$ & & $\square$ & \\
\hline
\end{tabular}

6.3 Which type of co-operation partner did you find the most valuable for your enterprise's innovation activities? Describe. 
6.4 List the name of organizations you had set up collaborations.

6.4.1 List of organizations in Armenia you are collaborating

\begin{tabular}{|c|c|c|c|c|c|c|}
\hline $\begin{array}{c}\text { Organization } \\
\text { in Armenia }\end{array}$ & $\begin{array}{l}\text { Duration of } \\
\text { Agreement }\end{array}$ & Purpose & $\begin{array}{l}\text { Why do you } \\
\text { choose the } \\
\text { firm? }\end{array}$ & $\begin{array}{l}\text { How you } \\
\text { learn } \\
\text { about the } \\
\text { firms }\end{array}$ & $\begin{array}{c}\text { Your } \\
\text { Expectati } \\
\quad \text { ons }\end{array}$ & $\begin{array}{c}\text { What was } \\
\text { you } \\
\text { outcome }\end{array}$ \\
\hline & & $\begin{array}{ll}\text { R\&D } & \square \\
\text { Produ } & \square \\
\text { ction } & \square \\
\text { Comm } & \\
\text { ercializ } & \square \\
\text { ation } & \\
\text { Other } & \end{array}$ & $\begin{array}{l}\text { Leader } \quad \square \\
\text { in the } \\
\text { market } \quad \square \\
\text { Other/ } \\
\text { specify }\end{array}$ & $\begin{array}{ll}\text { Previ } & \square \\
\text { ous } & \\
\text { experi } & \square \\
\text { ence } & \\
\text { Marke } & \square \\
\mathrm{t} & \\
& \\
\text { Intern } & \\
\text { et } & \end{array}$ & & \\
\hline
\end{tabular}

6.4.2 List of organizations in abroad you are collaborating

\begin{tabular}{|l|l|l|l|l|l|l|}
\hline $\begin{array}{c}\text { Organization } \\
\text { abroad/Cou } \\
\text { ntry }\end{array}$ & $\begin{array}{c}\text { Duration of } \\
\text { Agreement }\end{array}$ & Purpose & $\begin{array}{c}\text { Why do } \\
\text { you choose } \\
\text { the firm? }\end{array}$ & $\begin{array}{c}\text { How you } \\
\text { learn about } \\
\text { the firms }\end{array}$ & $\begin{array}{c}\text { Your } \\
\text { Expectat } \\
\text { ions }\end{array}$ & $\begin{array}{c}\text { What was } \\
\text { your } \\
\text { outcome }\end{array}$ \\
\hline & $\begin{array}{l}\text { R\&D } \square \\
\text { Produ } \\
\text { ction } \\
\text { Comm } \\
\text { ercializ } \\
\text { ation } \\
\text { Other }\end{array}$ & $\begin{array}{l}\text { Leader } \square \\
\text { in the } \\
\text { market } \\
\text { Other/ } \\
\text { specify }\end{array}$ & $\begin{array}{l}\text { Previo } \square \\
\text { us } \\
\text { experi } \square \\
\text { ence } \\
\text { Marke } \square \\
\text { th }\end{array}$ & & \\
& & $\begin{array}{l}\text { Intern } \\
\text { et }\end{array}$ & & \\
\hline
\end{tabular}

6.4.3 List of Universities and research Institutes you are collaborating

\begin{tabular}{|c|c|c|c|c|c|c|}
\hline $\begin{array}{l}\text { University or } \\
\text { Research } \\
\text { institutes }\end{array}$ & $\begin{array}{l}\text { Duration of } \\
\text { Agreement }\end{array}$ & Purpose & $\begin{array}{l}\text { Why do } \\
\text { you choose } \\
\text { the } \\
\text { University } \\
\text { /or } \\
\text { Research } \\
\text { Institute? }\end{array}$ & $\begin{array}{l}\text { How you } \\
\text { learn about } \\
\text { the them }\end{array}$ & $\begin{array}{c}\text { Your } \\
\text { Expectat } \\
\text { ions }\end{array}$ & $\begin{array}{c}\text { What was } \\
\text { your } \\
\text { outcome }\end{array}$ \\
\hline & & $\begin{array}{ll}\text { Gradu } & \square \\
\text { ate } & \square \\
\text { licensi } & \square \\
\text { ng } & \square \\
\text { Intern } & \\
\text { ship } & \\
\text { Other } & \end{array}$ & $\begin{array}{l}\text { Leader } \quad \square \\
\text { in the } \\
\text { market } \quad \square \\
\text { Other/ } \\
\text { specify }\end{array}$ & $\begin{array}{ll}\text { Previo } & \square \\
\text { us } & \\
\text { experi } & \square \\
\text { ence } & \square \\
\text { Marke } & \\
\text { t } & \\
\text { Intern } & \\
\text { et } & \end{array}$ & & \\
\hline
\end{tabular}


7 SOURCES OF INFORMATION AND CO-OPERATION FOR INNOVATION ACTIVITIES

7.1 During the three years 2008 to 2010, how important to your enterprise's innovation activities were each of the following information sources? Please identify information sources that provided information for new innovation projects or contributed to the completion of existing innovation projects.

Circle the relevant number

\begin{tabular}{|c|c|c|c|c|c|}
\hline \multicolumn{2}{|c|}{ Information source } & \multicolumn{4}{|c|}{$\begin{array}{c}\text { Scale: } \\
1=\text { Not important } \\
4=\text { Very important }\end{array}$} \\
\hline \multicolumn{6}{|c|}{ Internal } \\
\hline 7.1.1 & Within your enterprise or enterprise group & 1 & 2 & 3 & 4 \\
\hline \multicolumn{6}{|c|}{ Market Sources } \\
\hline 7.1 .2 & $\begin{array}{l}\text { Suppliers of equipment, materials, components, or } \\
\text { software }\end{array}$ & 1 & 2 & 3 & 4 \\
\hline 7.1 .3 & Clients or customers & 1 & 2 & 3 & 4 \\
\hline 7.1.4 & Competitors or other enterprises in your sector & 1 & 2 & 3 & 4 \\
\hline 7.1 .5 & Consultants, commercial labs, or private R\&D institutes & 1 & 2 & 3 & 4 \\
\hline \multicolumn{6}{|c|}{ Institutional sources } \\
\hline 7.1.6 & Universities or other higher education institutions & 1 & 2 & 3 & 4 \\
\hline 7.1.7 & Government or public research institutes & 1 & 2 & 3 & 4 \\
\hline \multicolumn{6}{|c|}{ Other sources } \\
\hline 7.1 .8 & Conferences, trade fairs, exhibitions & 1 & 2 & 3 & 4 \\
\hline 7.1.9 & Scientific journals and trade/technical publications & 1 & 2 & 3 & 4 \\
\hline 7.1 .10 & Professional and industry associations & 1 & 2 & 3 & 4 \\
\hline
\end{tabular}

7.2 During the three years 2008 to 2010 , did your enterprise co-operate on any of your innovation activities with other enterprises or institutions?

Innovation co-operation is active participation with other enterprises or non-commercial institutions on innovation activities. Both partners do not need to commercially benefit. Exclude pure contracting out of work with no active co-operation.

\begin{tabular}{|ll|l|l|l|}
\hline $7.2 .1 \quad$ Yes & $\square$ & If 'yes' What type of method do you use to collect the information? \\
\hline 7.2 .2 No & $\square$ & & \\
\hline
\end{tabular}




\section{INNOVATION OBJECTIVES DURING 2008-2010 AND IN THE FUTURE}

8.1 How important were each of the following objectives for your activities to develop product (good or service) or process innovations between 2008 and 2010?

If your enterprise had several projects for product and process innovations, make an overall evaluation
Scale:

$1=$ Not important

$4=$ Very important

(Circle the relevant number here)
Will this be valid for 20112015?

(Tick the box)

\begin{tabular}{|c|c|c|c|c|c|c|}
\hline 8.1 .1 & Increase range of goods or services & 1 & 2 & 3 & 4 & $\begin{array}{l}\text { Yes } \square \\
\text { No } \square\end{array}$ \\
\hline 8.1 .2 & $\begin{array}{l}\text { Replace outdated products or } \\
\text { processes }\end{array}$ & 1 & 2 & 3 & 4 & $\begin{array}{l}\text { Yes } \square \\
\text { No } \square\end{array}$ \\
\hline 8.1 .3 & Enter new markets & 1 & 2 & 3 & 4 & $\begin{array}{l}\text { Yes } \square \\
\text { No } \square\end{array}$ \\
\hline 8.1 .4 & Increase market share & 1 & 2 & 3 & 4 & $\begin{array}{l}\text { Yes } \square \\
\text { No } \square\end{array}$ \\
\hline 8.1 .5 & $\begin{array}{l}\text { Improve quality of goods or } \\
\text { services }\end{array}$ & 1 & 2 & 3 & 4 & $\begin{array}{l}\text { Yes } \square \\
\text { No } \square\end{array}$ \\
\hline 8.1 .6 & 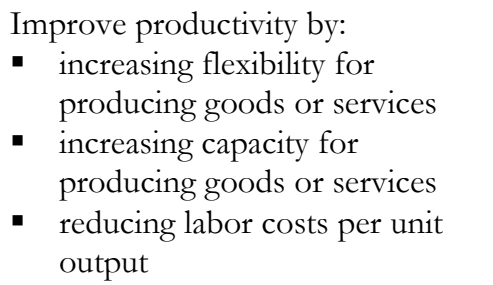 & 1 & 2 & 3 & 4 & $\begin{array}{l}\text { Yes } \square \\
\text { No } \square\end{array}$ \\
\hline 8.1 .7 & Improve health and safety & 1 & 2 & 3 & 4 & $\begin{array}{l}\text { Yes } \square \\
\text { No } \square\end{array}$ \\
\hline 8.1 .8 & Other reasons & 1 & 2 & 3 & 4 & $\begin{array}{l}\text { Yes } \square \\
\text { No } \square\end{array}$ \\
\hline
\end{tabular}




\section{Protection METHODS FOR INNOVATION}

8.2 Between 2008 and 2010 please indicate the importance of the following methods to protect innovation in your company:

Circle the relevant number

\begin{tabular}{|c|c|c|c|c|c|}
\hline \multirow[b]{3}{*}{8.2 .1} & & \multirow{2}{*}{\multicolumn{4}{|c|}{$\begin{array}{c}\text { Scale: } \\
1=\text { Not important } \\
4=\text { Very important }\end{array}$}} \\
\hline & \multirow[b]{2}{*}{ Registration of design } & & & & \\
\hline & & 1 & 2 & 3 & 4 \\
\hline 8.2 .2 & Trademarks & 1 & 2 & 3 & 4 \\
\hline 8.2 .3 & Patents & 1 & 2 & 3 & 4 \\
\hline 8.2 .4 & Confidentiality agreements & 1 & 2 & 3 & 4 \\
\hline 8.2 .5 & Copyright & 1 & 2 & 3 & 4 \\
\hline 8.2.6 & Secrecy & 1 & 2 & 3 & 4 \\
\hline 8.2 .7 & Complexity of design & 1 & 2 & 3 & 4 \\
\hline 8.2 .8 & Lead-time advantage on competitors & 1 & 2 & 3 & 4 \\
\hline 8.2 .9 & Other & 1 & 2 & 3 & 4 \\
\hline
\end{tabular}

9 ONGOING OR ABANDONED INNOVATION ACTIVITIES FOR PROCESS AND PRODUCT INNOVATIONS

\section{Definition:}

Innovation activities include the acquisition of machinery, equipment, software, and licenses; engineering and development work, industrial design, training, marketing and $R \& D$ when they are specifically undertaken to develop and/or implement a product or process innovation. Also include basic R\&D as an innovation activity even when not related to a product and/or process innovation.

9.1 Between 2008 and 2010, did your enterprise have any innovation activities that did not result in a product or process innovation because of one of the two reasons below:

\begin{tabular}{|ll|c|c|}
\cline { 2 - 3 } \multicolumn{1}{c|}{} & Yes & No \\
\hline 9.1 .1 & Abandoned or suspended before completion & $\square$ & $\square$ \\
\hline 9.1 .2 & Still ongoing at the end of the 2010 & $\square$ & $\square$ \\
\hline
\end{tabular}

\section{If "No" to 9.1, go directly to Section 11}

9.2 For the activities that were abandoned or suspended before completion, please describe and give the reason below.

What projects?

What reasons? 
10 CONSTRAINTS ON INNOVATION

10.1 How important were the factors below in preventing, stopping or slowing down innovation in your firm between 2008 and 2010 ?

Circle the relevant number

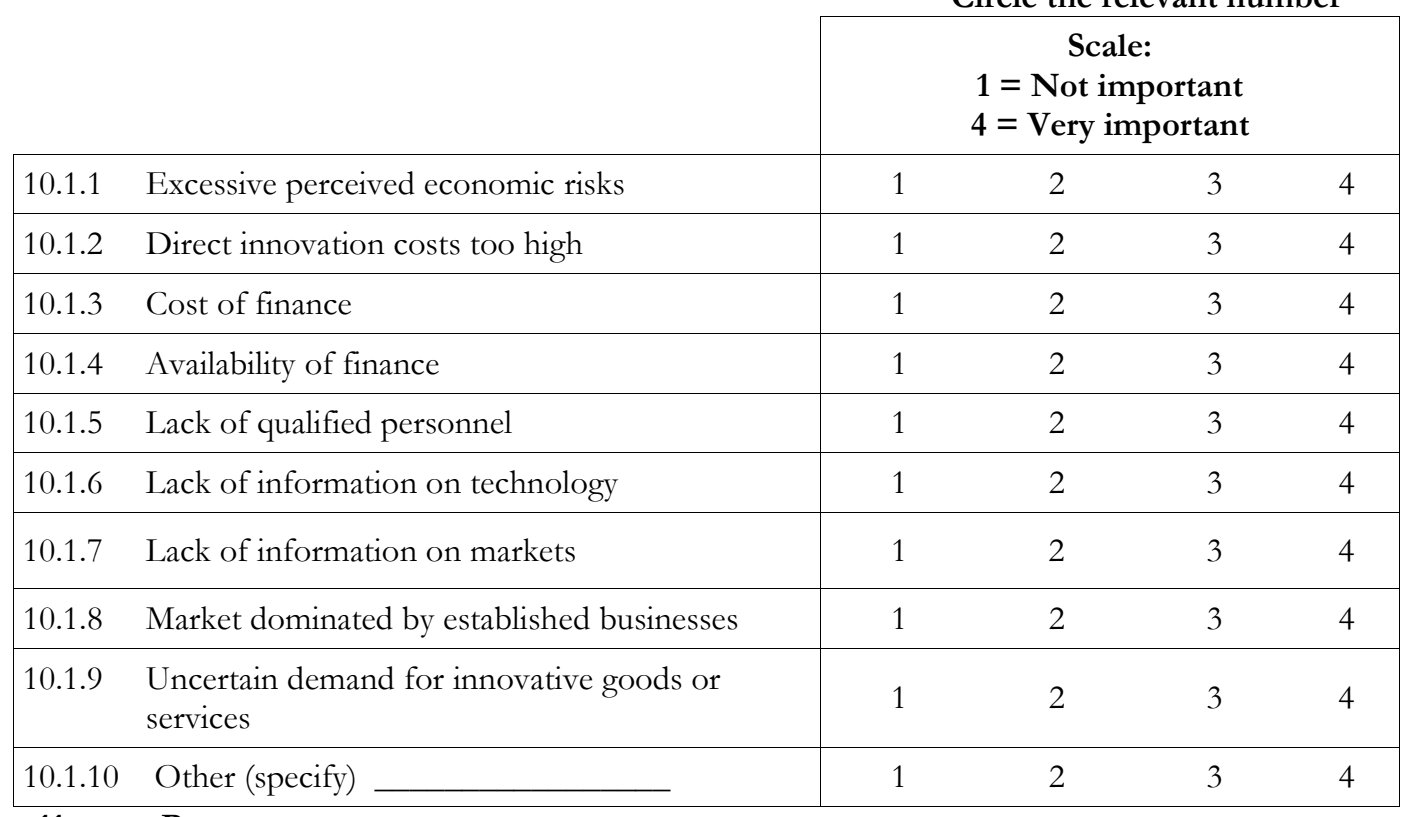

11 BUSINESSES WITH NO INNOVATION ACTIVITY

11.1 If this business had no innovation activity between 2008 and 2010, please indicate why it has not been necessary or possible to innovate.

\begin{tabular}{|ll|c|c|}
\multicolumn{1}{|c}{ Yes } & No \\
\hline 11.1.1 & No need due to prior innovations & $\square$ & $\square$ \\
\hline 11.1.2 & No need due to market conditions & $\square$ & $\square$ \\
\hline 11.1.3 $\quad$ Factors constraining innovation & $\square$ & $\square$ \\
\hline 11.1.4 $\quad$ Other(specify) & $\square$ & $\square$ \\
\hline
\end{tabular}

11.2 Please explain in more details the items where you answered yes above.

12 BASIC ECONOMIC INFORMATION ON YOUR ENTERPRISE

12.1 What was your enterprise's total turnover for 2008 and 2010? Turnover is defined as the market sales of goods and services (Include all taxes except VAT).
12.1.1 Year 2008
12.1.2 Year 2009
12.1.3 Year 2010

AMD

AMD

AMD

12.2 What was your enterprise's total number of employees in 2008 and 2010?
12.2.1 Year 2008
12.2.2 Year 2009
12.2.3 Year 2010 


\section{BIBLIOGRAPHY}

Abor, J. 2005. "The Effect of Capital Structure on Profitability: An Empirical Analysis of Listed Firms in Ghana." The Journal of Risk Finance 6 (5): 438-45.

Abramovitz, M. 1986. "Catching Up, Forging Ahead, and Falling Behind.” Journal of Economic History 46 (2): 385-406.

Abramovsky, L., E. Kremp, A. Lopez, and H. Simpson. 2005. "Understanding CoOperative R\&D Activity: Evidence from Four European Countries." Institute for Fiscal Studies Working Paper no. W05/23.

Abreu, M., and V. Mendes. 2001. "Commercial Bank Interest Margins and Profitability: Evidence for Some EU Countries." Paper presented at the PanEuropean Conference, Jointly Organized by the IEFS-UK \& University of Macedonia Economic \& Social Sciences, Thessaloniki, Greece, 2001.

Acharya, V. V., and Zh. Xu. 2013. "Financial Dependence and Innovation: The Case of Public versus Private Firms." National Bureau of Economic Research Working Paper no. 19708.

Acs, Z. J., and David B. Audretsch. 2003. “Innovation and Technological Change.” In Handbook of Entrepreneurship Research, edited by Zoltan J. Acs and David B. Audretsch, 55-79. International Handbook Series on Entrepreneurship. Boston: Springer.

Adams, R. B., H. Almeida, and D. Ferreira. 2005. "Powerful CEOs and Their Impact on Corporate Performance." Review of Financial Studies 18 (4): 1403-32.

Aghion, Ph., S. Bond, A. Klemm, and I. Marinescu. 2004. "Technology and Financial Structure: Are Innovative Firms Different?" Journal of the European Economic Association 2 (2-3): 277-88.

Aghion, Ph., W. Carlin, and M. E. Schaffer. 2002. "Competition, Innovation and Growth in Transition: Exploring the Interactions between Policies." Social Science Research Network. Scholarly Paper no. 311407. Rochester, NY:

Ahuja, G. 2000. "The Duality of Collaboration: Inducements and Opportunities in the Formation of Interfirm Linkages." Strategic Management Journal 21 (3): 317-43.

Ahuja, G, F. Polidoro, and W. Mitchell. 2004. "Structural Homophily or Social Asymmetry? The Formation of Alliances by Poorly Embedded Firms." Strategic Management Journal 30 (9), 941-958

Allison, P. D. 1977. "Testing for Interaction in Multiple Regression." American Journal of Sociology 83 (1): 144-53.

Anderson, R. Jerome. 2006. "Industrial Firm Linkages in a Post-Soviet Urban Economy: Implications for Development Policy and Programmes." Progress in Development Studies 6 (3): 224-41.

Aoki, M. 2013. "Comparative Institutional Analysis: Theory, Corporations and East Asia." Selected Papers of Masahiko Aoki. Cheltenham: Edward Elgar Publishing.

Arakelyan, V. 2005. "Privatization as a Means of Property Redistribution in the Republic of Armenia and in the Russian Federation."(diss.) University of Tampere. 
Aral, S., E. Brynjolfsson, and M. Van Alstyne. 2007. "Information, Technology and Information Worker Productivity: Task Level Evidence.” National Bureau of Economic Research Working Paper no. 13172.

Arocena, R., and J. Sutz. 2000. "Looking at National Systems of Innovation from the South." Industry and Innovation 7 (1): 55-75.

2002. "Innovation Systems and Developing Countries." DRUID Working Paper no. 02-05. Copenhagen Business School, Department of Industrial Economics and Strategy, Aalborg University, Department of Business Studies.

Arora, A. 1996. "Testing for Complementarities in Reduced-Form Regressions: A Note." Economics Letters 50 (1): 51-55.

Arora, A., and A. Gambardella. 1990a. "Complementarity and External Linkages: The Strategies of the Large Firms in Biotechnology." The Journal of Industrial Economics 38 (4): 361-79.

1990b. "Complementarity and External Linkages: The Strategies of the Large Firms in Biotechnology." The Journal of Industrial Economics 38 (4): 361-79.

Arundel, A., C. Bordoy, and M. Kanerva. 2008. "Neglected Innovators: How Do Innovative Firms That Do Not Perform R\&D Innovate? Results of an Analysis of the Innobarometer 2007 Survey No. 215.'INNO-Metrics Thematic Paper.

Ayyagari, M, Th. Beck, and A. Demirguc-Kunt. 2007. "Small and Medium Enterprises across the Globe." Small Business Economics 29 (4): 415-34.

Baker, W. E. 1990. "Market Networks and Corporate Behavior." American Journal of Sociology 96 (3): 589-625.

Baković, T. 2010. "Managing Innovation Systems in Transition Economies." EFZG Working Paper no. 01: 1-11. Faculty of Economics and Business University of Zagreb

Baković T., T. Lazibat, and I. Sutić. 2013. "Radical Innovation Culture in Croatian Manufacturing Industry." Journal of Enterprising Communities: People and Places in the Global Economy 7 (1): 74-80.

Barbosa, N., A. P. Faria, and V. Eiriz. 2013. "Industry- and Firm-Specific Factors of Innovation Novelty." Industrial and Corporate Change 23 (3): 865-902.

Batjargal, B. 2003. "Social Capital and Entrepreneurial Performance in Russia: A Longitudinal Study." Organization Studies 24 (4): 535-56.

—. 2006. "The Dynamics of Entrepreneurs' Networks in a Transitioning Economy: The Case of Russia." Entrepreneurship \& Regional Development 18 (4): 305-20.

2007. "Network Triads: Transitivity, Referral and Venture Capital Decisions in China and Russia." Journal of International Business Studies 38 (6): 998-1012.

Baum, J. A. C., A. V. Shipilov, and T. J. Rowley. 2003. "Where Do Small Worlds Come From?" Industrial and Corporate Change 12 (4): 697-725.

Becker, G. S. 1962. "Investment in Human Capital: A Theoretical Analysis." Journal of Political Economy 70 (5): 9-49.

Beckman, Ch. M., P. R. Haunschild, and D. J. Phillips. 2004. "Friends or Strangers? Firm-Specific Uncertainty, Market Uncertainty, and Network Partner Selection." Organization Science 15 (3): 259-75. 
Belderbos, R., M. Carree, B. Diederen, B. Lokshin, and R. Veugelers. 2004. "Heterogeneity in R\&D Cooperation Strategies." International Journal of Industrial Organization 22 (8-9): 1237-63.

Belderbos, R., M. Carree, and B. Lokshin. 2006. "Complementarity in R\&D Cooperation Strategies." Review of Industrial Organization 28 (4): 401-26.

Berglof, E. 2015a. "New Structural Economics Meets European Transition." Journal of Economic Policy Reform 18 (2): 114-30.

Berglöf, E., Von Thadden, and Ernst-Ludwig. 1999. "The Changing Corporate Governance Paradigm: Implications for Transition and Developing Countries." Social Science Research Network Scholarly Paper no. 183708. Rochester, NY.

Bernard, A. B., and J. Bradford Jensen. 2004. "Why Some Firms Export." Review of Economics and Statistics 86 (2): 561-69.

Black, B., R. Kraakman, and A. Tarassova. 2000. "Russian Privatization and Corporate Governance: What Went Wrong?” Stanford Law Review 52 (6): 1731.

Borgatti, SP, M.G. Everett, and L.C. Freeman. 2002. "UCINET for Windows: Software for Social Network Analysis." Analytic Technologies, Harvard, MA.

Boschma, R. 2005. "Proximity and Innovation: A Critical Assessment". Regional studies 39(1): 61-74

Bosma, N., M. van Praag, R. Thurik, and G. de Wit. 2004. "The Value of Human and Social Capital Investments for the Business Performance of Startups." Small Business Economics 23 (3): 227-36.

Bourdieu, P. 1986. "The Forms of Capital." Handbook of Theory and Research for the Sociology of Education. New York.

Boycko, M. 1997. Privatizing Russia. Cambridge, Mass.: The MIT Press.

Breschi, S., and F. Lissoni. 2001. "Knowledge Spillovers and Local Innovation Systems: A Critical Survey." Industrial and Corporate Change 10 (4): 975-1005.

Burt, R. S. 1997. "The Contingent Value of Social Capital." Administrative Science Quarterly 42 (2): 339-65.

. 2000a. "The Network Structure of Social Capital." Research in Organizational Behavior 22: 345-423.

Burt, R. S. 2000b. "Decay Functions." Social Networks 22 (1): 1-28.

. 2004. "Structural Holes and Good Ideas." American Journal of Sociology 110 (2): 349-99.

- S. 2005. "Brokerage and Closure: An Introduction to Social Capital." Oxford.

Bye, B., T. Fæhn, and T-R. Heggedal. 2009. "Welfare and Growth Impacts of Innovation Policies in a Small, Open Economy; an Applied General Equilibrium Analysis." Economic Modelling 26 (5): 1075-88.

Cameron, A. C., and P. K. Trivedi. 2005. "Microeconometrics: Methods and Applications." Cambridge ; New York: Cambridge University Press.

Ca, T. N. 1999. "Technological Capability and Learning in Firms." Aldershot: Ashgate.

European Bank for Reconstruction and Development (EBRD). 2013:

Transition report:

http://www.gowerpublishing.com/pdf/tis/9781840149173_US.pdf 
Cefis, E., and L. Orsenigo. 2001. "The Persistence of Innovative Activities: A CrossCountries and Cross-Sectors Comparative Analysis." Research Policy 30 (7): 1139-58.

Chandra, V. 2006. “Technology, Adaptation, and Exports: How Some Developing Countries Got It Right." World Bank Publications no. 7118. Washington

Chatman, J. A., J. T. Polzer, S. G. Barsade, and M. A. Neale. 1998. "Being Different Yet Feeling Similar: The Influence of Demographic Composition and Organizational Culture on Work Processes and Outcomes." Administrative Science Quarterly 43 (4): 749-80.

Cheng, Sh. 2008. "Board Size and the Variability of Corporate Performance." Journal of Financial Economics 87 (1): 157-76.

Chuang, C-H., Ch-J. Huang, and A. Wu. 2013. "Market Competition, Social Network and Firm Performance: An Emerging Economy Test." Social Science Research Network Scholarly Paper no. 2312555. Rochester, NY.

Chung, S., H. Singh, and K. Lee. 2000. "Complementarity, Status Similarity and Social Capital as Drivers of Alliance Formation." Strategic Management Journal 21(1): $1-22$.

Cimoli, M., A. A. Hofman, and N. Mulder. 2010. Innovation and Economic Development. Edward Elgar Publishing.

Cimoli, M., A. Primi, and S. Rovira. 2011. "National Innovation Surveys in Latin America: Empirical Evidence and Policy Implications.” UN ECLAC report.

Cohen, W. M., and D. A. Levinthal. 1990. "Absorptive Capacity: A New Perspective on Learning and Innovation.” Administrative Science Quarterly, 128-52.

Coleman, J. S. 1987. "Creation and Destruction of Social Capital: Implications for the Law." Notre Dame Journal of Law, Ethics \& Public Policy 3: 375.

- 1988. "Social Capital in the Creation of Human Capital." American Journal of Sociology 94 (1): 95-120.

. 1990. "Foundations of Social Theory." Harvard University Press.

Commander, S. 1998. Enterprise Restructuring and Unemployment in Models of Transition. World Bank Publications.

Cooper, R., and R. Slagmulder. 2004. "Inter-organizational Cost Management and Relational Context." Accounting, Organizations and Society 29 (1): 1-26.

Cowan, R., and N. Jonard. 2007. "Structural Holes, Innovation and the Distribution of Ideas." Journal of Economic Interaction and Coordination 2 (2): 93-110.

-. 2009a. "Knowledge Portfolios and The Organization of Innovation Networks." Academy of Management Review 34 (2): 320-42.

-. 2009b. "Knowledge Portfolios and the Organization of Innovation Networks." Academy of Management Review 34 (2): 320-42.

Crespi, G., and P. Zuñiga. 2010. "Innovation and Productivity: Evidence from Six Latin American Countries." Inter-American Development Bank Publications: Working Paper no. 6875.

Dabla-Norris, E., E. K. Kersting, and G. Verdier. 2012. "Firm Productivity, Innovation, and Financial Development." Southern Economic Journal 79 (2): 422-49.

Dahlin, K. B., L. R. Weingart, and P. J. Hinds. 2005. "Team Diversity and Information Use." Academy of Management Journal 48 (6): 1107-23. 
Dasgupta, P., and I. Serageldin. 2000. Social Capital: A Multifaceted Perspective. World Bank Publications.

Dicko, S., and G. Breton. 2010a. "Social Network and Firm Performance: An Empirical Analysis of Canadian Boards.” SSRN Scholarly Paper ID 1533931. Rochester, NY: Social Science Research Network http:/ / papers.ssrn.com/abstract=1533931.

2010b. "Social Network and Firm Performance: An Empirical Analysis of Canadian Boards." Social Science Research Network Scholarly Paper no. 1533931. Rochester, NY:

Dinnelo, N. 1999. "The Russian f-connection: Finance, firms, friends, families, and favorites." Problems of Post-Communism 46 (1): 24-33

Dussauge, P., B. Garrette, and W. Mitchell. 2000. "Learning from Competing Partners: Outcomes and Durations of Scale and Link Alliances in Europe, North America, and Asia." Strategic Management Journal 21(2): 99-126.

Duysters, G., J. Jacob, Ch. Lemmens, and Y. Jintian. 2009. "Internationalization and Technological Catching up of Emerging Multinationals: A Comparative Case Study of China's Haier Group." Industrial and Corporate Change 18 (2): 325-49.

Duysters, G. M., J. Hagedoorn, and C. E. A. V. Lemmens. 2002. "The Effect of Alliance Block Membership on Innovative Performance." Eindhoven Center for Innovation Studies (ECIS) Working Paper no. 02.06.

Earle, J. S, and Á. Telegdy. 2002. "Privatization Methods and Productivity Effects in Romanian Industrial Enterprises.” Journal of Comparative Economics 30 (4): 65782.

Economic Commission for Latin America (ECLA). 2011. "National Innovation Surveys in Latin America: Empirical Evidence and Policy Implication."

Ees, H. van, and R. Bachmann. 2006. "Transition Economies and Trust Building: A Network Perspective on EU Enlargement." Cambridge Journal of Economics 30 (6): 923-39.

European Bank for Reconstruction and Development (EBRD). 2013. "Transition Report 2013.” London

Evangelista, R., and V. Mastrostefano. 2006. "Firm Size, Sectors and Countries as Sources of Variety in Innovation." Economics of Innovation and New Technology 15 (3): $247-70$.

EV Consulting. 2012. "National Competitiveness Report of Armenia.” Annual Report. Yerevan.

Filatotchev, I., M. Wright, K. Uhlenbruck, L. Tihanyi, and R. E Hoskisson. 2003. "Governance, Organizational Capabilities, and Restructuring in Transition Economies." Journal of World Business, Corporate Governance in Transitioning Economies, 38 (4): 331-47.

Fischer, S., L. Summers, and W. Nordhaus. 1992. "Stabilization and Economic Reform in Russia." Brookings Papers on Economic Activity 1992 (1): 77-126.

Flap, H., and B. Völker. 2004. "Creation and Returns of Social Capital.” Routledge.

Freeman, L.C. 1982. "Technological Infrastructure and International Competitiveness." OECD.

. 1977. "A Set of Measures of Centrality Based on Betweenness." Sociometry 40 (1): 35-41. 
Frydman, R., Ch. Gray, M. Hessel, and A. Rapaczynski. 1999. "When Does Privatization Work? The Impact of Private Ownership on Corporate Performance in the Transition Economies." The Quarterly Journal of Economics 114 (4): 1153-91.

Gabbay, S.M., and R.Th.A.J Leenders. 2014. "Social Capital of Organizations: From Social Structure to the Management of Corporate Social Capital." In Social Capital of Organizations, 18:1-20. Research in the Sociology of Organizations 18. Emerald Group Publishing Limited.

Galunic, Ch., and P. Moran. 2000. "Social Capital and Productive Exchange Structural and Relational Embeddedness and Managerial Performance Link." INSEAD Working Paper no. 2000/07/OB.

Garrido, C., and R. Padilla. 2011. "Cooperation for Innovation in the Manufacturing Industry in Mexico." National innovation surveys in Latin America: empirical evidence and policy implications: ECLAC.

Gault, F. 2015. Handbook of Innovation Indicators and Measurement. Edward Elgar Pub.

Gevorkyan, A. V. 2014. "The Legends of the Caucasus: Economic Transformation of Armenia and Georgia." International Business Review, December.

Gilsing, V., B. Nooteboom, W. Vanhaverbeke, G. Duysters, and A. van den Oord. 2008. "Network Embeddedness and the Exploration of Novel Technologies: Technological Distance, Betweenness Centrality and Density." Research Policy, Special Section Knowledge Dynamics out of Balance: Knowledge Biased, Skewed and Unmatched, 37 (10): 1717-31.

Gilsing, V. \& B. Nooteboom, 2005. "Density and strength of ties in innovation networks, an analysis of multimedia and biotechnology". European Management Review 2 (3): 179-197.

Godinho M.M., Mendonça S. F., and S. Pereira, 2005. "Towards a taxonomy of innovation systems," Working Papers Department of Economics 2005/13, ISEG - Lisbon School of Economics and Management, Department of Economics, Universidade de Lisboa.

Godoy, S., and J. Stiglitz. 2006. "Growth, Initial Conditions, Law and Speed of Privatization in Transition Countries: 11 Years Later." National Bureau of Economic Research Working Paper no.11992.

Goerzen, A., and P. W. Beamish. 2005. "The Effect of Alliance Network Diversity on Multinational Enterprise Performance." Strategic Management Journal 26 (4): 333-54.

Gokhberg, L. and Roud, V. 2016. "Structural changes in the national innovation system: longitudinal study of innovation modes in the Russian industry." Economic Change and Restructuring .49(2), 269-288.

Golub, B., and M. O. Jackson. 2012. "How Homophily Affects the Speed of Learning and Best-Response Dynamics." The Quarterly Journal of Economics, May, qjs021.

Granovetter, M. 1985. "Economic Action and Social Structure: The Problem of Embeddedness." The American Journal of Sociology.

Greeven, M., and G. van de Kaa. 2014. "Strategic Alliances for Innovation in China: Institutional Alliance Capability." In T. K Das (Eds.) Strategic Alliances for Innovation and R\&D: 231-47. Charlotte: Information Age Publishing. 
Grigoriou, K., and F. T. Rothaermel. 2014. "Structural Microfoundations of Innovation: The Role of Relational Stars." Journal of Management 40 (2): 586615.

Grimaldi R., M. Kenney, D. Siegel, M. Wright. 2011. “30 years after Bayh-Dole: reassessing academic entrepreneurship". Research Policy 40 (8): 1045-1057

Grossman, G. M., and E. Helpman. 1991. "Trade, Knowledge Spillovers, and Growth.” European Economic Review 35 (2-3): 517-26.

Guest, P. M. 2009. "The Impact of Board Size on Firm Performance: Evidence from the UK." The European Journal of Finance 15 (4): 385-404.

Gulati, R., N. Nohria, and A. Zaheer. 2000. "Strategic Networks." Strategic Management Journal 21 (3): 203-15.

Guseva, A., and A. Rona-Tas. 2001. "Uncertainty, Risk, and Trust: Russian and American Credit Card Markets Compared.” American Sociological Review 66 (5): 623-46.

$\mathrm{Gu}$, Sh. 1999. "Implications of National Innovation Systems for Developing Countries: Managing Change and Complexity in Economic Development." UNU-INTECH Discussion Paper Series 03:

https://ideas.repec.org/p/unm/unuint/199903.html.

Hansen, M.T. 1999. "The search-transfer problem: the role of weak ties in sharing knowledge across organization subunits". Administrative Science Quarterly 44: 82111.

Hart, S. L., and G. Ahuja. 1996. "Does It Pay to Be Green? An Empirical Examination of the Relationship between Emission Reduction and Firm Performance." Business Strategy and the Environment 5 (1): 30-37.

Helliwell, J. F. 1996. "Economic Growth and Social Capital in Asia." Working Paper 5470. National Bureau of Economic Research. http://www.nber.org/papers/w5470.

Huang C., Arundel A., Hollanders H. 2010. "How firms innovate: R\&D, non-R\&D, and technology adoption." UNU-MERIT working paper 2010-027

Humphrey, C. 2000a. "An anthropological view of barter in Russia". In P. Seabright (ed.), The Vanishing Rouble: Barter Networks and Non-Monetary Transactions in Post-Soviet Societies. Cambridge: Cambridge University Press, 71-90.

Ibarra, H. 1992. "Homophily and Differential Returns: Sex Differences in Network Structure and Access in an Advertising Firm." Administrative Science Quarterly 37 (3): 422-47.

Intarakumnerd, P., P.Chairatana, and T. Tangchitpiboon. 2002. "National Innovation System in Less Successful Developing Countries: The Case of Thailand." Research Policy, 20 (31): 1445-57.

International Monetary Fund. 1998. "Armenia: Recent Economic Developments." Washington, D.C.

2014. "25 Years of Transition: Post-Communist Europe and the IMF." Regional Economic Issues. Washington, D.C.

Ivanenko, V., and D. Mikheyev. 2002. "The Role of Non-Monetary Trade in Russian Transition.” Post-Communist Economies 14 (4): 405-19. 
Jiang, R. J., Q. T. Tao, and M. D. Santoro. 2010. "Alliance Portfolio Diversity and Firm Performance.” Strategic Management Journal 31 (10): 1136-44.

Johnson, S., D. Kaufmann, J. McMillan, and Ch. Woodruff. 2000. "Why Do Firms Hide? Bribes and Unofficial Activity after Communism." Journal of Public Economics 76 (3): 495-520.

Kale, P., H. Singh, and H. Perlmutter. 2000. "Learning and Protection of Proprietary Assets in Strategic Alliances: Building Relational Capital." Strategic Management Journal 21 (3): 217-37.

Khnkoyan, A. 2011. "Development of Scientific and Innovation Policy in Armenia in 2000s." Proceedings. $\quad$ September 17. https://smartech.gatech.edu/handle/1853/42417.

Kikeri, S, J.Nellis, and M. Shirley. 1994. "Privatization: Lessons from Market Economies." The World Bank Research Observer 9 (2): 241-72.

Kim, J. W., and M. C. Higgins. 2005. "Where Do Alliances Come from? The Effects of Upper Echelons on Alliance Formation." Academy of Management Proceedings 2005 (1): J1-6.

Kim, Y. 2005. "Board Network Characteristics and Firm Performance in Korea." SSRN Scholarly Paper ID 856654. Rochester, NY: Social Science Research Network. http://papers.ssrn.com/abstract $=856654$.

Kiss, A. N., and W. M. Danis. 2010. "Social Networks and Speed of New Venture Internationalization during Institutional Transition: A Conceptual Model." Journal of International Entrepreneurship 8 (3): 273-87.

Kitanovic, J. 2007. "The Applicability of the Concept of National Innovation Systems to Transition Economies." Innovation 9 (1): 28-45.

Klepper, S. 2002. "Firm Survival and the Evolution of Oligopoly." The RAND Journal of Economics 33 (1): 37-61.

Kline, S. J, and N. Rosenberg. 1986. An Overview of Innovation. An overview of innovation, In Landau, R., Rosenberg, N. (eds), The Positive Sum Strategy: Harnessing Technology for Economic Growth, Washington, National Academy Press.

Klochikhin, E. A. 2013. "Innovation System in Transition: Opportunities for Policy Learning between China and Russia." Science and Public Policy, February, sct021.

Knoke, D., and S. Yang. 2007. Social Network Analysis. (2nd edition) Cambridge: SAGE Publications, Inc.

Kogut, B., and A. Spicer. 2000. "Institutional Technology and the Chains of Trust: Capital Markets and Privatization in Russia and the Czech Republic." William Davidson Institute Working Paper no. 291.

2002. "Capital Market Development and Mass Privatization Are Logical Contradictions: Lessons from Russia and the Czech Republic." Industrial and Corporate Change, 11 (1): 1-37.

2004. "Critical and Alternative Perspectives on International Assistance to Post-Communist Countries: A Review and Analysis." The World Bank.

Koka, B. R., and J. E. Prescott. 2002. "Strategic Alliances as Social Capital: A Multidimensional View.” Strategic Management Journal 23 (9): 795-816. 
Kortunov, V. 2014. “The Formation of Capitalist Consciousness in Russia." Proceedings in GV - Global Virtual Conference, no. 1 (April).

http://www.gvconference.com/archive/?vid=1\&aid=2\&kid=30201-10.

Krammer, S. M. S. 2009. "Drivers of National Innovation in Transition: Evidence from a Panel of Eastern European Countries." Research Policy 38 (5): 845-60.

Krugman, P. 1993. "First Nature, Second Nature, and Metropolitan Location." Journal of Regional Science 33 (2): 129-44.

Kuznetsov, A., and O. Kuznetsova. 1996. "Privatization, Shareholding and the Efficiency Argument: Russian Experience.” Europe-Asia Studies, 48 (7): 117385.

Labeaga J. M., E. Martínez-Ros (2002). Modeling Innovative Activities using Discrete Choice Panel Data Models. Kleinknecht, A., Mohnen, P. (Eds.) Innovation and Firm Performance: Econometric Explorations of Survey Data chapter 7. Palgrave Macmillan UK)

Lahiri, N., and S. Narayanan. 2013. "Vertical Integration, Innovation, and Alliance Portfolio Size: Implications for Firm Performance." Strategic Management Journal, 34 (9): 1042-64.

Larcker, D. F., E. C. So, and Ch. Y. Wang. 2013. "Boardroom Centrality and Firm Performance - HBS Working Knowledge." Journal of Accounting and Economics, 55(2013): 225-250.

Ledeneva, A. 1998. Russia's Economy of Favours: Blat, Networking and Informal Exchange. Cambridge University Press.

2009. "From Russia with Blat: Can Informal Networks Help Modernize Russia?" Social Research: An International Quarterly 76 (1): 257-88.

Lee, J. 2010. "Heterogeneity, Brokerage, and Innovative Performance: Endogenous Formation of Collaborative Inventor Networks." Organization Science 21 (4): 804-22.

Li, H., Lingsheng M., Q. Wang, and L. Zhou. 2008. "Political Connections, Financing and Firm Performance: Evidence from Chinese Private Firms." Journal of Development Economics 87 (2): 283-99.

Lin, N. 2002a. Social Capital: A Theory of Social Structure and Action. Cambridge: Cambridge University Press.

- 2002b. Social Capital: A Theory of Social Structure and Action. Cambridge: Cambridge University Press.

Lin, Zh., H. Yang, and B. Arya. 2009. "Alliance Partners and Firm Performance: Resource Complementarity and Status Association." Strategic Management Journal 30 (9): 921-40.

List, F. 1941. The National System of Political Economy. English Edition (1904). London: Longman.

Lobel, I., and E. Sadler. 2013. "Preferences, Homophily, and Social Learning."

Working Paper no. 13-01. NET Institute. https://ideas.repec.org/p/net/wpaper/1301.html.

Lock, L. L. 2008. "Corporate Social Capital and Firm Performance in the Global Information Technology Services Sector" (Doctoral dissertation). Retrieved from http://ses.library.usyd.edu.au:80/handle/2123/2316. 
Longenecker, C. O. 2001. "Why Managers Fail in Post-Soviet Russia: Causes and Lessons." European Business Review 13 (2): 101-9.

Lonkila, M. 2010. "Networks in the Russian Market Economy." Palgrave Macmillan.

Lööf, H., and A. Heshmati. 2002. "Knowledge Capital and Performance Heterogeneity:: A Firm-Level Innovation Study." International Journal of Production Economics 76 (1): 61-85.

Lundvall, B-Å. 1985. "Product Innovation and User-Producer Interaction." Aalborg: Aalborg University Press.

Lundvall, B- $\AA$, and B. Johnson. 1994. "The Learning Economy." Journal of Industry Studies 1 (2): 23-42.

Lundvall, B-Å, B. Johnson, E. S. Andersen, and B. Dalum. 2002a. "National Systems of Production, Innovation and Competence Building." Research Policy, Innovation Systems, 31 (2): 213-31.

2002b. "National Systems of Production, Innovation and Competence Building." Research Policy, Innovation Systems, 31 (2): 213-31.

Lynall, M. D., B. R. Golden, and A. J. Hillman. 2003. "Board Composition from Adolescence to Maturity: A Multitheoretic View." Academy of Management Review 28 (3): 416-31.

Mairesse, J., and P. Mohnen. 2010. "Using Innovation Surveys for Econometric Analysis.” CIRANO Working Paper. CIRANO.

http://econpapers.repec.org/paper/circirwor/2010s-15.htm.

- 2005. "The Importance of R\&D for Innovation: A Reassessment Using French Survey Data." The Journal of Technology Transfer 30(1): 183-197.

Manasyan, H. and T. Jrbashyan, 2004. "Explaining growth in Armenia: the pivotal role of human capital." In Ofer, G. \& Pomfret, R. (Eds.), The Economic Prospects of the CIS: Ch. 6. The Netherlands: Edward Elgar Publishing

Malerba, F., and L.i Orsenigo. 1996. "Schumpeterian Patterns of Innovation Are Technology-Specific.” Research Policy 25 (3): 451-78.

Martin, G., R. Gözübüyük, and M. Becerra. 2015. "Interlocks and Firm Performance: The Role of Uncertainty in the Directorate Interlock-Performance Relationship." Strategic Management Journal 36 (2): 235-53.

Martin, Ph., Th. Mayer, and F. Mayneris. 2011. "Spatial Concentration and Plant-Level Productivity in France." Journal of Urban Economics 69 (2): 182-95.

Maurer, I., V. Bartsch, and M. Ebers. 2011. "The Value of Intra-Organizational Social Capital: How It Fosters Knowledge Transfer, Innovation Performance, and Growth.” Organization Studies 32 (2): 157-85.

McDermott, G. A. 2002. "Embedded Politics: Industrial Networks and Institutional Change in Post communism." University of Michigan Press.

2007. "Politics, Power, and Institution Building: Bank Crises and Supervision in East Central Europe.” Review of International Political Economy 14 (2): 220-50.

McEvily, B., J. Jaffee, and M. Tortoriello. 2011. "Not All Bridging Ties Are Equal: Network Imprinting and Firm Growth in the Nashville Legal Industry, 19331978." Organization Science 23 (2): 547-63.

McPherson, M., L. Smith-Lovin, and J. M. Cook. 2001. "Birds of a Feather: Homophily in Social Networks." Annual Review of Sociology 27 (1): 415-44. 
Meske, W. 2000. "Changes in the Innovation System in Economies in Transition: Basic Patterns, Sectoral and National Particularities." Science and Public Policy 27 (4): 253-64.

Mizruchi, M. S. 1983. "Who Controls Whom? An Examination of the Relation Between Management and Boards of Directors in Large American Corporations." Academy of Management Review 8 (3): 426-35.

Moran, P. 2005a. "Structural vs. Relational Embeddedness: Social Capital and Managerial Performance." Strategic Management Journal 26 (12): 1129-51.

2005b. "Structural vs. Relational Embeddedness: Social Capital and Managerial Performance." Strategic Management Journal 26 (12): 1129-51.

Mors, M-L. 2010. "Innovation in a Global Consulting Firm: When the Problem Is Too Much Diversity." Strategic Management Journal 31 (8): 841-72.

Murrell, P., and Y. Wang. 1993. "When Privatization Should Be Delayed: The Effect of Communist Legacies on Organizational and Institutional Reforms." Journal of Comparative Economics 17 (2): 385-406.

Mytelka, L. K. 1992. "Ivorian Industry at the Cross-Roads." In F. Stewart, S. Lall and S. Wangwe (Eds.), Alternative development strategies in SubSabaran Africa (pp. 243264). London: Palgrave Macmillan.

Nahapiet, J., and S. Ghoshal. 1998a. "Social Capital, Intellectual Capital, and the Organizational Advantage." The Academy of Management Review 23 (2): 242.

1998b. "Social Capital, Intellectual Capital, and the Organizational Advantage." Academy of Management Review 23 (2): 242-66.

Nellis, J. R. 1999. "Time to Rethink Privatization in Transition Economies?" World Bank Publications.

Nellis, John R., and Mary Shirley. 1992. Privatization: The Lessons of Experience. World Bank Publications.

Non, M. C., and Ph. H. Franses. 2007. "Interlocking Boards and Firm Performance: Evidence from a New Panel Database." Social Science Research Network Working Paper no. 978189..

North, D. C. 1990. "Institutions, Institutional Change and Economic Performance." Cambridge ; New York: Cambridge University Press.

O'Brien, D. 2006. Das Social Kapital: Institutions and Entrepreneurial Networks in Russia's Exit from Socialism: $\mathrm{PhD}$ thesis, Wageningen University, at:

http://library.wur.nl/wda/dissertations/dis4018.pdf.

Organization for Economic Co-operation and Development (OECD).1999a. "Managing National Innovation Systems." Paris

OECD, Eurostat. 2005. Oslo Manual: Guidlines for Collecting and Interpreting Innovation Data. Paris

Offe, C., and P. Adler. 1991. "Capitalism by Democratic Design? Democratic Theory Facing the Triple Transition in East Central Europe." Social Research 58 (4): 865-92.

Ong, Ch-H., D. Wan, and K-S. Ong. 2003. "An Exploratory Study on Interlocking Directorates in Listed Firms in Singapore." Corporate Governance: An International Review 11 (4): 322-34.

Padula, G. 2008. "Enhancing the Innovation Performance of Firms by Balancing Cohesiveness and Bridging Ties.” Long Range Planning 41 (4): 395-419. 
Pahor, M, J. Prašnikar, and A. Ferligoj. 2004. "Building a Corporate Network in a Transition Economy: The Case of Slovenia." Post-Communist Economies 16 (3): 307-31.

Parkhe, A. 1993. "Strategic Alliance Structuring: A Game Theoretic and Transaction Cost Examination of Interfirms Cooperation." Academy of Management Journal 36 (4): 794-829.

Parra-Requena, G., F. X. Molina-Morales, and P. M. García-Villaverde. 2010. "The Mediating Effect of Cognitive Social Capital on Knowledge Acquisition in Clustered Firms." Growth and Change 41 (1): 59-84.

Peneder M., 2010. Technological Regimes and the Variety of Innovation Behaviour Creating Integrated Taxonomies of Firms and Sectors. WIFO working paper $362 / 2010$

Peng, M. W, T. Buck, and I. Filatotchev. 2003. "Do Outside Directors and New Managers Help Improve Firm Performance? An Exploratory Study in Russian Privatization." Journal of World Business, Corporate Governance in Transitioning Economies, 38 (4): 348-60.

Perry, M. 2001. "Shared Trust in Small Industrial Countries? An Evaluation from New Zealand." Norsk Geografisk Tidsskrift - Norwegian Journal of Geograpby 55 (1): 1-8.

Portes, A. 1998. "Social Capital: Its Origins and Applications in Modern Sociology." Annual Review of Sociology 24 (1): 1-24.

Powell, W. W., K. W. Koput, and L. Smith-Doerr. 1996. "Interorganizational Collaboration and the Locus of Innovation: Networks of Learning in Biotechnology." Administrative Science Quarterly 41 (1): 116-45.

Puga, D. 2010. "The Magnitude and Causes of Agglomeration Economies*." Journal of Regional Science 50 (1): 203-19.

Radosevic, S. 2002. "Regional Innovation Systems in Central and Eastern Europe: Determinants, Organizers and Alignments." The Journal of Technology Transfer 27 (1): 87-96.

Radosevic, S., and B. M. Sadowski. 2007. "International Industrial Networks and Industrial Restructuring in Central and Eastern Europe.” Springer Science \& Business Media.

Reagans, R., and B. McEvily. 2003. "Network Structure and Knowledge Transfer: The Effects of Cohesion and Range." Administrative Science Quarterly 48 (2): 240-67. Roberson, Q. M. 2013. The Oxford Handbook of Diversity and Work. OUP USA.

Roberts, P. W., and G. R. Dowling. 2002. "Corporate Reputation and Sustained Superior Financial Performance." Strategic Management Journal 23(12): 10771093.

Rodan, S., and D. Ch. Galunic. 2004. "More than Network Structure: How Knowledge Heterogeneity Influences Managerial Performance and Innovativeness." Strategic Management Journal 25(6): 541-562

Rogers, E. M. 2003. "Diffusion of Innovations"( 5th edition) New York: Simon and Schuster.

Rooks, G., D. Dolech, A. Szirmai, and A. Serwanga. 2009. "Social Capital and Innovative Performance in Developing Countries: The Case of Ugandan Entrepreneurs." Proceedings.

October

8. https://smartech.gatech.edu/handle/1853/36654. 
Roolaht, T. 2012. "The Characteristics of Small Country National Innovation Systems." In Innovation Systems in Small Catching-Up Economies, edited by Elias G. Carayannis, U. Varblane, and T. Roolaht, 21-37. Innovation, Technology, and Knowledge Management 15. Springer New York.

http://link.springer.com/chapter/10.1007/978-1-4614-1548-0_2.

Rost, K. 2011. "The Strength of Strong Ties in the Creation of Innovation." Research Policy 40 (4): 588-604.

Salancik, G. R., and J. Pfeffer. 1978. "A Social Information Processing Approach to Job Attitudes and Task Design." Administrative Science Quarterly 23 (2): 224-53.

Salazar, M., and A. Holbrook. 2004. "A Debate on Innovation Surveys." Science and Public Policy 31 (4): 254-66.

Salmi, A. 1996. "Russian Networks in Transition: Implications for Managers." Industrial Marketing Management 25 (1): 37-45.

Sargsyan, H., and A. Markosyan. 2014. "Reforms and Perspectives of Rise of the Economy of Armenia." Yerevan

Saunders, A., M. M. Cornett, and P. A. McGraw. 2006. "Financial Institutions Management: A Risk Management Approach.” McGraw-Hill/Irwin.

Saxenian, A. L. 1996. "Regional Advantage." Harvard University Press.

Scherer, F. M., and D. Ross. 1990. "Industrial Market Structure and Economic Performance.” SSRN Scholarly Paper ID 1496716. Rochester, NY: Social Science Research Network. http://papers.ssrn.com/abstract=1496716.

Schultz, Th. W. 1960. "Capital Formation by Education.” Journal of Political Economy 68.

Schumpeter, J. A. 1934. "The Theory of Economic Development: An Inquiry Into Profits, Capital, Credit, Interest, and the Business Cycle." Transaction Publishers.

Seabright, P. 2000. “The Vanishing Rouble: Barter Networks and Non-Monetary Transactions in Post-Soviet Societies." Cambridge University Press.

Soda, G., A. Usai, and A. Zaheer. 2004. "Network Memory: The Influence of Past and Current Networks on Performance." Academy of Management Journal 47 (6): 893-906.

Som, O., and E. Kirner. 2014. Low-Tech Innovation: Competitiveness of the German Manufacturing Sector. Springer.

Smolny W. (2003). Determinants of Innovation Behaviour and Investment estimates for Wes-German manufacturing Firms. Econ. Innov. New Techn., 2003, October, Vol. 12(5), pp. 449-463

Spector, J. M., M. D. Merrill, J. Elen, and M. J. Bishop. 2013. "Handbook of Research on Educational Communications and Technology." Springer Science \& Business Media.

Spicer, A., G. A. McDermott, and B. Kogut. 2000. "Entrepreneurship and Privatization in Central Europe: The Tenuous Balance between Destruction and Creation." The Academy of Management Review 25 (3): 630.

Srubar, I. 1994. "Variants of the Transformation Process in Central Europe. A Comparative Assessment." Zeitschrift Für Soziologie 23 (3): 198-221.

Stark, D. 1991. "Path Dependence and Privatization Strategies in East Central Europe." East European Politics \& Societies 6 (1): 17-54. 
1996. "Recombinant Property in East European Capitalism." American Journal of Sociology 101 (4): 993-1027.

Stark, D., and L. Bruszt. 1998. "Postsocialist Pathways: Transforming Politics and Property in East Central Europe. " Cambridge University Press.

Stearns, L. B., and M.S. Mizruchi. 1993. "Board Composition and Corporate Financing: The Impact of Financial Institution Representation on Borrowing." Academy of Management Journal 36 (3): 603-18.

Stuart, T. E. 1998. "Network Positions and Propensities to Collaboration: An Investigation of Strategic Alliance Formation in a High-Technology Industry." Administrative Science Quarterly 43 (3): 668-98.

Supartika, N., and F. Margaretha. 2015. "Factors Affecting Profitability of Small Medium Enterprises." Saarbrücken: LAP LAMBERT Academic Publishing.

Su, X., and F. Zhang. 2008. "Strategic Customer Behavior, Commitment, and Supply Chain Performance." Management Science 54 (10): 1759-73.

Talke, K., S. Salomo, and K. Rost. 2010. "How Top Management Team Diversity Affects Innovativeness and Performance via the Strategic Choice to Focus on Innovation Fields." Research Policy 39 (7): 907-18.

Tang, J. 2006. "Competition and Innovation Behaviour." Research Policy 35 (1): 68-82.

Tatsi, E.i, and T. Zafar. 2011. "Social Capital and Economic Growth: Evidence from OECD Countries." Social Science Research Network Scholarly Paper no. 2370375. Rochester, NY.

Thorgren, S., J. Wincent, and H. Boter. 2012. "Small Firms in Multipartner R\&D Alliances: Gaining Benefits by Acquiescing." Journal of Engineering and Technology Management 29 (4): 453-67.

Tsai, W. 2001. "Knowledge Transfer in Intraorganizational Networks: Effects of Network Position and Absorptive Capacity on Business Unit Innovation and Performance." Academy of Management Journal 44 (5): 996-1004.

Tsai, W., and S. Ghoshal. 1998. "Social Capital and Value Creation: The Role of Intrafirm Networks." The Academy of Management Journal 41 (4): 464-76.

Tung, F., and X. Wang. 2012. "Bank CEOs, Inside Debt Compensation, and the Global Financial Crisis." Social Science Research Network Scholarly Paper no. 1570161. Rochester, NY.

Uddin, M. B. 2012. "Interfirm Cooperation And Information Sharing Through Interlocking Directorates.” Management \& Marketing-Craiova, no. 2: 205-14.

United Nations Economic Commission for Europe (UNECE). 2014. "Innovation Performance Review of Armenia." UNECE. Country Report. New York and Geneva

Uzzi, B. 1996. "The Sources and Consequences of Embeddedness for the Economic Performance of Organizations: The Network Effect." American Sociological Review 61 (4): 674.

1997. "Social Structure and Competition in Interfirm Networks: The Paradox of Embeddedness." Administrative Science Quarterly 42 (1): 35.

Uzzi, B., and J. J. Gillespie. 1999. "Corporate Social Capital and the Cost of Financial Capital: An Embeddedness Approach." In Corporate Social Capital and Liability, 446-59. Springer. http://link.springer.com/chapter/10.1007/978-1-46155027-3_25. 
Uzzi, B., and R. Lancaster. 2003. "Relational Embeddedness and Learning: The Case of Bank Loan Managers and Their Clients." Management Science 49 (4): 383-99.

Vafeas, N. 1999. "Board Meeting Frequency and Firm Performance." Journal of Financial Economics 53 (1): 113-42.

Vedres, B., and D. Stark. 2008. "Opening Closure: Intercohesion and Entrepreneurial Dynamics in Business Groups.” Social Science Research Network Scholarly Paper no. 1288100. Rochester, NY.

- 2010. "Structural Folds: Generative Disruption in Overlapping Groups." American Journal of Sociology 115 (4): 1150-90.

Veugelers, R., and B. Cassiman. 1999. "Make and Buy in Innovation Strategies: Evidence from Belgian Manufacturing Firms.” Research Policy 28 (1): 63-80.

Von Hippel, E. 1986. "Lead Users: A Source of Novel Product Concepts." Management Science 32 (7): 791-805.

1994. "'Sticky Information' and the Locus of Problem Solving: Implications for Innovation." Management Science 40 (4): 429-39.

. 1988. The Sources of Innovation, Oxford University Press, New York.

Waheed, A. 2012a. "Employment Effect of Innovation: Microdata Evidence from Bangladesh and Pakistan." UNU-MERIT Working Paper no. 2012-024.

2012b. "Innovation Determinants and Innovation as a Determinant: Evidence from Developing Countries.”(diss.) Maastricht University

Walker, G., B. Kogut, and W. Shan. 1997. "Social Capital, Structural Holes and the Formation of an Industry Network." Organization Science 8 (2): 109-25.

Walter, J., Ch. Lechner, and F. W. Kellermanns. 2007. "Knowledge Transfer between and within Alliance Partners: Private versus Collective Benefits of Social Capital." Journal of Business Research 60 (7): 698-710.

Wasserman, S. 1994. Social Network Analysis: Methods and Applications. $1^{\text {stedition. }}$ Cambridge ; New York: Cambridge University Press.

Watson, J. 2007a. "Modeling the Relationship between Networking and Firm Performance." Journal of Business Venturing 22 (6): 852-74.

-. 2007b. "Modeling the Relationship between Networking and Firm Performance." Journal of Business V enturing 22 (6): 852-74.

Wignaraja, G. 2003. Competitiveness Strategy in Developing Countries: A Manual for Policy Analysis. London: Routledge.

Wincent, J., S. Anokhin, and D. Örtqvist. 2010a. "Does Network Board Capital Matter? A Study of Innovative Performance in Strategic SME Networks." Journal of Business Research 63 (3): 265-75.

—. 2010b. "Does Network Board Capital Matter? A Study of Innovative Performance in Strategic SME Networks." Journal of Business Research 63 (3): 265-75.

Woodruff, D. M. 1999. “It's Value That's Virtual: Bartles, Rubles, and the Place of Gazprom in the Russian Economy." Post-Soviet Affairs 15 (2): 130-48.

Wooldridge, J. M. 2012. Introductory Econometrics: A Modern Approach. 5 edition. Mason, OH: Cengage Learning.

Woo, W. Th., S. Parker, and J. Sachs. 1997. Economies in Transition: Comparing Asia and Eastern Europe. London: MIT Press. 
World Intellectual Property Organization (WIPO). 2014. Global Innovation Index . Geneva

Wu, H-L. 2008. “When Does Internal Governance Make Firms Innovative?” Journal of Business Research 61 (2): 141-53.

Yalcinkaya, G., R. J. Calantone, and D. A. Griffith. 2007. "An Examination of Exploration and Exploitation Capabilities: Implications for Product Innovation and Market Performance." Journal of International Marketing 15 (4): 63-93.

Zaheer, A., and G. G. Bell. 2005. "Benefiting from Network Position: Firm Capabilities, Structural Holes, and Performance." Strategic Management Journal 26 (9): 809-25.

Zinnes, C., Y. Eilat, and J. Sachs. 2001. "The Gains from Privatization in Transition Economies: Is 'Change of Ownership' Enough?” IMF Staff Papers 48 (January): 146-70. 


\section{Valorization}

In accordance with Article 23 of the regulation governing the attainment of doctoral degrees at Maastricht University, this section discusses the valorization opportunities of the dissertation.

This thesis studies the role of social capital in countries experiencing radical institutional transformation such as former USSR countries. The study was based on historical empirical evidence from Armenia.

The findings showed that the institutional environment matters in determining opportunities for firms in Armenia, and it is particularly significant if we consider firms' embeddedness in social networks. Social networks serve as a mechanism for firms to cope with and overcome uncertainty of volatile market conditions. Social networks have been used to compensate for the difficulties of market exchange between firms, to access financial resources and to gain information. These networks played an important role in knowledge and skills transfer and diffusion, as well as in the effectiveness with which firms used new knowledge and skills.

The institutional aspect was presented to show how volatile and newly created marketsupporting institutions were not functioning very efficiently and were not sufficient to secure a proper transition from a planned to a market economy given the inherited soviet past. As the transition was not smooth and gradual, it has disrupted not only the "bad" institutions, but also the "good" ones such as the science and education system that Armenia had developed during the soviet past. The thesis discussed that the lack of experience and understanding of the soviet past caused lost opportunities while creating a new national innovation system.

Today, when societal transition is a hot topic for both developed and developing countries, studying post-soviet experience provides insights on the hidden factors that affect the transition such as past experience, people's mentality and social networks. The contexts and conditions may differ from country to country, yet some lessons learned from the former-soviet countries can be very useful and applicable for steering the transition processes in other countries. For example, in the era of distuptive technologies, developed countries are transitioning to a more technological society, while some developing countries are passing from closed to market-supporting institutional changes (e.g., Cuba, Burma). The examination of former soviet countries including Armenia, showed that one of the most important aspects is to understand and evaluate the country's existing potential and create better conditions to secure its transformation into a new system (e.g., transformation of National Innovation System).

Neo-liberal reforms and the lack of state policies in promoting the country's innovation system left economic agents alone to find solutions. In this situation, preexisting social networks became the only trustworthy channels with which economic agents were able to observe reality, and deal with ambiguity and uncertainties arising with the process of economic transformation. The central concern of this study was to 
analyze how newly privatized firms were able to utilize the local networks, and what kind of value these networks provided to those firms.

One of the important inter-firm networks, examined this thesis, is the board members network (the network formed by individual board members who have membership on one or more firm boards). This study extends the application of social capital theory to board networks which were relatively less examined compared to alliance literature. Applying insights from social capital theory, the study proposes that "structural" and "content" attributes of board member networks are key levers underlying the level of social capital presented by these networks for firms. The rationale behind these two aspects of the social capital is that there is a value how a firm is positioned in the board network levels as well as what are the qualities of the partner firms. In addition, it was found that there is a complementarity between a firm's position in the network and certain qualities possessed by its partners. For example, if a firm is embedded in a network where linked firms have greater financial resources, the focal firm has a greater likelihood of accessing financial support from partners than a firm that is not connected to a "rich" network.

One of the interesting findings is that the analysis shows that social capital may have differentiated impact on firm finances vs. innovative performance: for example, our results show that network closure is negative for firm innovation, while it has a positive impact on financial performance. Interestingly, for financial performance, findings suggest that both structural holes and network closure are important. This supports arguments related to transition economies, where firms need to pass through re-structuring in order to adapt to a new and turbulent environment caused by the collapse of the centralized planning system. Market instability and a volatile institutional environment (e.g., underdeveloped banking system, limited access to formal financial support) enhance the value of reciprocal ties, as they are credible guarantees for market exchange. In this case, network closure provides more opportunities for reciprocity. However, at the same time, a brokerage position also provides the firm more opportunities to navigate and to access resources that others are not able to access, which became more important when a firm is seeking new and innovative solutions. Therefore, when firm innovativeness is measured, network closure is an impediment as it opposes the brokerage position.

Corporate governance was a new phenomenon in Armenia, and the board governing rules and regulations are still under consideration. The results of the studies have an implication for the design of these rules. If the board network became too cliquish and homogenous in terms of industry, for example, it can induce a big concentration of market power in a small number of firms. This will reduce the chances of firm entry in the market outside of the "group". Similarly, if the distribution of betweeness centrality became too skewed, there will be a small number of firms that control information and resources available through board network. Depending on the structure of the board network, it can potentially produce either economic benefits or inefficiencies.

As the market-supporting reforms in transition economies started with privatization reforms which created conditions for unequal distribution of national property and wealth, the board directorship can be a useful instrument to soften or harden the 
further evolution of the power concentration in the economy. In addition, due to the weak institutional set-up, board networks were instrumental for the firms in Armenia to access various resources they depended on to reduce environmental uncertainty and maintain their position in the market. Yet, trough creating better board membership rules targeted towards diversity and inclusiveness, it can offset the initial power concentration in the economy and create better opportunities for equal access to capital and competitiveness.

The results and the empirical evidence provided by this study can be implemented to improve and design better $g$ board governing rules in the transitional countries, where the corporate governance is a relatively new institution. 


\section{Samenvatting}

\section{Doelen}

Dit proefschrift onderzoekt netwerken van bestuursleden, en hun invloed op de prestaties en innovatie van bedrijven, en presenteert een conceptueel kader voor het begrijpen en uiteindelijk voorspellen van de invloed van bepaalde kenmerken van netwerken van bestuursleden op bedrijven in zowel gevestigde als overgangseconomieën. Een netwerk van bestuursleden verwijst naar de verbondenheid tussen bedrijven in een economie, voortkomend uit het feit dat individuele bestuursleden deel uitmaken van één of meer raden van bestuur van bedrijven. In deze studie worden deze netwerken geacht intrinsieke bedrijfswaarde te hebben voor bedrijven, wat in de literatuur ook wel wordt beschreven als "sociaal kapitaal". Het proefschrift stelt dat "structurele eigenschappen" en "inhoudseigenschappen" van netwerken van bestuursleden de belangrijkste hefbomen zijn voor het sociale kapitaal van deze netwerken, en hun waarde voor bedrijven. Met inzichten uit de theorie over sociaal kapitaal benadrukt het structurele aspect van sociaal kapitaal de rol van de positie van het bedrijf in het netwerk van bestuursleden, terwijl netwerkinhoud suggereert dat ook eigenschappen van partnerbedrijven belangrijke factoren zijn voor de prestaties en innovatie van bedrijven. Deze studie behandelt ook hoe sociaal kapitaal door bedrijven kan worden herkend en gebruikt, en welke mechanismen het meest veelbelovend zijn voor het benutten van de waarde van dit sociale kapitaal.

\section{Aanpak}

We hebben paneldata verzameld van 200 bedrijven (openbare naamloze vennootschappen), voor de periode 2000-2010, waaronder data over bestuursleden, de financiële resultaten van de bedrijven, branche, winst, en andere relevante variabelen. Daarnaast hebben we voor een selectie aan bedrijven het eerste bedrijfsinnovatieonderzoek uitgevoerd.

Voor elk jaar hebben we een netwerk van bestuursleden in kaart gebracht, en door gebruik te maken van analytische netwerksoftware verschillende variabelen gegenereerd voor sociaal kapitaal. Het eerste deel van de empirische analyse richt zich op de invloed van sociaal kapitaal op de financiële resultaten van bedrijven, zoals gemeten middels de ROA en ROE. In het tweede deel schatten we de invloed van sociaal kapitaal op de innovatie van bedrijven.

\section{Bevindingen en Conclusie}

Uit ons empirische bewijs blijkt dat het sociaal kapitaal dat voortkomt uit de verbondenheid van bedrijven een significante invloed heeft op de prestaties van bedrijven. Gedeelde bestuursleden dienen als kanaal voor de overdracht van informatie en kennis en de uitwisseling van bronnen en middelen tussen bedrijven, wat zowel hun innovativiteit als hun financiële prestaties positief beïnvloedt. Onder bepaalde omstandigheden kunnen hiaten in de verbondenheid zelfs een positief effect hebben op de prestaties van bedrijven. 
Uit de studie blijkt dat de diversiteit van netwerken, de activa van partners, en het exportvolume belangrijk zijn voor het verbeteren van de financiële prestaties en innovativiteit van bedrijven (waaronder de mate van vernieuwendheid bij innovatie). Als een bedrijf bijvoorbeeld onderdeel uitmaakt van een rijk netwerk, waarin haar partners meer financiële middelen bezitten, is het waarschijnlijker dat het bedrijf zal profiteren van leningen van haar partners als het netwerk meer gesloten is, daar het vertrouwen in andere partijen in samenhangende netwerken groter is, en omdat er hier mogelijkheden bestaan voor het monitoren en sanctioneren, in het bijzonder wanneer de juridische infrastructuur van het land zelf de bedrijven niet beschermt. Ter ondersteuning van het meten en benutten van sociaal kapitaal, dragen we bij met maatstaven voor het beoordelen van de inhoud van netwerken, en bieden we empirisch bewijs voor hoe zulke maatstaven de prestaties van bedrijven verklaren.

Verder onderzoek zou zich kunnen richten op de gezamenlijke effecten van netwerken van bestuursleden en de eigenschappen van bestuursleden op de leer- en innovatieresultaten van bedrijven. Onze aanpak kan worden toegepast in de context van andere landen, en de bevindingen kunnen belangrijke inzichten bieden aan beleidsmakers op het gebied van corporate governance, bedrijfsgroei, en innovatie. 


\section{Biography}

Tatevik Poghosyan was born in Yerevan, Armenia. She obtained a Bachelor degree in Philosophy at Yerevan State University (Yerevan, Armenia). Then she graduated two Masters Programs one in Public Administration (School of Public Administration) and the other one in Political Science (Yerevan State University) in Yerevan. Tatevik has decided to further her studies abroad in Economics field.

Before joining UNU-MERIT in 2009, Tatevik Poghosyan studied Economics with majoring Economic Development at Tsukuba University in Japan. She was granted the Japanese Government Scholarship for her post graduate studies in Japan. Her work experience prior to joining UNU MERIT includes research conducted at the Economic Research Institute of the Ministry of Finance in Armenia, teaching various courses at the universities in Armenia and a microeconomics course at the World Bank Graduate program at Tsukuba University, and work experience in the Ministry of Foreign Affairs in Armenia.

During her Ph.D. studies at UNU-MERIT, she has conducted the "Firm's Innovation and Collaboration" survey in Armenia, which was the first country-wide survey on the innovation of firms conducted in Armenia. The pilot stage of this survey was conducted in collaboration with World Bank and Ministry of Economy of the Republic of Armenia under the scope of the Innovation Readiness Project. She received a research award in 2013 from International Development Research Center (IDRC) in Canada. As the IDRC awardee she conducted her individual research, and also was responsible for the coordination and implementation of the projects carried out by IDRC's Science and Innovation division. She was invited as a guest lecturer at the Institute of European, Russian and Eurasian Studies at Carleton University, Canada.

Since 2016, Tatevik is working as a Policy Analyst and Economist at the Federal Government of Canada. 


\section{UNU-MERIT/MGSoG Dissertation Series}

2018

\section{Arip Muttaqien}

Essays on Inequality and Polirization:

Empirical Studies in Developing Asia

UNU-MERIT/MGSoG Dissertation

Series № 217

\section{Katrin Marchand}

Essays on Forced Migration and

Labour Market Participation in

Developing Countries

UNU-MERIT/MGSoG Dissertation

Series № 216

\section{Ortrun Merkle}

The Myth of Gender Neutral Power:

Corruption and Gender Norms

UNU-MERIT/MGSoG Dissertation

Series № 215

\section{Biljana Meshkovska}

Life after Trafficking:

(re)integration processes of women that have been trafficked for the purpose of sexual exploitation in Europe

UNU-MERIT/MGSoG Dissertation

Series № 214

\section{Vincenzo Vinci}

The Relevance of Institutions and

People's Preferences for Social

Protection

UNU-MERIT/MGSoG Dissertation

Series № 213

\section{Silke Heuser}

The Effectiveness of Environmental

Policies on Reducing Deforestation in

the Brazilian Amazon

UNU-MERIT/MGSoG Dissertation

Series № 212

\section{Jennifer Waidler}

Social Assistance and Remittances and Their Role in the Fight Against

Poverty

UNU-MERIT/MGSoG Dissertation

Series № 211

\section{Choolwe Muzyamba}

The role of community mobilization in the promotion of maternal health of women living with HIV in Zambia UNU-MERIT/MGSoG Dissertation Series № 210

\section{Juan Carlos A. Castillo Sánchez} Assessing the Role of the Export Sector in Mexican Economic

Development,1965-2014

UNU-MERIT/MGSoG Dissertation

Series № 209

\section{Tareq Abuelhaj}

Food Security Policy Impact Analysis:

The Econometrics of Cash and Food Assistance Cost Effectiveness UNU-MERIT/MGSoG Dissertation Series № 208 
Marta Férnandez de Arroyabe Arranz

Essays on MEAS and Innovation

UNU-MERIT/MGSoG Dissertation

Series № 207

\section{Clotilde Mahé}

Essays on Migration and Occupational

Choice

UNU-MERIT/MGSoG Dissertation

Series № 206

\section{Simone Sasso}

Talent on the move. Essays on Human

Capital, Graduate Mobility and

Economic Development

UNU-MERIT/MGSoG Dissertation

Series № 205

\section{Khaled Walid Rajab}

Strategic Planning under Fragility

UNU-MERIT/MGSoG Dissertation

Series № 204

\section{Mutinta Hambayi Nseluke}

A Tall Order: Improving Child Linear Growth

UNU-MERIT/MGSoG Dissertation

Series № 203

\section{Elvis Korku Avenyo}

Innovations and Firm Performance

in sub-Saharan Africa: Empirical

Analyses

UNU-MERIT/MGSoG Dissertation

Series № 202

\section{Ni Zhen}

Employment Dynamics, Firm

Performance and Innovation

Persistence in the Context of

Differentiated Innovation Types:

Evidence from Luxembourg

UNU-MERIT/MGSoG Dissertation

Series № 201

\section{Caroline Wehner}

Too Scared to Achieve: The Relation

Between Neuroticism,

Conscientiousness

and Socioeconomic Outcomes

UNU-MERIT/MGSoG Dissertation

Series № 200

\section{Stefania Innocenti}

On Institutional Persistence

UNU-MERIT/MGSoG Dissertation

Series № 199

\section{Hassen Abda Wako}

Economic Globalization, Institutions and Development: Essays on Aid, Foreign Direct Investment and Trade UNU-MERIT/MGSoG Dissertation Series № 198

\section{7}

\section{Hans-Erik Edsand}

Winds of Change

UNU-MERIT/MGSoG Dissertation

Series № 197

\section{Ana Patricia Silva Vara}

Redressing the Gender Gap

UNU-MERIT/MGSoG Dissertation

Series № 196 


\section{Andrés Iván Mideros Mora}

Essays on the Economic Effects of Noncontributory Social Protection

UNU-MERIT/MGSoG Dissertation

Series № 195

\section{Tobias Broich}

New Actors in the Global Economy

UNU-MERIT/MGSoG Dissertation

Series № 194

\section{Bernard Nikaj}

From No-government to E-government

UNU-MERIT/MGSoG Dissertation

Series № 193

\section{Ali Safarnejad}

Prioritizing the HIV Response

UNU-MERIT/MGSoG Dissertation

Series № 192

\section{Clovis Freire}

Diversification and Structural

Economic Dynamics

UNU-MERIT/MGSoG Dissertation

Series № 191

\section{Michael Verba}

Innovation and Knowledge Dynamics:

Essays on the Knowledge Economy

UNU-MERIT/MGSoG Dissertation

Series № 190

\section{Pui Hang Wong}

The Hearts and Minds in Conflict and

Peace: The Economics of

Counterinsurgency and the Psychology

of Reconstruction

UNU-MERIT/MGSoG Dissertation

Series № 189

\section{Brenda Yamba}

Schooling Despite All Odds: Evidence from Lesotho on Female Child Carers who Stayed in School

UNU-MERIT/MGSoG Dissertation Series № 188

\section{Sheng Zhong}

Moving towards An Energy Efficient

Future: Essays on Energy Efficiency,

Technology and Development

UNU-MERIT/MGSoG Dissertation

Series № 187

\section{Julieta Marotta}

Access to Justice and Legal

Empowerment of Victims of Domestic

Violence through Legal Organizations

in the City of Buenos Aires: A

Qualitative Empirical Legal Study

UNU-MERIT/MGSoG Dissertation

Series, № 186

\section{Andrea Franco-Correa}

On the Measurement of

Multidimensional Poverty as a Policy

Tool: Empirical Applications to Chile,

Colombia, Ecuador and Peru

UNU-MERIT/MGSoG Dissertation

Series, № 185

\section{6}

\section{Yesuf Awel}

Insurance for Growth: Empirical

Essays on Insurance Demand and

Impacts in Africa

UNU-MERIT Dissertation Series, № 108 
Tigist Mekonnen Melesse

Grow More Food using Fewer

Resources: Agricultural Technology

Adoption and Innovation Practices for

Inclusive and Sustainable

Development

UNU-MERIT Dissertation Series, № 107

\section{Eleni Yitbarek}

Getting Ahead or left Behind? Essays on Poverty Dynamics and Social

Mobility in Africa

UNU-MERIT Dissertation Series, № 106

\section{Thuy Dieu Nguyen}

Firm-Level Theory and Evidence of

Corruption

UNU-MERIT Dissertation Series,

№ 105

\section{Raquel Tsukada Lehman}

Essays on Household Production with

Labor-Saving Technology

UNU-MERIT Dissertation Series,

№ 104

\section{Eva Barteková}

Multi-Problem Challenges for a

Renewable Future: Empirical Studies

on Competitive Disadvantages from

Electricity Price Differentials and

Mineral Supply Risk in an Open

Economy

UNU-MERIT Dissertation Series, № 103

\section{Jocelyn Olivari}

Entrepreneurial Traits and Innovation:

Evidence from Chile

UNU-MERIT Dissertation Series,

№ 102

\section{Muhammad Shafique}

Essays on the role of knowledge, RED, and Technology-based Firms in the Evolution of Socio-techno-economic System

UNU-MERIT Dissertation Series, № 101

\section{Serdar Türkeli}

Governance of Innovation Policy:

Empirical Studies on Applied Political Economy by Multi-Methods Analysis UNU-MERIT Dissertation Series, № 100

\section{Ayokunu Adedokun}

Pathways to Sustainable Peace building in Divided Societies: Lessons and Experiences from Mozambique MGSoG Dissertation Series, № 75

\section{Luiz Rothier Bautzer}

Organizing Concurrent Engineering through ICT Platforms Blueprinting Product Lifecycle Management Platforms across Disciplinary Agencies MGSoG Dissertation Series, № 74 


\section{Natalia Popova}

Migration in the Periphery of the

European Union:

Determinants of Successful and

Sustainable Labour Market Integration of Return Migrants in Albania, Egypt, Moldova and Tunisia

MGSoG Dissertations Series, № 73

\section{Richard A. Martina}

Uncertainty and Resource Constraint in the Small Island Developing States: Essays in Entrepreneurial Cognition MGSoG Dissertations Series, № 72

\section{Cécile Cherrier}

The Expansion of Basic Social

Protection in Low-income Countries:

An Analysis of Foreign Aid Actors'

Role in the Emergence of Social

Transfers in Sub-Saharan Africa

MGSoG Dissertations series, № 71

\section{Paul Caldron}

The Tacit Bargain in Short-Term

Medical Missions: Why U.S.

physicians go and what it costs

MGSoG Dissertation Series, № 70

\section{Mahmut Kobal}

Customs E Excellence: A Comparative Approach on Administrative and

Regulatory Compliance Perspectives of the EU-Turkey Customs Union

MGSoG Dissertation Series, № 69

\section{Craig Loschmann}

Essays on Conflict-related Migration

and Development in the Case of

Afghanistan

MGSoG Dissertations Series, № 68

\section{Andrea Milan}

Rural Livelihoods, Location and

Vulnerable Environments: Approaches

to Migration in Mountain areas of

Latin America

MGSoG Dissertation Series, № 67

\section{Farida Lada}

On Guarding the Welfare of Clinical

Trial Subjects While Promoting Novel

Drug Innovation

A Game Theoretical Approach

MGSoG Dissertation Series, № 66

\section{5}

\section{Hibret Belete Maemir}

Dissecting Aggregate Productivity:

International Integration and Growth with Heterogeneous Firms

UNU-MERIT Dissertation Series, № 96

\section{Giorgio Triulzi}

Looking for the Right Path: Technology

Dynamics, Inventive Strategies and

Catching-up in the Semiconductor

Industry

UNU-MERIT Dissertation Series, № 95
Abdul Baseer Qazi
Knowledge flows and networks in the ICT sector: The case of Pakistan UNU-MERIT Dissertation Series, № 94 


\section{Ajay Thutupalli}

Technology Paradigm Shifts in

Agriculture: Drivers of Sustainability

and Catch up

UNU-MERIT Dissertation Series,

№ 93

\section{Eduardo Urias}

Improving access to HIV/AIDS

treatment in Brazil: When are

Compulsory Licenses effective in Price

Negotiations?

UNU-MERIT Dissertation Series,

№ 92

\section{Francesca Guadagno}

Why have so few Countries

Industrialised?

UNU-MERIT Dissertation Series,

№ 91

\section{Daniel Opolot}

The Evolution of Beliefs and Strategic

Behaviour

UNU-MERIT Dissertation Series, № 90

\section{Alejandro Lavopa}

Structural Transformation and

Economic Development: Can

Development Traps be Avoided

UNU-MERIT Dissertation Series, № 89

\section{Jinjin Zhao}

Urban water management reform: The

Case of China

UNU-MERIT Dissertation Series,

№ 88

\section{Simona Vezzoli}

Borders, Independence and Post-

colonial Ties: the Role of the State in

Caribbean Migration

MGSoG Dissertation Series, № 65

\section{Silvia Consuelo Gómez Soler}

Civil Conflict and Education: How

Does Exposure to Civil Conflict Affect

Human Capital Accumulation?

Evidence from Standardized Exit

Exams in Colombia

MGSoG Dissertation Series, № 64

\section{Paula Nagler}

Occupational Choice in the Developing

World

MGSoG Dissertation Series, № 63

\section{Jasmin Kientzel}

Determinants of Professional

Commitment to Environmental

Sustainability

MGSoG Dissertation Series, № 62

\section{Mehmet Güney Celbiş}

Regional Policies: Convergence, Trade, and the Allocation of Public Capital MGSoG Dissertation Series, № 61

\section{Florian Henning}

Living Up to Standard:

Interoperability Governance and

Standards Adoption in Government

Information Networks

MGSoG Dissertation Series, № 60 
Niels P. Groen

2014

The Never-Ending Project

Understanding E-Government Project

Escalation

MGSoG Dissertation Series, № 59

\section{Derek Copp}

Teacher-Based Reactivity to Provincial

Large-scale Assessment in Canada

MGSoG Dissertation Series, № 58

\section{Michaella Vanore}

Family-Member Migration and the

Psychosocial Health Outcomes of

Children in Moldova and Georgia

MGSoG Dissertation Series, № 57

\section{Sonja Fransen}

The Economic and Social Effects of

Remittances and Return Migration in

Conflict-Affected Areas: The Case of

Burundi

MGSoG Dissertation Series, № 56

\section{Ibrahim Khalil Conteh}

The Impact of Floods on Primary

School Education in Zambia

MGSoG Dissertation Series, № 55

\section{Richard Bluhm}

Growth Dynamics and Development

Essays in Applied Econometrics and

Political Economy

MGSoG Dissertation Series, № 54

\section{Nevena P. Zhelyazkova}

Work-Family Reconciliation and Use of

Parental Leave in Luxembourg:

Empirical Analysis of Administrative

Records

MGSoG Dissertation Series, № 53

\section{Dirk Crass}

The Impact of Brands on Innovation and Firm Performance: Empirical Evidence from Germany

UNU-MERIT Dissertation Series, № 87

\section{Samyukta Bhupatiraju}

The Geographic Dimensions of Growth and Development

UNU-MERIT Dissertation Series, № 86

\section{François Lafond}

TheEvolution of Knowledge Systems UNU-MERIT Dissertation Series, № 85

\section{Annalisa Primi}

Promoting Innovation in Latin

America: What Countries Have

Learned (and What They Have Not) in

Designing and Implementing

Innovation and Intellectual Property

Policies

UNU-MERIT Dissertation Series,

\section{№ 84}

\section{Fatoumata Lamarana Diallo}

Evaluation of Meal and Deworming

Programs for Primary Schools in Rural Senegal

UNU-MERIT Dissertation Series, № 83 


\section{Sachin Kumar Badkas}

Metachoice and Metadata: Innovating with Environmental Policy Analysis in Europe

MGSoG Dissertation Series, № 52

\section{Irina S. Burlacu}

An Evaluation of Tax-Benefit Systems Impact on the Welfare of Frontier

Worker:

The Case of Luxembourg and Belgium MGSoG Dissertation Series, № 51

\section{Özge Bilgili}

Simultaneity in Transnational

Migration Research: Links Between

Migrants' Host and Home Country

Orientation

MGSoG Dissertation Series, № 50

\section{Yulia Privalova Krieger}

Reshaping the Big Agenda:

Transnational Politics and Domestic ResistanceFinancial crisis and social protection reform in Bosnia and Herzegovina

MGSoG Dissertation Series, № 49

\section{Marieke van Houte}

Moving Back or Moving Forward?

Return migration after Conflict

MGSoG Dissertation Series, № 48

\section{Oxana Slobozhan}

Global Governance in the Management of Natural Resources: The Case of the Extractive Industries Transparency Initiative (EITI)

MGSoG Dissertation Series, № 47

\section{Luis Bernardo Mejia Guinand}

The Changing Role of the Central

Planning Offices in Latin America: A

Comparative Historical Analysis

Perspective (1950-2013)

MGSoG Dissertation Series, № 46

\section{Cheng Boon Ong}

Ethnic Segregation in Housing,

Schools and Neighbourhoods in the

Netherlands

MGSoG Dissertation Series, № 45

\section{Luciana V. Cingolani}

Bureaucracies for Development:

Oxymoron or Reality? Studies on State

Capacity in Challenging Governance

Contexts

MGSoG Dissertation Series, № 44

\section{Carlos Cadena Gaitán}

Green Politics in Latin American

Cities - Sustainable Transport Agendas

MGSoG Dissertation Series, № 43

\section{Katie Kuschminder}

Female Return Migration and

Reintegration Strategies in Ethiopia

MGSoG Dissertation Series, № 42

\section{Metka Hercog}

Highly-Skilled Migration and New

Destination Countries

MGSoG Dissertation Series, № 41

\section{Margaret Agaba Rugadya}

Can Remittances Influence the Tenure and Quality of Housing in Uganda? MGSoG Dissertation Series, № 40 


\section{Ilire Agimi}

New Governance Under Limited

Statehood: The Case of Local

Government Reform in Kosovo

MGSoG Dissertation Series, № 39

\section{3}

\section{Anant Kamath}

Information Sharing through Informal

Interaction in Low-Tech Clusters

UNU-MERIT Dissertation Series, № 82

\section{Flavia Pereira de Carvalho}

What we talk about when we talk about

Brazilian Multinationals: An

Investigation on Brazilian FDI,

Economic Structure, Innovation and

the Relationship between them

UNU-MERIT Dissertation Series, № 81

\section{Jun Hou}

Complementarity in Innovation and

Development: A Cross-country

Comparison

UNU-MERIT Dissertation Series, № 80

\section{Rufin Baghana}

Impacts of Government Incentives to $R \mathcal{E}$, Innovation and Productivity: A Microeconometric Analysis of the Québec Case

UNU-MERIT Dissertation Series, № 79

\section{Lilia I. Stubrin}

High-Tech Activities in Emerging Countries: A Network perspective on the Argentinean Biotech Activity UNU-MERIT/MGSoG Dissertation Series, № 78

\section{Kristine Farla}

Empirical Studies on Institutions, Policies and Economic Development MGSoG Dissertation Series, № 38

\section{Marina Petrovic}

Social Assistance and Activation in the Pursuit of Happiness: Shedding New Light on Old Policy Solutions to Social Exclusion

MGSoG Dissertation Series, № 37

\section{Laura Torvinen}

Assessing Governance Assessments: The Case of Mozambique: Governance Assessments in the Context of Aid Effectiveness Discourse MGSoG Dissertation Series, № 36

\section{Biniam Egu Bedasso}

Institutional Change in the Long Shadow of Elite: Essays on Institutions, Human Capital and Ethnicity in Developing Countries MGSoG Dissertation Series, № 35

\section{Sepideh Yousefzadeh Faal}

\section{Deghati}

Childhoods Embargoed: Constructing and Reconstructing Multidimensional Child Poverty in Iran 1984-2009

MGSoG Dissertation Series, № 34 


\section{Robert Bauchmüller}

Investing in Early Childhood Care and

Education: The Impact of Quality on

Inequality

MGSoG Dissertation Series, № 33

\section{Martin Rehm}

Unified Yet Separated: Empirical

Study on the Impact of Hierarchical

Positions within Communities of

Learning

MGSoG Dissertation Series, № 32

2012

\author{
Abdul Waheed \\ Innovation Determinants and \\ Innovation as a Determinant: Evidence \\ from Developing Countries \\ UNU-MERIT Dissertation Series, \\ № 77
}

\section{Bilal Mirza}

Energy Poverty and Rural Energy

Markets in Pakistan

UNU-MERIT Dissertation Series,

№ 76

\section{Benjamin Engelstätter}

Enterprise Software and Video Games:

An Empirical Analysis

UNU-MERIT Dissertation Series,

№ 75

\section{Fulvia Farinelli}

Natural Resources, Innovation and

Export Growth: The Wine Industry in

Chili and Argentina

UNU-MERIT Dissertation Series

\section{Rodolfo Lauterbach}

Innovation in Manufacturing: From

Product Variety and Labor

Productivity Growth to Economic

Development in Chile

UNU-MERIT Dissertation Series

\section{Kirsten Wiebe}

Quantitative Assessment of

Sustainable Development and Growth in Sub-Saharan Africa

UNU-MERIT Dissertation Series, № 74

\section{Julio Miguel Rosa}

Organizational Strategies, Firms'

Performance and Spatial Spillovers:

The Canadian Case in Research and

Development.

UNU-MERIT Dissertation Series, № 73

Johannes Wilhelmus Marie Boels Joseph Schumpeter, Honderd Jaar Economische Ontwikkeling: Een Historisch-theoretische Beschouwing. UNU-MERIT Dissertation Series

\section{Dorcas Mbuvi}

Utility Reforms and Performance of the Urban Water Sector in Africa

MGSoG Dissertation Series, № 31

\section{Lina Salanauskaite}

Distributional Impacts of Public

Policies: Essays in Ex-Ante and Ex-

Post Evaluation

MGSoG Dissertation Series, № 30 


\section{Esther Schüring}

To Condition or not - is that the

Question?

An Analysis of the Effectiveness of ExAnte and Ex-Post Conditionality in

Social Cash Transfer Programs

MGSoG Dissertation Series, № 29

\section{Joe Abah}

Strong Organisations in Weak States:

Atypical Public Sector Performance in

Dysfunctional Environments

MGSoG Dissertation Series, № 28

\section{Zina Samih Nimeh}

Social Citizenship Rights: Inequality and Exclusion

MGSoG Dissertation Series, № 27

2011

\section{Daniel Vertesy}

Interrupted Innovation: Emerging

Economies in the Structure of the

Global Aerospace Industry

UNU-MERIT Dissertation Series,

№ 72

\section{Tina Saebi}

Successfully Managing Alliance

Portfolios: AnAlliance Capability View

UNU-MERIT Dissertation Series,

№ 71

\section{Nora Engel}

Tuberculosis in India: A Case of

Innovation and Control

UNU-MERIT/MGSoG Dissertation

Series, № 70

\section{Evans Mupela}

Connectivity and growth in Sub-

Saharan Africa: The Role of

Communication Satellites

UNU-MERIT Dissertation Series, № 69

\section{Nantawan Kwanjai}

Cross Cultural Intelligence amid

Intricate Cultural Webs: A Tale of the

UnDutchables in the Land of 1002

Smiles

UNU-MERIT Dissertation Series, № 68

\section{Lina Sonne}

Innovation in Finance to Finance

Innovation: Supporting Pro-poor

Entrepreneur-based Innovation

UNU-MERIT Dissertation Series, № 67

\section{Lenka Eisenhamerová}

Legitimacy of 'Humanitarian Military Intervention'

MGSoG Dissertation Series, № 26

\section{Sonila Tomini}

Informal Payments for Health Care

Services in Albania

MGSoG Dissertation Series, № 25

\section{Jinjing Li}

Dynamic Microsimulation in Public

Policy Evaluation

MGSoG Dissertation Series, № 24 


\section{Aziz Atamanov}

Rural Nonfarm Employment and

International Migration as

Alternatives to Agricultural

Employment: The Case of Kyrgyzstan

MGSoG Dissertation Series, № 23

\section{Frieda Vandeninden}

Poverty Alleviation: Aid and Social

Pensions

MGSoG Dissertation Series, № 22

\section{Juliana Nyasha Tirivayi}

The Welfare Effects of Integrating

AIDS Treatment with Food Transfers:

Evidence from Zambia

MGSoG Dissertation Series, № 21

\section{Agnieska Ewa Sowa}

Who's Left Behind? Social Dimensions of Health Transition and Utilization of Medical Care in Poland

MGSoG Dissertation Series, № 20

\section{Emmanaouil Sfakianakis}

The Role of Private Actors in the

Provision of Public Goods with

Applications to Infrastructure and

Financial Stability

MGSoG Dissertation Series, № 19

\section{Siu Hing Lo}

White Collars Green Sleeves: An Interorganizational Comparison of

Determinants of Energy-Related

Behaviors among Office Workers

MGSoG Dissertation Series, № 18

\section{Treena $\mathbf{W u}$}

Constraints to Human Capital

Investment in Developing Countries:

Using the Asian Financial Crisis in

Indonesia as a Natural Experiment

MGSoG Dissertation Series, № 17

\section{Henry Espinoza Peña}

Impact Evaluation of a Job-Training

Programme for Disadvantaged Youths:

The Case of Projoven

MGSoG Dissertation Series, № 16

2010

Fernando Santiago

Human Resources Management

Practices and Learning for Innovation in Developing Countries:

Pharmaceutical Firms in Mexico

UNU-MERIT Dissertation Series,

№ 66

\section{Zakaria Babutsidze}

Essays on Economies with

Heterogeneous Interacting Consumers

UNU-MERIT Dissertation Series,

№ 65

\section{Bertha Vallejo}

Learning and Innovation Under

Changing Market Conditions: The

Auto Parts Industry in Mexico

UNU-MERIT Dissertation Series,

№ 64 


\section{Donatus Ayitey}

Technical Change, Competitiveness and Poverty Reduction: A Study of the Ghanaian Apparel Industry UNU-MERIT Dissertation Series, № 63

\section{Sergey Filippov}

Multinational Subsidiary Evolution:

Corporate Change in New EU Member States

UNU-MERIT Dissertation Series, № 62

\section{Asel Doranova}

Technology Transfer and Learning under the Kyoto Regime: Exploring the Technological Impact of CDM Projects in Developing Countries

UNU-MERIT Dissertation Series, № 61

\section{Florian Tomini}

Between Family and Friend:

Understanding the Interdependency of Private Transfers

MGSoG Dissertation Series, № 15

\section{Michał Polalowski}

The Institutional Transformation of Social Policy in East Central Europe: Poland and Hungary in Comparative and Historical Perspective MGSoG Dissertation Series, № 14

\section{Maha Ahmed}

Defining, Measuring and Addressing Vulnerability: The Case of Post Conflict Environments MGSoG Dissertation Series, № 13

\section{Pascal Beckers}

Local Space and Economic Success: The Role of Spatial Segregation of Migrants in the Netherlands

MGSoG Dissertation Series, № 12

\section{Victor Cebotari}

Conflicting Demands in Ethnically

Diverse Societies: Ethno political

Contention and Identity Values in

Europe

MGSoG Dissertation Series, № 11

\section{Dennis Gyllensporre}

Competing and Complementary Perspectives on the EU as a Crisis Management Actor:

An Examination of the Common Security and Defence Policy through the Lenses of Idealism and Realism MGSoG Dissertation Series, № 10

\section{Judit Vall Castello}

Business Cycle and Policy Effects on Labour Market Transitions of Older and Disabled Workers in Spain MGSoG Dissertation Series, № 9

\section{Keetie Roelen}

False Positives or Hidden Dimensions:

The Definition and Measurement of Child Poverty

MGSoG Dissertation Series, № 8

\section{Denisa Maria Sologon}

Earning Dynamics in Europe

MGSoG Dissertation Series, № 7 


\section{Melissa Siegel}

Money and Mobility: Migration and

Remittances

MGSoG Dissertation Series, № 6

\section{Jessica S. Hagen-Zanker}

Modest Expectations: Causes and

Effects of Migration on Migrant

Households inSource Countries

MGSoG Dissertation Series, № 5

2009

\section{Alexis Habiyaremye}

From Primary Commodity Dependence to Diversification and Growth:

Absorptive Capacity and Technological Catch Up in Botswana and Mauritius. UNU-MERIT Dissertation Series, № 60

\section{Yoseph Getachew}

The Role of Public Capital in Economic Development

UNU-MERIT Dissertation Series, № 59

\section{Sandra Leitner}

Embodied Technological Change and

Patterns of Investment in Austrian

Manufacturing

UNU-MERIT Dissertation Series, № 58

\section{Semih Akçomak}

The Impact of Social Capital on Economic and Social Outcomes UNU-MERIT Dissertation Series, № 57
Abraham Garcia
The Role of Demand in Technical
Change
UNU-MERIT Dissertation Series, № 56

\section{Saurabh Arora}

Coherence in Socio-technical Systems:

A Network Perspective on the

Innovation Process

UNU-MERIT Dissertation Series, № 55

\section{Mirtha R. Muniz Castillo}

Human Development and Autonomy in Project Aid: Experiences from four bilateral projects in Nicaragua and El Salvador

MGSoG Dissertation Series, № 4

\section{Christiane Arndt}

Governance Indicators

MGSoG Dissertation Series, № 3

\section{Britta Augsburg}

Microfinance: Greater Good or Lesser Evil?

MGSoG Dissertation Series, № 2

\section{8}

\section{Rutger Daems}

Medicines for the Developing World UNU-MERIT Dissertation Series, № 54 
Johannes Hanel

Assessing Induced Technology:

Sombart's Understanding of Technical

Change in the History of Economics

UNU-MERIT Dissertation Series,

№ 53

\section{Rifka Weehuizen}

Mental Capital: the Economic

Significance of Mental Health

UNU-MERIT Dissertation Series,

№ 52

\section{Danielle Cloodt}

The Relationship between RED

Partnership Formation, Social

Embeddedness and Innovative

Performance

UNU-MERIT Dissertation Series, № 51

\section{Sabine Fuss}

Sustainable Energy Development under Uncertainty

UNU-MERIT Dissertation Series, № 50

\section{Geranda Notten}

Measuring and Managing Poverty

Risks

MGSoG Dissertation Series, № 1

2007

\section{Tobias Kronenberg}

Reconciling Environmental

Conservation with Economic

Prosperity: The Feasibility of Double

Dividends in the Short and Long Run

UNU-MERIT Dissertation Series, № 49

\section{Viktoria Kravtsova}

Assessing the Impact of Foreign Direct Investment in Transition Economies UNU-MERIT Dissertation Series, № 48

\section{Suhail Sultan}

The Competitive Advantage of Small and Medium Sized Enterprises: The Case of Jordan's Natural Stone Industry

UNU-MERIT Dissertation Series, № 47

2006

\section{Bulat Sanditov}

Essays on Social Learning and Imitation

UNU-MERIT Dissertation Series, № 46

\section{Mamata Parhi}

Dynamics of New Technology Diffusion: A Study of the Indian Automotive Industry UNU-MERIT Dissertation Series, № 45

\section{Andreas Reinstaller}

Social Structures and the Innovation Process: Their Role in the Demand of Firms and Consumers

UNU-MERIT Dissertation Series, № 44 


\section{Rose Kiggundu}

Innovation systems and Development:

The Journey of a Beleaguered Nile

Perch Fishery in Uganda

UNU-MERIT Dissertation Series,

№ 43

\section{Thomas Pogue}

The Evolution of Research

Collaboration in South African Gold

Mining: 1886-1933

UNU-MERIT Dissertation Series,

№ 42

\section{Geoffrey Gachino}

Foreign Direct Investment, Spillovers and Innovation: The Case of Kenyan

Manufacturing Industry

UNU-MERIT Dissertation Series,

№ 41

\section{Önder Nomaler}

Technological Change, International

Trade and Growth: An Evolutionary,

Multi-Agents-Based Modeling

Approach

UNU-MERIT Dissertation Series, № 40

\section{5}

\section{Samia Satti Osman Mohamed-}

Nour

Change and Skill Development in the Arab Gulf Countries

UNU-MERIT Dissertation Series, № 39

\section{Elad Harison}

Intellectual Property Rights:

Economics and Policy Analysis

UNU-MERIT Dissertation Series,

№ 38

\section{Marina Petrovic}

Social Assistance and Activation in the Pursuit of Happiness: Shedding New

Light on Old Policy Solutions to Social Exclusion

MGSoG Dissertation Series,

№ 37

\section{Müge Ozman}

Networks, Organizations and

Knowledge

UNU-MERIT Dissertation Series,

№ 36

\section{Bas Straathof}

Product Variety and Economic

Growth: The Counteracting Effects of

Scale and Idiosyncrasy

UNU-MERIT Dissertation Series, № 35

\section{Wilfred Schoenmakers}

Knowledge Flows between

Multinational Companies: A Patent

Data Analysis

UNU-MERIT Dissertation Series, № 34

\section{Myriam Cloodt}

Mergers and Acquisitions ( $M$ and As)

in High-Tech Industries: Measuring

the Post-M and A Innovative

Performance of Companies

UNU-MERIT Dissertation Series, № 33 


\section{Paola Criscuolo}

$R \mathcal{E D}$ Internationalisation and

Knowledge Transfer: Impact on MNEs and their Home Countries

UNU-MERIT Dissertation Series, № 32

\section{Maarten Verkerk}

Trust and Power on the Shop Floor UNU-MERIT Dissertation Series, № 31

\section{Gottfried Leibbrandt}

Adoption, Harmonization and Succession of Network Technologies across Countries

UNU-MERIT Dissertation Series, № 30

\section{Mark Sanders}

Skill Biased Technical change: Its Origins, the Interaction with the Labour Market and Policy Implications UNU-MERIT Dissertation Series, № 29

2003

\section{Nadine Roijakkers}

Inter-firm Cooperation in High-tech Industries: a Study of RED

Partnerships in Pharmaceutical

Biotechnology

UNU-MERIT Dissertation Series, № 28
Speed, Scale and Sustainability

UNU-MERIT Dissertation Series, № 27

\section{Masaru Yarime}

From End-of-Pipe Technology to Clean Technology

UNU-MERIT Dissertation Series, № 26

\section{Stéphane Malo}

The Combinatorial Chemistry

Revolution: Sustaining a Superior

Performance Position through

Technological Learning

UNU-MERIT Dissertation Series, № 25

2002

\section{Annelies Hogenbirk}

Determinants of Inward Foreign Direct Investment: the Case of the Netherlands

UNU-MERIT Dissertation Series, № 24

\section{Bastiaan Johan terWeel}

The Computerization of the Labour Market

UNU-MERIT Dissertation Series 
Marjolein Caniëls

Regional Growth Differentials: The

\section{John Adeoti}

Technology Investment in Pollution Control in Sub-Saharan Africa: The

Case of the Nigerian Manufacturing Industry

UNU-MERIT Dissertation Series, № 23

\section{Edward Huizenga}

Innovation Management: How

Frontrunners Stay Ahead: An

Empirical Study on Key Success

Factors in the ICT sector

UNU-MERIT Dissertation Series, № 22

2000

\section{Machiel van Dijk}

Technological Change and the

Dynamics of Industries: Theoretical Issues and Empirical evidence from

Dutch Manufacturing

UNU-MERIT Dissertation Series, № 21

1999

\section{Jan Cobbenhagen}

Managing Innovation at the Company Level: A Study on Non-Sector-Specific Success Factors

UNU-MERIT Dissertation Series, № 20
Impact of Locally Bounded Knowledge

Spillovers

UNU-MERIT Dissertation Series, № 19

\section{8}

\begin{abstract}
Aldo Geuna
Resource Allocation and Knowledge production: Studies in the Economics of University Research
\end{abstract}

UNU-MERIT Dissertation Series, № 18

1996

\section{Reinoud Joosten}

Dynamics, Equilibria, and Values UNU-MERIT Dissertation Series, № 17

\section{Hugo Kruiniger}

Investment, $R \mathcal{E} D$, and the Financing Decisions of the Firm

UNU-MERIT Dissertation Series, № 16

\section{5}

\section{Hans van Meijl}

Endogenous Technological Change: The Case of Information Technology, Theoretical Considerations and

Empirical Results

UNU-MERIT Dissertation Series, № 15 


\section{René Kemp}

Environmental Policy and Technical

Change: A Comparison of the

Technological Impact of Policy

Instruments

UNU-MERIT Dissertation Series, № 14

\section{Rohini Acharya}

The Impact of New Technologies on

Economic Growth and Trade: A Case

Study of Biotechnology

UNU-MERIT Dissertation Series, № 13

\section{Geert Duysters}

The Evolution of Complex Industrial Systems: The Dynamics of Major IT Sectors

UNU-MERIT Dissertation Series, № 12

\section{Marjan Groen}

Technology, Work and Organisation: A Study of the Nursing Process in Intensive Care Units

UNU-MERIT Dissertation Series, № 11

1994

\section{Huub Meijers}

On the Diffusion of Technologies in a Vintage Framework: Theoretical Considerations and Empirical Results UNU-MERIT Dissertation Series, № 10

\section{Theon van Dijk}

The Limits of Patent Protection: Essays on the Economics of Intellectual

Property Rights

UNU-MERIT Dissertation Series, № 9

\section{Hans Voordijk}

Naar Integrale Logistiek in

Bedrijfsketens: Ontwikkelingen in de Bouw

UNU-MERIT Dissertation Series, № 8

1993

\section{Paul Diederen}

Technological Progress in Enterprises and Diffusion of Innovation:

Theoretical Reflections and Empirical Evidence

UNU-MERIT Dissertation Series, № 7

\section{Ben Dankbaar}

Economic Crisis and Institutional Change: The Crisis of Fordism from the Perspective of the Automobile Industry UNU-MERIT Dissertation Series, № 6

\section{Hanno Roberts}

Accountability and Responsibility: The Influence of Organisation Design on Management Accounting UNU-MERIT Dissertation Series, № 5 


\section{Bart Verspagen}

Uneven Growth between

Interdependent Economies: An

Evolutionary View on Technology

Gaps, Trade and Growth

UNU-MERIT Dissertation Series,

№ 4

\section{Sjoerd Romme}

A Self-organization Perspective on

Strategy Formation

UNU-MERIT Dissertation Series,

№ 3

1989

\section{John Spangenberg}

Economies of Scale, and Atmosphere in

Research Organisations

UNU-MERIT Dissertation Series,

№ 2

1988

\section{John Hagedoorn}

Evolutionary and Heterodox

Innovation Analysis: A Study of

Industrial and Technological

Development in Process Control and

Information Technology

UNU-MERIT Dissertation Series, № 1 
